\title{
Complex formation of cadmium with sugar residues, nucleobases, phosphates, nucleotides, and nucleic acids
}

\author{
Sigel, Roland K O ; Skilandat, Miriam ; Sigel, Astrid ; Operschall, Bert P ; Sigel, Helmut
}

\begin{abstract}
Cadmium(II), commonly classified as a relatively soft metal ion, prefers indeed aromaticnitrogen sites (e.g., N7 of purines) over oxygen sites (like sugar-hydroxyl groups). However, matters are not that simple, though it is true that the affinity of $\mathrm{Cd}(2+)$ towards ribose-hydroxyl groups is very small; yet, a correct orientation brought about by a suitable primary binding site and a reduced solvent polarity, as it is expected to occur in a folded nucleic acid, may facilitate metal ion-hydroxyl group binding very effectively. $\mathrm{Cd}(2+)$ prefers the guanine(N7) over the adenine(N7), mainly because of the steric hindrance of the $(\mathrm{C} 6) \mathrm{NH}(2)$ group in the adenine residue. This $\mathrm{Cd}(2+)-(\mathrm{N} 7)$ interaction in a guanine moiety leads to a significant acidification of the (N1)H meaning that the deprotonation reaction occurs now in the physiological $\mathrm{pH}$ range. $\mathrm{N} 3$ of the cytosine residue, together with the neighboring $(\mathrm{C} 2) \mathrm{O}$, is also a remarkable $\mathrm{Cd}(2+)$ binding site, though replacement of $(\mathrm{C} 2) \mathrm{O}$ by $(\mathrm{C} 2) \mathrm{S}$ enhances the affinity towards $\mathrm{Cd}(2+)$ dramatically, giving in addition rise to the deprotonation of the $(\mathrm{C} 4) \mathrm{NH}(2)$ group. The phosphodiester bridge is only a weak binding site but the affinity increases further from the mono- to the di- and the triphosphate. The same also holds for the corresponding nucleotides. Complex stability of the pyrimidine-nucleotides is solely determined by the coordination tendency of the phosphate $\operatorname{group}(\mathrm{s})$, whereas in the case of purine-nucleotides macrochelate formation takes place by the interaction of the phosphate-coordinated $\mathrm{Cd}(2+)$ with N7. The extents of the formation degrees of these chelates are summarized and the effect of a non-bridging sulfur atom in a thiophosphate group (versus a normal phosphate group) is considered. Mixed ligand complexes containing a nucleotide and a further mono- or bidentate ligand are covered and it is concluded that in these species N7 is released from the coordination sphere of $\mathrm{Cd}(2+)$. In the case that the other ligand contains an aromatic residue (e.g., 2,2'-bipyridine or the indole ring of tryptophanate) intramolecular stack formation takes place. With buffers like Tris or Bistris mixed ligand complexes are formed. $\mathrm{Cd}(2+)$ coordination to dinucleotides and to dinucleoside monophosphates provides some insights regarding the interaction between $\mathrm{Cd}(2+)$ and nucleic acids. $\mathrm{Cd}(2+)$ binding to oligonucleotides follows the principles of coordination to its units. The available crystal studies reveal that N7 of purines is the prominent binding site followed by phosphate oxygens and other heteroatoms in nucleic acids. Due to its high thiophilicity, $\mathrm{Cd}(2+)$ is regularly used in so-called thiorescue experiments, which lead to the identification of a direct involvement of divalent metal ions in ribozyme catalysis.
\end{abstract}

DOI: https://doi.org/10.1007/978-94-007-5179-8_8

Posted at the Zurich Open Repository and Archive, University of Zurich

ZORA URL: https://doi.org/10.5167/uzh-79639

Book Section

Accepted Version 
Originally published at:

Sigel, Roland K O; Skilandat, Miriam; Sigel, Astrid; Operschall, Bert P; Sigel, Helmut (2013). Complex formation of cadmium with sugar residues, nucleobases, phosphates, nucleotides, and nucleic acids. In: Sigel, Astrid; Sigel, Helmut; Sigel, Roland K O. Cadmium: From Toxicity to Essentiality. Dordrecht: Springer, 191-274.

DOI: https://doi.org/10.1007/978-94-007-5179-8_8 


\title{
Chapter 8
}

\section{Complex Formation of Cadmium with Sugar Residues, Nucleobases, Phosphates, Nucleotides, and Nucleic Acids}

\author{
Roland K. O. Sigel, Miriam Skilandat, Astrid Sigel, Bert P. Operschall, and Helmut Sigel
}

\section{Contents}

ABSTRACT

1 INTRODUCTION

2 COMPARISONS OF THE PROPERTIES OF CADMIUM(II) WITH THOSE OF ZINC(II), CALCIUM(II), MAGNESIUM(II), AND OTHER RELATED METAL IONS

3 CADMIUM(II)-SUGAR INTERACTIONS

3.1 Hydroxyl Coordination in Carboxyhydrates Is Rare

3.2 The Metal Ion Affinity of Ribose-Hydroxyl Groups Is Small

3.3 A Favorable Steric Setting and a Reduced Solvent Polarity May Promote Metal IonHydroxyl (or Carbonyl) Group Binding

4 INTERACTIONS OF CADMIUM(II) WITH NUCLEOBASE RESIDUES

4.1 Cadmium(II) Complexes of Purine Derivatives

4.2 Cadmium(II) Complexes of Pyrimidine Derivatives

4.3 Cadmium(II) Complexes of Some Less Common Nucleobase Residues 4.3.1 Tubercidin

R. K. O. Sigel ()) $\cdot$ M. Skilandat Institute of Inorganic Chemistry, University of Zürich, Winterthurerstrasse 190, CH-8057 Zürich, Switzerland e-mail: roland.sigel@aci.uzh.ch

A. Sigel • B. P. Operschall $・$ H. Sigel ())

Department of Chemistry, Inorganic Chemistry, University of Basel, Spitalstrasse 51, CH-4056 Basel, Switzerland e-mail: Astrid.Sigel@unibas.ch; Bert.Operschall@unibas.ch; Helmut.Sigel@unibas.ch

A. Sigel, H. Sigel, and R. K. O. Sigel, Cadmium: From Toxicity to Essentiality 


\subsubsection{Orotidine}

4.3.3 Xanthosine

4.3.4 Thiouridines

4.3.5 2-Thiocytidine

\section{COMPLEXES OF CADMIUM(II) WITH PHOSPHATES}

6 CADMIUM(II) COMPLEXES OF NUCLEOTIDES

6.1 Some General Considerations

6.2 Complexes of Nucleoside 5'-Monophosphates

6.2.1 Equilibrium Constants to Be Considered

6.2.2 Properties of Pyrimidine-Nucleoside 5'-Monophosphate Complexes

6.2.3 Properties of Purine-Nucleoside 5'-Monophosphate Complexes

6.3 Complexes of 5'-Di- and Triphosphates

6.4 Complexes of Less Common Nucleotides

6.4.1 Tubercidin 5'-Monophosphate

6.4.2 Nucleoside 2'- and 3'-Monophosphates

6.4.3 Orotidinate 5'-Monophosphate

6.4.4 Xanthosinate 5'-Monophosphate

6.4.5 Thiouracil Nucleotides

6.4.6 Flavin Mononucleotide

7 CADMIUM(II) COMPLEXES OF NUCLEOTIDE ANALOGUES

7.1 Properties of $1, \mathrm{~N}^{6}$-Ethenoadenosine and of Its Phosphates

7.2 Complexes of Nucleoside 5'-O-Thiomonophosphates

7.3 Complexes of Acyclic Nucleotide Analogues

7.4 Cadmium(II) Binding to Nucleotides Containing a Platinum(II)-Coordinated Nucleobase Residue

8 A SHORT APPRAISAL OF MIXED LIGAND COMPLEXES CONTAINING A NUCLEOTIDE

8.1 Definitions and Some General Comments

8.2 Ternary Cadmium(II) Complexes Containing $\mathrm{ATP}^{4-}$ and a Buffer Molecule 
8.3 Mixed Ligand Complexes Containing a Nucleotide and a Further Monodentate or Bidentate Ligand. Release of Purine-N7 and Formation of Stacks

9 CADMIUM(II) BINDING IN DINUCLEOTIDES AND DINUCLEOSIDE MONOPHOSPHATES

9.1 The Phosphodiester Link

9.2 The Guanine Residue in a Dinucleotide

9.3 The Non-bridging Sulfur of the Thiophosphodiester Link

9.4 Dinucleoside Monophosphates

10 CADMIUM(II) BINDING TO NUCLEIC ACIDS

10.1 Cadmium(II)-Rescue Experiments

10.2 Crystal Structures of RNA or DNA-Protein Complexes Containing $\mathrm{Cd}^{2+}$

10.3 Cadmium(II)-Induced EPR Silencing

11 CONCLUDING REMARKS

ABBREVIATIONS AND DEFINITIONS

ACKNOWLEDGMENTS

REFERENCES

Abstract Cadmium(II), commonly classified as a relatively soft metal ion, prefers indeed aromatic-nitrogen sites (e.g., N7 of purines) over oxygen sites (like sugar-hydroxyl groups). However, matters are not that simple, though it is true that the affinity of $\mathrm{Cd}^{2+}$ towards ribosehydroxyl groups is very small; yet, a correct orientation brought about by a suitable primary binding site and a reduced solvent polarity, as it is expected to occur in a folded nucleic acid, may facilitate metal ion-hydroxyl group binding very effectively. $\mathrm{Cd}^{2+}$ prefers the guanine(N7) over the adenine(N7), mainly because of the steric hindrance of the (C6) $\mathrm{NH}_{2}$ group in the adenine residue. This $\mathrm{Cd}^{2+}-(\mathrm{N} 7)$ interaction in a guanine moiety leads to a significant acidification of the $(\mathrm{N} 1) \mathrm{H}$ meaning that the deprotonation reaction occurs now in the physiological $\mathrm{pH}$ range. $\mathrm{N} 3$ of the cytosine residue, together with the neighboring $(\mathrm{C} 2) \mathrm{O}$, is also a remarkable $\mathrm{Cd}^{2+}$ binding site, though replacement of $(\mathrm{C} 2) \mathrm{O}$ by $(\mathrm{C} 2) \mathrm{S}$ enhances the affinity towards $\mathrm{Cd}^{2+}$ dramatically, giving in addition rise to the deprotonation of the $(\mathrm{C} 4) \mathrm{NH}_{2}$ group. 
The phosphodiester bridge is only a weak binding site but the affinity increases further from the mono- to the di- and the triphosphate. The same also holds for the corresponding nucleotides. Complex stability of the pyrimidine-nucleotides is solely determined by the coordination tendency of the phosphate group(s), whereas in the case of purine-nucleotides macrochelate formation takes place by the interaction of the phosphate-coordinated $\mathrm{Cd}^{2+}$ with $\mathrm{N} 7$. The extent of the formation degrees of these chelates are summarized and the effect of a non-bridging sulfur atom in a thiophosphate group (versus a normal phosphate group) is considered. Mixed ligand complexes containing a nucleotide and a further mono- or bidentate ligand are covered and it is concluded that in these species N7 is released from the coordination sphere of $\mathrm{Cd}^{2+}$. In the case that the other ligand contains an aromatic residue (e.g., 2,2'-bipyridine or the indole ring of tryptophanate) intramolecular stack formation takes place. With buffers like Tris or Bistris mixed ligand complexes are formed. $\mathrm{Cd}^{2+}$ coordination to dinucleotides and to dinucleoside monophosphates provides some insights regarding the interaction between $\mathrm{Cd}^{2+}$ and nucleic acids. $\mathrm{Cd}^{2+}$ binding to oligonucleotides follows the principles of coordination to its units. The available crystal studies reveal that N7 of purines is the prominent binding site followed by phosphate oxygens and other heteroatoms in nucleic acids. Due to its high thiophilicity, $\mathrm{Cd}^{2+}$ is regularly used in so-called thiorescue experiments, which lead to the identification of a direct involvement of divalent metal ions in ribozyme catalysis.

Keywords cadmium $\cdot$ calcium $\cdot$ equilibrium constants $\cdot$ magnesium $\cdot$ metal ions $\cdot$ methods $\cdot$ ribozymes $\cdot$ RNA $\cdot$ zinc

\section{Introduction}

Cadmium is widely distributed in the environment at relatively low concentrations, except where it accumulated due to anthropogenic activities [1] (see also Chapters 2 and 3 of this book). Cadmium chemically resembles zinc and any differences are attributable to the larger size of $\mathrm{Cd}^{2+}$ compared with that of $\mathrm{Zn}^{2+}$ [2]. Indeed, cadmium occurs in the earth's crust and the upper 
lithosphere mainly together with zinc (zinc being present to ca. $0.02 \%$ [3]). The $\mathrm{Cd} / \mathrm{Zn}$ ratio has been estimated to be about 1:250 [4], and cadmium is thus gained as by-product from zinc ores (Chapter 3).

Cadmium is a toxic element (see Chapters $1,14,15$ ) that accumulates especially in kidney and liver [4] being bound preferably to metallothionein (Chapters 6,11). On the other hand, the chemical similarity of $\mathrm{Cd}^{2+}$ to $\mathrm{Zn}^{2+}$ is confirmed by the fact that carbonic anhydrase of marine phytoplankton contains $\mathrm{Cd}^{2+}$ (Chapter 16), whereas the corresponding zinc enzymes are found in organisms from all kingdoms [5] catalyzing the reversible hydration of carbon dioxide. In marine diatoms cadmium, cobalt, and zinc can functionally substitute for one another to maintain optimal growth [6]. Cadmium-carbonic anhydrase is involved in the acquisition of inorganic carbon for photosynthesis [6].

Interestingly, already more than 50 years ago Wacker and Vallee detected cadmium as well as other metal ions in RNA from horse kidney cortex [7], but there is no indication for a "positive" role of any cadmium-nucleic acid interaction. However, nowadays $\mathrm{Cd}^{2+}$ is often applied as a probe to study the effects of metal ions on ribozymes $[8,9]$ as well as the metal ionbinding properties of nucleic acids in general [10]. With this general analytical use in mind, this chapter has been written, concentrating on $\mathrm{Cd}^{2+}$ and several related metal ions (see Section 2) as well as on the nucleobases (NB) and their derivatives which are important for RNA and DNA (Figure 1) [11-14]. The four main nucleobases of RNA are adenine (Ade), guanine (Gua),

\section{insert Figure 1 close to here (width: $8 \mathrm{~cm}$ )}

cytosine (Cyt), and uracil (Ura); in DNA uracil is replaced by thymine (Thy). Hypoxanthine (Hyp) is included for comparisons with guanine. Below we will first consider some physicochemical properties of $\mathrm{Cd}^{2+}$ and related metal ions. Next, the interaction of these metal ions with sugar, phosphate, and nucleobase residues will be addressed, followed by nucleotides and nucleic acid complexes.

\section{Comparisons of the Properties of Cadmium(II) with Those of Zinc(II), Calcium(II), Magnesium(II), and Other Related Metal Ions}


Despite its essentiality for marine diatoms [5,6], cadmium is best known for its toxicity to mammals $[1,4,15,16]$ and in this context it is interesting to consider the interdependencies between $\mathrm{Cd}^{2+}$ and other elements. In Figure 2, which may not be complete, the most obvious interdependencies with $\mathrm{Cd}^{2+}$ are shown [17]. An arrow from element $\mathrm{A}$ to $\mathrm{B}, \mathrm{A} \rightarrow \mathrm{B}$, indicates that administration of element A may reduce toxicity due to element B. Hence, the toxicity of $\mathrm{Cd}^{2+}$ may be reduced by the ions of $\mathrm{Ca}, \mathrm{Zn}, \mathrm{Cu}, \mathrm{Fe}, \mathrm{Co}$, and the metalloid Se. However, low levels of element $\mathrm{A}$, e.g., of $\mathrm{Ca}^{2+}, \mathrm{Zn}^{2+}$, and $\mathrm{Cu}^{2+}$, may increase the toxicity of element $\mathrm{B}\left(\mathrm{Cd}^{2+}\right)$, or high levels of element $\mathrm{B}\left(\mathrm{Cd}^{2+}\right)$ may inhibit salutary effects of element $\mathrm{A}\left(\mathrm{Zn}^{2+}\right)$. Such interrelations are common, though not easy to reveal and to understand.

\section{insert Figure 2 close to here (width: $6 \mathrm{~cm}$ )}

Ignoring strontium and lead from the nine metals shown in Figure 2, we are left with the essential divalent metal ions $\mathrm{Mg}^{2+}, \mathrm{Ca}^{2+}, \mathrm{Fe}^{2+}, \mathrm{Co}^{2+}, \mathrm{Zn}^{2+}$, and $\mathrm{Cu}^{2+}$, and the toxic $\mathrm{Cd}^{2+} \cdot \mathrm{Cd}^{2+}$, larger than $\mathrm{Zn}^{2+}$, has nearly the size of $\mathrm{Ca}^{2+}$ (see below) and this has led to its use as $\mathrm{Ca}^{2+}$ probe $[15,18]$ (see also Chapter 6). However, in its binding strength to ligands $\mathrm{Cd}^{2+}$ is more like $\mathrm{Zn}^{2+}$ (see below) and thus, it is employed as a $\mathrm{Zn}^{2+}$ probe as well [15] (Chapter 6). Although $\mathrm{Cd}^{2+}$ has a larger ionic radius than $\mathrm{Mg}^{2+}$, it has recently been widely applied to mimic $\mathrm{Mg}^{2+}$ in ribozymes $[8,19]$. Like $\mathrm{Mg}^{2+}, \mathrm{Cd}^{2+}$ preferentially forms non-distorted octahedral complexes, and it selectively replaces $\mathrm{Mg}^{2+}$ bound to purine-N7 sites via an innersphere coordination mode [19].

Based on the mentioned observations, we focus now on the properties of $\mathrm{Cd}^{2+}$ in comparison to those of $\mathrm{Zn}^{2+}, \mathrm{Ca}^{2+}$, and $\mathrm{Mg}^{2+}$ as well as their interactions with the bio-ligands relevant for nucleic acids as considered in this chapter. The properties and complexes of $\mathrm{Fe}^{2+}$, $\mathrm{Co}^{2+}$, and $\mathrm{Cu}^{2+}$ are to some extent taken into account as well, to allow, where needed, more systematic-type comparisons. With this in mind the content of Table 1 has been assembled [20$27]$.

\section{insert Table 1 close to here (landscape)}

Columns 2 to 4 of Table 1 list the coordination numbers of the divalent metal ions considered together with their corresponding ionic radii. Evidently, the radii of $\mathrm{Zn}^{2+}$ and $\mathrm{Mg}^{2+}$ 
are very similar, as are those of $\mathrm{Cd}^{2+}$ and $\mathrm{Ca}^{2+}$. The alkaline earth ions like to bind to oxygen donors (column 6) whereas the $3 \mathrm{~d}$ metal ions as well as $\mathrm{Zn}^{2+}$ and $\mathrm{Cd}^{2+}$ have a preference for $\mathrm{N}$ sites, especially heteroaromatic amines, as we will see later. Among all these metal ions $\mathrm{Cd}^{2+}$ has the highest affinity for thiolate sites $[15,17]$, which is of relevance for so-called rescue experiments [8,28] (see Sections 9.3 and 10.1).

Column 6 of Table 1 provides the acidity constants $\left(\mathrm{p} K_{\mathrm{a} / \mathrm{aq}}\right)$ for the hydrolysis reaction (1), charges being omitted:

$$
\begin{aligned}
\mathrm{M}\left(\mathrm{H}_{2} \mathrm{O}\right)_{\mathrm{n}} \rightleftharpoons \mathrm{M}(\mathrm{OH})\left(\mathrm{H}_{2} \mathrm{O}\right)_{\mathrm{n}-1}+\mathrm{H}^{+} & \\
K_{\mathrm{M}\left(\mathrm{H}_{2} \mathrm{O}\right)_{\mathrm{n}}}^{\mathrm{H}} & =\frac{\left[\mathrm{M}(\mathrm{OH})\left(\mathrm{H}_{2} \mathrm{O}\right)_{\mathrm{n}-1}\right]\left[\mathrm{H}^{+}\right]}{\left[\mathrm{M}\left(\mathrm{H}_{2} \mathrm{O}\right)_{\mathrm{n}}\right]}=K_{\mathrm{a} / \mathrm{aq}}
\end{aligned}
$$

This hydrolysis reaction leads to hydroxo complexes and the coordinated $\mathrm{OH}^{-}$species can act as nucleophiles [24,29] or participate in general base catalysis [24], important for metal ioncontaining catalytic cores of ribozymes, where also large $\mathrm{p} K_{\mathrm{a}}$ shifts can occur [30]. The $\mathrm{p} K_{\mathrm{a} / \mathrm{aq}}$ values of Table 1 show that in a simple aqueous solution at neutral $\mathrm{pH}$ all metal ions listed are present as $\mathrm{M}^{2+}$ ions, except $\mathrm{Cu}^{2+}$, which forms a $\mathrm{CuO}$ precipitate [15]; of course, such a solid does not occur in plasma where $\mathrm{Cu}^{2+}$ is complexed by proteins [15].

Columns 7 and 8 of Table 1 provide the stability constants as defined by equation (2), of simple acetate, $\mathrm{CH}_{3} \mathrm{COO}^{-}$, and ammonia, $\mathrm{NH}_{3}$, complexes (charges omitted):

$$
\begin{aligned}
\mathrm{M}^{2+}+\mathrm{L} & \rightleftharpoons \mathrm{M}(\mathrm{L}) \\
K_{\mathrm{M}(\mathrm{L})}^{\mathrm{M}} & =[\mathrm{M}(\mathrm{L})] /\left(\left[\mathrm{M}^{2+}\right][\mathrm{L}]\right)
\end{aligned}
$$

At first sight the $\mathrm{M}\left(\mathrm{NH}_{3}\right)^{2+}$ complexes of the transition elements seem to be much more stable than those of the corresponding $\mathrm{M}\left(\mathrm{CH}_{3} \mathrm{COO}\right)^{+}$complexes. However, in the physiological $\mathrm{pH}$ range around 7.5 one needs to take into account the competition between $\mathrm{M}^{2+}$ and $\mathrm{H}^{+}$for binding at the ligand, that is, the size of the acidity constant of the protonated ligands is important. The acidity constants are defined by equation (3) (charges omitted):

$$
\begin{aligned}
\mathrm{H}(\mathrm{L}) \rightleftharpoons \mathrm{L} & +\mathrm{H}^{+} \\
& K_{\mathrm{H}(\mathrm{L})}^{\mathrm{H}}=[\mathrm{L}]\left[\mathrm{H}^{+}\right] /[\mathrm{H}(\mathrm{L})]=K_{\mathrm{a}}
\end{aligned}
$$

Considering that the $\mathrm{p} K_{\mathrm{a}}$ of acetic acid, $\mathrm{CH}_{3} \mathrm{COOH}$, is close to 4.6 and the one of the ammonium 
ion, $\mathrm{NH}_{4}^{+}$, close to 9.4 , it is evident that at $\mathrm{pH}$ ca. 7.5 the acetate ion is freely accessible for $\mathrm{M}^{2+}$ binding, whereas $\mathrm{NH}_{3}$ exists overwhelmingly in the form of the $\mathrm{NH}_{4}^{+}$ion. The competition between $\mathrm{M}^{2+}$ and $\mathrm{H}^{+}$for binding at the ligand can be accounted for by defining so-called conditional or apparent (app) stability constants, which then hold only for a given $\mathrm{pH}$. This constant, $K_{\mathrm{M}(\mathrm{L}) \text { app }}^{\mathrm{M}}$, depends on the acidity constant of the ligand (eq. 3) and the stability constant of the complex (eq. 2) and is defined by equation (4) [15,22]:

$$
\begin{aligned}
K_{\mathrm{M}(\mathrm{L}) \mathrm{app}}^{\mathrm{M}} & =K_{\mathrm{M}(\mathrm{L})}^{\mathrm{M}} \frac{1}{1+\left[\mathrm{H}^{+}\right] / K_{\mathrm{H}(\mathrm{L})}^{\mathrm{H}}} \\
& =K_{\mathrm{M}(\mathrm{L})}^{\mathrm{M}} \frac{K_{\mathrm{H}(\mathrm{L})}^{\mathrm{H}}}{\left[\mathrm{H}^{+}\right]+K_{\mathrm{H}(\mathrm{L})}^{\mathrm{H}}}
\end{aligned}
$$

$$
\log K_{\mathrm{M}(\mathrm{L}) \mathrm{app}}^{\mathrm{M}}=\log K_{\mathrm{M}(\mathrm{L})}^{\mathrm{M}}+\log \left[K_{\mathrm{H}(\mathrm{L})}^{\mathrm{H}} /\left(\left[\mathrm{H}^{+}\right]+K_{\mathrm{H}(\mathrm{L})}^{\mathrm{H}}\right)\right]
$$

For $\mathrm{pH} \gg \mathrm{p} K_{\mathrm{H}(\mathrm{L})}^{\mathrm{H}}$ the unbound ligand is predominantly in its basic form and $\log K_{\mathrm{M}(\mathrm{L}) \text { app }}^{\mathrm{M}}=\log$ $K_{\mathrm{M}(\mathrm{L})}^{\mathrm{M}}$. Examples are neutral solutions of carboxylic acids with $\mathrm{p} K_{\mathrm{a}}$ ca. 4 to 5 . For $\mathrm{pH} \ll<\mathrm{p} K_{\mathrm{H}(\mathrm{L})}^{\mathrm{H}}$ the unbound ligand is predominantly protonated and equation $(4 \mathrm{c})$ reduces to $\log K_{\mathrm{M}(\mathrm{L}) \mathrm{app}}^{\mathrm{M}}=\log$ $K_{\mathrm{M}(\mathrm{L})}^{\mathrm{M}}-\mathrm{p} K_{\mathrm{H}(\mathrm{L})}^{\mathrm{H}}+\mathrm{pH}$. An example for neutral solutions is the ammonium side chain of aliphatic amino acids with $\mathrm{p} K_{\mathrm{a}}$ ca. 9.5 to 10 . When the $\mathrm{pH}$ is within $\pm 2 \log$ units of $\mathrm{p} K_{\mathrm{a}}$, the complete equation (4) should be employed.

With the above reasonings in mind, columns 7 to 9 of Table 1 should be compared: For acetate $\mathrm{pH}=7.5 \gg \mathrm{p} K_{\mathrm{H}(\mathrm{Ac})}^{\mathrm{H}}=4.56$ [25], that is, virtually all ligand is in its basic $\mathrm{CH}_{3} \mathrm{COO}^{-}$ form and the apparent and conventional stability constants are equal. For ammonia this is different; at $\mathrm{pH} 7.5$ only about $1.3 \%$ of the ligand is present in its free $\mathrm{NH}_{3}$ form but $98.7 \%$ exist as $\mathrm{NH}_{4}^{+}$. Consequently, $\log K_{\mathrm{M}\left(\mathrm{NH}_{3}\right) \text { app }}^{\mathrm{M}}<\log K_{\mathrm{M}\left(\mathrm{NH}_{3}\right)}^{\mathrm{M}}$; in fact, only for $\mathrm{Cu}^{2+}$ it holds $\log$ $K_{\mathrm{M}(\mathrm{Ac})}^{\mathrm{M}}<\log K_{\mathrm{M}\left(\mathrm{NH}_{3}\right) \text { app }}^{\mathrm{M}}$; for all other metal ions the $\mathrm{M}(\mathrm{Ac})^{+}$complexes are more stable than the $\mathrm{M}\left(\mathrm{NH}_{3}\right)^{2+}$ species.

The above lesson is of relevance for nucleic acids and their constituents. Considering that the monoprotonated phosphate groups of nucleotides have $\mathrm{p} K_{\mathrm{a}}$ values of about 6.2 to 6.5 [31,32], the competition of the proton is not very pronounced at the physiological $\mathrm{pH}$ of about 7.5 and for $\mathrm{RO}-\mathrm{P}(\mathrm{O})_{2}-\mathrm{OR}$ ' bridges of nucleic acids ( $K_{\mathrm{a}}$ ca. $\left.1[33,34]\right)$ no proton competition exists at all. This is also true for the $(\mathrm{N} 3) \mathrm{H}^{+}$sites of cytidine residues $\left(\mathrm{p} K_{\mathrm{a}}\right.$ ca. $\left.4.3[31,35]\right)$, the $(\mathrm{N} 1) \mathrm{H}^{+}$sides 
of adenosines ( $K_{\mathrm{a}}$ ca. $\left.3.8[31,36]\right)$ as well as the $(\mathrm{N} 7) \mathrm{H}^{+}$of guanosines ( $K_{\mathrm{a}}$ ca. $\left.2.5[31,37,38]\right)$, but not for the (N1)H units of guanosines with $\mathrm{p} K_{\mathrm{a}}$ values of about $9.4[31,37,38]$. In these latter cases a strong competition for binding at $(\mathrm{N} 1)^{-}$between the proton and metal ion exists. These general considerations will be reflected in the discussions to follow.

\section{Cadmium(II)-Sugar Interactions}

\subsection{Hydroxyl Coordination in Carboxylates Is Rare}

Knowledge on binding of metal ions to carbohydrates is scarce $[32,39,40]$ and little information exists on $\mathrm{Cd}^{2+} \cdot \mathrm{Ca}^{2+}$ binding to neutral monosaccharides is very weak unless they form a favorable tridentate disposition of three hydroxyl groups [18]. The same may be surmised for $\mathrm{Cd}^{2+}$, though it has been concluded based on crystal structure studies that sugar-hydroxyl groups are good ligands for alkaline earth ions but not for transition and heavy metal ions [41]. The reason for this conclusion is most likely that it is based on solid-state studies of nucleosides (and derivatives) and there the $\mathrm{N}$-sites become important for the latter type of metal ions (vide infra), but still there is a polymeric $\mathrm{Cd}^{2+} / 5^{\prime}-\mathrm{IMP}^{2-}$ complex with a $\mathrm{M}-\mathrm{O} 2^{\prime} / 3^{\prime}$ chelation [11]: This polymer consists of $\left[\mathrm{Cd}_{2}(\mathrm{IMP} \cdot \mathrm{H})_{2}(\mathrm{IMP})\left(\mathrm{H}_{2} \mathrm{O}\right)_{6}\right] \cdot 6 \mathrm{H}_{2} \mathrm{O}$ units with two independent $\mathrm{Cd}^{2+}$ ions, one of which binds two ribose oxygen atoms, a purine-N7, and three water molecules [42]. There are also indications that in $\mathrm{M}(\mathrm{D}-$ fructose $) \mathrm{X}_{2} \cdot 4 \mathrm{H}_{2} \mathrm{O}\left(\mathrm{X}=\mathrm{Cl}^{-}\right.$or $\left.\mathrm{Br}^{-}\right)$species, where $\mathrm{M}^{2+}=\mathrm{Mg}^{2+}$, $\mathrm{Zn}^{2+}$ or $\mathrm{Cd}^{2+}, \mathrm{M}^{2+}$ binds $\mathrm{O} 2$ and $\mathrm{O} 3$ of D-fructose [43].

Metal ion binding to sugars is strengthened when a suitable primary binding site is provided, e.g., a carboxylate group [18]. Similarly, potentiometric and spectroscopic studies in aqueous solution $\left(25^{\circ} \mathrm{C} ; I=0.15 \mathrm{M}, \mathrm{KNO}_{3}\right)$ indicate that with 2-amino-2-deoxy-D-mannose metal ions bind not only to the primary amino site but also to the hydroxyl group (O3)H [44]: $\mathrm{Cu}^{2+}, \mathrm{Ni}^{2+}$, and $\mathrm{Co}^{2+}$ form 5-membered chelates and the same may be surmised for $\mathrm{Cd}^{2+}$. With 2amino-2-deoxy-D-glucose the complexes are less stable, which is in accord with the less favorable arrangements of the hydroxyl groups [44]. Similarly, metal ions coordinate initially via 
a 6-membered chelate to 1,3-diamino-2-propyl $\alpha$-D-mannopyranoside and these coordinated metal ions should then, at least in theory, be able to interact with a hydroxyl group forming an 8membered chelate, which, however, is not observed for the complexes of $\mathrm{Cu}^{2+}, \mathrm{Ni}^{2+}$, and $\mathrm{Zn}^{2+}$ [45].

\subsection{The Metal Ion Affinity of Ribose-Hydroxyl Groups Is Small}

How is the situation with the ribose and 2-deoxyribose residues, which are of significance for the nucleoside derivatives considered herein? The cis arrangement of the 2- and 3-hydroxyl groups as present in a ribose moiety favors deprotonation of one of the two $\mathrm{OH}$ groups because in the resulting anion intramolecular hydrogen bond formation occurs [34]. Yet, this favored deprotonation with $\mathrm{p} K_{\mathrm{a}}=12.5$ is far above the physiological $\mathrm{pH}$ range, meaning that such a deprotonation can occur in a biological system only in a very special environment [30].

However, e.g., it can be facilitated by metal ions like $\mathrm{Cu}^{2+}$ which is apparently able to bind to the cis-glycol unit of a ribose moiety in aqueous solution at high $\mathrm{pH}$ values $[43,46,47]$, as proven in experiments with adenosine. In contrast, 2'-deoxyadenosine shows no deprotonation of the 3'hydroxyl group under the corresponding conditions. Since the acidifying power of $\mathrm{Cd}^{2+}$ is much smaller than the one of $\mathrm{Cu}^{2+}$ (cf. the $\mathrm{p} K_{\mathrm{a} / \mathrm{aq}}$ values in Table 1 , column 6), $\mathrm{Cd}^{2+}$ is not expected to achieve this type of binding.

In this context also a stability constant study in aqueous solution $\left(25^{\circ} \mathrm{C} ; I=0.1 \mathrm{M}, \mathrm{NaNO}_{3}\right)$ of complexes formed with $2^{\prime} \mathrm{AMP}^{2-}$ and $3^{\prime} \mathrm{AMP}^{2-}$ is of relevance [48]. The complex stability of $\mathrm{Cu}\left(2^{\prime} \mathrm{AMP}\right)$ is enhanced by $0.25 \log$ unit compared to the stability expected for a sole phosphate coordination; the stability of the $\mathrm{Cu}\left(3^{\prime} \mathrm{AMP}\right)$ complex is only very slightly enhanced, if at all. The different stability enhancements point to different structural properties of the two ligands. In case 7-membered chelates were formed by coordination of the phosphate-bound $\mathrm{Cu}^{2+}$ with the neighboring hydroxyl group, the situation in $2^{\prime} \mathrm{AMP}^{2-}$ and $3^{\prime} \mathrm{AMP}^{2-}$ would be equivalent and the same stability enhancement would be expected. Hence, a significant hydroxyl group interaction needs to be ruled out and this leaves as the only explanation of the observed results an interaction of $\mathrm{Cu}^{2+}$ in $\mathrm{Cu}\left(2^{\prime} \mathrm{AMP}\right)$ with $\mathrm{N} 3$ of the purine residue giving rise to an 8 -membered macrochelate. 
Indeed, space-filling molecular models indicate that $2^{\prime} \mathrm{AMP}^{2-}$ in its preferred anti conformation is perfectly suited for this type of macrochelate formation [48]. Furthermore, a crystal structure study [49] shows that $\mathrm{Mg}^{2+}$ is coordinated in $\mathrm{Mg}$ (2'AMP) to the phosphate group and that it interacts in addition in an outersphere manner, i.e., via a water molecule, with $\mathrm{N} 3$ of the adenine residue. Finally, among the 10 metal ions studied in solution, only $\mathrm{Ni}^{2+}, \mathrm{Zn}^{2+}$, and $\mathrm{Cd}^{2+}$ are likely to form small amounts of base-backbound species [50]; the stability enhancements for their M(2'AMP) complexes are just at the edge of significance [48]. No stability enhancement is observed for $\mathrm{Cd}\left(3^{\prime} \mathrm{AMP}\right)$ [48].

\subsection{A Favorable Steric Setting and a Reduced Solvent Polarity May Promote Metal Ion-Hydroxyl (or -Carbonyl) Group Binding}

More insight into $\mathrm{Cd}^{2+}$ binding to hydroxyl (and carbonyl) groups in solution encompassing the neutral $\mathrm{pH}$ range and having a phosphate group as a primary binding site, can be gained by considering the metal ion-binding properties of the keto-triose derivative dihydroxacetone phosphate $\left(\mathrm{DHAP}^{2-}\right)$ and the other three related compounds shown in Figure 3. The combination

\section{insert Figure 3 close to here (width: $8 \mathrm{~cm}$ )}

of coordinating groups seen at $\mathrm{C} 1$ and $\mathrm{C} 2$ for $\mathrm{DHAP}^{2-}$ and glycerol 1-phosphate $\left(\mathrm{G}^{2} \mathrm{P}^{2-}\right)$ is representative for many sugar moieties. From a steric point of view, an interaction of a phosphate-coordinated metal ion with the neighboring keto or hydroxyl group is very well possible in both instances. The questions are: Does such an interaction occur in aqueous solution? Are 7-membered chelates formed as expressed in a simplified manner (with charge neglection) in equilibrium (5)?

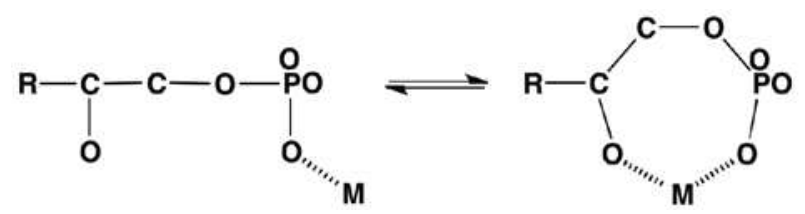

Any kind of chelate formation has to enhance complex stability [51]. Hence, a possibly increased stability, defined as $\log \Delta_{\mathrm{M} / \mathrm{L}}$, of $\mathrm{Cd}(\mathrm{DHAP})$ or $\mathrm{Cd}(\mathrm{G} 1 \mathrm{P})$, if compared with a pure 
phosphate coordination, could therefore be attributed to the participation of the oxygen at $\mathrm{C} 2$ in $\mathrm{Cd}^{2+}$ binding, i.e., equilibrium (5) would then truly exist and at least in part be on its right side. However, the results $\log \Delta_{\mathrm{Cd} / \mathrm{DHAP}}=0.02 \pm 0.05$ and $\log \Delta_{\mathrm{Cd} / \mathrm{GlP}}=-0.02 \pm 0.06\left(25^{\circ} \mathrm{C} ; I=0.1 \mathrm{M}\right.$, $\mathrm{NaNO}_{3}$ ) [52,53] are both zero within their error limits, and thus, no increased complex stability is observed and it must therefore be concluded that in aqueous solution equilibrium (5) is on its left side and that the $(\mathrm{C} 2)=\mathrm{O}$ and $(\mathrm{C} 2)-\mathrm{OH}$ groups do not participate in $\mathrm{Cd}^{2+}$ binding.

Corresponding results have been obtained for the complexes of $\mathrm{Co}^{2+}, \mathrm{Cu}^{2+}$, and $\mathrm{Zn}^{2+}[52,53]$.

However, it needs to be added that a decreased solvent polarity is expected to increase the affinity in general, as has been shown to occur also in larger RNAs [54], and to favor weakly coordinating oxygen sites [30]. Indeed, for $\mathrm{Cu}(\mathrm{DHAP})$ and $\mathrm{Cu}(\mathrm{G} 1 \mathrm{P})$ it has been shown that in water containing 50\% 1,4-dioxane (v/v) the chelated species in equilibrium (5) reach a formation degree of about $45 \%[52,53]$. A similar chelate formation must be anticipated for the corresponding $\mathrm{Cd}^{2+}$ complexes in solutions with a reduced dielectric constant or permittivity $(\varepsilon)$. It is worthwhile to note that in the discussed examples the hydroxyl and carbonyl groups behave within the error limits quite alike.

A change in size of the potential 7-membered chelate ring (eq. 5) to a 6-membered one, demonstrates the importantce of the steric orientation for weak interactions. Acetyl phosphate $\left(\mathrm{AcP}^{2-}\right)$ and acetonylphosphonate $\left(\mathrm{AnP}^{2-}\right)$ may form with metal ions 6-membered chelates as is show in equilibrium (6), where $\mathrm{X}=\mathrm{O}\left(\mathrm{AcP}^{2-}\right)$ or $\mathrm{CH}_{2}\left(\mathrm{AnP}^{2-}\right)$ :

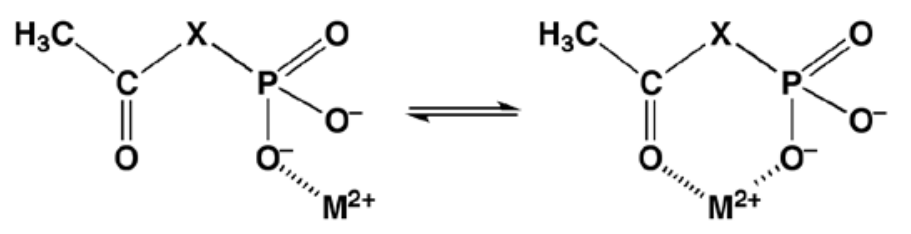

In fact, for $\mathrm{Cd}(\mathrm{AcP})$ and $\mathrm{Cd}(\mathrm{AnP})$ small, but significant, stability enhancements are observed, i.e., $\log \Delta_{\mathrm{Cd}(\mathrm{AcP}}=0.19 \pm 0.06$ and $\log \Delta_{\mathrm{Cd} / \mathrm{AnP}}=0.18 \pm 0.06$, respectively [52,55]. These stability enhancements correspond to a formation degree of about $35 \%$ for the chelate in the intramolecular equilibrium (6); the interrelation between $\log \Delta_{\mathrm{M} / \mathrm{L}}$ and $\% \mathrm{M}(\mathrm{L})_{\mathrm{cl}}$ will be presented in Section 4.2 [51]. For now it is enough to add that the formation degree of the chelated species is hardly affected in mixed ligand complexes as is evidenced from examples with $\mathrm{Cu}(\mathrm{Arm})^{2+}$, where Arm = 2,2'-biypridine or 1,10-phenanthroline [52,56]. 
From the information presented above it follows that sugar hydroxyl (or carbonyl) groups are weak binding sites which will interact with $\mathrm{Cd}^{2+}$ (or other $\mathrm{M}^{2+}$ ) in aqueous solution only under rather specific conditions. Indeed, from comparison of the results to be discussed in Section 6.2.3 for M(NMP) complexes, where $\mathrm{NMP}^{2-}=$ nucleoside 5'-monophosphate, with the above data it follows that $\mathrm{N} 7$ of purine-nucleobase residues has a more pronounced affinity for $\mathrm{Cd}^{2+}$ than a sugar hydroxyl group. On the other hand, the ligands shown in Figure 4, which contain different primary binding sites next to a hydroxyl group, allowing formation of 5membered chelates, provide some further insights into hydroxyl group coordination as relevant for nucleic acids.

\section{insert Figure 4 close to here (width: $8 \mathrm{~cm}$ )}

The experimentally measured stability constants (eq. 2), the stability enhancements, log $\Delta_{\mathrm{M} / \mathrm{L}}$, and the percentages of the closed isomers, $\% \mathrm{M}(\mathrm{L})_{\mathrm{cl}}$ (in analogy to equilibria 5,6 ) are listed in Table 2 [57] for the 1:1 complexes of several metal ions with the three ligands seen in Figure 4.

\section{insert Table 2 close to here (landscape)}

Unfortunately, not all desired data, especially for the $\mathrm{Cd}^{2+}$ complexes are available, but enough to draw a number of conclusions. Also, part of the data available for the complexes of hydroxyacetate refer to the rather high ionic strength of $2 \mathrm{M}$. Fortunately, the change in $I$ from 0.1 to $2 \mathrm{M}$ affects the overall stability constant (eq. 2), especially in the case of $\mathrm{Zn}(\mathrm{HOAc})^{+}$, but has no remarkable influence on $\log \Delta_{\mathrm{M} / \mathrm{HOAc}}$ and $\% \mathrm{M}(\mathrm{HOAc})_{\mathrm{cl}}^{+}$, as is proven by the results for

$\mathrm{Cu}^{2+}$ and $\mathrm{Zn}^{2+}$. Consequently, all the listed values in Table 2 for the stability enhancements and the percentages of the chelated isomers can directly be compared with each other. Many comparisons are possible, a few follow below:

(i) The possibility to form 5-membered chelates is evidently a favorable setting; metal ionhydroxyl group interactions occur in all instances. By taking also the preceding results into account, it follows that the stability of the chelates decreases with increasing ring size in the order 5-membered $>6$-membered $>7$-membered ring.

(ii) There is no correlation between the global stability of a complex (eq. 2) and the formation 
degree of the chelated isomer, which is the result of an intramolecular and thus concentrationindependent equilibrium (see eqs. 5, 6). For example, $\mathrm{Ca}(\mathrm{HOAc})^{+}$is less stable than $\mathrm{Cd}(\mathrm{HOAc})^{+}$, yet the formation degree of the closed isomer is significantly larger in $\mathrm{Ca}(\mathrm{HOAc})^{+}$.

(iii) However, there is a correlation between the charge of the primary binding site and the extent of chelate formation; the percentages of the closed forms increase in the order $\mathrm{M}(\mathrm{HMP})_{\mathrm{cl}}$ $<\mathrm{M}(\mathrm{HOAc})_{\mathrm{cl}}^{+}<\mathrm{M}(\mathrm{HOMPy})_{\mathrm{cl}}^{2+}$. This is a reflection of charge neutralization at $\mathrm{M}^{2+}$ leading to a reduced affinity of the metal ion towards hydroxyl groups [57].

(iv) Point (iii) has an interesting bearing for nucleic acids: It allows the conclusion that a metal ion coordinated to the singly negatively charged phosphodiester bridge is better suited for a hydroxyl group interaction than a metal ion bound to a twofold negatively charged terminal phosphate group. Regarding ribozymes this result is revealing. It may be added that the acetate ion, $\mathrm{CH}_{3} \mathrm{COO}^{-}$, may be considered as a mimic of the phosphodiester unit, $\mathrm{RO}-\mathrm{P}(\mathrm{O})_{2}^{-}-\mathrm{OR}^{\prime}$ in the nucleic acid backbone as far as metal ion coordination is concerned [58] (see also Section 5).

(v) Similarly, the fact that pyridine-type nitrogens are ideal primary binding sites is in agreement with the suggested chelate formation in $\mathrm{Cu}\left(2^{\prime} \mathrm{AMP}\right)$ involving $\mathrm{N} 3$ of the adenine residue and the (C2)OH group (see Section 3.2). Note, the basicity, and thus the metal ion affinity, of $\mathrm{N} 3$ should not be underestimated: The micro acidity constant for the $(\mathrm{N} 3) \mathrm{H}^{+}$site in otherwise neutral adenosine was estimated as $\mathrm{p} k_{\mathrm{a} /(\mathrm{N} 3) \mathrm{H}}=1.5 \pm 0.3$ [36]; such a value is ideal for outersphere interactions [59-61], e.g., with $\mathrm{Mg}^{2+}$ (see the discussed solid-state structure of $\operatorname{Mg}\left(2^{\prime} \mathrm{AMP}\right)$ in Section 3.2).

(vi) The stability enhancements observed for the $\mathrm{Cd}(\mathrm{L})$ species are about half the size of those found for the corresponding $\mathrm{Zn}(\mathrm{L})$ complexes; consequently, it holds $\% \mathrm{Cd}(\mathrm{L})_{\mathrm{cl}}<\% \mathrm{Zn}(\mathrm{L})_{\mathrm{cl}}$. Yet, here a caveat is needed: If ligands are synthesized with a pocket that fits well the size of $\mathrm{Cd}^{2+}$ (but not of $\mathrm{Zn}^{2+}$ ), then the situation towards hydroxyl group interactions may change dramatically [57]. Clearly, a nucleic acid cavity fitting the size of $\mathrm{Ca}^{2+}$ is expected to be also ideal for $\mathrm{Cd}^{2+}$. Some ribozymes show a distinct specificity for $\mathrm{Ca}^{2+}$, e.g., the antigenomic HDV ribozyme [62], group I introns [63-65], and group II introns, the latter being severely hampered in catalysis [66] and folding [67,68].

(vii) The results given in the lower part of Table 2 confirm the earlier conclusions (see the 
discussed $\mathrm{Cu}(\mathrm{DHAP})$ and $\mathrm{Cu}(\mathrm{G} 1 \mathrm{P})$ complexes $[52,53])$ that a reduced solvent polarity favors $\mathrm{M}^{2+}$-hydroxyl interactions.

(viii) A final point, which follows by taking the results of the whole section as well as further data [57] into account, is that, assuming a suitable primary binding site is present, the metal ion affinity to hydroxyl and carbonyl groups is quite alike, but the one towards ether oxygen atoms is much smaller, e.g., the stability enhancement for the $\mathrm{Cu}^{2+}$ complex of methoxyacetate, $\mathrm{CH}_{3} \mathrm{OAc}^{-}$ $=\mathrm{CH}_{3} \mathrm{OCH}_{2} \mathrm{COO}^{-}$, amounts only to $\log \Delta_{\mathrm{Cu} / \mathrm{CH}_{3} \mathrm{OAc}}=0.36 \pm 0.11$ [57] compared to $\log \Delta_{\mathrm{Cu} / \mathrm{HOAc}}=$ $0.79 \pm 0.08$ (Table 2).

\section{Interactions of Cadmium(II) with Nucleobase Residues}

The common purine and pyrimidine nucleobases are shown in Figure 1. We will concentrate in this section on (N9)-substituted purines and (N1)-substituted pyrimidines, the substituent being an alkyl group, and on the nucleosides which carry a (2'-deoxy)ribose residue at the corresponding position. Metal ion binding of the free nucleobases is not of relevance in the present context. It is evident from Figure 1 that these nucleobase residues possess quite a number of potential metal ion-binding sites [30,58], yet from a narrow point of view one may say that N7 is the crucial site for purines and $\mathrm{N} 3 /(\mathrm{N} 3)^{-}$for the pyrimidines. The details will be discussed below.

\subsection{Cadmium(II) Complexes of Purine Derivatives}

The dominance of the N7 site for the coordination chemistry of the purine nucleosides and related systems is even true under rather exceptional circumstances, that is, even protonation at N1 does not necessarily prevent metal ion binding at N7 though it certainly diminishes it [69].

Considering the importance of N7, it seemed appropriate for us to evaluate its metal ionbinding properties somewhat more in detail. We are doing this by mimicking the N7 site of the purine nucleobases by the imidazole derivatives shown in the upper part of Figure 5. The N1 site 
of the adenine residue may be mimicked by pyridine and derivatives (Figure 5, lower part). The acidity constants of these ligands and the stability constants of their corresponding $\mathrm{Cd}^{2+}$ complexes are defined by equations (3) and (2), respectively. The corresponding results are listed in entries 1 to 6 of Table 3 [70-75].

\section{insert Figure 5 close to here (width: $7 \mathrm{~cm}$ )}

\section{insert Table 3 close to here}

Annelation at imidazole giving benzimidazole reduces the basicity of N3 as is obvious from the first two entries of Table 3, but it also somewhat inhibits metal ion coordination. For $\mathrm{Cd}^{2+}$ the inhibition amounts to $0.25 \pm 0.05 \log$ unit if the basicity differences are taken into account [60]. However, a drastic inhibition occurs if at the neighboring C4 a methyl group is introduced (see Figure 5, top, right). Because the basicity of $\mathrm{N} 3$ in $1 \mathrm{MBI}$ is close to the one in DMBI (Table 3; entries 2, 3), the stability constants of the two $\mathrm{Cd}^{2+}$ complexes, $\mathrm{Cd}(1 \mathrm{MBI})^{2+}$ and $\mathrm{Cd}(\mathrm{DMBI})^{2+}$, may directly be compared: The methyl substituent lowers complex stability by about $1.4 \log$ units $(=2.10-0.72)$. Since the steric requests of a methyl and an amino substituent at an aromatic ring are comparable [59] (see also the straight-line plots in Figure 6; vide infra), that is, there is a shape complementarity between the 4-methylbenzimidazole and adenine residues [76], it follows that the steric inhibition of the (C6) $\mathrm{NH}_{2}$ group on $\mathrm{Cd}^{2+}$ coordination at $\mathrm{N} 7$ is expected to be of a similar size: Indeed, this is in accord with results of other divalent metal ions [61]. Interestingly, the steric inhibition of the (C6) $\mathrm{NH}_{2}$ group on $\mathrm{N} 1$ coordination is less severe; a comparison of the values given in entries 4 and 5, 6 of Table 3 (see also the structures in Figure 5) shows that it corresponds to about $0.8 \log$ unit (see also refs $[61,71]$ ).

Considering that the $\mathrm{p} K_{\mathrm{a}}$ values for both, the $\mathrm{N} 7$ and the $\mathrm{N} 1$ sites of monoprotonated adenosine are such that no competition between the proton and metal ions for binding at either site in the neutral $\mathrm{pH}$ range occurs, one expects that metal ions including $\mathrm{Cd}^{2+}$ actually may coordinate at either site. Indeed, for the $\mathrm{Cd}(\mathrm{Ado})^{2+}$ complex a dichotomy exists and it was previously concluded that the N7 isomer occurs with $61 \pm 10 \%$ [77]; a more recent evaluation [73] arrives at $35 \pm 11 \%$. The discrepancy between these results is no surprise as the evaluation methods differ significantly; in any case, the dichotomy is certain and occurs also, e.g., with $\mathrm{Cu}(9 \text {-methyladenine })^{2+}$ where $59 \pm 12 \%$ exist as the N7 isomer [61]. 
The N7 sites of inosine or (2'-deoxy)guanosine exist also deprotonated in the neutral $\mathrm{pH}$ range (Table 3, entries 8-10) and thus are easily accessible for metal ions. Such (N7)-bound metal ions form commonly a hydrogen bond from a ligated water molecule to (C6)O (cf. Figure 1) $[11,78]$; in contrast to an amino group a carbonyl or keto group at C6 does not exercize any steric hindrance (see also Section 4.2). Of course, at higher $\mathrm{pH}$ values the neutral (N1)H sites may be deprotonated. This reaction is expressed in eq. (7), where L represents a nucleobase residue. Naturally, the $(\mathrm{L}-\mathrm{H})^{-}$species formed in this way may also form complexes according to eq. (8) , and the $\mathrm{M}(\mathrm{L})^{2+}$ complex may be deprotonated at (N1)H as well (eq. 9):

$$
\begin{gathered}
\mathrm{L} \rightleftharpoons(\mathrm{L}-\mathrm{H})^{-}+\mathrm{H}^{+} \\
K_{\mathrm{L}}^{\mathrm{H}}=\left[(\mathrm{L}-\mathrm{H})^{-}\right]\left[\mathrm{H}^{+}\right] /[\mathrm{L}] \\
\mathrm{M}^{2+}+(\mathrm{L}-\mathrm{H})^{-} \rightleftharpoons \mathrm{M}(\mathrm{L}-\mathrm{H})^{+} \\
K_{\mathrm{M}(\mathrm{L}-\mathrm{H})}^{\mathrm{M}}=\left[\mathrm{M}(\mathrm{L}-\mathrm{H})^{+}\right] /\left(\left[\mathrm{M}^{2+}\right]\left[(\mathrm{L}-\mathrm{H})^{-}\right]\right) \\
\mathrm{M}(\mathrm{L})^{2+} \rightleftharpoons \mathrm{M}(\mathrm{L}-\mathrm{H})^{+}+\mathrm{H}^{+} \\
K_{\mathrm{M}(\mathrm{L})}^{\mathrm{H}}=\left[\mathrm{M}(\mathrm{L}-\mathrm{H})^{+}\right]\left[\mathrm{H}^{+}\right] /\left[\mathrm{M}(\mathrm{L})^{2+}\right]
\end{gathered}
$$

Evidently, equilibria (2a) and (7a) to (9a) are connected with each other via the equilibrium scheme (10) [79]:

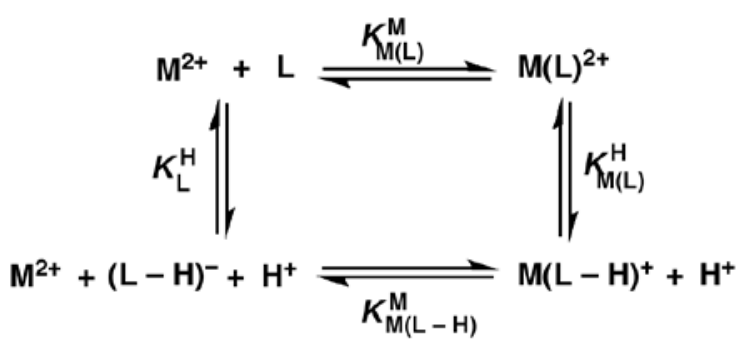

This scheme involves four equilibrium constants and because it is of a cyclic nature, only three constants are independent of each other; the fourth constant is automatically determined by the other three as follows from eq. (11):

$$
\begin{aligned}
& \log K_{\mathrm{M}(\mathrm{L})}^{\mathrm{M}}-\mathrm{p} K_{\mathrm{M}(\mathrm{L})}^{\mathrm{H}}=\log K_{\mathrm{M}(\mathrm{L}-\mathrm{H})}^{\mathrm{M}}-\mathrm{p} K_{\mathrm{L}}^{\mathrm{H}} \\
& \mathrm{p} K_{\mathrm{M}(\mathrm{L})}^{\mathrm{H}}=\mathrm{p} K_{\mathrm{L}}^{\mathrm{H}}+\log K_{\mathrm{M}(\mathrm{L})}^{\mathrm{M}}-\log K_{\mathrm{M}(\mathrm{L}-\mathrm{H})}^{\mathrm{M}}
\end{aligned}
$$

The acidification of the (N1)H sites in $\mathrm{M}(\mathrm{L})^{2+}$ complexes, as caused by the (N7)- 
coordinated metal ion, is defined by eq. (12):

$$
\Delta \mathrm{p} K_{\mathrm{a}}=\mathrm{p} K_{\mathrm{L}}^{\mathrm{H}}-\mathrm{p} K_{\mathrm{M}(\mathrm{L})}^{\mathrm{H}}
$$

The corresponding results for the $\mathrm{Cd}^{2+}$ systems with Ino and dGuo, based on the data in Table 3 , are summarized in Table 4, where also some results obtained for related $\mathrm{Ni}^{2+}$ systems are listed $[40,80]$. It is remarkable that the (N7)-coordinated metal ion facilitates (N1)H deprotonation to such an extent that this reaction occurs now in or close to the physiological $\mathrm{pH}$ range (Table 4 , column 5).

\section{insert Table 4 close to here}

The results of Table 4 are in accord with previous conclusions [80] and by taking into account the present insights for the $\mathrm{Cd}^{2+}$ systems, one may define the following series in which the acidifying effect of the (N7)-coordinated divalent metal ion decreases (the $\Delta \mathrm{p} K_{\mathrm{a}}$ values being inserted in parentheses): $\mathrm{Cu}^{2+}(2.2 \pm 0.3)>\mathrm{Ni}^{2+}(1.7 \pm 0.15) \sim \mathrm{Cd}^{2+}\left(\sim \mathrm{Zn}^{2+}\right)>\mathrm{Pt}^{2+}(1.4 \pm$ $0.1) \sim \mathrm{Pd}^{2+} . \mathrm{Zn}^{2+}$ is tentatively inserted into this series based on data given in ref. [80]. These results also indicate that in the $(\mathrm{N} 1) \mathrm{H}$-deprotonated $\mathrm{M}(\mathrm{NB}-\mathrm{H})^{+}$complexes the labile divalent metal ions are still largely at N7, though some dichotomy involving also (N1) ${ }^{-}$cannot be excluded. The reason why we favor mainly N7 coordination is the fact that the $\mathrm{p} K_{\mathrm{a}}$ values for the kinetically inert and (N7)-bonded $\mathrm{Pt}^{2+}$ complexes fit perfectly into the given series [40]. Of course, in the complexes formed by purine-nucleotides and $\mathrm{Cd}^{2+}$ or other $\mathrm{M}^{2+}$, even if (N1)H is deprotonated, the phosphate-coordinated metal ion interacts always with N7 [81] because (N1) ${ }^{-}$ could only be reached in the syn conformation. However, this is not achieved because the antisyn barrier is too high in energy [35].

Three more points may be added in the present context:

(i) The acidification $\left(\Delta \mathrm{p} K_{\mathrm{a}}\right)$ by $\mathrm{Cd}^{2+}$ and $\mathrm{Ni}^{2+}$ is identical within the error limits for all examples in Table 4, even though the acidity of the various (N1)H sites differs significantly.

(ii) The acidification of $\mathrm{Cd}^{2+}$ as observed in the $\mathrm{Cd}(\mathrm{GpG})^{+}$and $\mathrm{Cd}[\mathrm{d}(\mathrm{GpG})]^{+}$complexes is with $\Delta \mathrm{p} K_{\mathrm{a}}=1.8 \pm 0.4[38]$ within the error limits the same as given above in Table 4 .

(iii) For the (Dien) $\mathrm{Pt}(9 \mathrm{EtG}-N 7)^{2+}$ complex it has been shown that the (N7)-coordinated $\mathrm{Pt}^{2+}$ not only acidifies $(\mathrm{N} 1) \mathrm{H}\left(\Delta \mathrm{p} K_{\mathrm{a}}=1.40 \pm 0.06\right)$, but that the released proton can be replaced by another $\mathrm{M}^{2+}$, such as $\mathrm{Mg}^{2+}$ or $\mathrm{Cu}^{2+}$, giving complexes of the type (Dien) $\operatorname{Pt}(N 7-9 \mathrm{EtG}-N 1 \cdot \mathrm{M})^{3+}$ 
[82]. The same may be surmised for $\mathrm{Cd}^{2+}$. This shows that "clustering" of metal ions at a guanine residue is possible; an observation relevant for ribozymes [30].

\subsection{Cadmium(II) Complexes of Pyrimidine Derivatives}

Among the three pyrimidine-nucleobase residues shown in Figure 1 only the cytosine moiety is not protonated at $\mathrm{N} 3$ in the physiological $\mathrm{pH}$ range and hence, freely available for metal ion coordination. Therefore, this residue will be discussed first. The cytosine residue is an ambivalent ligating site as follows from crystal structure studies; e.g., $\mathrm{Pt}^{2+}$ coordinates to $\mathrm{N} 3$, $\mathrm{Ba}^{2+}$ to $(\mathrm{C} 2) \mathrm{O}$, and $\mathrm{Cu}^{2+}$ binds to both sites $[35,40]$. Thus, in the latter instance chelate formation occurs and for aqueous solution then the intramolecular equilibrium (13) needs to be considered:

$$
\mathrm{M}(\mathrm{Cyd})_{\mathrm{op}}^{2+} \rightleftharpoons \mathrm{M}(\mathrm{Cyd})_{\mathrm{cl}}^{2+}
$$

Of course, a $\mathrm{M}^{2+}$ interaction may be innersphere or outersphere, but in any case a 'closed' (cl) species results. The 'open' (op) species may be N3- or (C2)O-bound, depending on the metal ion involved. Overall, one may imagine that 4-membered chelates exist, or if a water molecule participates, that a 6-membered so-called semichelate forms. In addition, a complete outersphere interaction with both sites can also not be excluded. As a consequence, the $\mathrm{M}(\mathrm{Cyd})_{\mathrm{cl}}^{2+}$ species are actually expected to be mixtures of chelated isomers [35].

Any kind of chelate formation must lead to a stability enhancement [51], which is defined in a general manner in equation (14), where for the present $\mathrm{L}=\mathrm{Cyd}$ :

$$
\begin{aligned}
\log \Delta_{\mathrm{M} / \mathrm{L}} & =\log K_{\mathrm{M}(\mathrm{L})}^{\mathrm{M}}-\log K_{\mathrm{M}(\mathrm{L}) \text { op }}^{\mathrm{M}} \\
& =\log K_{\mathrm{M}(\mathrm{L}) \exp }^{\mathrm{M}}-\log K_{\mathrm{M}(\mathrm{L}) \text { calc }}^{\mathrm{M}}=\log \Delta
\end{aligned}
$$

The first term in eq. (14) is experimentally accessible as it can be measured directly (eq. 2). To obtain a value for the open $\mathrm{M}(\mathrm{L})_{\mathrm{op}}$ complex is commonly more difficult. Most often plots of log $K_{\mathrm{M}(\mathrm{L})}^{\mathrm{M}}$ versus $\mathrm{p} K_{\mathrm{H}(\mathrm{L})}^{\mathrm{H}}$ are employed, which result for families of structurally related ligands in straight lines [51] as defined by equation (15),

$$
\log K_{\mathrm{M}(\mathrm{L})}^{\mathrm{M}}=m \cdot \mathrm{p} K_{\mathrm{H}(\mathrm{L})}^{\mathrm{H}}+b
$$


where $m$ represents the slope of the straight line and $b$ the intercept with the $y$-axis. Clearly, if the parameters of eq. (15) are known, one may calculate with $\mathrm{p} K_{\mathrm{H}(\mathrm{L})}^{\mathrm{H}}$ the stability of the $\mathrm{M}(\mathrm{L})$ complex.

The position of equilibrium (13) for Cyd $=\mathrm{L}$ is defined by the dimension-less intramolecular equilibrium constant $K_{\mathrm{I}}$ (eq. 16),

$$
K_{\mathrm{I}}=\left[\mathrm{M}(\mathrm{L})_{\mathrm{cl}}\right] /\left[\mathrm{M}(\mathrm{L})_{\mathrm{op}}\right]
$$

which may be calculated according to equation (17) [51]:

$$
K_{\mathrm{I}}=\frac{K_{\mathrm{M}(\mathrm{L})}^{\mathrm{M}}}{K_{\mathrm{M}(\mathrm{L}) \text { op }}^{\mathrm{M}}}-1=10^{\log \Delta}-1
$$

Equation (14) defines $\log \Delta$, whereas $K_{\mathrm{M}(\mathrm{L})}^{\mathrm{M}}$ (eq. 2) and $K_{\mathrm{M}(\mathrm{L}) \text { op }}^{\mathrm{M}}$ are defined by equations (18) and (19), respectively:

$$
\begin{aligned}
& K_{\mathrm{M}(\mathrm{L})}^{\mathrm{M}}=\frac{[\mathrm{M}(\mathrm{L})]}{[\mathrm{M}][\mathrm{L}]}=\frac{\left(\left[\mathrm{M}(\mathrm{L})_{\mathrm{op}}\right]+\left[\mathrm{M}(\mathrm{L})_{\mathrm{cl}}\right]\right)}{[\mathrm{M}][\mathrm{L}]} \\
& K_{\mathrm{M}(\mathrm{L}) \text { op }}^{\mathrm{M}}=\frac{\left[\mathrm{M}(\mathrm{L})_{\mathrm{op}}\right]}{[\mathrm{M}][\mathrm{L}]}
\end{aligned}
$$

Of course, knowledge of $K_{\mathrm{I}}$ allows to calculate the formation degree of the closed or chelated species (eq. 13) according to equation (20):

$$
\% \mathrm{M}(\mathrm{L})_{\mathrm{cl}}=100 \cdot K_{\mathrm{I}} /\left(1+K_{\mathrm{I}}\right)
$$

Some examples of $\log K_{\mathrm{M}(\mathrm{L})}^{\mathrm{M}}$ versus $\mathrm{p} K_{\mathrm{H}(\mathrm{L})}^{\mathrm{H}}$ straight-line plots for simple pyridine-type (PyN; open circles) as well as for ortho-aminopyridine-type (oPyN; crossed circles) ligands [59] are shown in Figure 6 [35,83]. Combination of these plots with the data points due to log $K_{\mathrm{M}(\mathrm{Cyd})}^{\mathrm{M}} / \mathrm{p} K_{\mathrm{H}(\mathrm{Cyd})}^{\mathrm{H}}$ (full circles) [83] allows immediately several interesting conclusions:

\section{insert Figure 6 close to here (width: $6 \mathrm{~cm}$ )}

(i) The $\mathrm{M}(o \mathrm{PyN})^{2+}$ complexes of all studied metal ions [35,59] are less stable than the $\mathrm{M}(\mathrm{PyN})^{2+}$ species. This proves the steric inhibition of an ortho-amino group next to the coordinating pyridine nitrogen.

(ii) The data point for the $\mathrm{Co}(\mathrm{Cyd})^{2+}$ complex fits on the reference line defined by the $\mathrm{M}(o \mathrm{PyN})^{2+}$ species, meaning that the neighboring carbonyl group does not participate in metal 
ion binding and that only the steric inhibition of the (C6) $\mathrm{NH}_{2}$ group is in action.

(iii) This is different for the $\mathrm{Cd}(\mathrm{Cyd})^{2+}$ complex which shows an increased complex stability, thus indicating the participation of the $(\mathrm{C} 2) \mathrm{O}$ group in metal ion binding. That is, the steric inhibition of the (C6) $\mathrm{NH}_{2}$ group is partially offset by the $(\mathrm{C} 2) \mathrm{O}$ group.

(iv) The stabilities of the $\mathrm{Ca}(\mathrm{PyN})^{2+}$ and the $\mathrm{Ca}(o \mathrm{PyN})^{2+}$ complexes differ only little. The scatter of the data points originates in the low stability of these complexes [59], which is independent of the $\mathrm{p} K_{\mathrm{a}}$ value of the pyridine derivative considered in the $\mathrm{pH}$ range 3-7. This indicates [59] that complex formation takes place in an outersphere manner [35].

(v) Furthermore, $\mathrm{Ca}(\mathrm{Cyd})^{2+}$ is even more stable than the sterically unhindered $\mathrm{Ca}(\mathrm{PyN})^{2+}$ species proving the importance of the $(\mathrm{C} 2) \mathrm{O}$ interaction in $\mathrm{Ca}(\mathrm{Cyd})^{2+}$. The corresponding observations were made for the $\mathrm{Mg}^{2+}$ complexes [35,59].

Of course, the data as summarized in Figure 6 can be evaluated in a quantitative manner by application of equations (14)-(20). Table 5 contains in column 2 the stability constants measured previously [83] for the $\mathrm{M}(\mathrm{Cyd})^{2+}$ complexes. The stability constants for the open isomers (eqs $13,19)$ were calculated based on $\mathrm{p} K_{\mathrm{H}(\mathrm{Cyd})}^{\mathrm{H}}=\mathrm{p} K_{\mathrm{H}(o \mathrm{PyN})}^{\mathrm{H}}=4.24 \pm 0.02$ [83] and the straight-line parameters as defined in equation (15) and listed in ref. [59]; these values for $\mathrm{M}(\mathrm{Cyd}) \mathrm{op}^{2+}$ are given in column 3. From the mentioned constants the $\log \Delta$ values (eq. 14) (column 4) follow; they correspond to the vertical distances seen in Figure 6 between the experimentally determined points of a given $\mathrm{M}(\mathrm{Cyd})^{2+}$ complex (solid circle) and its reference line (crossed circles); these values are listed in column 4 of Table 5. Application of equations (17) and (20) allows to calculate values for $K_{\mathrm{I}}($ eqs 16,17$)$ and $\% \mathrm{M}(\mathrm{Cyd})_{\mathrm{cl}}^{2+}$ (eq. 20), respectively; these results are listed in columns 5 and 6 of Table 5.

\section{insert Table 5 close to here}

From column 6 in Table 5 it follows that the closed species in the $\mathrm{M}(\mathrm{Cyd})^{2+}$ systems reach remarkable formation degrees and that equilibrium (13) in many instances truly exists. Indeed, exceptions are only $\mathrm{Co}(\mathrm{Cyd})^{2+}$ and $\mathrm{Ni}(\mathrm{Cyd})^{2+}$ [35]. Furthermore, Table 5 allows some additional interesting conclusions:

(i) The closed complex, $\mathrm{Mg}(\mathrm{Cyd})_{\mathrm{cl}}^{2+}$, formed to about $35 \%$, is most likely a semichelate which is mainly innersphere bound to $(\mathrm{C} 2) \mathrm{O}$ and outersphere to $\mathrm{N} 3$. This view is supported by 
the crystal structure of $\mathrm{Ba}(\mathrm{CMP}) \cdot 8.5 \mathrm{H}_{2} \mathrm{O}$ where the alkaline earth ion is bonded to $(\mathrm{C} 2) \mathrm{O}$ (and the sugar, but not to N3 or the phosphate) $[11,84]$.

(ii) The same type of semichelate is also suggested for $\mathrm{Ca}(\mathrm{Cyd})_{\mathrm{cl}}^{2+}$. Interestingly, despite the significant stability difference between $\mathrm{Ca}(\mathrm{Cyd})^{2+}$ and $\mathrm{Cd}(\mathrm{Cyd})^{2+}$ (column 2; eq. 2) both complexes reach formation degrees of about $50 \%$ for the chelated isomer. Note, this is possible because $K_{\mathrm{I}}$ is a dimension-less constant which quantifies the position of an intramolecular equilibrium (eq. 13).

(iii) However, for $\mathrm{Cd}(\mathrm{Cyd}){ }_{\mathrm{cl}}^{2+}$ one expects innersphere coordination of $\mathrm{N} 3$ and possibly outersphere binding to $(\mathrm{C} 2) \mathrm{O}$. In this context it is revealing to note that in the polymeric $\mathrm{Cd}(\mathrm{dCMP})$ complex binding of the octahedral $\mathrm{Cd}^{2+}$ occurs to both $\mathrm{N} 3(2.30 \AA)$ and $(\mathrm{C} 2) \mathrm{O}(2.64$ $\AA$ A) by formation of a 4-membered ring [85]. The same may be surmised for $\mathrm{Cd}(\mathrm{Cyd})_{\mathrm{cl}}^{2+}$, but in aqueous solution one expects it to be, at least, in equilibrium with the indicated semichelate.

(iv) In the polymeric Co(CMP) complex the metal ion coordinates to N3 (1.99 $\AA$ ) and does not interact with (C2)O [86]; this agrees with the properties of $\mathrm{Co}(\mathrm{Cyd})^{2+}$ for which equilibrium (13) is far to its left. However, considering the small slope of the $\mathrm{Co}(o \mathrm{PyN})^{2+}$ reference line seen in Figure 6 (compare with the $\mathrm{Mg}^{2+}$ situation) [59], it could well be that a significant amount of the metal ion in $\mathrm{Co}(\mathrm{Cyd})^{2+}$ is also outersphere bound to $\mathrm{N} 3$.

The other two pyrimidine nucleobases, i.e., the uracil and thymine residues (Figure 1), bind strongly to metal ions only after deprotonation of their (N3)H site [87]. This means that carbonyl groups interact significantly with metal ions only if a suitable primary binding site is available (Section 3.3). To establish a sound basis for comparisons equilibria (7a) and (8a) were studied for several metal ion complexes of (N3)H-deprotonated uridine-type ligands (U), i.e., 5fluorouridine, 5-chloro-2'-deoxyuridine, uridine, and thymidine (=2'-deoxy-5-methyluridine). Plots of $\log K_{\mathrm{M}(\mathrm{U}-\mathrm{H})}^{\mathrm{M}}$ versus $\mathrm{p} K_{\mathrm{U}}^{\mathrm{H}}$ result for the four ligand systems in straight lines [88] and these may be compared with the plots discussed above for pyridine- and $o$-aminopyridine-type ligands. Figure 7 shows the situation for the $\mathrm{Cd}^{2+}$ complexes together with the data for the corresponding $\mathrm{Ca}^{2+}$ and $\mathrm{Co}^{2+}$ complexes for comparison.

insert Figure 7 close to here (width: $10 \mathrm{~cm}$ )

From the $\mathrm{Ca}^{2+}$ and $\mathrm{Cd}^{2+}$ parts of Figure 7 it follows that their $\mathrm{M}(\mathrm{U}-\mathrm{H})^{+}$complexes are 
more stable than the $\mathrm{Ca}(\mathrm{PyN})^{2+}$ and $\mathrm{Cd}(\mathrm{PyN})^{2+}$ species, whereas the $\mathrm{Co}(\mathrm{U}-\mathrm{H})^{+}$complexes are less stable than their $\mathrm{Co}(\mathrm{PyN})^{2+}$ counterparts. Furthermore, the $\mathrm{Co}(\mathrm{U}-\mathrm{H})^{+}$straight line is placed (although with a somewhat steeper slope) between the lines of the $\mathrm{Co}^{2+}$ complexes of the PyNand $o$ PyN-type ligands. This indicates that $\mathrm{Co}^{2+}\left(\right.$ like $\left.\mathrm{Ni}^{2+}[88]\right)$ suffers in its coordination to $(\mathrm{N} 3)^{-}$of $(\mathrm{U}-\mathrm{H})^{+}$from a steric hindrance by the neighboring $(\mathrm{C} 2) \mathrm{O} /(\mathrm{C} 4) \mathrm{O}$ groups. This hindrance, however, is less pronounced than that by an $o$-amino (or $o$-methyl) group. In contrast, in $\mathrm{Ca}(\mathrm{U}-\mathrm{H})^{+}$and $\mathrm{Cd}(\mathrm{U}-\mathrm{H})^{+},(\mathrm{C} 2) \mathrm{O}$ and $(\mathrm{C} 4) \mathrm{O}$ facilitate $\mathrm{M}^{2+}$ binding leading thus to an increased complex stability.

In a careful evaluation, taking into account the situation in $\mathrm{M}(\mathrm{Cyd})^{2+}$ complexes [88], it was concluded that the 'lower limits' for the formation degrees of chelates can be assessed; 'lower limits' because in $(\mathrm{U}-\mathrm{H})^{-}$there is no steric hindrance by an $o-\mathrm{NH}_{2}$ group, and two $(\mathrm{C}) \mathrm{O}$ groups (not only one; see Figure 1) may participate in complex formation. Hence, the 'lower limits' for the formation degrees of chelates in $\mathrm{Ca}(\mathrm{U}-\mathrm{H})^{+}$and $\mathrm{Cd}(\mathrm{U}-\mathrm{H})^{+}$are about $50 \%$ and $60 \%$, respectively. In $\mathrm{Cd}(\mathrm{U}-\mathrm{H})^{+}$4-membered chelates may form, but in aqueous solution it is highly likely that in addition semichelates occur via ligated water molecules to $(\mathrm{C} 2) \mathrm{O}$ and $(\mathrm{C} 4) \mathrm{O}$. In contrast, no chelate formation is anticipated for the $\mathrm{Co}^{2+}\left(\right.$ and $\left.\mathrm{Ni}^{2+}\right)$ complex of $(\mathrm{U}-\mathrm{H})^{-}$, i.e., the metal ion coordinates most likely in a monodentate fashion to (N3)- ${ }^{-}$of the uridinates [88].

\subsection{Cadmium(II) Complexes of Some Less Common Nucleobase Residues}

In this section we will consider tubercidin (Figure 5; bottom, left) and the five nucleosides seen in Figure 8 [89].

\subsubsection{Tubercidin}

Tubercidin (Tu), also known as 7-deazaadenosine, is synthesized by molds and fungi [90] and has antibiotic properties. From its structure it follows that Tu is an $o$-aminopyridine-type ligand $[59,72]$, and as we have already seen in Figure 6 (Section 4.2), it fits with its (C6) $\mathrm{NH}_{2} / \mathrm{N} 1$ unit and the connected metal ion-binding properties, including for $\mathrm{Cd}^{2+}$, perfectly into this picture 
[59] and no further discussion is therefore warranted.

\section{insert Figure 8 close to here (width: $8 \mathrm{~cm}$ )}

\subsubsection{Orotidine}

Orotidine and its derivatives play an important role as intermediates in the metabolism of pyrimidine-nucleotides [91]. Its structure is shown in Figure 8 (top, left); it is closely related to uridine (see Figure 1), but due to the (C6)-carboxylate group it exists in solution mainly in the syn conformation [89]. The (C6)COOH group is very acidic; for aqueous solution it was estimated that $\mathrm{p} K_{\mathrm{a}}=0.5 \pm 0.3$ [92]. Consequently, the stability constants of the orotidinate $\left(\mathrm{Or}^{-}\right)$ complexes of $\mathrm{Mg}^{2+}, \mathrm{Cu}^{2+}$, and $\mathrm{Zn}^{2+}$ (only these metal ions have been studied [92]) are somewhat below of those measured for the corresponding $\mathrm{M}(\mathrm{Ac})^{+}$complexes (see Table 1, column 7). There is no evidence for any significant chelate formation in aqueous solution [92]. Therefore, one may assume that all this also holds for the $\mathrm{Cd}(\mathrm{Or})^{+}$complex, which gives as an estimate for its stability $\log K_{\mathrm{Cd}(\mathrm{Or})}^{\mathrm{Cd}}=1.0 \pm 0.3$.

The acidity constant of $\mathrm{Or}^{-}$for the deprotonation of its (N3)H site in aqueous solution, $\mathrm{p} K_{\mathrm{Or}}^{\mathrm{H}}=9.12 \pm 0.02$ [92], is quite close to the corresponding one of its parent nucleoside, uridine, for which it holds $\mathrm{p} K_{\mathrm{Urd}}^{\mathrm{H}}=9.18 \pm 0.02$ [88]. Consequently, it is safe to assume that the stabilities of the $\mathrm{M}(\mathrm{Or}-\mathrm{H})$ and $\mathrm{M}(\mathrm{Urd}-\mathrm{H})^{+}$complexes, including $\mathrm{Cd}^{2+}$, are also very similar (see also Figure 7). Hence, it is no surprise that the stabilities of the complexes formed with orotidinate 5'monophosphate $\left(\mathrm{OMP}^{3-}\right)$ are determined by the basicity of the phosphate group [93]. No evidence was observed for macrochelate formation between the phosphate-coordinated metal ions and the carboxylate group, though there is a charge effect of about $0.4 \log$ unit [93]. Hence, in $\mathrm{Cd}(\mathrm{OMP})^{-}$no interaction with the pyrimidine ring occurs, what corresponds to the situation in $\mathrm{Cd}(\mathrm{UMP})$.

\subsubsection{Xanthosine}

Xanthosine (Xao) and its derivatives are of relevance for the metabolism of purinenucleosides/nucleotides $[91,94]$. Monoprotonated $\mathrm{H}(\mathrm{Xao})^{+}$carries a proton at $\mathrm{N} 7$, which is 
released with $\mathrm{p} K_{\mathrm{H}(\mathrm{Xao})}^{\mathrm{H}}=0.74 \pm 0.06$ [95]. The neutral Xao, as shown in Figure 8, loses a further proton already with $\mathrm{p} K_{\mathrm{Xao}}^{\mathrm{H}}=5.47 \pm 0.03$ [95] from the $(\mathrm{N} 1) \mathrm{H} /(\mathrm{N} 3) \mathrm{H}$ sites and there is evidence for a tautomeric equilibrium between $(\mathrm{N} 3)^{-} /(\mathrm{N} 1) \mathrm{H}$ and $(\mathrm{N} 3) \mathrm{H} /(\mathrm{N} 1)^{-}[96,97]$. In any case, in the physiological $\mathrm{pH}$ range of about 7.5 this nucleoside is present in its anionic form, xanthosinate, and it differs therefore considerably from its relatives inosine and guanosine (Section 4.1; Table 3).

Stability constants of $\mathrm{M}(\mathrm{Xao}-\mathrm{H})^{+}$complexes (including for $\mathrm{Cd}^{2+}$ ) have been determined [95] and there is evidence that a dichotomy for $\mathrm{M}^{2+}$ binding between $\mathrm{N} 1$ and N7 occurs [95,98]; of course, the negative charge in the xanthine residue can be delocalized over many atoms, that is, $\mathrm{N} 3,(\mathrm{C} 2) \mathrm{O}, \mathrm{N} 1$, and (C6)O. There is no doubt that the indicated dichotomy exists, yet the percentages given for the isomers should be considered with some care, even though the agreement between the rather different evaluation methods is surprisingly good. For example, it is concluded that in $\mathrm{Cd}(\mathrm{Xao}-\mathrm{H})^{+}$about $75 \%$ are N7-coordinated $[95,98]$; the value for $\mathrm{Co}(\mathrm{Xao}$ $-\mathrm{H})^{+}$is about 50\% [95,98], whereas for $\mathrm{Zn}(\mathrm{Xao}-\mathrm{H})^{+} \mathrm{N7}$ binding is given as 58\% in ref. [95] and as $38 \%$ in ref. [98]. Here more work is needed.

\subsubsection{Thiouridines}

Thiolation of uracil residues, especially in RNA wobble positions, affect the conformation of the nucleic acid in solution [99] and has implications for recognition processes. Furthermore, 4thiouridine is found in bacterial and archaeal tRNA [100,101]. Therefore, we shall have a short look on 2-thiouridine (U2S) and 4-thiouridine (U4S) (see Figure 8, bottom part) and their complexes formed with $\mathrm{Cd}^{2+}$ and $\mathrm{Cu}^{2+}[102,103]$. The exchange of an $\mathrm{O}$ atom by a $\mathrm{S}$ atom in uridine (see Figure 1) is expected, of course, to alter not only the acid-base but also the metal ion-binding properties $[15,17,104]$. Indeed, the acidity of (N3)H is increased by about one $\mathrm{pK}$ unit as follows from column 3 in Table 6 [105]. However, despite the reduced basicity of (N3)in $(\mathrm{U} 2 \mathrm{~S}-\mathrm{H})^{-}$and $(\mathrm{U} 4 \mathrm{~S}-\mathrm{H})^{-}$the stabilities of their complexes with $\mathrm{Cd}^{2+}$ and $\mathrm{Cu}^{2+}$ are by about 1 and $1.8 \log$ units higher than those of $\mathrm{Cd}(\mathrm{Urd}-\mathrm{H})^{+}$and $\mathrm{Cu}(\mathrm{Urd}-\mathrm{H})^{+}($Table 6 , column 5).

\section{insert Table 6 close to here}


A more careful evaluation of the data via $\log \Delta$ (eq. 14) by taking the differences in acidity of the $(\mathrm{N} 3) \mathrm{H}$ sites into account, reveals that the true stability enhancement amounts for the $\mathrm{Cd}^{2+}$ complexes to more than $1.3 \log$ units and for the $\mathrm{Cu}^{2+}$ species to about $2.3 \log$ units (Table 6, column 7). Of course, the negative charge at (N3) ${ }^{-}$may be delocalized to the sulfur atoms at

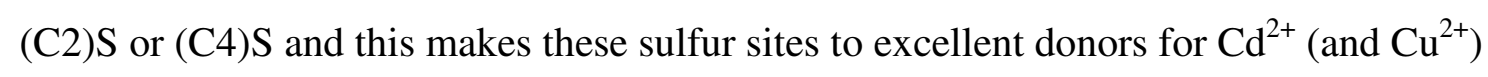
coordination $[15,17,104]$. Most likely the enhanced complex stability is not only due to monodentate $(\mathrm{C}) \mathrm{S}-\mathrm{M}^{2+}$ coordinations (next to a (N3)- $-\mathrm{M}^{2+}$ one), but due to chelate formation involving both sites as well. From X-ray crystal structure studies it is known that $\mathrm{Cd}^{2+}[85]$ and $\mathrm{Cu}^{2+}[106]$ are able to form 4-membered chelates with the cytosine residue involving the N3 and (C2)O sites. For the present study this means that $\mathrm{Cd}^{2+}$ and $\mathrm{Cu}^{2+}$ most likely form 4-membered rings involving $[\mathrm{N} 3 /(\mathrm{C}) \mathrm{S}]^{-}$, especially since such low-membered chelates are more easily formed if a (C)O is replaced by a (C)S site [107]. Of course, in aqueous solution there is the possibility that semichelates involving a ligated water molecule form [105].

In the terminating paragraph of Section 4.2 we have already concluded that the formation degree of chelates in the $\mathrm{M}(\mathrm{Urd}-\mathrm{H})^{+}$species must be larger than it is in the $\mathrm{M}(\mathrm{Cyd})^{2+}$ complexes. Considering the additional stability enhancement observed for the $\mathrm{M}(\mathrm{U} 2 \mathrm{~S}-\mathrm{H})^{+}$and $\mathrm{M}(\mathrm{U} 4 \mathrm{~S}-\mathrm{H})^{+}$complexes, these lower limits must be even more true for the complexes of the thiouridinates, that is, $\mathrm{Cd}(\mathrm{US}-\mathrm{H})_{\mathrm{cl}}^{+}>\mathrm{Cd}(\mathrm{Cyd})_{\mathrm{cl}}^{2+}\left(=\mathrm{ca} .60 \%\right.$; see Table 5) and $\mathrm{Cu}(\mathrm{U} 2 \mathrm{~S}-\mathrm{H})_{\mathrm{cl}}^{+}$

$>\mathrm{Cu}(\mathrm{Cyd}){ }_{\mathrm{cl}}^{2+}(=\mathrm{ca} .80 \%)$. In fact, we believe that the formation degree of the chelated species in the $\mathrm{Cd}(\mathrm{US}-\mathrm{H})^{+}$and $\mathrm{Cu}(\mathrm{U} 2 \mathrm{~S}-\mathrm{H})^{+}$systems is larger than $90 \%$ because this number corresponds to a stability enhancement of about $1 \log$ unit being solely due to chelate formation (and attributing the remaining part of $\log \Delta$ to the general participation of $\mathrm{S}$ in metal ion binding).

\subsubsection{2-Thiocytidine}

The thionucleoside 2-thiocytidine (C2S; Figure 8, lower part, right) occurs in Nature in tRNAs [108].In addition, it also receives attention in diverse fields [109] like drug research [110] or nanotechnology [111]. The acidity constants of $\mathrm{H}(\mathrm{C} 2 \mathrm{~S})^{+}$and the stability constants of the $\mathrm{M}(\mathrm{C} 2 \mathrm{~S})^{2+}$ and $\mathrm{M}(\mathrm{C} 2 \mathrm{~S}-\mathrm{H})^{+}$complexes $\left(\mathrm{M}^{2+}=\mathrm{Zn}^{2+}, \mathrm{Cd}^{2+}\right)$ were determined by potentiometric pH titrations. These results [112] can be compared with those obtained for the parent nucleoside 
cytidine (Cyd; Figure 1; Section 4.2). Replacement of the (C2)=O unit by $(\mathrm{C} 2)=\mathrm{S}$ facilitates the release of the proton from $(\mathrm{N} 3) \mathrm{H}^{+}$in $\mathrm{H}(\mathrm{C} 2 \mathrm{~S})^{+}\left(\mathrm{p} K_{\mathrm{a}}=3.44 \pm 0.01[112] ; 25^{\circ} \mathrm{C} ; I=0.5 \mathrm{M}, \mathrm{KNO}_{3}\right)$ somewhat, compared with $\mathrm{H}(\mathrm{Cyd})^{+}\left(\mathrm{p} K_{\mathrm{a}}=4.24 \pm 0.02[83] ; 25^{\circ} \mathrm{C} ; I=0.5 \mathrm{M}, \mathrm{NaNO}_{3}\right)$. This moderate effect of about $0.8 \mathrm{p} K$ unit contrasts with the strong acidification of about $4 \mathrm{p} K$ units of the $(\mathrm{C} 4) \mathrm{NH}_{2}$ group in $\mathrm{C} 2 \mathrm{~S}\left(\mathrm{p} K_{\mathrm{a}}=12.65 \pm 0.12\right.$ [112]) compared with Cyd (p $K_{\mathrm{a}}$ ca. 16.7 [34,113]). The reason [112] for this result is that the amino-thione tautomer, which dominates for the neutral C2S molecule, is transformed upon deprotonation into the imino-thioate form with the negative charge largely located on the sulfur; this is indicated in equilibrium (21):

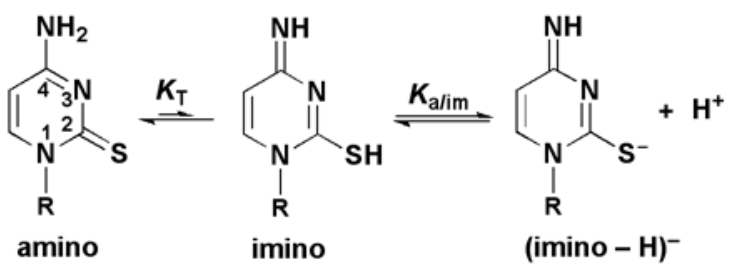

The intramolecular and dimensionless equilibrium constant $K_{\mathrm{T}}=[\mathrm{imino}] /[\mathrm{amino}]$ was estimated as being on the order of $10^{-4}$ to $10^{-6}$, which leads to values for the acidity constant $K_{\text {a/imino }}$ of $10^{-8.65}$ to $10^{-6.65}$ [112].

In the $\mathrm{M}(\mathrm{C} 2 \mathrm{~S})^{2+}$ complexes the (C2)S group is the primary binding site [112] rather than $\mathrm{N} 3$ as is the case in the $\mathrm{M}(\mathrm{Cyd})^{2+}$ complexes (Section 4.2), though owing to chelate formation $\mathrm{N} 3$ is to some extent still involved in metal ion binding. Based on $\log K_{\mathrm{M}(\mathrm{L})}^{\mathrm{M}}$ versus $\mathrm{p} K_{\mathrm{H}(\mathrm{L})}^{\mathrm{H}}$ plots (eq. 15) for $o$ PyN-type ligands [59] (see also Figure 6), the stability enhancements amount to log $\Delta_{\mathrm{Cd} / \mathrm{C} 2 \mathrm{~S}}=3.3$ and $\log \Delta_{\mathrm{Zn} / \mathrm{C} 2 \mathrm{~S}}=2.6$ [112]. They are much larger than those observed for the corresponding $\mathrm{M}(\mathrm{Cyd})^{2+}$ complexes (see Table 5) and lead to the conclusion that $(\mathrm{C} 2) \mathrm{S}-\mathrm{M}^{2+}$ binding is important and dominates with more than 99\%; a number which encompasses both, monodentate $\mathrm{S}$ coordination as well as chelate formation of an $(\mathrm{C} 2 \mathrm{~S})$-bound metal ion with N3. The structure of these chelates has been discussed [112]. Clearly, the monodentate (N3)- $\mathrm{M}^{2+}$ isomer occurs only in traces.

Similarly, in the $\mathrm{Zn}(\mathrm{C} 2 \mathrm{~S}-\mathrm{H})^{+}$and $\mathrm{Cd}(\mathrm{C} 2 \mathrm{~S}-\mathrm{H})^{+}$complexes the main metal ion binding site is the (C2) $\mathrm{S}^{-}$unit and the formation degree of its complex is above $99.9 \%$ (compared with that of N3). However, again a large degree of chelate formation with N3 must be surmised for the $\mathrm{M}(\mathrm{C} 2 \mathrm{~S}-\mathrm{H})^{+}$species, and their structure was discussed [112]. It needs to be emphasized that upon metal ion binding the deprotonation of the $(\mathrm{C} 4) \mathrm{NH}_{2}$ group $\left(\mathrm{p} K_{\mathrm{a}}=12.65\right)$ is dramatically 
acidified ( $\mathrm{p} K_{\mathrm{a}}$ ca. 3), confirming the very high stability of the $\mathrm{M}(\mathrm{C} 2 \mathrm{~S}-\mathrm{H})^{+}$complexes and the importance of equilibrium (21). To conclude, the metal ion-binding capabilities of C2S differ strongly from those of its parent Cyd; this also holds for hydrogen-bond formation because (C)S is a much poorer $\mathrm{H}$-acceptor than (C)O. Clearly, these differences must have consequences for the properties of those RNAs which contain this thionucleoside.

\section{Complexes of Cadmium(II) with Phosphates}

In Figure 9 the general structures for the monoesters of mono-, di-, and triphosphates, symbolized by $\mathrm{R}_{-\mathrm{MP}}{ }^{2-}, \mathrm{R}_{-} \mathrm{DP}^{3-}$, and $\mathrm{R}_{-} \mathrm{TP}^{4-}$, respectively, are shown together with the structure of a phosphodiester bridge, $(\mathrm{RO})_{2} \mathrm{PO}_{2}^{-}$, as it occurs in the backbone of nucleic acids. This diester of a phosphate group may be mimicked to some extent herein by acetate ( $\left.\mathrm{Ac}^{-}\right)$as both ligands carry a charge of minus one. The most basic phosphate residue in the phosphomonoesters is always the terminal one, which carries a charge of two minus. In addition, the effect of the residue $\mathrm{R}$ on the basicity of such a phosphate group will be the more pronounced the closer they are. For example, the effect of a phenyl and a butyl residue in $\mathrm{R}-\mathrm{MP}^{2-}$ leads to the $\mathrm{p} K_{\mathrm{a}}$ values of $5.81 \pm 0.01$ and $6.72 \pm 0.02$, respectively [114], whereas the effect of the same residues in R$\mathrm{DP}^{3-}$ leads to the much smaller $\mathrm{p} K_{\mathrm{a}}$ span of $6.32 \pm 0.02$ to $6.65 \pm 0.02$ [115]. In the case of the triphosphates the residue $\mathrm{R}$ has practically no effect [37,116-118].

\section{insert Figure 9 close to here (width: $6.5 \mathrm{~cm}$ )}

Pyrimidine-nucleoside phosphates furnish representative values for nucleotide comparisons because the pyrimidine residue does commonly not participate in metal ion binding with labile ions like $\mathrm{Cd}^{2+}[114-119]$. The corresponding acidity constants for the terminal phosphate groups of pyrimidine-nucleotides are $\mathrm{p} K_{\mathrm{H}(\mathrm{R}-\mathrm{MP})}^{\mathrm{H}}=6.20$ (eq. 3 ) for monophosphate monoesters [50,114], $\mathrm{p} K_{\mathrm{H}(\mathrm{R}-\mathrm{DP})}^{\mathrm{H}}=6.40$ for diphosphate monoesters [115], and $\mathrm{p} K_{\mathrm{H}(\mathrm{R}-\mathrm{TP})}^{\mathrm{H}}=6.50$ for triphosphate monoesters [37,116-118,120]. The stability constants (eq. 2), which correspond to these $\mathrm{p} K_{\mathrm{a}}$ values [115,117], are listed in columns 3 to 5 of Table 7 (upper part) [121,122] for several M(R-MP), M(R-DP)-, and M(R-TP) ${ }^{2-}$ complexes. 


\section{insert Table 7 close to here}

Unfortunately, no comprehensive set of stability constants of metal ion complexes formed with a phosphodiester has been measured [25]; the reason is the low basicity of $(\mathrm{RO})_{2} \mathrm{PO}_{2}^{-}$, i.e., $\mathrm{p} K_{\mathrm{H}\left[(\mathrm{RO})_{2} \mathrm{PO}_{2}\right]}^{\mathrm{H}}=$ ca. $1[33,34]$, which precludes potentiometric $\mathrm{pH}$ titrations which are based on the competition between $\mathrm{H}^{+}$and $\mathrm{M}^{2+}$ for binding at a given ligating site. Since in a first approximation the negative charge is distributed on two $\mathrm{O}$ atoms in $\mathrm{CH}_{3} \mathrm{CO}_{2}^{-}$like in $(\mathrm{RO})_{2} \mathrm{PO}_{2}^{-}$ (see Figure 9), the metal ion affinities of acetate (or chloroacetate or formate) may be assumed to reflect those of the phosphodiester bridge. Certainly, there is a difference in basicity between R$\mathrm{CO}_{2}^{-}$and $(\mathrm{RO})_{2} \mathrm{PO}_{2}^{-}$(Table 7), but the slopes of $\log K_{\mathrm{M}(\mathrm{R}-\mathrm{COO})}^{\mathrm{M}}$ versus $\mathrm{p} K_{\mathrm{H}(\mathrm{R}-\mathrm{COO})}^{\mathrm{H}}$ plots are relatively small [57], which indicates that outersphere binding is important, and in fact, this agrees with observations made at bridging phosphate groups in nucleic acids [30]. This conclusion agrees further with studies of poly(U) and $\mathrm{Mg}^{2+}$ or $\mathrm{Ni}^{2+}$ [123] where it was found that the apparent stability constants for the two metal ions are identical within the error limits: log $K_{\mathrm{Mg}(\mathrm{pU}) \text { app }}^{\mathrm{Mg}}=1.80$ and $\log K_{\mathrm{Ni}(\mathrm{pU}) \text { app }}^{\mathrm{Ni}}=1.83\left(25^{\circ} \mathrm{C} ; I=0.1 \mathrm{M}-0.3 \mathrm{M}\right)$. From these results, and for $\mathrm{Cd}^{2+}$ the analogous ones are expected, it was concluded "that innersphere coordination ... does not occur to a significant extent. Rather, the metal ions are bound in these systems mainly by electrostatic forces, forming a mobile cloud" [123].

The stability constants listed in column 2 of Table 7 (upper part) are reliable enough for the comparisons to be made herein with regard to the stability of $\mathrm{M}\left[(\mathrm{RO})_{2} \mathrm{PO}_{2}\right]^{+}$complexes. Indeed, these values are only slightly larger than those proposed recently in another somewhat more comprehensive estimate [58]. That the listed values in Table 7 are on the correct order is further confirmed by the stability constant of the $\mathrm{Ni}^{2+}$ complex formed with monoprotonated D-ribose 5monophosphate $\left(\mathrm{RibMP}^{2-}\right)$, i.e., $\log K_{\mathrm{Ni}(\mathrm{H} ; \mathrm{RibMP})}^{\mathrm{Ni}}=0.7\left(15^{\circ} \mathrm{C} ; I=0.1 \mathrm{M}, \mathrm{KNO}_{3}\right)[124]$ and the

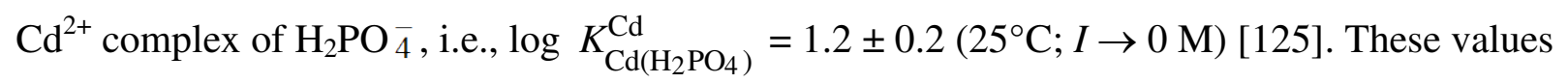
are rather close to those given for $\mathrm{Fe}(\mathrm{Ac})^{+}, \mathrm{Co}(\mathrm{Ac})^{+}$, and $\mathrm{Cd}(\mathrm{Ac})^{+}$in Table 7 . In this context one may note that with all types of phosphate complexes the Irving-Williams series $[22,126]$ is not strictly followed $[19,22,115-117,119]$, the complexes of $\mathrm{Co}^{2+}$ and especially $\mathrm{Ni}^{2+}$ are commonly somewhat lower in stability than those of $\mathrm{Mn}^{2+}$ and $\mathrm{Zn}^{2+}$. In fact, this is also reflected to some extent by the data in columns 3 to 5 of Table 7 (upper part). One may note here that the strength 
of the metal ion-phosphate interaction is crucial for the activity of ribozymes: For example, the catalytic cleavage rate of hammerhead ribozymes shows a direct correlation to the above mentioned "irregular" phosphate affinities of the divalent metal ions [127].

To facilitate comparisons between the various types of complexes the log-stability differences listed in the lower part of Table 7 have been prepared. As one would expect, increase of the charge from minus one in $\mathrm{Ac}^{-} /(\mathrm{RO})_{2} \mathrm{PO}_{2}^{-}$to minus two in $\mathrm{R}_{-} \mathrm{MP}^{2-}$ (Figure 9) increases the stabilities of the complexes: The stability increases amount to about $0.9\left(\mathrm{Ca}^{2+}\right)$ to $1.2\left(\mathrm{Cd}^{2+}\right) \log$ units; only for the $\mathrm{Cu}^{2+}$ complexes the effect is a bit more pronounced with $\log \Delta_{\mathrm{R}-\mathrm{MP} / \mathrm{Ac}}=1.4$ (lower part, column 2). In contrast, the stability increase of the complexes by going from $\mathrm{M}(\mathrm{R}-$ MP) to M(R-DP) ${ }^{-}$varies significantly from metal ion to metal ion, i.e., within the relatively large span of about 1.45 to $2.4 \log$ units. This changes again by going from $\mathrm{M}(\mathrm{R}-\mathrm{DP})^{-}$to $\mathrm{M}(\mathrm{R}-\mathrm{TP})^{2-}$, then the stability increase is quite constant within the narrow range of about 0.8 to $1.0 \log$ units, if the special case of $\mathrm{Cu}^{2+}$ with its distorted octahedral coordination sphere [128] is ignored. Overall this indicates in our view that outersphere species play a significant role in M(R-MP) complexes, which also include six-membered semichelates with one of the terminal oxygens innersphere and the other one outersphere [114]. Such outersphere interactions are hardly of relevance in the corresponding di- and triphosphate species where two neighboring phosphate units allow the formation of six-membered innersphere chelates. This is in accord with the log $K_{\mathrm{M}(\mathrm{R}-\mathrm{MP})}^{\mathrm{M}}$ versus $\mathrm{p} K_{\mathrm{H}(\mathrm{R}-\mathrm{MP})}^{\mathrm{H}}$ plots where the slopes are much lower $\left(\mathrm{Ca}^{2+}: m=0.131 \pm 0.020\right.$; $\mathrm{Cd}^{2+}: 0.329 \pm 0.019$ [122] (thus indicating partial outersphere binding) than for the $\log K_{\mathrm{M}(\mathrm{R}-\mathrm{DP})}^{\mathrm{M}}$ versus $\mathrm{p} K_{\mathrm{H}(\mathrm{R}-\mathrm{DP})}^{\mathrm{H}}$ plots $\left(\mathrm{Ca}^{2+}: 0.379 \pm 0.097 ; \mathrm{Cd}^{2+}: 0.945 \pm 0.104\right.$ [115]). Clearly, for di- and triphosphates the formation of innersphere complexes is more pronounced compared with monophosphates, owing to the increased negative charge of these ligands. Overall, the situation may be summarized with the earlier statement [129], "the lower the charge, the more predominant are outersphere complexes".

\section{Cadmium(II) Complexes of Nucleotides}

\subsection{Some General Considerations}


The evaluations presented in this section are carried out in part in a manner analogous to our previous review on $\mathrm{Ni}^{2+}$-nucleotide complexes [40]; of course, concentrating now on $\mathrm{Cd}^{2+}$ which was not a part of the previous account. As is well known, nucleotides exist in solution mainly in the so-called anti conformation. Two such examples are shown in Figure 10 [11-14,50]. It is the phosphate residue in nucleotides which determines to a very large part the stability of the complexes formed with labile metal ions including $\mathrm{Cd}^{2+}[74,117,119,130]$ independent of the kind of nucleobase involved or whether a nucleoside mono-, di-, or triphosphate is considered.

\section{insert Figure 10 close to here (width: $7 \mathrm{~cm}$ )}

For purine-nucleoside 5'-phosphates the formation of macrochelates was proposed nearly 60 years ago [131] and more than 50 years ago it was concluded that they actually exist [132135], i.e., a metal ion coordinated to the phosphate residue of a purine nucleotide may also interact in the dominating anti conformation with N7 of the purine moiety. Nowadays formation of macrochelates in complexes formed by purine nucleotides with various metal ions including $\mathrm{Cd}^{2+}$ is well established $[117,120,136-138]$. Clearly, the formation of such a macrochelate must give rise to the intramolecular equilibrium (22):

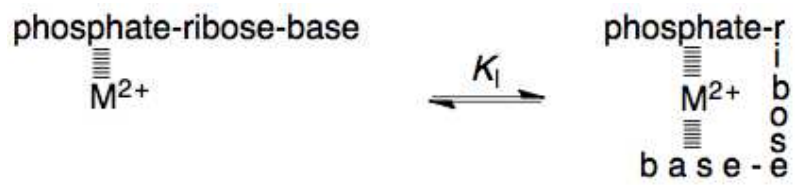

As already discussed in Section 4.2, any kind of equilibrium between an 'open' isomer, $\mathrm{M}(\mathrm{L})_{\mathrm{op}}$, and a chelated or 'closed' isomer, $\mathrm{M}(\mathrm{L})_{\mathrm{cl}}$, must be reflected in an increased complex stability compared to the situation where only the open complex can form [51]. This stability enhancement, $\log \Delta_{\mathrm{M} / \mathrm{L}}$ (eq. 14), can be evaluated by equations (16) to (20) (Section 4.2), which furnish values for $K_{\mathrm{I}}$ (eqs 16, 17) and thus for the formation degree of the closed species, $\%$ $\mathrm{M}(\mathrm{L})_{\mathrm{cl}}$ (eq. 20).

One important aspect needs to be emphasized and kept in mind when dealing with purine derivatives: All of them show a pronounced tendency for self-association, which occurs via stacking of the purine rings $[117,137,139,140]$. Hence, experiments aimed at determining the properties of monomeric metal ion complexes of purine nucleosides or their phosphates should 
not be carried out in concentrations higher than $10^{-3} \mathrm{M}$. To be on the safe side, actually a maximum concentration of only $5 \times 10^{-4} \mathrm{M}$ is recommended (cf., e.g., $\left.[122,136]\right)$. The equilibrium constants discussed below were mostly obtained by potentiometric $\mathrm{pH}$ titrations and the corresponding experimental conditions adhere to the above request.

\subsection{Complexes of Nucleoside 5'-Monophosphates}

\subsubsection{Equilibrium Constants to Be Considered}

A combination of the information provided in Figures 1 and 10 reveals that there are nucleoside 5'-monophosphates $\left(\mathrm{NMP}^{2-}\right)$, which contain a nucleobase that may accept a proton, e.g., $\mathrm{AMP}^{2-}$, whereas others contain a nucleobase that can only release one, e.g., $\mathrm{UMP}^{2-}$. Therefore, if one neglects a twofold protonated phosphate group because this is not of relevance for a biological system due to its large acidity (e.g., for $\mathrm{H}_{2}(\mathrm{UMP}) \mathrm{pK}_{\mathrm{H}_{2}(\mathrm{UMP})}^{\mathrm{H}}=0.7 \pm 0.3$ [114]), one has to consider eqs (3) and (7), next to equilibrium (23) (charges neglected):

$$
\begin{aligned}
\mathrm{H}_{2}(\mathrm{~L}) & \rightleftharpoons \mathrm{H}(\mathrm{L})+\mathrm{H}^{+} \\
K_{\mathrm{H}_{2}(\mathrm{~L})}^{\mathrm{H}} & =[\mathrm{H}(\mathrm{L})]\left[\mathrm{H}^{+}\right] /\left[\mathrm{H}_{2}(\mathrm{~L})\right]
\end{aligned}
$$

Based on the structures of the various NMPs, it is clear that equilibria (23) and (3) hold for $\mathrm{H}_{2}(\mathrm{CMP})^{ \pm}$and $\mathrm{H}_{2}(\mathrm{AMP})^{ \pm}$, and that equilibria (3) and (7) are of relevance for $\mathrm{H}(\mathrm{UMP})^{-}$and H(dTMP)- , whereas all three equilibria (23), (3), and (7) are needed to describe the acid-base properties of $\mathrm{H}_{2}(\mathrm{IMP})^{ \pm}$and $\mathrm{H}_{2}(\mathrm{GMP})^{ \pm}$. In all cases equilibrium (3) refers to the deprotonation of the $\mathrm{P}(\mathrm{O})_{2}(\mathrm{OH})^{-}$group in the $\mathrm{H}(\mathrm{NMP})^{-}$species.

Correspondingly, one has to consider the complexes $\mathrm{M}(\mathrm{H} ; \mathrm{NMP})^{+}$and $\mathrm{M}(\mathrm{NMP})$, the stabilities of which are defined in equilibria (24) and (2), respectively (charges neglected):

$$
\begin{aligned}
\mathrm{M}^{2+}+\mathrm{H}(\mathrm{L}) & \rightleftharpoons \mathrm{M}(\mathrm{H} ; \mathrm{L}) \\
K_{\mathrm{M}(\mathrm{H} ; \mathrm{L})}^{\mathrm{M}} & =[\mathrm{M}(\mathrm{H} ; \mathrm{L})] /\left(\left[\mathrm{M}^{2+}\right][\mathrm{H}(\mathrm{L})]\right)
\end{aligned}
$$

At high $\mathrm{pH}$ values also $\mathrm{Cd}(\mathrm{NMP}-\mathrm{H})^{-}$species (eq. 8) might form but at present no information is available about these. 
$\mathrm{M}(\mathrm{H} ; \mathrm{NMP})^{+}[=\mathrm{M}(\mathrm{H} ; \mathrm{L})]$ complexes form with $\mathrm{CMP}^{2-}, \mathrm{AMP}^{2-}, \mathrm{IMP}^{2-}$, and $\mathrm{GMP}^{2-}$. In these cases, $\mathrm{M}^{2+}$, including $\mathrm{Cd}^{2+}$, is mainly located at the nucleobase residue and the proton at the phosphate group $[50,130,141]$. However, because the proton is lost with a $\mathrm{p} K_{\mathrm{a}}$ value of about 5 or below $[50,130,141]$, these species are of relevance for biological systems only under very special conditions. At the common physiological $\mathrm{pH}$ of about 7.5 they are not important and therefore not considered further in the present context.

\subsubsection{Properties of Pyrimidine-Nucleoside 5'-Monophosphate Complexes}

The acidity constants of the pyrimidine-NMPs are listed in Table 8 together with the stability constants of their $\mathrm{Cd}(\mathrm{NMP})$ complexes (eq. 2), including the corresponding data for tubercidin $5^{\prime}$-monophosphate $\left(\mathrm{TuMP}^{2-}=7\right.$-deaza-AMP $\left.{ }^{2-}\right)$. This nucleotide has the structure of $\mathrm{AMP}^{2-}$ except that $\mathrm{N} 7$ is replaced by a $\mathrm{CH}$ unit (see Figures 5 and 10) and this exchange transforms this purine-type nucleotide into one with pyrimidine-type properties (vide infra).

\section{insert Table 8 close to here}

The $\alpha$-phosphate group is close in distance to the nucleoside residue and its basicity properties are therefore somewhat affected by this residue (see also Section 5). Indeed, the acidity constants of $\mathrm{H}(\mathrm{NMP})^{-}$species as defined by equation (3) vary roughly between $\mathrm{p} K_{\mathrm{H}(\mathrm{NMP})}^{\mathrm{H}}=5.7$ and $6.3[48,136]$. As a consequence, a direct comparison of stability constants of M(NMP) complexes, like those given in Table 8, does not allow unequivocal conclusions regarding the solution structures of these species.

To overcome the indicated handicap, $\log K_{\mathrm{M}\left(\mathrm{R}-\mathrm{PO}_{3}\right)}^{\mathrm{M}}$ (eq. 2) versus $\mathrm{p} K_{\mathrm{H}\left(\mathrm{R}-\mathrm{PO}_{3}\right)}^{\mathrm{H}}$ (eq. 3) plots were established for $\mathrm{R}^{-\mathrm{PO}_{3}^{2-}}$ systems ( $\mathrm{R}$ being a non-interacting residue), i.e., for simple phosphate monoesters, like phenyl phosphate or $n$-butyl phosphate, and phosphonate ligands, like methanephosphonate [122]. The resulting straight lines are defined by equation (15). The equilibrium data for the methyl phosphate and the hydrogen phosphate systems fit on these same reference lines, including those for $\mathrm{Cd}\left(\mathrm{CH}_{3} \mathrm{OPO}_{3}\right)$ and $\mathrm{Cd}\left(\mathrm{HOPO}_{3}\right)$ [142], as do the data for $\mathrm{RibMP}^{2-}$ and for the pyrimidine-NMPs, $\mathrm{UMP}^{2-}$ and dTMP, given in Table 8 (see also Figure 11 below) $[114,122]$. 
In the light of the results discussed in Sections 3.2 and 4.2, it is no surprise that the ribose residue and the uracil and thymine moieties do not participate in metal ion binding in M(RibMP), M(UMP), and M(dTMP) complexes [122]. How is the situation with Cd(CMP)? The mentioned straight-line parameters [122] are summarized for $\mathrm{Cd}\left(\mathrm{R}-\mathrm{PO}_{3}\right)$ in equation (25) [the error limit $(3 \sigma)$ for a calculated $\log K_{\mathrm{Cd}\left(\mathrm{R}-\mathrm{PO}_{3}\right)}^{\mathrm{Cd}}$ value is \pm 0.05 (for details see ref. [122]):

$$
\log K_{\mathrm{Cd}\left(\mathrm{R}-\mathrm{PO}_{3}\right)}^{\mathrm{Cd}}=(0.329 \pm 0.019) \cdot \mathrm{p} K_{\mathrm{H}\left(\mathrm{R}-\mathrm{PO}_{3}\right)}^{\mathrm{H}}+(0.399 \pm 0.127)
$$

Application of $\mathrm{p} K_{\mathrm{H}(\mathrm{CMP})}^{\mathrm{H}}=6.19$ (Table 8) to eq. (25) allows to calculate the stability of the 'open' isomer $\mathrm{Cd}(\mathrm{CMP})_{\mathrm{op}}$ in equilibrium (22), i.e., $\log K_{\mathrm{Cd}\left(\mathrm{R}-\mathrm{PO}_{3}\right)}^{\mathrm{Cd}}=\log K_{\mathrm{Cd}(\mathrm{CMP}) \text { op }}^{\mathrm{Cd}}=2.44 \pm$ 0.05. This calculated stability constant is within the error limits identical with the measured one given in Table 8 . Hence, there is no indication for an increased stability of the $\mathrm{Cd}(\mathrm{CMP})$ complex, which means that equilibrium (22) is far on its left side and that no remarkable amounts of macrochelates are formed. At first sight this result for $\mathrm{Cd}(\mathrm{CMP})$, which also holds for $\mathrm{Cu}(\mathrm{CMP})$ and other $\mathrm{M}(\mathrm{CMP})$ species [50], may seem surprising because the ability of the N3 site of the cytosine residue to interact with metal ions is well known (Section 4.2; Table 5).

However, it should be recalled that $\mathrm{CMP}^{2-}$ exists predominately in the anti conformation (Figure 10) in which $\mathrm{N} 3$ is pointing away from the metal ion coordinated at the phosphate group. Evidently, for all divalent metal ions considered (Table 5) the anti-syn energy barrier, which has been estimated to be on the order of about $7 \mathrm{~kJ} / \mathrm{mol}$ [35], is too large to be overcome by macrochelate formation.

\subsubsection{Properties of Purine-Nucleoside 5'-Monophosphate Complexes}

Purine-nucleosides represent a favored situation because not only N7 of the purine moiety is able to bind metal ions (Section 4.1; Table 3) but also a metal ion coordinated at the phosphate residue can reach N7 in the dominating anti conformation (Figure 10) as was already pointed out in Section 6.1. Such a possible N7 interaction, depending on the kind of metal ion involved, may give rise to macrochelate formation and if this occurs it must be reflected in an increased complex stability. Indeed, a very significant stability enhancement is observed for the Cd(NMP) complexes of $\mathrm{AMP}^{2-}, \mathrm{IMP}^{2-}$, and $\mathrm{GMP}^{2-}$ (Figure 11), whereas that for the corresponding $\mathrm{Ca}^{2+}$ 
complexes is much smaller. This confirms the well known high affinity of $\mathrm{Cd}^{2+}$ for $\mathrm{N}$ sites, the one of $\mathrm{Ca}^{2+}$ being much lower [22] (see also Section 2; Table 1).

\section{insert Figure 11 close to here (width: $8 \mathrm{~cm}$ )}

The vertical distances between M(NMP) data points and their corresponding straightreference line can easily be quantified. Application of the acidity constant $\mathrm{p} K_{\mathrm{H}(\mathrm{NMP})}^{\mathrm{H}}$ to the straight-line equation (15), the parameters of which are listed in refs [50,52,122], provides the value of the intercept with the straight line and thus the stability constant of the 'open' species (eq. 19). In other words, with equation (14) one may now define the stability enhancement, if any, for the $\mathrm{M}^{2+}$ complexes of the purine-NMPs. Clearly, the calculated value for log $K_{\mathrm{M}\left(\mathrm{R}-\mathrm{PO}_{3}\right)}^{\mathrm{M}}$ reflects the stability of the 'open' isomer in equilibrium (22), in which $\mathrm{M}^{2+}$ is only phosphatecoordinated. Now, with known values for $\log \Delta_{\mathrm{M} / \mathrm{NMP}}(=\log \Delta$; eq. 14), the evaluation procedure defined in equations (16) through (20) (Section 4.2) can be applied and the formation degree of the macrochelate which appears in equilibrium (22) can be calculated (eq. 20). The corresponding results are summarized in Table 9 for the $\mathrm{Cd}(\mathrm{NMP})$ complexes of $\mathrm{AMP}^{2-}, \mathrm{IMP}^{2-}$, and $\mathrm{GMP}^{2-}$, together with the analogous results of some other metal ions for comparisons.

\section{insert Table 9 close to here}

The results of column 6 in Table 9 demonstrate that in all $\mathrm{M}^{2+} 1: 1$ complexes with purineNMPs [with the possible exception of $\mathrm{Ca}(\mathrm{AMP})]$ at least some macrochelation occurs. Macrochelation by an interaction of the phosphate-coordinated $\mathrm{M}^{2+}$ with $\mathrm{N} 7$ is thereby proven with the $\mathrm{Cd}^{2+} / \mathrm{TuMP}^{2-}$ system (Table 8). In TuMP ${ }^{2-}$ a $\mathrm{CH}$ unit replaces the $\mathrm{N} 7$ of $\mathrm{AMP}^{2-}$ (Figures 5 and 10) which means that TuMP ${ }^{2-}$ is no longer able to form the mentioned macrochelates. Indeed, the stability constants of its M(TuMP) complexes fit on the reference lines, thus proving that $\mathrm{TuMP}^{2-}$ behaves like a simple phosphate monoester that binds metal ions only to its phosphate group $[50,136]$. Similar to the situation with pyrimidine NMPs and their N3 site, also with purines the $\mathrm{N} 1$ site cannot be reached in the anti conformation.

The data assembled in Table 9 allow at least one more interesting conclusion: In all instances the formation degree of the macrochelates increases in the order $\mathrm{M}(\mathrm{AMP})_{\mathrm{cl}}<\mathrm{M}(\mathrm{IMP})_{\mathrm{cl}}$ $<\mathrm{M}(\mathrm{GMP})_{\mathrm{cl}}$. This increase for $\mathrm{M}(\mathrm{IMP})_{\mathrm{cl}}<\mathrm{M}(\mathrm{GMP})_{\mathrm{cl}}$ is in accord with the increased basicity of 
$\mathrm{N} 7$ in $\mathrm{GMP}^{2-}$ compared with that of $\mathrm{N} 7$ in $\mathrm{IMP}^{2-}[74]$. However, with $\mathrm{AMP}^{2-}$ the situation is more complicated: 9-methylguanine has a $\mathrm{p} K_{\mathrm{a}}$ of $3.11 \pm 0.06[143,144]$ for its $(\mathrm{N} 7) \mathrm{H}^{+}$site and this value is rather close to the micro acidity constant for the same site in 9-methyladenine, $\mathrm{P}_{\mathrm{H}}^{\mathrm{N} 7-\mathrm{N} 1} \mathrm{~N} 7 \mathrm{N1}=2.96 \pm 0.10$ [143]. Hence, the N7 basicity cannot be responsible for the decreased complex stability. Similar to the situation with pyrimidine derivatives as discussed in Section 4.2, the reduced stability by about $0.5 \log$ unit of $\mathrm{Cd}(\mathrm{AMP})$, compared to that of $\mathrm{Cd}(\mathrm{GMP})$, is to be attributed to the steric inhibition which $(\mathrm{C} 6) \mathrm{NH}_{2}$ exercises on a metal ion coordinated at $\mathrm{N} 7$ [71]. The (C6)O group does not have such an effect. In contrast, it rather promotes the stability by forming outersphere bonds to a water molecule of the N7-bound metal ion [74].

Finally, a comment is needed about the effect of the ribose versus the 2'-deoxyribose residue on the metal ion-binding properties of purine nucleotides. Unfortunately no data for $\mathrm{Cd}^{2+}$ complexes are available, but for those of $\mathrm{Mg}^{2+}, \mathrm{Ni}^{2+}, \mathrm{Cu}^{2+}$, and $\mathrm{Zn}^{2+}$ it was shown [121] that complex stability and extent of macrochelate formation (eq. 22) between the phosphatecoordinated metal ion and N7 of the purine residue is very similar (or even identical) for the $\mathrm{AMP}^{2-} / \mathrm{dAMP}^{2-}$ pair. This is different for the $\mathrm{GMP}^{2-} / \mathrm{dGMP}^{2-}$ pair: The stabilities of the $\mathrm{M}(\mathrm{dGMP})$ complexes are clearly higher, as are the formation degrees of the macrochelates compared to the M(GMP) complexes. This can be attributed to the enhanced basicity ( $\Delta \mathrm{p} K_{\mathrm{a}} \mathrm{ca}$. $0.2[31,121])$ of $\mathrm{N} 7$ in the 2 -deoxy compound. It may be surmised that the complexes of $\mathrm{Cd}^{2+}$ also fit into the indicated picture. One may further add that the extent of macrochelation (eq. 22) is altered, if the permittivity (dielectric constant) of the solvent is changed, e.g., by adding 1,4dioxane to an aqueous solution, as was shown for $\mathrm{Cu}^{2+}$ complexes of several purine-nucleotides [145-147].

\subsubsection{Complexes of Nucleoside 5'-Di- and Triphosphates}

All the NDPs and NTPs considered here (Figures 1 and 10) form $\mathrm{Cd}(\mathrm{H} ; \mathrm{NDP})$ and $\mathrm{Cd}(\mathrm{H} ; \mathrm{NTP})^{-}$ complexes $[115,116,119,130,148]$, the proton being mainly at the terminal phosphate group. For the reasons already indicated in Section 6.2 .1 for the $\mathrm{M}(\mathrm{H} ; \mathrm{NMP})^{+}$species, the corresponding $\mathrm{Cd}(\mathrm{H} ; \mathrm{NDP})$ and $\mathrm{Cd}(\mathrm{H} ; \mathrm{NTP})^{-}$complexes are also expected to play no or at best only a minor role at physiological $\mathrm{pH}$ and will therefore not be discussed here. 
In the $\mathrm{NDP}^{3-}$ species the residue R (Figures 9 and 10) is still close enough to the terminal $\beta$-phosphate group to have a small influence on the basicity of this group. Therefore log $K_{\mathrm{M}(\mathrm{R}-\mathrm{DP})}^{\mathrm{M}}$ versus $\mathrm{p} K_{\mathrm{H}(\mathrm{R}-\mathrm{DP})}^{\mathrm{H}}$ straight-line plots were constructed [115] to detect any possible stability enhancements for the complexes of purine-nucleoside 5'-diphosphates (vide infra). The important issue at this point is that in all instances the data points of the pyrimidine-nucleoside

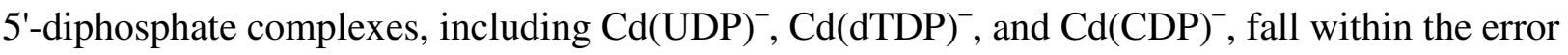
limits on the reference line constructed of ligands like phenyl diphosphate or $n$-butyl diphosphate as can be seen in Figure 12. Hence, in none of these cases does the pyrimidine-nucleobase interact with the metal ion coordinated at the phosphate residue. This corresponds to the observations discussed in Section 6.2.2 for the complexes of the pyrimidine-NMPs.

\section{insert Figure 12 close to here (width: $6.5 \mathrm{~cm}$ )}

The situation for the complexes of the pyrimidine-nucleoside 5'-triphosphates is also quite similar: Here all the $\mathrm{H}(\mathrm{NTP})^{3-}$ species have the same acidity constant, i.e., $\mathrm{p} K_{\mathrm{H}(\mathrm{NTP})}^{\mathrm{H}}=6.50 \pm$ 0.05 [31,37,116-120] (see also Section 5 and footnote "b" of Table 12, vide infra). Indeed, for a given metal ion the stability constants of the $\mathrm{M}(\mathrm{UTP})^{2-}, \mathrm{M}(\mathrm{dTTP})^{2-}$, and $\mathrm{M}(\mathrm{CTP})^{2-}$ complexes are identical within the error limits [with the single exception of $\left.\mathrm{Cu}(\mathrm{CTP})^{2-}[116]\right)$. Thus, these values can be averaged to obtain the stability of the 'open' complex in equilibrium (22), in which $\mathrm{M}^{2+}$ is only coordinated to the phosphate chain [116,119].

With the above information at hand we are now in the position to investigate the situation for the complexes of purine-NDPs and purine-NTPs in analogy to the procedure discussed in Section 6.2.3 for M(NMP) complexes. Consequently, all the equations applied earlier, i.e., equations (16) to (20) as well as (2), (3), (7), (14), (23), and (24), are also valid here as long as L is replaced by $\mathrm{NDP}^{3-}$ or $\mathrm{NTP}^{4-}$.

It follows from the enhanced stabilities of the purine-NDP complexes seen in Figure 12 that the formation degree of the macrochelated species according to equilibrium (22) increases within the series $\mathrm{Cd}(\mathrm{ADP})^{-} \sim \mathrm{Cd}(\mathrm{IDP})^{-}<\mathrm{Cd}(\mathrm{GDP})^{-}$. Indeed, this is confirmed by \% $\mathrm{M}(\mathrm{NDP})_{\mathrm{cl}}^{-}$ as listed in column 6 of Table 10. A similar observation is made for the $\mathrm{Cd}(\mathrm{NTP})^{2-}$ complexes, that is, $\mathrm{Cd}(\mathrm{ATP})_{\mathrm{cl}}^{2-}<\mathrm{Cd}(\mathrm{ITP})_{\mathrm{cl}}^{2-}<\mathrm{Cd}(\mathrm{GTP})_{\mathrm{cl}}^{2-}$, the data of which are listed in Table 11. 
At this point it is interesting to compare the results assembled in Tables 9 to 11. Of the many comparisons possible, only a few shall be indicated here. The extent of macrochelate formation in the $\mathrm{Cd}^{2+}$ complexes of the adenine-nucleotides is within the error limits identical, that is, $\mathrm{Cd}(\mathrm{AMP})_{\mathrm{cl}} \sim \mathrm{Cd}(\mathrm{ADP})_{\mathrm{cl}}^{--} \sim \mathrm{Cd}(\mathrm{ATP})_{\mathrm{cl}}^{2-}$. This means that the steric fit for a N7 interaction is about the same in all these complexes despite the fact that the overall stability spans a range from about 2.7 to $5.3 \log$ units. Interestingly, for the $\mathrm{Co}^{2+}$ and $\mathrm{Zn}^{2+}$ complexes it holds $\mathrm{M}(\mathrm{AMP})_{\mathrm{cl}}>\mathrm{M}(\mathrm{ADP})_{\mathrm{cl}}^{-} \sim \mathrm{M}(\mathrm{ATP})_{\mathrm{cl}}^{2-}$; this is possibly the effect of the smaller radii of $\mathrm{Co}^{2+}$ and $\mathrm{Zn}^{2+}$ compared with the one of $\mathrm{Cd}^{2+}$ (Table 1). For situations with a lower formation degree of macrochelates, like with $\mathrm{Mg}^{2+}$ and $\mathrm{Ca}^{2+}$, again $\mathrm{M}(\mathrm{AMP})_{\mathrm{cl}} \sim \mathrm{M}(\mathrm{ADP})_{\mathrm{cl}}^{-} \sim \mathrm{M}(\mathrm{ATP})_{\mathrm{cl}}^{2-}$ holds. For the $\mathrm{ADP}^{3-} / \mathrm{dADP}^{3-}$ pair (just as described for $\mathrm{AMP}^{2-} / \mathrm{dAMP}^{2-}$ in Section 6.2.3) complex stability and extent of macrochelate formation between the phosphate-coordinated metal ion and N7 of the adenine residue is very similar or even identical for the complexes of $\mathrm{Mg}^{2+}, \mathrm{Ni}^{2+}, \mathrm{Cu}^{2+}$, and $\mathrm{Zn}^{2+}[121]$. In the case of $\mathrm{ATP}^{4-} / \mathrm{dATP}^{4-}$ the 2'-deoxy complexes are somewhat more stable and show also a slightly enhanced tendency for macrochelate formation. The same may be surmised for the corresponding $\mathrm{Cd}^{2+}$ complexes.

For all metal ion complexes, including those with $\mathrm{Cd}^{2+}$, and for all ribose-purine nucleotides the extent of macrochelate formation increases in a first approximation for the nucleobase residues within the series adenine $<$ hypoxanthine $<$ guanine (Tables 9-11). This order is due to the steric influence of the $(\mathrm{C} 6) \mathrm{NH}_{2}$ group in adenine, the likely partial (outersphere) participation of the (C6)O unit, and the higher basicity of $\mathrm{N} 7$ in guanine than in hypoxanthine as discussed already for the NMPs in Section 6.2.3. The significant formation degrees of the macrochelates involving N7 in the order of about 50 and $70 \%$ for $\mathrm{Zn}(\mathrm{ITP})_{\mathrm{cl}}^{2-}$ and $\mathrm{Zn}(\mathrm{GTP})_{\mathrm{cl}}^{2-}$, respectively (Table 11), lead to an acidification of the corresponding (N1)H sites, which amounts to $\Delta \mathrm{p} K_{\mathrm{a}}=0.95$ and 1.40 for $\mathrm{Zn}(\mathrm{ITP})^{2-}$ and $\mathrm{Zn}(\mathrm{GTP})^{2-}$, respectively [81]. Consequently, a similar acidification is to be expected for the $\mathrm{Cd}(\mathrm{ITP})^{2-}$ and $\mathrm{Cd}(\mathrm{GTP})^{2-}$ complexes. Remarkably, the formation of ternary M(Bpy)(NTP $)^{2-}$ complexes with intramolecular stacks (Section 8.3) between the pyridyl and purine residues [81,140], diminishes the acidification considerably because of the removal of the metal ion from $\mathrm{N} 7$ [81].

There is one more point in the context of macrochelate formation. N7 may be innersphere 
but also outersphere bound to the already phosphate-coordinated metal ion. For example, based on several methods it was concluded for $\mathrm{Ni}(\mathrm{ATP})^{2-}$ that about $30 \%$ are $\mathrm{N} 7$ innersphere, $25 \%$ are N7 outersphere, and 45\% exist as $\mathrm{Ni}(\mathrm{ATP})_{\mathrm{op}}^{2-}$, i.e., the open form in equilibrium (22) $[50,120]$. In contrast, macrochelation occurs with $\mathrm{Mg}^{2+}$ only outersphere at $\mathrm{N} 7$ and with $\mathrm{Cu}^{2+}$ only innersphere [120]. For Cd(ATP) ${ }^{2-}$ it was concluded that about $30 \%$ are N7 innersphere, $20 \%$ N7 outersphere, and ca. 50\% exist as Cd(ATP) ${ }_{\text {op }}^{2-}[116,120]$. Similarly, based on ${ }^{1} \mathrm{H}$ NMR shift experiments it became evident that $\mathrm{Mg}(\mathrm{ITP})_{\mathrm{cl}}^{2-}$ and $\mathrm{Mg}(\mathrm{GTP})_{\mathrm{cl}}^{2-}$ are of an outersphere type $[119,137]$, but that $\mathrm{Cd}(\mathrm{ITP})_{\mathrm{cl}}^{2-}$ and $\mathrm{Cd}(\mathrm{GTP})_{\mathrm{cl}}^{2-}$ are largely innersphere bound to N7. For the three $\mathrm{Mg}(\mathrm{NDP})^{-}$complexes with $\mathrm{ADP}^{3-}, \mathrm{IDP}^{3-}$, and $\mathrm{GDP}^{3-}$ again only outersphere binding to $\mathrm{N} 7$ is postulated, and for $\mathrm{Cd}(\mathrm{IDP})_{\mathrm{cl}}$ and $\mathrm{Cd}(\mathrm{GDP})_{\mathrm{cl}}$ it is concluded that they occur with nearly $100 \%$ innersphere coordination to N7 [149]. For Cd(ADP) $\overline{\mathrm{cl}}$ also a significant N7 innersphere binding is surmised [149].

Finally, it is well known that metal ions promote the dephosphorylation of NTPs $[117,150]$ and for the promoted hydrolysis of ATP at $\mathrm{pH} 7.5$ the order $\mathrm{Cu}^{2+}>\mathrm{Cd}^{2+}>\mathrm{Zn}^{2+}>>\mathrm{Mn}^{2+} \geq \mathrm{Ni}^{2+}$ $>\mathrm{Mg}^{2+}$ was established [29,150]. It should be noted that $\mathrm{M}_{2}(\mathrm{NTP})$ complexes are especially reactive in the hydrolysis reaction, which is actually a transphosphorylation to a water molecule; the reactive coordination mode is $\mathrm{M}(\alpha, \beta)-\mathrm{M}(\gamma)$ because this facilitates the break between the $\beta$ and $\gamma$-phosphate groups $[29,117]$.

\subsection{Complexes of Less Common Nucleotides}

The structures of the nucleoside residues of the nucleotides considered in this section are shown in Figures 1 (Ado), 5 (Tu), and 8 (Or- Xao, U2S, U4S). The corresponding nucleoside monophosphates result if the (C5)OH group is phosphorylated (see also Figure 10) with the exception of 2'- and $3 \mathrm{AMP}^{2-}$ where the phosphate group is located at $\mathrm{C} 2$ or $\mathrm{C} 3$, respectively.

\subsubsection{Tubercidin 5'-Monophosphate}

Tubercidin 5'-monophosphate, an analogue of $\mathrm{AMP}^{2-}$, is synthesized by molds and fungi, as 
already indicated in Section 4.3.1. The corresponding nucleoside is identical in its structure with adenosine (Figures 1 and 5) except that N7 is substituted by $\mathrm{CH}[50,136]$. As already indicated in Section 6.2.2, TuMP $^{2-}$ behaves in its binding properties towards $\mathrm{Cd}^{2+}$ like a pyrimidine-NMP, that is, like a simple phosphate monoester ligand. This conclusion is confirmed by calculating the expected stability constant of the 'open' isomer (eqs 14, 19) for $\mathrm{Cd}(\mathrm{TuMP})$ by application of equation (25) and $\mathrm{p} K_{\mathrm{H}(\mathrm{TuMP})}^{\mathrm{H}}=6.32$ (Table 8): The result $\log K_{\mathrm{Cd}(\mathrm{TuMP}) \text { calc }}^{\mathrm{Cd}}=2.48 \pm 0.05$ is within the error limits identical with the measured stability constant $K_{\mathrm{Cd}(\mathrm{TuMP}) \exp }^{\mathrm{Cd}}=2.42 \pm 0.07$ (Table 8), thus proving that equilibrium (22) is far to its left side. Because N7 is not present and the N1 site cannot be reached in TuMP ${ }^{2-}$ by a phosphate-coordinated metal ion, the tubercidin moiety has no effect on the stability of $\mathrm{M}(\mathrm{TuMP})$ complexes [136]. The steric inhibition exercised by the (C6) $\mathrm{NH}_{2}$ group on $\mathrm{Cd}^{2+}$ coordination to $\mathrm{N} 1$ has been quantified with $o$ amino(methyl)pyridine-type ligands [59] (see also Figure 6). This is mentioned here because this compound and derivatives thereof are often used as structural analogues of their corresponding parent adenine compounds.

\subsubsection{Nucleoside 2'- and 3'-Monophosphates}

Other adenine-nucleotides, which occur in nature and which are important for nucleic acids, are $2^{\prime} \mathrm{AMP}^{2-}$ and $3 \mathrm{AMP}^{2-}$; several of their complexes have been studied $[32,48]$. What types of macrochelates are possible with these two AMPs? By considering their structures (cf. with Figure 10) it is evident that N7, though crucial for the properties of the M(5'AMP) complexes (Section 6.2.3; Table 9), is for steric reasons not accessible to a metal ion already bound to either the 2'- or 3'-phosphate group. Indeed, the stability enhancements observed for $\operatorname{Cd}\left(2^{\prime} \mathrm{AMP}\right)$ and $\mathrm{Cd}\left(3^{\prime} \mathrm{AMP}\right)$ are with $\log \Delta_{\mathrm{Cd} / 2^{\prime} \mathrm{AMP}}=0.06 \pm 0.07$ and $\log \Delta_{\mathrm{Cd} / 3^{\prime} \mathrm{AMP}}=0.02 \pm 0.06(3 \sigma)$ (eq. 14$)$ very small or even zero [48] (cf. with $\log \Delta_{\mathrm{Cd} / 5{ }^{\prime} \mathrm{AMP}}=0.30 \pm 0.07$; Table 9$)$ and within the error limits also identical allowing no sophisticated conclusions. Nevertheless, one might be tempted to postulate some chelate formation with the neighboring $\mathrm{OH}$ groups of the ribose ring for both AMPs.

However, in the light of the discussion in Sections 3.2 and 3.3 the above indication appears as highly unlikely and based on the results obtained with $\mathrm{Cu}\left(2^{\prime} \mathrm{AMP}\right)$ and $\mathrm{Cu}\left(3^{\prime} \mathrm{AMP}\right)$ it 
can actually be excluded: The steric conditions for $2^{\prime} \mathrm{AMP}^{2-}$ and $3^{\prime} \mathrm{AMP}^{2-}$ to form such 7membered chelates are identical and therefore equivalent properties for both complexes are expected, yet the results are $\log \Delta_{\mathrm{Cu} / 2^{\prime} \mathrm{AMP}}=0.26 \pm 0.08$ and $\log \Delta_{\mathrm{Cu} / 3^{\prime} \mathrm{AMP}}=0.08 \pm 0.08$ corresponding to formation degrees of $45 \pm 10 \%$ and $17 \pm 16 \%$ for $\mathrm{Cu}\left(2^{\prime} \mathrm{AMP}\right)_{\mathrm{cl}}$ and $\mathrm{Cu}\left(3^{\prime} \mathrm{AMP}\right)_{\mathrm{cl}}$, respectively [48]. Thus, different structural qualities of the two AMPs must be responsible for the different properties of the two complexes. The obvious conclusion is that in $\mathrm{Cu}\left(2^{\prime} \mathrm{AMP}\right)$ partial macrochelate formation occurs by an interaction of the 2'-phosphatecoordinated metal ion with $\mathrm{N} 3$ of the adenine residue. Actually, $2^{\prime} \mathrm{AMP}^{2-}$ in its preferred anti conformation is perfectly suited for this type of macrochelate formation [48], whereas in $\mathrm{Cu}\left(3^{\prime} \mathrm{AMP}\right)$ an $\mathrm{N} 3$ interaction can only be achieved if the nucleotide adopts the less favored syn conformation - and this costs energy and results thus in the observed lower formation degree of the macrochelate.

The following results obtained for the $\mathrm{Cd}^{2+}$ complexes of $2 \mathrm{GMP}^{2-}, 3 \mathrm{GMP}^{2-}$, and 2'deoxy-3'GMP ${ }^{2-}$ [151] corroborate at least to some extent with the above conclusions:

$$
\begin{array}{llll}
\log \Delta_{\mathrm{Cd} / 2^{\prime} \mathrm{GMP}}=0.35 \pm 0.07 & \% \mathrm{Cd}\left(2^{\prime} \mathrm{GMP}\right)_{\mathrm{cl}} & =55 \pm 7 \\
\log \Delta_{\mathrm{Cd} / 3^{\prime} \mathrm{GMP}}=0.34 \pm 0.09 & \% \mathrm{Cd}\left(3^{\prime} \mathrm{GMP}\right)_{\mathrm{cl}} & =54 \pm 9 \\
\log \Delta_{\mathrm{Cd} / 2^{\prime} 3^{\prime} \mathrm{GMP}}=0.29 \pm 0.09 & \% \mathrm{Cd}\left(2^{\prime} \mathrm{d} 3^{\prime} \mathrm{GMP}\right)_{\mathrm{cl}} & =49 \pm 10
\end{array}
$$

The stability enhancements for $\mathrm{Cd}\left(2^{\prime} \mathrm{GMP}\right)$ and $\mathrm{Cd}\left(3^{\prime} \mathrm{GMP}\right)$ are of about the same size, indicating that for the larger $\mathrm{Cd}^{2+}\left(\right.$ compared with $\left.\mathrm{Cu}^{2+}\right)$ the anti/syn transformation is apparently of lower relevance. The most important conclusion from this list, however, is the fact that removal of the 2'-hydroxy group from the ribose ring does not affect the stability enhancement and the degree of chelate formation. Hence, one may conclude that the 2'-OH group is not involved in metal ion binding and that an interaction with N3 is responsible for the stability enhancement. It should be added here that it is becoming increasingly clear from solution [152154] as well as X-ray crystal structure studies that the N3 site of a purine may bind metal ions [155-160]. For example, $\mathrm{Pt}^{2+}[155]$ and $\mathrm{Cd}^{2+}[156]$ bind via $\mathrm{N} 3$ to adenine derivatives, $\mathrm{Pd}^{2+}$ to $\mathrm{N6}$ ',N6',N9-trimethyladenine [157], $\mathrm{Pt}^{2+}$ to a guanine derivative [158], as well as $\mathrm{Cu}^{2+}$ [159] and $\mathrm{Ni}^{2+}[160]$ to neutral adenine. 


\subsubsection{Orotidinate 5'-Monophosphate}

In Figure 8 (top, left) the structure of orotidine, the nucleoside of the above nucleotide, is shown; a stability constant of its $\mathrm{Cd}^{2+}$ complex has been measured [93]. Orotidinate 5'-monophosphate $\left(\mathrm{OMP}^{3-}\right)$ is involved in the biosynthesis of pyrimidine-nucleotides: $\mathrm{OMP}^{3-}$ is decarboxylated to $\mathrm{UMP}^{2-}$ (cf. Figures 1 and 8), which is then further transformed, e.g., to $\mathrm{UTP}^{4-}$ or $\mathrm{CTP}^{4-}$ (Figure 10). $\mathrm{OMP}^{3-}$ itself exists predominately in the syn conformation, which is depictured for $\mathrm{H}(\mathrm{Or})$ in Figure 8 (top, left) (i.e., the (C2)O group being above the ribose ring).

The carboxylic acid group at C6 of OMP is very acidic and is deprotonated with $\mathrm{p} K_{\mathrm{a}}=$ $1.46 \pm 0.10$ [93]. Due to the resulting negative charge the deprotonation of the $\mathrm{P}(\mathrm{O})_{2}(\mathrm{OH})^{-}$group of $\mathrm{H}(\mathrm{OMP})^{2-}$ occurs at a slightly higher $\mathrm{pH}$, i.e., $\mathrm{p} K_{\mathrm{a}}=6.40 \pm 0.02$ [93], than that of the corresponding group of $\mathrm{H}(\mathrm{UMP})^{-}$, i.e., $\mathrm{p}_{\mathrm{H}(\mathrm{UMP})}^{\mathrm{H}}=6.15 \pm 0.01$ (Table 8). Consequently, at the physiological $\mathrm{pH}$ of 7.5 the species $\mathrm{OMP}^{3-}$ and $\mathrm{UMP}^{2-}$ dominate. For $\mathrm{Cd}(\mathrm{UMP})$ we have seen that the uracil moiety does not participate in metal ion binding (Section 6.2.2) and that its stability constant fits on the reference line (Figure 11). This is different for the stability of $\mathrm{Cd}(\mathrm{OMP})^{-}$which is by $\log \Delta_{\mathrm{Cd} / \mathrm{OMP}}=0.49 \pm 0.07$ above this line and hence, this complex is more stable than expected on the basis of the basicity of the phosphate group. However, this enhanced complex stability is solely a charge effect of the non-coordinating (C6) $\mathrm{COO}^{-}$group as follows from the average of the stability enhancements observed for 10 different $\mathrm{M}^{2+}$ ions in their $\mathrm{M}(\mathrm{OMP})^{-}$complexes, i.e., $\log \Delta_{\mathrm{M} / \mathrm{OMP}}=0.40 \pm 0.06(3 \sigma)$ (defined according to eq. 14) [93]. At higher $\mathrm{pH}$ values when the $(\mathrm{N} 3) \mathrm{H}$ site is becoming deprotonated, the different metal ions behave differently due to their different affinity for an (N3)- site (Section 4.2; Figure 7): Now Cd(OMP $-\mathrm{H})^{2-}$ exists as a macrochelate with a formation degree of $93 \pm 2 \%$ (see equilibrium 22 ); the phosphate-bound $\mathrm{Cd}^{2+}$ interacts with the (N3) ${ }^{-}$site [93], which is sterically easily reached (see Figure 8, top, left).

\subsubsection{Xanthosinate 5'-Monophosphate}

Like OMP being an intermediate in the metabolism of pyrimidines, XMP is one in the metabolism of purines (Section 4.3.3). It is most important to note that XMP exists at the 
physiological $\mathrm{pH}$ of 7.5 as a xanthine-deprotonated $(\mathrm{XMP}-\mathrm{H})^{3-}$ species, more exactly written as $(\mathrm{X}-\mathrm{H} \cdot \mathrm{MP})^{3-}($ see Figure 13) [96]. This fact has so far mostly been overlooked $[96,161]$ and $\mathrm{XMP}$ is commonly written in textbooks in analogy to $\mathrm{GMP}^{2-}$ (see Figures 1 and 10), which is not correct. It must further be noted that in XMP the deprotonation of the xanthine moiety $\left(\mathrm{p} K_{\mathrm{a}}=\right.$ $5.30 \pm 0.02)$ takes place before that of the $\mathrm{P}(\mathrm{O})_{2}(\mathrm{OH})^{-}$group $\left(\mathrm{p} K_{\mathrm{a}}=6.45 \pm 0.02\right)$ [96]. Naturally, these acid-base properties affect the coordination chemistry of XMP $[97,162,163]$.

\section{insert Figure 13 close to here (width: 9 cm)}

The $\mathrm{M}(\mathrm{XMP})$ complexes are quite special and they are better written as $(\mathrm{M} \cdot \mathrm{X}-$ $\mathrm{H} \cdot \mathrm{MP} \cdot \mathrm{H})^{ \pm}$to indicate that the phosphate group carries a proton, and that the metal ion is coordinated to $\mathrm{N} 7$ possibly also undergoing an (outersphere) interaction with (C6)O. With the nine metal ions $\mathrm{Ba}^{2+}, \mathrm{Sr}^{2+}, \mathrm{Ca}^{2+}, \mathrm{Mg}^{2+}, \mathrm{Mn}^{2+}, \mathrm{Co}^{2+}, \mathrm{Cu}^{2+}, \mathrm{Zn}^{2+}$, and $\mathrm{Cd}^{2+}$ the average stability enhancement for these complexes amounts to $\log \Delta_{\mathrm{M} / \mathrm{XMP}}=0.46 \pm 0.11(3 \sigma)$ [162]. These stability enhancements are based on the basicity- and charge-corrected stabilities of the $\mathrm{M}(\mathrm{xanthosinate})^{+}$complexes [162]. This equality indicates that the interaction of the N7-bound $\mathrm{M}^{2+}$ ions with the monoprotonated phosphate group occurs in an outersphere manner $[97,162]$. The stability enhancement for the $(\mathrm{Cd} \cdot \mathrm{X}-\mathrm{H} \bullet \mathrm{MP} \cdot \mathrm{H})^{ \pm}$complex is at the lower limit of the mentioned average, but with $\log \Delta_{\mathrm{Cd} / \mathrm{XMP}}=0.30 \pm 0.16$ still within the error limits. From the given stability enhancements formation degrees of $64 \pm 9 \%(3 \sigma)$ follow on average for the $(\mathrm{M} \cdot \mathrm{X}$ $-\mathrm{H} \cdot \mathrm{MP} \cdot \mathrm{H}) \underset{\mathrm{cl}}{ \pm}\left[=\mathrm{M}(\mathrm{XMP})_{\mathrm{cl}}\right]$ species $($ eq. 22$)$, and $50 \pm 18 \%$ if $(\mathrm{Cd} \cdot \mathrm{X}-\mathrm{H} \cdot \mathrm{MP} \cdot \mathrm{H}) \frac{ \pm}{\mathrm{cl}}$ is considered specifically, but again, the values overlap within the error limits [97,162].

Upon deprotonation of the phosphate group, which then becomes the primary binding site, the metal ions show, as expected (see, e.g., Figure 11), their common individual properties. Macrochelate formation according to equilibrium (22) involving N7 [and possibly also (C6)O)] results for the $\mathrm{M}(\mathrm{XMP}-\mathrm{H})^{-}$complexes, also written as $(\mathrm{X}-\mathrm{H} \cdot \mathrm{MP} \cdot \mathrm{M})^{-}[162]$. The stability enhancement $\log \Delta_{\mathrm{Cd}(\mathrm{XMP}-\mathrm{H})}=1.05 \pm 0.17$ (eq. 14) corresponds to a formation degree of $91 \pm$ $3 \%$ for $(\mathrm{X}-\mathrm{H} \cdot \mathrm{MP} \cdot \mathrm{Cd}) \overline{\mathrm{cl}}$. The corresponding complexes with $\mathrm{Cu}^{2+}$ and $\mathrm{Zn}^{2+}$ form to $95 \pm 2 \%$ $\left(\log \Delta_{\mathrm{Cu}(\mathrm{XMP}-\mathrm{H})}=1.33 \pm 0.17\right)$ and $88 \pm 5 \%\left(\log \Delta_{\mathrm{Zn}(\mathrm{XMP}-\mathrm{H})}=0.92 \pm 0.17\right)$, respectively, whereas for $\mathrm{Mn}^{2+}$ only to $48 \pm 22 \%$ form $\left(\log \Delta_{\mathrm{Mn}(\mathrm{XMP}-\mathrm{H})}=0.28 \pm 0.18\right)$ [162]. It may be added that by a different evaluation method [164], in which the various binding sites were considered 
independently [97], it was concluded that the total amount of $\mathrm{Cd}(\mathrm{XMP}-\mathrm{H}) \overline{\mathrm{cl}}[=(\mathrm{X}-$ $\mathrm{H} \cdot \mathrm{MP} \cdot \mathrm{Cd})_{\mathrm{cl}}^{-}$] (eq. 22) equals $87 \pm 4 \%$ (which agrees within the error limits with the above result of $93 \pm 3 \%$ ), but that there are two open isomers, one in which $\mathrm{Cd}^{2+}$ is coordinated to the phosphate group of $(\mathrm{XMP}-\mathrm{H})^{3-}$ and one where it is at the xanthinate residue (Figure 13), the formation degrees being 9 and $14 \%$, respectively [97].

\subsubsection{Thiouracil Nucleotides}

Though rare, thiouracil nucleotides occur in nature (see also Section 4.3.4), for example, 4thiouridine 5'-monophosphate $\left(\mathrm{U} \mathrm{SMP}^{2-}\right)$ in bacterial and archaeal tRNA [100,101]. This nucleotide and its relative, 2-thiouridine 5'-monophosphate $\left(\mathrm{U}_{2} \mathrm{SMP}^{2-}\right)$, will be considered in this section. The structure of both nucleotides is evident if the formula shown in Figure 8 are combined with the content of Figure 10.

It is revealing to compare first the acidity constants of the two thiouracil nucleotides with those of the parent compound, that is, uridine 5'-monophosphate (Figures 1 and 10):

Deprotonation of the monoprotonated phosphate groups in $\mathrm{H}(\mathrm{U} 2 \mathrm{SMP})^{-}$and $\mathrm{H}(\mathrm{U} 4 \mathrm{SMP})^{-}$occurs with $\mathrm{p} K_{\mathrm{H}(\mathrm{U} 2 \mathrm{SMP})}^{\mathrm{H}}=6.10 \pm 0.02$ and $\mathrm{p} K_{\mathrm{H}(\mathrm{U} 4 \mathrm{SMP})}^{\mathrm{H}}=6.07 \pm 0.03$, respectively [105]; these values are very similar to that of the parent $\mathrm{H}(\mathrm{UMP})^{-}$species, $\mathrm{p} K_{\mathrm{H}(\mathrm{UMP})}^{\mathrm{H}}=6.15 \pm 0.01$ [114]. This is very different for the deprotonation of the (N3)H sites in these compounds: For U2SMP ${ }^{2-}$ and $\mathrm{U}_{4} \mathrm{SMP}^{2-} \mathrm{p} K_{\mathrm{U} 2 \mathrm{SMP}}^{\mathrm{H}}=8.30 \pm 0.01$ and $\mathrm{p} K_{\mathrm{U} 4 \mathrm{SMP}}^{\mathrm{H}}=8.23 \pm 0.02$, respectively [165], hold, showing that, if compared with $\mathrm{UMP}^{2-}$, i.e., $\mathrm{p} K_{\mathrm{UMP}}^{\mathrm{H}}=9.45 \pm 0.02$ [114], the exchange of $(\mathrm{C}) \mathrm{O}$ by a (C)S group has a very pronounced effect.

The problem is that $\mathrm{M}(\mathrm{USMP})$ complexes, where $\mathrm{USMP}^{2-}=\mathrm{U}_{2} \mathrm{SMP}^{2-}$ or $\mathrm{U}_{4} \mathrm{SMP}^{2-}$, form, at least in part $[105,165]$, but that these species are better written as $[\mathrm{M} \cdot(\mathrm{US}-\mathrm{H}) \mathrm{MP} \cdot \mathrm{H}]^{ \pm}$, that is, the proton is at the phosphate group and the metal ion at the deprotonated uracil residue; of course, these species lose easily their proton from the $\mathrm{P}(\mathrm{O})_{2}(\mathrm{OH})^{-}$group $\left(\mathrm{p} K_{\mathrm{a}}\right.$ ca. 5.7 [165]). This result is not surprising if one compares, e.g., the stability of the $\mathrm{Cd}(\mathrm{U}-\mathrm{H})^{+}$complexes in Figure 7 with that of $\mathrm{Cu}(\mathrm{UMP})$ in Figure 11; there is clearly the tendency visible that qualifies the (N3)deprotonated thiouracil group as the primary binding site.

For the above reason the open species of the thiouracilate and phosphate groups were 
individually evaluated by considering also a potential chelate formation [105]. The result is that for $\mathrm{Cd}[(\mathrm{U} 4 \mathrm{~S}-\mathrm{H}) \mathrm{MP}]^{-}$the complex is to $99 \%$ present as $[\mathrm{Cd} \cdot(\mathrm{U} 4 \mathrm{~S}-\mathrm{H}) \mathrm{MP}]^{-}$(base-bound) and only $1 \%$ exists as $[(\mathrm{U} 4 \mathrm{~S}-\mathrm{H}) \mathrm{MP} \cdot \mathrm{Cd}]^{-}$(phosphate-bound), hence, the $\mathrm{Cd}^{2+}$-thiouracilate isomer dominates strongly; no indication for chelate formation was found. This is understandable because the structure of $[(\mathrm{U} 4 \mathrm{~S}-\mathrm{H}) \mathrm{MP}]^{3-}$ is such that a metal ion bound at the $(\mathrm{C} 4) \mathrm{S} /(\mathrm{N} 3)^{-}$unit can hardly reach the phosphate group and vice versa (see Figure 8). Of course, the two open species are also in equilibrium with each other.

For $\mathrm{Cd}[(\mathrm{U} 2 \mathrm{~S}-\mathrm{H}) \mathrm{MP}]^{-}$exactly the same isomer distribution may be surmised [105] because for the chelate effect [164] only $0.11 \pm 0.15 \log$ unit were derived [105]. Hence, within the error limits the chelate effect is zero, meaning that no chelate forms. However, based on the mentioned $0.11 \log$ unit it could be that about $20 \%$ chelate, $\mathrm{M}[(\mathrm{U} 2 \mathrm{~S}-\mathrm{H}) \mathrm{MP}]_{\mathrm{cl}}^{-}$, exist and that the remaining $80 \%$ of the open species are then present to ca. $79 \%$ with $\mathrm{Cd}^{2+}$ at the thiouracilate residue and about $1 \%$ bound at the phosphate group [105]. Of course, chelate formation of a metal ion coordinated at the $(\mathrm{C} 2) \mathrm{S} /(\mathrm{N} 3)^{-}$site with the phosphate group (or vice versa) is only possible if the nucleotide is transformed into the syn conformer (Figure 8). In any case, it is evident that replacement of $(\mathrm{C}) \mathrm{O}$ by $(\mathrm{C}) \mathrm{S}$ in the nucleobase residue enhances the stability of the $\mathrm{Cd}^{2+}$ complexes considerably.

\subsubsection{Flavin Mononucleotide}

Flavin mononucleotide $\left(\mathrm{FMN}^{2-}\right)$, also known as riboflavin 5'-phosphate, is a coenzyme of a large number of enzymes which catalyze redox reactions in biological systems [90,91]. It is composed of the 7,8-dimethyl isoalloxazine (i.e., the flavin) ring system, which is bound via N10 to the methylene group of the sugar-related ribit, giving 7,8-dimethyl-10-ribityl-isoalloxazine, also known as riboflavin or vitamin $\mathrm{B}_{2}[90,91]$, which carries at its 5 ' position a phosphate monoester residue (see Figure 13, bottom). The corresponding $\mathrm{P}(\mathrm{O})_{2}(\mathrm{OH})^{-}$group has an acidity constant of the expected order, i.e., $\mathrm{p} K_{\mathrm{a}}=6.18 \pm 0.01$ [166].

Surprisingly, the stability constants of the $\mathrm{M}(\mathrm{FMN})$ complexes, where $\mathrm{M}^{2+}=\mathrm{Mg}^{2+}, \mathrm{Ca}^{2+}$, $\mathrm{Sr}^{2+}, \mathrm{Ba}^{2+}, \mathrm{Mn}^{2+}, \mathrm{Co}^{2+}, \mathrm{Ni}^{2+}, \mathrm{Cu}^{2+}, \mathrm{Zn}^{2+}$, and $\mathrm{Cd}^{2+}$, are throughout slightly more stable than is expected from the basicity of the phosphate group. This stability enhancement, as already 
summarized in the context of a $\mathrm{Ni}^{2+}$ review [40], amounts on average to $\log \Delta_{\mathrm{M} / \mathrm{FMN}}=0.16 \pm 0.04$ $(3 \sigma)$ (eq. 14) including also the value for the $\mathrm{Cd}(\mathrm{FMN})$ complex, $\log \Delta_{\mathrm{Cd} / \mathrm{FMN}}=0.17 \pm 0.06(3 \sigma)$ [166]. This slight stability increase cannot be attributed to the formation of a 7-membered chelate according to equilibrium (5) (see Section 3.3) involving the ribit-hydroxyl group at C4'. This is demonstrated by the stabilities of the $\mathrm{M}(\mathrm{G} 1 \mathrm{P})$ complexes which contain the same structural unit (Figure 13) but show no enhanced stability as already discussed in Section 3.3. Hence, in agreement with the results of a kinetic study [167] one has to conclude that the slight stability increase of the $\mathrm{M}(\mathrm{FMN})$ complexes has to be attributed to the isoalloxazine ring.

However, the equality of the stability increase of the complexes for all ten mentioned metal ions precludes its attributions to an interaction with a $\mathrm{N}$ site of the neutral isoalloxazine ring and makes a specific interaction with an $\mathrm{O}$ site also rather unlikely (note, deprotonation of (N3)H of $\mathrm{FMN}^{2-}$ occurs only with $\mathrm{p} K_{\mathrm{a}}=10.08 \pm 0.05$ [166]). Furthermore, carbonyl oxygens in aqueous solution are no favored binding sites in macrochelate formation (see Section 3.3). Maybe an outersphere interaction could be proposed - but to which site? The most likely explanation is the earlier proposal [166] that the small but overall significant stability increase originates from "bent" $\mathrm{M}(\mathrm{FMN})$ species in which the hydrophobic flavin residue $[168,169]$ is getting close to the metal ion at the phosphate group, thereby lowering the intrinsic dielectric constant (permittivity) in the microenvironment of the metal ion and thus promoting indirectly the $\mathrm{PO}_{3}^{2-} / \mathrm{M}^{2+}$ interaction [166].

The above mentioned average stability enhancement, $\log \Delta_{\mathrm{M} / \mathrm{FMN}}=0.16 \pm 0.04$, results in $K_{\mathrm{I}}=0.45 \pm 0.13(3 \sigma)$ and a formation degree of the "bent" $\mathrm{M}(\mathrm{FMN})$ species of $31 \pm 6 \%(3 \sigma)$ [166]. It is amazing to note that this average formation degree is within the error limits identical with the one calculated [166] for $\mathrm{Ni}(\mathrm{FMN})_{\mathrm{cl}}$, i.e., $38( \pm 10) \%$, based on kinetic results [167]. Moreover, the stability data of Stuehr et al. [167], also for the Ni(FMN) complex, lead to log $\Delta_{\mathrm{Ni} / \mathrm{FMN}}=0.17$ and yield $32 \%$ for $\mathrm{Ni}(\mathrm{FMN})_{\mathrm{cl}}$. To conclude, though the given explanation for the enhanced stability of the $\mathrm{M}(\mathrm{FMN})$ complexes remains somewhat uncertain, the occurrence of such a stability enhancement for the $\mathrm{M}(\mathrm{FMN})$ complexes including $\mathrm{Cd}^{2+}$ is definite.

\section{Cadmium(II) Complexes of Nucleotide Analogues}


The use of structurally altered nucleotides as probes is one way to study reactions of enzymes which involve nucleotides as substrates. Another goal for structural alterations is the hope to obtain compounds with useful pharmaceutical properties. In fact, over the years all three parts of nucleotides have been systematically modified, i.e., the nucleobases, the ribose, and the phosphate residues $[170,171]$. In this section we shall discuss (at least) one example each by concentrating on such derivatives for which also the $\mathrm{Cd}^{2+}$ complexes have been studied. Therefore, the (N1)-oxides of the adenosine and inosine 5'-monophosphates will not be covered, though it needs to be pointed out that upon N-oxide formation the nucleobase residues become more acidic, e.g., $\mathrm{p} K_{\text {Ado }}^{\mathrm{H}}=16.7[34,113]$ versus $\mathrm{p} K_{\text {AdogNO }}^{\mathrm{H}}=12.86$ [172], and their metal ionbinding properties increase dramatically upon the loss of a proton. As a consequence, e.g., $\mathrm{Zn}^{2+}$ switches at pH 6.9 from the phosphate group to the deprotonated $o$-amino N-oxide unit [173]. The analogous properties are expected for $\mathrm{Cd}^{2+}$. The properties of both (N1)-oxides have been reviewed $[40,174]$. Otherwise the organization of this section follows to a great deal one in which recently the properties of $\mathrm{Ni}^{2+}$ were summarized [40], but now, of course, the focus is on $\mathrm{Cd}^{2+}$.

\subsection{Properties of 1, $N^{6}$-Ethenoadenosine and of Its Phosphates}

Formation of a $1, \mathrm{~N}^{6}$-etheno bridge at the adenine residue leads to a 1,10-phenanthroline-like metal ion binding site in adenosine and gives so-called $\varepsilon$-adenosine ( $\varepsilon$-Ado) [171]. It is thus no surprise that the stability of the $\mathrm{Cd}^{2+}$ complexes increases by a factor of more than 10 by going from adenosine $\left(\log K_{\mathrm{Cd}(\text { Ado })}^{\mathrm{Cd}}=0.64\right.$; Table 3$)$ to $\varepsilon$-adenosine $\left(\log K_{\mathrm{Cd}(\varepsilon \text {-Ado })}^{\mathrm{Cd}}=\right.$ ca. 1.8 [175]). It may be added that $\mathrm{N} 6$ of $\varepsilon$-Ado can be protonated and that this proton is released with $\mathrm{p} K_{\mathrm{H}(\varepsilon-\mathrm{Ado})}^{\mathrm{H}}=4.05 \pm 0.01$ [169]. For the most likely resonance structure of $\mathrm{H}(\varepsilon-\mathrm{Ado})^{+}$ref. [175] should be consulted.

In accord with the above are the acid-base properties of $\mathrm{H}_{2}(\varepsilon-\mathrm{AMP})^{ \pm}$(for the structure see Figure 14, top $[176,171])$ which releases the proton from $(\mathrm{N} 6) \mathrm{H}^{+}$with $\mathrm{pK}_{\mathrm{H}_{2}(\varepsilon-\mathrm{AMP})}^{\mathrm{H}}=4.23 \pm$ 0.02 and the one from $\mathrm{P}(\mathrm{O})_{2}(\mathrm{OH})^{-}$with $\mathrm{p} K_{\mathrm{H}(\varepsilon \text {-AMP })}^{\mathrm{H}}=6.23 \pm 0.01[136,178]$. Hence, in the 
neutral $\mathrm{pH}$ range complexes of the type $\mathrm{M}(\varepsilon-\mathrm{AMP})$ are expected and actually observed $[136,178]$ though $\mathrm{M}(\mathrm{H} ; \varepsilon-\mathrm{AMP})^{+}$species are also known [178]. The stability enhancement for the $\mathrm{Zn}(\varepsilon-$ AMP) complex, compared with a sole $\mathrm{Zn}^{2+}$-phosphate binding (eq. 14), amounts to approximately $1 \log$ unit meaning that the macrochelated species (equilibrium 22) dominate with a formation degree of about $90 \%$ [136]. Unfortunately, no data about the corresponding $\mathrm{Cd}^{2+}$ complex are known, but it is to be expected that the stability enhancement for $\mathrm{Cd}(\varepsilon-\mathrm{AMP})$ is at least as large as the one for $\mathrm{Zn}(\varepsilon-\mathrm{AMP})$.

\section{insert Figure 14 close to here (width: $9 \mathrm{~cm}$ )}

In Section 6.3 we have seen that $\mathrm{Cd}(\mathrm{ATP})^{2-}$ experiences a stability enhancement of $\log$ $\Delta_{\mathrm{Cd} / \mathrm{ATP}}=0.27 \pm 0.04$ (Table 11) due to N7 binding of the phosphate-coordinated $\mathrm{Cd}^{2+}$ and that the macrochelate reaches a formation degree of about $45 \%$ (Table 11). There is no value known for $\mathrm{Cd}(\varepsilon-\mathrm{ATP})^{2-}$, but the extra stability enhancement for $\mathrm{Zn}(\varepsilon-\mathrm{ATP})^{2-}$ by going from $\mathrm{Zn}(\mathrm{ATP})^{2-}$ $\left(\log \Delta_{\mathrm{Zn} / \mathrm{ATP}}=0.27 ;\right.$ Table 11$)$ to $\mathrm{Zn}(\varepsilon-\mathrm{ATP})^{2-}\left(\log \Delta_{\mathrm{Zn} / \varepsilon-\mathrm{ATP}}=0.62\right.$ [179] $)$ amounts to about 0.35 $\log$ unit; hence, one estimates for $\mathrm{Cd}(\varepsilon-\mathrm{ATP})^{2-}$ a stability enhancement of about $0.6\left(=\log \Delta_{\mathrm{Cd} / \varepsilon-}\right.$

ATP) meaning that the formation degree of $\mathrm{Cd}(\varepsilon-\mathrm{ATP})_{\mathrm{cl}}^{2-}$ amounts to ca. $75 \%$ or more. The $\mathrm{Cd}^{2+}-$ promoted hydrolysis of $\varepsilon$-ATP has not been studied but from the results obtained with $\mathrm{Cu}^{2+}$ and $\mathrm{Zn}^{2+}[180]$ it is clear that the dephosphorylation reactions of $\varepsilon$-ATP differ significantly from those of ATP [150]. For example, the reaction in the $\mathrm{Cu}^{2+} / \mathrm{ATP}$ system proceeds via a dimeric complex as the dependence of the reaction rate on the square of the concentration shows [150], whereas in the hydrolysis of the $\mathrm{Cu}^{2+} / \varepsilon$-ATP system only a monomeric species is involved [180].

To conclude, it is evident that great care needs to be exercised if $\varepsilon$-adenosine phosphates are employed as probes for adenosine phosphates in the presence of $\mathrm{Cd}^{2+}$ or other divalent $3 \mathrm{~d}-$ transition metal ions.

\subsection{Complexes of Nucleoside 5'-O-Thiomonophosphates}

The phosphate group of nucleotides has been altered in many ways [170]. The most popular alteration probably is the substitution of one of the oxygens by a sulfur atom. Such derivatives are then commonly employed as probes in ribozymes $[28,181]$. Nevertheless, quantitative 
information on $\mathrm{Cd}^{2+}$ binding to $-\mathrm{OP}(\mathrm{S})(\mathrm{O})_{2}^{2-}$ groups is scarce. There are only two studies, one involving adenosine 5'-O-thiomonophosphate $\left(\mathrm{AMPS}^{2-}\right)[170]$ and the other uridine 5 '- $O$ thiomonophosphate (UMPS ${ }^{2-}$ ) (see Figure 14; bottom, left) [182]. Into the latter study also methyl thiophosphate $\left(\mathrm{MeOPS}^{2-}\right.$ ) was included for reasons of comparison. Thereby it was proven, in accord with the discussion in Section 6.2.2, that the uracil residue is not involved in metal ion binding in M(UMPS) complexes. It may be added that thiophosphates are considerably less basic than phosphates with $\mathrm{p} K_{\mathrm{a}}$ values of about $4.8[182,183]$. It was further concluded that one of the two negative charge units in a thiophosphate group is located on the sulfur atom whereas monoprotonation occurs at one of the two terminal oxygen atoms [183].

The stability constants of the $\mathrm{Cd}(\mathrm{PS})$ complexes, where $\mathrm{PS}^{2-}=\mathrm{MeOPS}^{2-}, \mathrm{UMPS}^{2-}$ or $\mathrm{AMPS}^{2-}$, are listed in column 2 of Table 12, together with the corresponding data for the $\operatorname{Mg}(\mathrm{PS})$

\section{insert Table 12 close to here}

and $\mathrm{Zn}(\mathrm{PS})$ species. For the M(AMPS) complex it is assumed that macrochelate formation occurs in the same extent as in the M(AMP) complexes (see Section 6.2.3). In this way the stability enhancement due to macrochelation can be corrected for (Table 12, column 3) and one obtains then stability values which reflect only the influence of the sulfur atom on metal ion binding in M(AMPS) species (column 4). Application of the previously defined straight-line plots (see Figure 11) allows then, together with the acidity constants of the H(PS) ${ }^{-}$species (see footnote "b" of Table 12), to calculate the stability of the complexes due to a (thio)phosphate$\mathrm{M}^{2+}$ coordination (Table 12, column 5). Together with these values the stability difference according to equation (25) (which is analogous to eq. 14) can be calculated and in this way the effect of the sulfur substitution can be quantified:

$$
\log \Delta_{\mathrm{M} / \mathrm{PS}}=\log K_{\mathrm{M}(\mathrm{PS})}^{\mathrm{M}}-\log K_{\mathrm{M}(\mathrm{PS}) \mathrm{calc}}^{\mathrm{M}}
$$

From the results listed in column 6 of Table 12 it is evident that there is no difference in stability between the $\mathrm{Mg}^{2+}$ complexes of phosphate $\left(\mathrm{R}^{2}-\mathrm{PO}_{3}^{2-}\right)$ or thiophosphate monoesters $\left(\mathrm{PS}^{2-}\right)$ if the different basicities of $\mathrm{R}^{-\mathrm{PO}_{3}^{2-}}$ and $\mathrm{PS}^{2-}$ are taken into account. On the other hand, all three $\mathrm{Zn}(\mathrm{PS})$ complexes show within the error limits the same remarkable enhanced complex stability proving that the $\mathrm{S}$ atom of the thiophosphate group participates in $\mathrm{Zn}^{2+}$ binding. 
However, for the Cd(PS) complexes a very dramatic stability enhancement is observed, which is within the error limits also identical for the Cd(MeOPS), $\mathrm{Cd}(\mathrm{UMPS})$, and $\mathrm{Cd}(\mathrm{AMPS})$ species. Interestingly, if one applies the procedure described in refs [170] and [182], one calculates for the $\mathrm{Zn}(\mathrm{PS})$ complexes from the average value, $\log \Delta_{\mathrm{Zn} / \mathrm{PS}}=0.63$, that about $77 \%$ of $\mathrm{Zn}^{2+}$ is $\mathrm{S}$ coordinated and $23 \%$ is $\mathrm{O}$-coordinated to the $-\mathrm{OP}(\mathrm{S})(\mathrm{O})_{2}^{2-}$ residue. Yet, for the $\mathrm{Cd}(\mathrm{PS})$ species it follows from the average value, $\log \Delta_{\mathrm{Cd} / \mathrm{PS}}=2.41$ (Table 12, column 6), that $99.6 \%$ of the complexes have a $\mathrm{Cd}^{2+}-\mathrm{S}$ coordination and that only traces of $\mathrm{Cd}^{2+}-\mathrm{O}$ coordination remain. Hence, it is clear that $\mathrm{Cd}^{2+}$ is considerably more thiophilic than $\mathrm{Zn}^{2+}$, which is in accord with the solubility products of $\mathrm{CdS}$ and $\mathrm{ZnS}$ [170] and also the well known properties of metallothionein, which has an approximately 10000 times larger affinity for $\mathrm{Cd}^{2+}$ compared to that for $\mathrm{Zn}^{2+}[184]$. Evidently $\mathrm{Cd}^{2+}$ is ideal for so-called "rescue" experiments, which are often applied in ribozyme chemistry [28,30] (see also Section 10.1).

\subsection{Complexes of Acyclic Nucleotide Analogues}

One way to alter the cyclic ribose residue of a nucleotide is to "delete" it. Indeed, acyclic nucleotide phosphonates, i.e., analogues of (2'-deoxy)nucleoside 5'-monophosphates, have been increasingly studied during the past 25 years. One of these compounds, 9-[2-

phosphonomethoxy)ethyl]adenine (PMEA; Adefovir; see Figure 14, bottom, right) was approved in 2002/2003 in the form of its bis(pivaloyloxymethyl)ester for use in the therapy of hepatitis B, a disease evoked by a DNA virus. Diphosphorylated PMEA $^{2-}$, i.e., PMEApp $^{4-}$, is initially recognized by nucleic acid polymerases as an excellent substrate, but after insertion into the growing nucleic acid chain, transcription is terminated due to the lack of a 3'-hydroxyl group. Based on the metal ion-binding properties of PMEApp ${ }^{4-}$ it can be explained why the ether oxygen in the aliphatic chain, $\mathrm{R}-\mathrm{CH}_{2}-\mathrm{O}-\mathrm{CH}_{2}-\mathrm{PO}_{3} \mathrm{pp}^{4-}$, is compulsory for a useful biological activity. The systematic progress made over the past 20 years [122] in understanding the coordination chemistry of these compounds can be followed in the reviews [153] (1995), [185] (1999), and [186] (2004) as well as in other recent works [187-189].

It can be seen from Figure 11 that the metal ion-binding properties of $\mathrm{PMEA}^{2-}$ and $\mathrm{AMP}^{2-}$ 
differ, if one considers the stability of the $\mathrm{Ca}^{2+}$ complexes: $\mathrm{Ca}(\mathrm{PMEA})$ is evidently somewhat more stable than $\mathrm{Ca}(\mathrm{AMP})$ ! By inclusion of the dianion of (phosphonylmethoxy)ethane $\left(\mathrm{PME}^{2-}\right)$ it could be shown that this increased stability is solely due to the formation of a 5-membered chelate involving the ether oxygen as expressed in equilibrium (26):

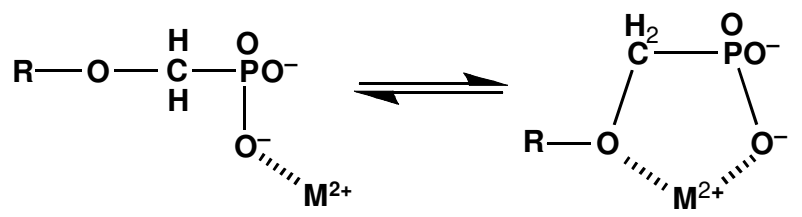

The percentage of the closed species amounts for $\mathrm{Ca}(\mathrm{PMEA})$ to $22 \pm 13 \%\left(\log \Delta_{\mathrm{Ca} / \mathrm{PMEA}}=\right.$ $0.11 \pm 0.07)$ [122]. For Mn(PMEA) and $\mathrm{Zn}(\mathrm{PMEA})$ the situation is similar and the enhanced complex stabilities, $\log \Delta_{\mathrm{Mn} / \mathrm{PMEA}}=0.21 \pm 0.08$ and $\log \Delta_{\mathrm{Zn} / \mathrm{PMEA}}=0.30 \pm 0.10$ (eq. 14) $[122,185]$, are solely explained with equilibrium (26). Exactly the same applies for the $\mathrm{Cd}(\mathrm{PMEA})$ complex with $\log \Delta_{\mathrm{Cd} / \mathrm{PMEA}}=0.33 \pm 0.06$ [122], which corresponds to a formation degree of the closed species of $53 \pm 7 \%$ in equilibrium (26), with no hint for the coordination of any of the $\mathrm{N}$ sites of the adenine residue $[185,186]$.

However, it ought to be mentioned that detailed studies over the years revealed that for $\mathrm{Cu}^{2+}[190]$ (and $\mathrm{Ni}^{2+}[191]$ ) the situation is more complicated and that the four M(PMEA) isomers indicated in scheme (27) are in equilibrium with each other:

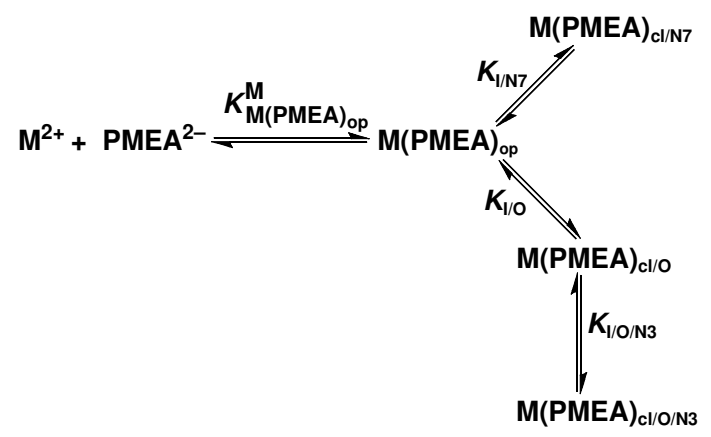

This means, there is an 'open' species in which $\mathrm{M}^{2+}$ is only phosphonate-coordinated, $\mathrm{M}(\mathrm{PMEA})_{\mathrm{op}}$, and which then interacts either with $\mathrm{N} 7$ or the ether $\mathrm{O}$ atom giving the chelated isomers, $\mathrm{M}(\mathrm{PMEA})_{\mathrm{cl} / \mathrm{N} 7}$ or $\mathrm{M}(\mathrm{PMEA})_{\mathrm{c} 1 / \mathrm{O}}$, respectively. Finally, the latter species may, in addition to the 5-membered chelate, also form a 7-membered ring by binding the coordinated $\mathrm{M}^{2+}$ also to

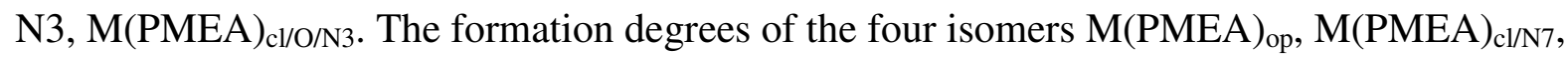
(eq. 22), $\mathrm{M}(\mathrm{PMEA})_{\mathrm{cl} / \mathrm{O}}$ (eq. 26), and $\mathrm{M}(\mathrm{PMEA})_{\mathrm{c} / \mathrm{O} / \mathrm{N} 3}$ are about 17, 8, 34, and 41\%, respectively, for the $\mathrm{Cu}^{2+}$ system [186,190-192]. 
Evidently, the dominating isomers in the case of $\mathrm{Cu}^{2+}$ are also those involving the ether $\mathrm{O}$. In fact, $\mathrm{Cu}(\mathrm{PMEA})_{\mathrm{cl} / \mathrm{O}}$ and $\mathrm{Cu}(\mathrm{PMEA})_{\mathrm{cl} / \mathrm{O} / \mathrm{N} 3}$ amount together to $75 \%$. This result confirms the rather high stability of the 5-membered chelates already indicated above in equilibrium (26). In contrast, the corresponding 6-membered chelate that could be formed with the dianion of 9-[2(phosphonoethoxy)ethyl]adenine $\left(\mathrm{PEEA}^{2-}\right.$ ) [one more $\mathrm{CH}_{2}$ group is inserted between $\mathrm{O}$ and $\mathrm{PO}_{3}^{2-}$ (Figure 14)] is considerably less stable, what agrees with the observations described in Section 3.3. Indeed, $\mathrm{Cu}(\mathrm{PEEA})_{\mathrm{c} / / \mathrm{O}}$ and $\mathrm{Cu}(\mathrm{PEEA})_{\mathrm{cl} / \mathrm{O} / \mathrm{N} 3}$ amount together now to only $61 \%$, but the formation degree of the macrochelate according to equilibrium (22), $\mathrm{Cu}(\mathrm{PEEA})_{\mathrm{cl} / \mathrm{N} 7}$, is now enhanced and amounts to about $18 \%$. Even more revealing, with $\mathrm{Ca}^{2+}$ and $\mathrm{Mg}^{2+}$ the 6-membered chelate does not form at all, that is, $\log \Delta_{\mathrm{Ca} / \mathrm{PEEA}}=-0.05 \pm 0.06$ and $\log \Delta_{\mathrm{Mg} / \mathrm{PEEA}}=-0.01 \pm 0.07$ [193]. Also in the $\mathrm{Cd}^{2+}$ system M(PEEA) $)_{\mathrm{cl} / \mathrm{O}}$ does not occur, only Cd(PEEA) $)_{\text {clN7 }}$ (eq. 22) occurs with $29 \pm 11 \%$, next to the open species with a formation degree of $71 \pm 11 \%$ [193].

Three lessons are to be learned here: (i) Five-membered chelates are more stable than 6membered ones (see also Section 3.3), and this observation offers an explanation why PMEA is a nucleotide analogue with excellent antiviral properties and PEEA is not. In the latter case the second metal ion needed for the nucleotidyl transfer is not properly adjusted at the triphosphate residue [186,193] (see also the last paragraph in Section 6.3). (ii) From the Cu(PMEA) system it follows that if properly pre-orientated by another primary binding site, N3 of a purine is well able to coordinate metal ions (see also Section 6.4.2). (iii) The small structural difference as it occurs between $\mathrm{PMEA}^{2-}$ (Figure 14) and $\mathrm{PEEA}^{2-}$ changes the coordinating properties of $\mathrm{Cd}^{2+}$ towards these nucleotide analogues completely: With $\mathrm{PMEA}^{2-}$ only the $\mathrm{Cd}(\mathrm{PMEA})_{\mathrm{c} / \mathrm{O}}$ isomer forms, whereas with $\mathrm{PEEA}^{2-}$ only $\mathrm{Cd}(\mathrm{PEEA})_{\mathrm{cl} / \mathrm{N} 7}$ occurs.

\subsection{Cadmium(II) Binding to Nucleotides Containing a Platinum(II)- Coordinated Nucleobase Residue}

A further way to alter nucleotides via their nucleobases (cf. Section 7.1) is to "fix" a kinetically inert metal ion to the nucleobase. Several such examples have been studied with $c i s-\left(\mathrm{NH}_{3}\right)_{2} \mathrm{Pt}^{2+}$ coordinated to $\mathrm{N} 3$ of $\mathrm{dCMP}^{2-}$ [141] or to N7 of dGMP ${ }^{2-}$ [194]. The main outcome of these 
studies is that the acid-base properties of the phosphate groups are only relatively little affected [195] and that this is also true for binding of divalent metal ions to the phosphate residues $[141,194]$.

To give a specific example: Coordination of cis- $\left(\mathrm{NH}_{3}\right)_{2} \mathrm{Pt}(\mathrm{dGuo}-\mathrm{N} 7)^{2+}$ to the $\mathrm{N} 7$ site of $\mathrm{dGMP}^{2-}$ results in the complex cis- $\left(\mathrm{NH}_{3}\right)_{2} \mathrm{Pt}(\mathrm{dGuo}-N 7)(\mathrm{dGMP}-N 7)$ which may be protonated at its phosphate group. Comparison of the corresponding acidity constant, $\mathrm{p} K_{\mathrm{H}[\mathrm{Pt}(\mathrm{dGuo})(\mathrm{dGMP})]}^{\mathrm{H}}=$ $5.85 \pm 0.04$, with $\mathrm{p} K_{\mathrm{H}(\mathrm{dGMP})}^{\mathrm{H}}=6.29 \pm 0.01$ reveals an acidification of the $\mathrm{P}(\mathrm{O})_{2}(\mathrm{OH})^{-}$group due to charge repulsion by the N7-coordinated $\mathrm{Pt}(\mathrm{II})$ of $\Delta \mathrm{p} K_{\mathrm{a}}=0.44 \pm 0.04$ [196]. The average acidification of cis- $\left(\mathrm{NH}_{3}\right)_{2} \mathrm{Pt}^{2+}$ in the same complex on the two (N1)H sites is somewhat more pronounced (as one would expect) and amounts to $\Delta \mathrm{p} K_{\mathrm{a} / \mathrm{av}}=0.78 \pm 0.11$ [196]. However, coordination of $\mathrm{Mg}^{2+}, \mathrm{Cu}^{2+}$ or $\mathrm{Zn}^{2+}$ to the phosphate group of $c i s-\left(\mathrm{NH}_{3}\right)_{2} \mathrm{Pt}(\mathrm{dGuo}-N 7)(\mathrm{dGMP}-$ $N 7$ is inhibited on average only by about $0.2 \log$ unit [196]. The same may be surmised for $\mathrm{Cd}^{2+}$ binding. This moderate effect of $-0.2 \log$ unit suggests with regard to DNA or RNA that cis$\left(\mathrm{NH}_{3}\right)_{2} \mathrm{Pt}^{2+}$, if coordinated to $\mathrm{N} 7$ of a guanine residue, affects metal ion binding to the nucleic acid phosphate backbone only little.

Another interesting case concerns the acyclic nucleotide analogue PMEA $^{2-}$ (Figure 12; bottom, left), already discussed in Section 7.3. Coordination of (Dien) $\mathrm{Pt}^{2+}$ either to N1 [197] or to $\mathrm{N} 7$ [198] leads, if monoprotonated, to the complexes $\mathrm{H}[(\mathrm{Dien}) \mathrm{Pt}(\mathrm{PMEA}-N 1)]^{+}$and $\mathrm{H}[(\text { Dien }) \mathrm{Pt}(\mathrm{PMEA}-N 7)]^{+}$. Acidification of the $\mathrm{P}(\mathrm{O})_{2}(\mathrm{OH})^{-}$group by $\mathrm{Pt}^{2+}$ at $\mathrm{N} 1$ gives $\Delta \mathrm{p} K_{\mathrm{a} / \mathrm{N} 1}=$ $0.21 \pm 0.03$ (based on $\mathrm{p}_{\mathrm{H}(\mathrm{PMEA})}^{\mathrm{H}}=6.90 \pm 0.01$ ) and by $\mathrm{Pt}^{2+}$ at $\mathrm{N} 7 \Delta \mathrm{p} K_{\mathrm{a} / \mathrm{N} 7}=0.44 \pm 0.01$ [197] The higher acidity of $\mathrm{H}\left[(\mathrm{Dien}) \mathrm{Pt}(\mathrm{PMEA}-N 7)^{+}\right.$provides evidence that in the (Dien)Pt(PMEA-N7) complex in aqueous solution an intramolecular, outersphere macrochelate is formed through hydrogen bonds between the $\mathrm{PO}_{3}^{2-}$ residue of $\mathrm{PMEA}^{2-}$ and a $\mathrm{Pt}(\mathrm{II})$-coordinated (Dien)- $\mathrm{NH}_{2}$ group. This formation amounts to about $40 \%$ and is in accord with several other related observations [197].

Unfortunately, complex stability with $\mathrm{Cd}^{2+}$ has only been measured for (Dien)Pt(PMEA$N 7$ ) as ligand: $\log K_{\mathrm{Cd}[(\operatorname{Dien}) \operatorname{Pt}(\mathrm{PMEA}-N 7)]}^{\mathrm{Cd}}=2.13 \pm 0.09$ [198]. If this value is compared with the expected, i.e., calculated, stability constant based on the straight-line plot seen in Figure 11 and the acidity constant $\mathrm{p} K_{\mathrm{H}[(\operatorname{Dien}) \mathrm{Pt}(\operatorname{PMEA}-N 7)]}^{\mathrm{H}}=6.46 \pm 0.01$, that is, $\log K_{\mathrm{Cd}[(\operatorname{Dien}) \operatorname{Pt}(\operatorname{PMEA}-N 7)] \text { calc }}^{\mathrm{Cd}}=$ 
$2.52 \pm 0.05$, one obtains the stability reduction $\log \Delta_{\mathrm{Cd} /(\operatorname{Dien}) \mathrm{Pt}(\mathrm{PMEA}-N 7)}=-0.39 \pm 0.10$ (in analogy to eq. 14), which is due to the repulsion between $\mathrm{Pt}^{2+}$ coordinated at $\mathrm{N} 7$ and $\mathrm{Cd}^{2+}$ bound at the $\mathrm{PO}_{3}^{2-}$ group (cf. Figure 14). This stability reduction is identical with the one observed for the corresponding complexes formed with $\mathrm{Mg}^{2+}, \mathrm{Ca}^{2+}, \mathrm{Mn}^{2+}, \mathrm{Co}^{2+}, \mathrm{Ni}^{2+}$ (and $\mathrm{Cd}^{2+}$ ), which is on average $\log \Delta_{\mathrm{M} /(\operatorname{Dien}) \mathrm{Pt}(\mathrm{PMEA}-N 7) / \mathrm{av}}=-0.42 \pm 0.04$ [198]. This result indicates that in all these complexes the metal ion is only coordinated to the phosphonate group of the (Dien)Pt(PMEAN7) ligand.

Overall, these results confirm the above conclusion that a purine-coordinated $\mathrm{Pt}^{2+}$ unit affects metal ion binding at the phosphate group of the same nucleotide only relatively little. This is of relevance for multiple metal ion binding to nucleotides and nucleic acids as is the already discussed result (Section 4.1) regarding (Dien)Pt(9EtG-N7) ${ }^{2+}$ and its metal ion-binding properties, which are, despite the $\mathrm{Pt}^{2+}$ at $\mathrm{N} 7$ of the guanine residue, still quite remarkable at the $(\mathrm{N} 1)^{-}$site [82] (see also ref. [69]).

\section{A Short Appraisal of Mixed Ligand Complexes Containing a Nucleotide}

\subsection{Some Definitions and General Comments}

In following previous considerations and pathways [40,117,139,189] we define that a mixed ligand or ternary complex of the kind to be considered here is composed of a metal ion and two different coordinated ligands. There are various ways to quantify the stability of such ternary complexes $[199,200]$. First we consider complexes in which a nucleotide $(=\mathrm{NP}=$ nucleoside phosphate) is bound in the coordination sphere of $\mathrm{M}^{2+}$ and to which a second ligand $\mathrm{L}$ binds, leading thus to the ternary $\mathrm{M}(\mathrm{NP})(\mathrm{L})^{2+}$ complex and equilibrium (28) (charges deleted):

$$
\begin{aligned}
\mathrm{M}(\mathrm{NP})^{2+}+\mathrm{L} & \rightleftharpoons \mathrm{M}(\mathrm{NP})(\mathrm{L})^{2+} \\
K_{\mathrm{M}(\mathrm{NP})(\mathrm{L})}^{\mathrm{M}(\mathrm{NP})} & =\left[\mathrm{M}(\mathrm{NP})(\mathrm{L})^{2+}\right] /\left(\left[\mathrm{M}(\mathrm{NP})^{2+}\right][\mathrm{L}]\right)
\end{aligned}
$$

Evidently, this equilibrium is best compared with the following one (see also eq. 2):

$$
\mathrm{M}^{2+}+\mathrm{L} \rightleftharpoons \mathrm{M}(\mathrm{L})^{2+}
$$




$$
K_{\mathrm{M}(\mathrm{L})}^{\mathrm{M}}=\left[\mathrm{M}(\mathrm{L})^{2+}\right] /\left(\left[\mathrm{M}^{2+}\right][\mathrm{L}]\right)
$$

The difference $\Delta \log K_{\mathrm{M} / \mathrm{NP} / \mathrm{L}}$ (eq. 30),

$$
\begin{aligned}
\Delta \log K_{\mathrm{M} / \mathrm{NP} / \mathrm{L}} & =\log K_{\mathrm{M}(\mathrm{NP})(\mathrm{L})}^{\mathrm{M}(\mathrm{NP})}-\log K_{\mathrm{M}(\mathrm{L})}^{\mathrm{M}} \\
& =\log K_{\mathrm{M}(\mathrm{L})(\mathrm{NP})}^{\mathrm{M}(\mathrm{L})}-\log K_{\mathrm{M}(\mathrm{NP})}^{\mathrm{M}}
\end{aligned}
$$

characterizes the coordination tendency of $\mathrm{L}$ towards $\mathrm{M}(\mathrm{NP})^{2+}$ (eq. 28) relative to $\mathrm{M}(\mathrm{aq})^{2+}$ (eq. 29) and vice versa (eq. 30b) [199,200]. The latter point is important because it means that the difference $\Delta \log K_{\mathrm{M} / \mathrm{NP} / \mathrm{L}}$ (eq. 30) also equals the one resulting from the following two equilibria:

$$
\begin{aligned}
& \mathrm{M}(\mathrm{L})^{2+}+\mathrm{NP} \rightleftharpoons \mathrm{M}(\mathrm{NP})(\mathrm{L})^{2+} \\
& K_{\mathrm{M}(\mathrm{NP})(\mathrm{L})}^{\mathrm{M})}=\left[\mathrm{M}(\mathrm{NP})(\mathrm{L})^{2+}\right] /\left(\left[\mathrm{M}(\mathrm{L})^{2+}\right][\mathrm{NP}]\right)=K_{\mathrm{M}(\mathrm{L})(\mathrm{NP})}^{\mathrm{M})} \\
& \mathrm{M}^{2+}+\mathrm{NP} \rightleftharpoons \mathrm{M}(\mathrm{NP})^{2+} \rightleftharpoons\left[\mathrm{M}(\mathrm{NP})^{2+}\right] /\left(\left[\mathrm{M}^{2+}\right][\mathrm{NP}]\right) \\
& K_{\mathrm{M}(\mathrm{NP})}^{\mathrm{M}} \quad=
\end{aligned}
$$

Factors which arise through direct $[139,189,201,202]$ or indirect (i.e., metal ion-mediated) [56,199,200,203,204] ligand-ligand interactions, being either favorable or unfavorable, will show up in this description.

One should note that $\Delta \log K_{\mathrm{M} / \mathrm{NP} / \mathrm{L}}$ is the difference between two $\log$ stability constants and thus has to be a constant itself. Indeed, it quantifies the position of equilibrium (33):

$$
\begin{aligned}
& \mathrm{M}(\mathrm{NP})^{2+}+\mathrm{M}(\mathrm{L})^{2+} \rightleftharpoons \mathrm{M}(\mathrm{NP})(\mathrm{L})^{2+}+\mathrm{M}^{2+} \\
& 10^{\Delta \log K_{\mathrm{M} / \mathrm{NP} / \mathrm{L}}}=\frac{\left[\mathrm{M}(\mathrm{NP})(\mathrm{L})^{2+}\right]\left[\mathrm{M}^{2+}\right]}{\left[\mathrm{M}(\mathrm{NP})^{2+}\right]\left[\mathrm{M}(\mathrm{L})^{2+}\right]}
\end{aligned}
$$

Since more coordination positions are available for binding of $\mathrm{L}$ to $\mathrm{M}^{2+}$ (eq. 29$)$ than to $\mathrm{M}(\mathrm{NP})^{2+}$ (eq. 28), one expects on statistical grounds [199,200] and in accord with the general rule [22]

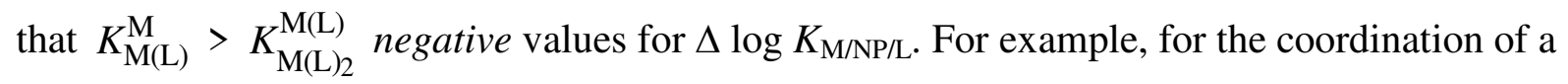
bidentate ligand followed by a monodentate one in a regular octahedral (oh) coordination sphere like the one of $\mathrm{Cd}^{2+}$, statistical considerations [205] provide the value $\Delta \log K_{2: 1 / \text { stat/oh }}=\log$ $(4: 1 / 6: 1)=-0.18$. For two different bidentate ligands $\Delta \log K_{2: 2 / \mathrm{stat} / \mathrm{oh}}=\log (5 / 12)=-0.38[199]$ results. Correspondingly, for the Jahn-Teller distorted octahedral coordination sphere of $\mathrm{Cu}^{2+} \mathrm{a}$ 
statistical value is more difficult to assess, but on the basis of previously advanced arguments [194] one obtains the values $\Delta \log K_{2: 1 / \text { stat } / \mathrm{Cu}}=-0.5$ and $\Delta \log K_{2: 2 / \mathrm{stat} / \mathrm{Cu}}=-0.9[199,205]$.

The available information on mixed ligand complexes formed with $\mathrm{Cd}^{2+}$ and a nucleotide is rather limited. In addition, we shall concentrate below mainly on ternary complexes containing NTPs because in these instances the available equilibrium constants are relatively well defined.

\subsection{Ternary Cadmium(II) Complexes Containing ATP ${ }^{4-}$ and a Buffer Molecule}

Considering that many experiments in biochemistry are carried out in buffers to stabilize the $\mathrm{pH}$ of a solution, it is important to indicate possible drawbacks of this procedure (as was done, e.g., in refs [206-208]). In fact, the $\mathrm{Zn}^{2+}$-promoted dephosphorylation of ATP is inhibited by acetate, Tris or borate buffers [150,209]. Similarly, buffers composed of imidazole [210] or phosphate [29,211] also inhibit the reactivity of $\mathrm{M}^{2+} /$ ATP systems. Corresponding effects must be anticipated for $\mathrm{Cd}^{2+} / \mathrm{NTP}$ systems.

Tris is one of the most popular buffers used in biochemical studies probably because its buffer region encompasses the physiological to slightly alkaline $\mathrm{pH}$ range [212]. The same is true for Bistris which buffers in the $\mathrm{pH}$ range 6 to 7.5 [213]. Another widely employed buffer is Bicine $[214,215]$ which is employed in the $\mathrm{pH}$ range 7.5 to 9 . The structures of the three mentioned buffers are shown in Figure 15.

\section{insert Figure 15 close to here (width: $8 \mathrm{~cm}$ )}

Because Bicine is derived from glycine, it was expected already nearly 50 years ago that this buffer forms complexes with metal ions [216]. For Tris and Bistris the awareness of metal ions interactions is much lower, and the fact that also mixed ligand complexes may form [212,213], has hardly been realized. Therefore, the stabilities of the ternary $\mathrm{Cd}^{2+}$ and some other metal ion complexes formed between these buffers and $\mathrm{ATP}^{4-}$ are briefly summarized. The stability constants according to equilibria (28) and (29) are listed in Table 13 together with the stability differences defined in equation (30). 
The stabilities of the binary $\mathrm{M}^{2+}$ complexes of Tris and Bistris are quite large (Table 13, column 3) and this fact has been attributed to chelate formation with the hydroxyl groups $[212,213]$. The significant role of the hydroxyl group of these buffers is also confirmed by a comparison of the stability constants of the $\mathrm{M}(\mathrm{Tris})^{2+}$ complexes with those of the corresponding $\mathrm{M}\left(\right.$ Bistris) ${ }^{2+}$ species (Table 13, column 3). The stability increase is between 0.05 and about 1.5 $\log$ units despite the fact that the basicity of the nitrogen in Bistris is about $1.5 \mathrm{p} K$ units lower (see footnote "b" in Table 13). This confirms the earlier conclusion that most of the hydroxyl groups of Bistris participate in metal ion binding [213]. The rather high stability of the $\mathrm{Ca}$ (Bistris) $^{2+}$ complex is kind of a surprise but it has been verified [206]. The reason is probably that $\mathrm{Ca}^{2+}$ with its relatively large ionic radius fits well into the "pocket" provided by Bistris [57]. Moreover, it is known that $\mathrm{Ca}^{2+}$ has an exceptionally high affinity towards hydroxyl groups [57]. The stability of Cd(Bistris) $)^{2+}$ is also relatively large, but again, it has been confirmed [208].

The hydroxyl groups also play an important role in the ternary complexes containing $\mathrm{ATP}^{4-}$ as is evident from the in general small negative values observed for $\Delta \log K_{\mathrm{M} / \mathrm{ATP} / \mathrm{L}}$ (Table 13, column 5). Indeed, the role of the hydroxyl groups for the stability of the M(ATP)(Tris) ${ }^{2-}$ complexes follows, e.g., from a comparison with the stability constant of the $\mathrm{Cu}(\mathrm{ATP})\left(\mathrm{NH}_{3}\right)^{2-}$ complex $\left(\log K_{\mathrm{Cu}(\mathrm{ATP})\left(\mathrm{NH}_{3}\right)}^{\mathrm{Cu}(\mathrm{ATP})}=3.4\right.$ [27]). This constant is somewhat smaller than that of the corresponding $\mathrm{Cu}(\mathrm{ATP})(\mathrm{Tris})^{2-}$ complex, $\log K_{\mathrm{Cu}(\mathrm{ATP})(\text { Tris })}^{\mathrm{Cu}}=3.5$ (Table 13, column 4), despite the much lower basicity of Tris $\left(\mathrm{p} K_{\mathrm{H}(\text { Tris })}^{\mathrm{H}}=8.13\right.$ [212] $)$ compared to that of $\mathrm{NH}_{3}\left(\mathrm{pK}_{\mathrm{NH}_{4}}^{\mathrm{H}}=9.38\right.$ [27]). On the other hand, for the $\mathrm{Cd}^{2+}$ complexes the situation is less clearcut $\left(\log K_{\mathrm{Cd}(\mathrm{ATP})\left(\mathrm{NH}_{3}\right)}^{\mathrm{Cd} \text { (ATP) }}\right.$ $\leq 2.2$ [27] versus $\log K_{\mathrm{Cd}(\mathrm{ATP})(\text { Tris })}^{\mathrm{Cd}(\mathrm{ATP})}=1.17$ ), but overall it follows that the $\mathrm{OH}$ groups play a role, though it is unclear to which extent they participate in different ternary complexes and if they do this via direct metal ion binding or via hydrogen bonding to the phosphate oxygens of the coordinated $\mathrm{ATP}^{4-}$.

However, the values for $\Delta \log K_{\mathrm{M} / \mathrm{ATP} / \mathrm{Bistris}}$ as observed for the $\mathrm{Ca}^{2+}$ and $\mathrm{Co}^{2+}$ complexes are relatively small (i.e., not strongly negative). Because the coordination spheres of these metal ions are already quite "saturated" by $\mathrm{ATP}^{4-}$ and the nitrogen of Bistris, the most plausible explanation for the relatively high complex stability is the additional formation of hydrogen bonds between some $\mathrm{OH}$ groups of the coordinated Bistris and phosphate oxygens of the also coordinated $\mathrm{ATP}^{4-}$. 
That $\Delta \log K_{\mathrm{Cu} / \mathrm{ATP} / \mathrm{Bistris}}$ is with $-1.65 \log$ units rather low, is no surprise because of the Jahn-Teller distorted coordination sphere of $\mathrm{Cu}^{2+}$ [128]. The value of $\Delta \log K_{\mathrm{Cd} / \mathrm{ATP} / \mathrm{Bistris}}=-1.33$ implies again that the $\mathrm{Cd}(\mathrm{ATP})^{2-} / \mathrm{OH}$ interactions are not very pronounced as already indicated by the $\mathrm{Cd}(\mathrm{ATP})(\text { Tris })^{2-}$ data.

The stability constants of the two examples for binary $\mathrm{M}(\text { Bicinate })^{+}$and ternary $\mathrm{M}(\mathrm{ATP})(\text { Bicinate })^{3-}$ complexes (no value for $\mathrm{Cd}^{2+}$ is known) provide an order and speak for themselves. These values are so large (Table 13) that Bicine, if used as buffer in the presence of metal ions, will certainly complex a very significant amount of metal ions present. It is further clear that the hydroxyl groups of Bicinate participate at least to some extent in metal ion binding. To put the observed negative values for $\Delta \log K_{\mathrm{M} / \mathrm{ATP} / \mathrm{L}}$ overall into perspective, it may be helpful to recall that the expected statistical value for a regular octahedral coordination sphere of $\mathrm{M}^{2+}$ (e.g., $\mathrm{Co}^{2+}$ ) and the coordination of two different but simple and symmetrical tridentate ligands amounts already to $\Delta \log K_{3: 3 / \mathrm{stat} / \mathrm{oh}}=-1.03$ [213].

\subsection{Mixed Ligand Complexes Containing a Nucleotide and a Further Monodentate or Bidentate Ligand. Release of Purine-N7 and Formation of Stacks}

About 40 years ago intramolecular aromatic-ring stacking was described for the first time [217,218] between heteroaromatic N bases (Arm), i.e., 2,2'-bipyridine or 1,10-phenanthroline, and $\mathrm{AMP}^{2-}, \mathrm{ADP}^{3-}$ or $\mathrm{ATP}^{4-}$, both ligands being bridged by a metal ion [200,219-221]. Originally the interactions had been proven by UV spectrophotometry [217-220] and ${ }^{1} \mathrm{H}$ NMR shift measurements [201,222,223]. Later, complexes of the type M(Arm)(adenine nucleotide) were also isolated in the solid state and the intramolecular stacking interaction was proven by Xray crystal structure studies (e.g., refs [11,224-226]. The formation degrees of these intramolecular stacks in aqueous solution were largely determined by potentiometric $\mathrm{pH}$ titrations. A few results are summarized in Table 14 below.

From the results discussed in Section 6.3 it is evident that the "weak" point in macrochelate formation of $\mathrm{M}(\mathrm{ATP})^{2-}$ complexes is the coordination of $\mathrm{N} 7$ of the adenine residue. Indeed, by 
${ }^{1} \mathrm{H}$ NMR shift experiments it has been shown for $\mathrm{Zn}^{2+}$ and $\mathrm{Cd}^{2+}$ that already the formation of the ternary $\mathrm{M}(\mathrm{ATP})(\mathrm{OH})^{3-}$ complexes releases N7 [227]. Similar observations have been made for $\mathrm{Cd}(\mathrm{ATP})\left(\mathrm{NH}_{3}\right)^{2-}$ [228]. For the ternary complexes of $\mathrm{M}(\mathrm{ATP})(\text { imidazole })^{2-}$, where $\mathrm{M}^{2+}=\mathrm{Mn}^{2+}$, $\mathrm{Co}^{2+}, \mathrm{Zn}^{2+}$ or $\mathrm{Cd}^{2+}$, it is shown, based on a careful analysis of stability data, that the adenine moiety is released from the coordination sphere [228]. However, there is also evidence that in these M(ATP)(imidazole $)^{2-}$ complexes intramolecular stacking between the purine moiety and the imidazole ring occurs to some extent (see Table 14 [229-232]).

\section{insert Table 14 close to here}

The first mixed ligand complex containing ATP and an amino acid was one with tryptophanate, i.e., $\mathrm{Zn}(\mathrm{ATP})(\mathrm{Trp})^{3-}$. By ${ }^{1} \mathrm{H}$ NMR shift experiments it was shown that an indoleadenine interaction takes place [233], which may be promoted by $\mathrm{Zn}^{2+}$. Later, the position of the intramolecular equilibrium (34) was determined:
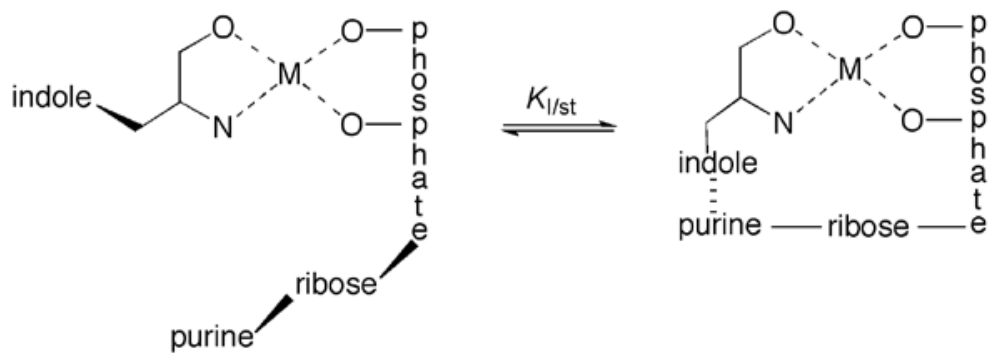

For $\mathrm{Zn}^{2+}$ as metal ion, it was concluded [230] that the stacked species occurs with a formation degree of approximately 75\% (Table 14). Other metal ions were studied as well [179,230,234], and the occurrence of intramolecular stacks in M(ATP)(Trp $)^{3-}$ complexes was confirmed by several groups $[235,236]$. It was further shown that the isopropyl residue of leucinate is also able to undergo a hydrophobic interaction in M(ATP)(Leu $)^{3-}$ complexes [230]; e.g., the formation degree of the "closed" species for the corresponding $\mathrm{Cd}^{2+}$ complex amounts from 5 to $25 \%$ [230]. The occurrence of such species with a hydrophobic interaction was again proven by ${ }^{1} \mathrm{H}$ NMR shift studies [230] and by comparisons of stability constants, mostly obtained via potentiometric $\mathrm{pH}$ titrations [230]. These stability data and their differences (stability enhancements) were evaluated in analogy to equations (14) and (16) - (20) in Section 4.2.

With $\mathrm{Cd}^{2+}$ only a few such complexes, allowing an intramolecular interaction, have been studied; the corresponding results, listed in entries 7, 8 and 11, 12 of Table 14, fit into the 
general picture: From entries 1 and 2 in Table 14 it is evident that the size of the aromatic-ring systems (uracil versus adenine) matters, whereas a replacement of $\mathrm{AMP}^{2-}$ by $\mathrm{ATP}^{4-}$ in the ternary complex (entry 3 ) does hardly affect the stacking intensity, even though the overall stability of the latter complex $\left(\log K_{\mathrm{Cu}(\text { Phen)(ATP) }}^{\mathrm{Cu}(\text { Phen) }}=6.88 \pm 0.07\right.$ [223] is by a factor of about 1000 larger $\left(\log K_{\mathrm{Cu}(\text { Phen)(AMP) }}^{\mathrm{Cu}(\mathrm{Phen})}=3.89 \pm 0.01\right.$ [232]). As expected, replacement of the 3-ring Phen by Bpy reduces the formation degree of the intramolecular stack (entries 4, 5). It is also expected that the stacking interaction between the indole moiety of tryptophanate $\left(\operatorname{Trp}^{-}\right)$and the adenine residue in $\mathrm{Zn}(\mathrm{ATP})(\mathrm{Trp})^{3-}$ is more pronounced than the hydrophobic interaction between the isopropyl residue of leucinate $\left(\mathrm{Leu}^{-}\right)$and adenine in $\mathrm{Zn}(\mathrm{ATP})(\mathrm{Leu})^{3-}$ (entries 9, 10). The $\mathrm{Cd}(\mathrm{ATP})(\mathrm{Leu})^{3-}$ complex fits into the picture. Maybe here it should be mentioned that the ${ }^{1} \mathrm{H}$ NMR experiments allow a direct proof of intramolecular adduct formation, but from potentiometric stability data usually the more exact formation degrees are obtained. The last entry (no. 12) in Table 14 refers to Cd(ATP)(imidazole) ${ }^{2-}$ for which, just like for $\mathrm{Zn}(\mathrm{ATP})(\text { imidazole })^{2-}$ [229], stack formation between the adenine residue and the coordinated imidazole could be proven [229]. This result is in line with a suggestion [237] based on thermodynamic parameters that in $\mathrm{Zn}(\mathrm{ATP})(\text { histamine })^{2-}$ stacking occurs.

Finally, the above discussion should not distract from the fact that certain ligand combinations, as discovered nearly 50 years ago [238], can give rise to enhanced complex stabilities, i.e., the combination of a heteroaromatic $\mathrm{N}$ base (Arm) and an $\mathrm{O}$ donor ligand in combination with a transition metal ion leads to indirect effects being mediated by the metal ion $[56,200,203,204]$. For example, the combinations $\mathrm{Cu}(\mathrm{Bpy} / \mathrm{Phen})^{2+} / \mathrm{HPO}_{4}^{2-}$ [239], $\mathrm{Mn}(\mathrm{Bpy})^{2+} /$ malonate [203] or M(Arm) $)^{2+} /$ pyrocatecholate [240] give rise to enhanced complex stabilities. Clearly, the direct (as discussed in this section) and indirect ligand-ligand interactions [200] that occur in mixed ligand complexes are of relevance regarding the discrimination and selectivity observed in nature.

\section{Cadmium(II) Binding in Dinucleotides and Dinucleoside Monophosphates}

One of the important questions in metal ion-nucleic acid coordination is to find out to what 
extent neighboring nucleotide units affect binding of a metal ion at a given site [58]. Some answers to this question can be found by studying ligands of the kind shown in Figure 16. Unfortunately, the information regarding $\mathrm{Cd}^{2+}$ complexes and dinucleotides in general is limited to the nucleotide/nucleoside derivatives shown in Figure 16.

\section{insert Figure 16 close to here (width: $9 \mathrm{~cm}$ )}

\subsection{The Phosphodiester Link}

If one recalls from Section 6.2.2 that the uracil moiety is not involved in metal ion binding, meaning that the log stability constants of the $\mathrm{Cd}(\mathrm{UMP})$ complex fits on the straight-reference line seen in Figure 11, one may expect that this "indifference" of the uracil residue also holds for the $\mathrm{pUpU}^{3-}$ ligand. Indeed, if one applies the acidity constant $\mathrm{p} K_{\mathrm{H}(\mathrm{pUpU})}^{\mathrm{H}}=6.44($ Table 15 ,

footnote "b") to the straight-line equation (25), one obtains $\log K_{\mathrm{Cd}\left(\mathrm{R}-\mathrm{PO}_{3}\right)}^{\mathrm{Cd}}=2.52 \pm 0.05$, which is $0.23 \pm 0.05 \log$ unit [33] lower than the measured stability constant $\log K_{\mathrm{Cd}(\mathrm{pUpU})}^{\mathrm{Cd}}=2.75 \pm$ 0.03 (Table 15 [241-243]).

Because a metal ion coordinated at the terminal phosphate group of $\mathrm{pUpU}^{3-}$ will "feel" the negative charge of the phosphodiester bridge even if no 10-membered chelate is formed, some stability enhancement (eq. 14) is expected. Interestingly, for the complexes $\mathrm{M}(\mathrm{pUpU})^{-}$of $\mathrm{Mg}^{2+}$, $\mathrm{Mn}^{2+}$, and $\mathrm{Cd}^{2+}$ the stability enhancement is within the error limits identical giving on average $\log \Delta_{\mathrm{M} / \mathrm{pUpU} / \mathrm{charge}}=0.24 \pm 0.04$. This result for the three metal ions having rather different properties can only mean that the given value represents indeed the charge effect and that none of the three metal ions forms a 10-membered chelate with the diester bridge (a chelate occurs with $\mathrm{Zn}^{2+}$ and $\left.\mathrm{Pb}^{2+}[33]\right)$ or interacts with the uracil moiety.

\section{insert Table 15 close to here}

\subsection{The Guanine Residue in a Dinucleotide}

If one views the data for the $\mathrm{Cd}[\mathrm{d}(\mathrm{pGpG})]^{-}$complex (second entry of Table 15) with the 
presented result for the $\mathrm{Cd}(\mathrm{pUpU})$ complex in mind, it is immediately evident that a new situation occurs: $\log \Delta_{\mathrm{Cd} / \mathrm{d}(\mathrm{pGpG})}=1.45 \pm 0.08$ [241] is far beyond the indicated charge effect (Section 9.1). In fact, the charge effect of the bridging phosphodiester unit is expected to be the same with $\mathrm{pUpU}^{3-}$ and $\mathrm{d}(\mathrm{pGpG})^{3-}$; furthermore, if coordinated to the terminal phosphate group $\mathrm{Cd}^{2+}$ does not interact with the diester bridge as seen from $\mathrm{Cd}(\mathrm{pUpU})^{-}$, thus, it follows that in $\mathrm{Cd}[\mathrm{d}(\mathrm{pGpG})]^{-}$a guanine-N7 interaction (eq. 22) must take place for which the charge-corrected stability enhancement $\log \Delta_{\mathrm{Cd} / \mathrm{d}(\mathrm{pGpG}) / \text { charge, } \mathrm{cor}}=(1.45 \pm 0.08)-(0.24 \pm 0.04)=1.21 \pm 0.09$, holds Application of equations (14) and (16) - (20) leads to a formation degree for $\mathrm{Cd}[\mathrm{d}(\mathrm{pGpG})]_{\mathrm{cl} / \mathrm{N} 7}^{-}$ of $94 \pm 1.5 \%$ [241]. Are both guanine residues involved in this macrochelate formation or only one? A tentative answer may be obtained if one considers the stability enhancement for the Cd(dGMP) complex, which is unfortunately not known, but which may be estimated because the information for both $\mathrm{Zn}(\mathrm{GMP})$ [50] and $\mathrm{Zn}(\mathrm{dGMP})$ [244] exists. This estimate is justified because $\mathrm{Zn}(\mathrm{GMP})$ and $\mathrm{Cd}(\mathrm{GMP})$ reach within the error limits the same formation degree [50] for $\mathrm{M}(\mathrm{GMP})_{\mathrm{cl} / \mathrm{N} 7}(\mathrm{ca} .82 \%)$, despite the different overall stability constants. Because of the somewhat higher basicity of N7 in dGMP, compared with that in GMP [245], one expects a somewhat larger formation degree of the chelate for the deoxy complex. Indeed, this follows from the given reasonings:

$$
\begin{aligned}
\log \Delta_{\mathrm{Cd} / \mathrm{dGMP}} & =\log \Delta_{\mathrm{Cd} / \mathrm{GMP}}+\log \Delta_{\mathrm{Zn} / \mathrm{dGMP}}-\log \Delta_{\mathrm{Zn} / \mathrm{GMP}} \\
& =(0.79 \pm 0.06)+(0.84 \pm 0.08)-(0.69 \pm 0.07) \\
& =0.94 \pm 0.12
\end{aligned}
$$

This result corresponds to $88.5 \pm 3.2 \%$ for $\mathrm{Cd}(\mathrm{dGMP})_{\mathrm{cl} / \mathrm{N} 7}$. This stability enhancement for the $\mathrm{Cd}(\mathrm{dGMP})$ complex is by $0.27 \pm 0.15 \log$ unit smaller than the one obtained for $\mathrm{Cd}[\mathrm{d}(\mathrm{pGpG})]^{-}$ indicating that in the dinucleotide complex both guanine residues (Figure 16) are involved to some extent.

It may be added that for the $\mathrm{Cd}[\mathrm{d}(\mathrm{pGpG})]^{-}$system also the monoprotonated species, that is, $\mathrm{Cd}[\mathrm{H} ; \mathrm{d}(\mathrm{pGpG})]$, was observed [241], where the proton is located at the terminal phosphate group and $\mathrm{Cd}^{2+}$ at guanine-N7. From other purine systems it is known that a metal ion bound to $\mathrm{N} 7$ in a nucleotide complex may form macrochelates by also interacting with the $\mathrm{P}(\mathrm{O})_{2}(\mathrm{OH})^{-}$ residue $[97,162]$. Indeed, a detailed evaluation provided a stability enhancement of log 
$\Delta_{\mathrm{Cd} / \mathrm{H} ; \mathrm{d}(\mathrm{pGpG})}=0.27 \pm 0.18$ for $\mathrm{Cd}[\mathrm{H} ; \mathrm{d}(\mathrm{pGpG})]$ and this corresponds to a formation degree for the chelated species of $46 \pm 22 \%$ [241]. Hence, taken together, all these results prove that metal ions are able to bridge the distance between a phosphate group and an N7 site in a d(GMP) unit. This is of relevance for the interaction of metal ions with nucleic acids.

\subsection{The Non-bridging Sulfur of the Thiophosphodiester Link}

Considering the already previously indicated importance of so-called "rescue" experiments in ribozyme chemistry (Sections 7.2 and 10.1), it is interesting to see that for $\mathrm{Cd}(\mathrm{pUp}(\mathrm{s}) \mathrm{U})^{-}$a stability enhancement of $\log \Delta_{\mathrm{Cd} / \mathrm{pUp}(\mathrm{s}) \mathrm{U}}=0.68 \pm 0.09$ is observed (Table 15 [242]) (Figure 16). If this value is charge-corrected in the way explained above, one obtains $\log \Delta_{\mathrm{Cd} / \mathrm{pUp}(\mathrm{s}) \mathrm{U} / \mathrm{charge,cor}}=$ $(0.68 \pm 0.09)-(0.24 \pm 0.04)=0.44 \pm 0.10$. Since no interaction with an oxygen in the diester bridge occurs in $\mathrm{Cd}(\mathrm{pUpU})^{-}$, the whole charge-corrected stability enhancement needs to be attributed to a $\mathrm{Cd}^{2+} / \mathrm{S}$ interaction with the non-bridging $\mathrm{S}$ of the thiophosphodiester link. The corresponding 10-membered chelate reaches a formation degree of $64 \pm 8 \%$ [242].

It is worth to note that no stability enhancement is observed for the $\mathrm{Mg}(\mathrm{pUp}(\mathrm{s}) \mathrm{U})^{-}$and $\mathrm{Mn}(\mathrm{pUp}(\mathrm{s}) \mathrm{U})^{-}$complexes. Clearly, this observation has consequences for the "rescue" experiments in ribozyme chemistry [28].

\subsection{Dinucleoside Monophosphates}

Another interesting molecule in the present context is $\mathrm{IpI}^{-}$(Figure 16) for which the $\mathrm{Cd}^{2+}$ complexes $\mathrm{Cd}(\mathrm{IpI})^{+}$and $\mathrm{Cd}(\mathrm{IpI}-\mathrm{H})$ have been studied [75]. Since the stability constant of $\mathrm{Cd}(\mathrm{IpI})^{+}$could only be estimated, we will not consider this complex further, though it ought to be mentioned that it is transformed to $\mathrm{Cd}(\mathrm{IpI}-\mathrm{H})$ with $\mathrm{p} K_{\mathrm{Cd}(\mathrm{IpI})}^{\mathrm{H}}=6.7 \pm 0.3$, meaning that the deprotonation reaction occurs close to the physiological $\mathrm{pH}$ range. By using the $\mathrm{Cd}^{2+}$ complexes of inosine as a basis a stability enhancement of $\log \Delta_{\mathrm{Cd} /(\mathrm{IpI}-\mathrm{H})}=0.40 \pm 0.30$ was estimated for the $\mathrm{Cd}(\mathrm{IpI}-\mathrm{H})$ complex and this corresponds to a formation degree of $60 \%$ (with lower and upper limits of 21 and $80 \%$, respectively) [75] for the chelate. 
Which is the structure of the closed or chelated species? Since N7 of a 5'-purine unit is in general somewhat more basic than the one of a $3^{\prime}$ unit $[38,48]$, one may assume that the initial complex formation in $\mathrm{IpI}^{-}$occurs preferably at $\mathrm{N} 7$ of the 5 '-inosine residue. This binding mode also allows an outersphere interaction with the (C6)O site, especially after deprotonation of (N1)H $[74,119,162]$, as well as a maximal electrostatic interaction with the negatively charged phosphoryl bridge and possibly even macrochelate formation to a certain extent, as has been suggested before for an intermediate $\mathrm{Pt}(\mathrm{II})$ complex with a related dinucleoside monophosphate [246]. Such a structure is also well known for M(IMP) and related complexes (Section 6.2.3) $[40,50,117]$. Hence, one may conclude that two types of macrochelates are possible: (i) the one indicated above between N7 and the phosphodiester bridge or (ii) one that involves both N7 sites of $(\mathrm{IpI}-\mathrm{H})^{2-}$. Of course, both types of macrochelates may occur in equilibrium with each other, and then the formation degree mentioned above encompasses both species.

Considering that $\mathrm{Mg}^{2+}$ does not form significant amounts of $\mathrm{Mg}(\mathrm{IpI}-\mathrm{H})_{\mathrm{cl}}$ macrochelates [75] (whereas $\mathrm{Co}^{2+}$ and $\mathrm{Zn}^{2+}$ do), we favor N7/N7 macrochelates. However, in doing so, one has to answer the question why no significant amounts of macrochelates are observed with the $\mathrm{Cd}(\mathrm{GpG}-\mathrm{H})$ and $\mathrm{Cd}[\mathrm{d}(\mathrm{GpG}-\mathrm{H})]$ systems (Figure 16) [38]. If one applies the indicated evaluation procedure [75] to the data of ref. [38], one notes that the $\log \Delta_{\mathrm{Cd} /(\mathrm{GpG}-\mathrm{H})}$ and $\log$ $\Delta_{\mathrm{Cd} / \mathrm{d}(\mathrm{GpG}-\mathrm{H})}$ values are zero within their error limits. This agrees with the earlier conclusion [38] that "no hint for the formation of significant amounts of intramolecular chelates involving both N7 sites" have been found, though low concentrations could still occur, of course. A possible explanation could be that the intramolecular stacking interaction in $(\mathrm{IpI}-\mathrm{H})^{2-}$ is smaller than in $(\mathrm{GpG}-\mathrm{H})^{2-}$, and in fact, this is expected [137,247,248]. Consequently, $(\mathrm{IpI}-\mathrm{H})^{2-}$ is more flexible for adapting to the configuration needed in aqueous solution for an N7/N7 macrochelate which is known to form with the kinetically inert cis- $\left(\mathrm{NH}_{3}\right)_{2} \mathrm{Pt}^{2+}$ and both dinucleotide monophosphates $[249,250]$. One should emphasize here that the amount of free energy involved to shift the situation from one side to another is very small; for example, a formation degree of $20 \%$ of a macrochelate at $25^{\circ} \mathrm{C}$ corresponds only to a stability enhancement of $\log \Delta_{\mathrm{M} / \text { ligand }}=0.1$ (eq. 14) and a change in free energy of $\Delta G^{0}=-0.57 \mathrm{~kJ} / \mathrm{mol}$ [52]. 


\section{Cadmium(II) Binding to Nucleic Acids}

Interest in the interaction of cadmium(II) with nucleic acids was triggered, at least in part, by the discovery of Wacker and Vallee [7] more than 50 years ago that RNA from the horse kidney cortex contained not only essential metal ions like those of $\mathrm{Mg}, \mathrm{Ca}, \mathrm{Mn}, \mathrm{Fe}$ or $\mathrm{Zn}$, but also $\mathrm{Cd}$. The toxicity of cadmium(II) is well established for many years (see Chapters 1, 14, and 15) and it appears that it is primarily due to $\mathrm{Cd}(\mathrm{II})$-protein interactions. However, due to its high affinity for $\mathrm{R}_{-} \mathrm{S}^{-}$groups $\mathrm{Cd}^{2+}$ may affect thiolate-disulfide equilibria and thus the redox state of the cell. This in turn means that $\mathrm{Cd}^{2+}$ may stimulate the production of reactive oxygen species (ROS) and these may lead to DNA damage [251]. In addition, cadmium(II) interferes with DNA repair pathways of the cell by directly inhibiting the relevant enzymes or by hampering their binding to aberrant DNA sites [251].

Despite the obvious toxic effects on living cells, $\mathrm{Cd}^{2+}$ is often used in in vitro studies as a probe of $\mathrm{Mg}^{2+}$ or $\mathrm{Ca}^{2+}$ (see Chapter 6) having the advantage of a higher affinity towards most ligands, including nucleotides and their constituents, as described in the previous sections. Below we consider now larger entities.

\subsection{Cadmium(II)-Rescue Experiments}

As indicated above in Section 7.2, $\mathrm{Cd}^{2+}$ binding to phosphorothioate nucleotides can be exploited in so-called rescue experiments where one takes advantage of the higher affinity of $\mathrm{Cd}^{2+}$ towards sulfur ligands compared to $\mathrm{Mg}^{2+}[170,252]$. Such a rescue is also part of so-called nucleotide analogue interference mapping/suppression (NAIM/NAIS) experiments, which are used to identify catalytically crucial atoms within a RNA and/or tertiary contacts [253-255]. This technique has been widely applied to study metal ion binding sites and their influence on catalytic RNAs, i.e., ribozymes [256-262]. Major limitations of this method are the fact that (i) T7 RNA polymerase, which is generally used for the transcription of defined RNA sequences, inserts only $S_{\mathrm{p}}$ thionucleotides under inversion of their conformation to $R_{\mathrm{p}}$. Consequently, in such T7-transcribed RNA molecules only the $R_{\mathrm{p}}$ configuration can be studied. (ii) Sulfur has a slightly 
larger radius compared to oxygen, which can lead to small perturbations in local geometry of a metal ion-binding pocket or a tertiary interaction within the global fold of the RNA. In such cases, the sulfur substitution cannot be rescued by the addition of $\mathrm{Cd}^{2+}$.

The principle of cadmium(II) rescue experiments is as follows (see also refs $[8,10]$ ): Phosphorothioate nucleotides are inserted into a RNA at single, defined sites. In cases of significantly decreased or abolished enzymatic activity of the RNA and subsequent restoration of activity upon addition of soft metal ions like $\mathrm{Cd}^{2+}$, one assumes that the respective phosphate moiety coordinates a metal ion which is relevant for the catalytic activity of the ribozymes.

The technique was first applied to the enzymes arginine kinase and creatinine kinase. Studies on ATP $\gamma \mathrm{S}$ and on the stereospecificity for diastereomers of ATP $\alpha \mathrm{S}$ and ATP $\beta S$ in the presence of $\mathrm{Mg}^{2+}$ and $\mathrm{Cd}^{2+}[263,264]$ proved that metal ions coordinate to the respective phosphate groups at certain steps of the catalytic cycle. Later, as the enzymatic nature of some RNA molecules was discovered, the technique proved powerful in shedding light on their catalytic mechanism as is exemplified with the following few examples.

The different metal ion-binding modes of the two classes of RNAse P, a ribonuclease and ribozyme, could be revealed $[265,266]$. For group II introns, it was shown that a metal ion is required to stabilize the leaving group in both steps of the splicing reaction [267]. In addition, the results of this study were consistent with the findings on the catalysis of the eukaryotic spliceosome [267,268], thus further corroborating a common ancestry of these two machineries. In the case of the group I intron, another large ribozyme, cadmium(II) rescue experiments helped to develop a very detailed understanding of the catalytic mechanism. It was found that three metal ions are required for the splicing mechanism, which bind in the active site and simultaneously contact the attacking nucleophile and the scissile phosphate $[269,270]$.

Cadmium(II) binding was also intensively used to study metal ion requirements for the catalysis of the self-cleaving hammerhead ribozyme. Also here, phosphorothioate studies helped to prove the coordination of divalent metal ions during catalysis $[271,272] . \mathrm{Cd}^{2+}$ binds with a $K_{\mathrm{D}}$ of $25 \mu \mathrm{M}$ in the ground state thereby increasing the activity $10^{4}$-fold. The $K_{\mathrm{D}}$ of $\mathrm{Cd}^{2+}$ in the transition state was calculated to be $2.5 \mathrm{nM}$ indicating that the metal ion recruits at least one more ligand in the transition state. Confusion was caused by the observation that this $\mathrm{Cd}^{2+}$ 
binding site was situated at a $20 \AA$ distance from the scissile phosphate; this discrepancy originated in the fact that earlier studies were performed with a minimal ribozyme construct that lacked important tertiary contacts [273]. The $\mathrm{Cd}^{2+}$ interactions were also investigated using ${ }^{31} \mathrm{P}$ and ${ }^{15} \mathrm{~N}$ NMR, $\mathrm{Cd}^{2+}$ binding leading to an upfield shift of the thiophosphate- ${ }^{31} \mathrm{P}$ or guanine- ${ }^{15} \mathrm{~N} 7$ resonance, respectively [274-277]. The catalytic activity of the hammerhead ribozyme was also shown to be in principle independent of divalent metal ions [278]: In the presence of unphysiologically high, i.e., molar, concentrations of monovalent cations, activity can be partly rescued, thus confirming that a direct $\mathrm{M}^{2+}$ binding to the active site is not mandatory but that also $\mathrm{M}^{+}$ions can be catalytically competent. Such an exchange of low concentration of divalent ions versus high concentrations of monovalent metal ions is well known and is explained by their differences in the binding affinities $[127,279,280]$.

\subsection{Crystal Structures of RNA or DNA-Protein Complexes Containing Cd ${ }^{2+}$}

More detailed information on cadmium(II) binding to nucleic acids is available from a small number of crystal structures of RNA as well as RNA- or DNA-protein complexes. There are only 23 entries in the Protein Data Base that contain $\mathrm{Cd}^{2+}$ ions interacting with at least one atom of a DNA or RNA and of these 18 structures represent different parts of the 50s subunit of the prokaryotic ribosome; the other five are structures of a Diels-Alder ribozyme (1YKQ [281]), the product complex of the hammerhead ribozyme (488D [282]), a prokaryotic enzyme mediating DNA bending called "integration host factor" in complex with a DNA substrate (1IHF [283], 2HT0 [284]) and DNA polymerase $\beta$ in complex with DNA and ATP (8ICE [285]).

Most of the binding sites identified in these structures confirm what is stated in the previous sections on $\mathrm{Cd}^{2+}$ binding to isolated nucleotides. Innersphere contacts are almost exclusively formed by guanine N7 or, to a lesser extent, by adenine N7 or one of the nonbridging phosphate oxygens (OP1 and OP2). Additional outersphere contacts are highly abundant. In case of innersphere binding the $\mathrm{Cd}^{2+}-$ ligand distance is about $2 \AA$. If guanine N7 is innersphere coordinated, then $\mathrm{O} 6$ of the same guanine is always in a distance to enable an outersphere interaction (usually at a distance of about $3 \AA$ ). One example of such a coordination 
pattern is found in the hammerhead ribozyme, where $\mathrm{Cd}^{2+}$ strongly influences catalytic activity (see Section 10.1). The sites G10.1 N7 and A9 OP2 constitute the innersphere contacs with the $\mathrm{Cd}^{2+}$ ion while numerous further atoms of five different nucleotides interact by outersphere coordination with the $\mathrm{Cd}^{2+}$ ion from distances between 2.9 and $5.6 \AA$ (Figure 17) [282,286].

\section{insert Figure 17 in color close to here (width: $10 \mathrm{~cm}$ )}

Apart from the above mentioned coordination pattern, $\mathrm{Cd}^{2+}$ contacts to nearly any nitrogen or oxygen atom in nucleotides can be observed. The total number of potential interactions to a single $\mathrm{Cd}^{2+}$ ion varies greatly depending on the binding site. The same is true for the number of involved residues that ranges from 2 to 6 . In general, one nucleobase (mostly the one coordinated via N7) provides most further atoms to bind the $\mathrm{Cd}^{2+}$ ion while the residues at the $\mathrm{n}+1$ and $\mathrm{n}-1$ position and, if available, its base pairing partners provide few additional liganding atoms.

The only $\mathrm{Cd}^{2+}$-containing RNA-protein complex deposited in the Protein Data Bank is the afore mentioned 50s subunit of the ribosome. Surprisingly for such a giant molecular assembly, the maximum number is eight $\mathrm{Cd}^{2+}$ atoms bound in one structure (1MMS [287]), seven of which comprise contacts to RNA. Two special $\mathrm{Cd}^{2+}$ coordination sites are detected in this 50s RNA. In the first case, uracil $\mathrm{O} 4$ is the only innersphere contact to $\mathrm{Cd}^{2+}$ with no $\mathrm{N} 7$ or phosphate oxygen being within $5 \AA$. In two further binding sites, one of which comprises numerous liganding atoms from six different nucleotides, rare innersphere contacts between $\mathrm{Cd}^{2+}$ and the ribose $\mathrm{O} 2{ }^{\prime}$ are observed. These special cases illustrate how increasingly complex molecular assemblies open up coordination options by providing a complex and defined overall geometry. This allows for a summation of contributions of several weak interactions or facilitates weak interactions by a spatial pre-arrangement of strong interactions.

To the best of our knowledge there is no structure available of only DNA with bound $\mathrm{Cd}(\mathrm{II})$ ions. The structures of the prokaryotic DNA-bending protein IHF (integration host factor) with doubly nicked DNA (PDB 2HT0) or singly-nicked DNA (PDB 1IHF) mostly display conservative binding modes involving guanine and adenine $\mathrm{N} 7$ or phosphate oxygens. Often, a combination of amino acids, DNA nucleotides, and water molecules constitute the binding sites for the single $\mathrm{Cd}^{2+}$ ions.

The PDB structure of DNA polymerase ${ }^{\circledR}$ with 7 base pairs of DNA and ATP bound 
(PDB 8ICE) contains just one binding site in which DNA is involved. The cadmium(II) has contacts to four different amino acids and two phosphate oxygens; it is also in coordination distance to $\mathrm{O5}^{\prime}$ of adenine and O3' of a guanine. Additionally, four oxygen atoms of pyrophosphate coordinate the $\mathrm{Cd}^{2+}$. This is a good example of how DNA-Cd ${ }^{2+}$ contacts can be facilitated by another main binding site. In this case, the pyrophosphate is required to bind a metal ion in this site as in its absence the site remains unoccupied [285].

\subsection{Cadmium(II) as Probe in EPR and NMR Spectroscopy}

Cadmium(II)-induced EPR silencing was applied to evaluate the affinity of $\mathrm{Mn}^{2+}$ to several distinct binding sites in the Diels-Alder ribozyme [288]. As $\mathrm{Cd}^{2+}$ is EPR-silent, it was used to saturate four of five binding sites for divalent metal ions of the ribozyme to selectively study the affinity of $\mathrm{Mn}^{2+}$ for each binding site separately. This method relies on the fact that a $\mathrm{Cd}^{2+}$ ion once bound to the ribozyme cannot be substituted by $\mathrm{Mn}^{2+}$ since its affinity to all five binding sites is higher.

As mentioned above in Section $10.1, \mathrm{Cd}^{2+}$ is readily applied in combination with thiophosphate derivatives using ${ }^{31} \mathrm{P}$ NMR making advantage of the chemical shift dispersion of the thiophosphate group as well as the higher affinity [274-277]. Similarly, $\mathrm{Cd}^{2+}$ can also be applied as mimic of $\mathrm{Mg}^{2+}$ in chemical shift titration experiments, its higher affinity being of advantage for better spectral quality [289]. In addition, ${ }^{111} \mathrm{Cd}$ or ${ }^{113} \mathrm{Cd}$ are very good NMR nuclei and regularly used in proteins to investigate $\mathrm{Cd}^{2+}$ binding [290,291] (see also Chapter 6). In larger nucleic acids, such studies are not as straight forward as with proteins due to the much lower affinity and faster exchange rates. Consequently, no distinct signal for ${ }^{111 / 113} \mathrm{Cd}$ is observed upon binding. We are aware of only one example where a change in chemical shift of the ${ }^{113} \mathrm{Cd}$ is observed upon addition to the central core of a group II intron ribozyme [292].

\section{Concluding Remarks}

Cadmium(II) is a metal ion that displays distinct coordinating properties with a mostly 
octahedral coordination sphere. It is commonly classified as a relatively soft ion and it prefers thus aromatic-nitrogen sites, especially N7 of purine residues. However, interactions with phosphate oxygens including those of the phosphodiester bridge are also not negligible and, provided a suitably located primary binding site is available, also hydroxyl and carbonyl groups may coordinate. Overall, one can conclude that the coordination chemistry of $\mathrm{Cd}^{2+}$ with nucleotides and the corresponding substituents is relatively well understood today; this includes the relations between the toxic $\mathrm{Cd}^{2+}$ and the essential $\mathrm{Zn}^{2+}, \mathrm{Ca}^{2+}$, and $\mathrm{Mg}^{2+}$ ions, for which it is often employed as a probe. However, with regard to less common nucleotides, which also occur in Nature, like thio-pyrimidine or -purine derivatives, our knowledge is very scarce and considerably more work is needed. This is of high relevance because $\mathrm{Cd}^{2+}$-thio interactions are very stable, meaning that such an interaction can totally change the properties of a nucleic acid complex because commonly metal ion-nucleic acid interactions are weak compared to those of proteins.

Indeed, $\mathrm{Cd}^{2+}$ coordinates to nucleic acids often not only directly, like with purine-N7 sites, but also indirectly to oxygen and (other) nitrogen sites as is exemplified by many outersphere interactions found in nucleic acid structures. Most important in this respect is also the high affinity of $\mathrm{Cd}^{2+}$ towards sulfur ligands. These characteristics make $\mathrm{Cd}^{2+}$ on the one hand a toxic element that interferes especially with proteins in numerous metabolic pathways, but on the other hand it is also an interesting mimic for other metal ions in in vitro studies. Especially as a replacement for $\mathrm{Ca}^{2+}$ and $\mathrm{Mg}^{2+}$ it is regularly applied in nucleic acid research.

The coordination chemistry of $\mathrm{Cd}^{2+}$ towards the building blocks of nucleic acids is well established and the intrinsic affinities to almost all possible coordinating atoms are known. This knowledge should provide a perfect basis to investigate in the future $\mathrm{Cd}^{2+}$ binding also to larger and more complex nucleic acid structures. The higher intrinsic affinity of $\mathrm{Cd}^{2+}$ compared to many other divalent metal ions, especially $\mathrm{Mg}^{2+}$ and $\mathrm{Ca}^{2+}$, allows in many cases a more detailed investigation of the coordination pattern. In the case of ribozymes, a differing catalytic rate in the presence of $\mathrm{Cd}^{2+}$ versus that of $\mathrm{Mg}^{2+}$ should in principle allow to draw conclusions on $\mathrm{Mg}^{2+}$ binding. However, such investigations are in many instances severely hampered by the fact that even with $\mathrm{Cd}^{2+}$ it is often highly challenging to characterize a binding pocket down to the single 
coordinating atoms. This is due to the size of the RNA itself and the limited chemical diversity of its building blocks, which make it very difficult to distinguish individual nucleotides. Highly promising in this respect are combinations of ${ }^{13} \mathrm{C},{ }^{15} \mathrm{~N}$, and ${ }^{113} \mathrm{Cd} \mathrm{NMR}$, which allow to observe both the RNA liganding sites and the metal ion simultaneously. Although hampered by the fast exchange of the metal ion in nucleic acids, the increasing sensitivity of NMR probeheads, also for hetero nuclei, will certainly lead to new developments and experiments in the future.

\section{Abbreviations and Definitions}

The abbreviations for the nucleobases and nucleosides are defined in Figure 1 and the labeling systems for the di- and triphosphate residues in Figure 9. Other abbreviations are defined below.

$\begin{array}{ll}\mathrm{Ac}^{-} & \text {acetate (Figure 9) } \\ \mathrm{AcP}^{2-} & \text { acetyl phosphate (Figure 3) } \\ \text { Ade } & \text { adenine (Figure 1) } \\ \text { Ado } & \text { adenosine (Figure 1) } \\ \mathrm{ADP}^{3-} & \text { adenosine 5'-diphosphate (Figure 10) } \\ \mathrm{AMP}^{2-} & \text { adenosine 5'-monophosphate (Figure 3) } \\ \mathrm{AMPS}^{2-} & \text { adenosine 5'-O-thiomonophosphate } \\ \mathrm{AnP}^{2-} & \text { acetonylphosphonate (Figure 3) } \\ \mathrm{ATP}^{4-} & \text { adenosine 5'-triphosphate (Figure 10) } \\ \text { Bicine }^{2, N \text {-bis(2-hydroxyethyl)glycine (Figure 15) }} \\ \text { Bistris } & 2 \text {-[bis(2-hydroxyethyl)amino]-2-(hydroxymethyl)-1,3-propanediol (Figure }\end{array}$

Bpy 2,2'-bipyridine

C2S 2-thiocytidine

$\mathrm{CDP}^{3-} \quad$ cytidine 5'-diphosphate (Figure 10)

$\mathrm{CMP}^{2-} \quad$ cytidine 5'-monophosphate (Figure 10)

CTP $\quad$ cytidine 5'-triphosphate (Figure 10) 


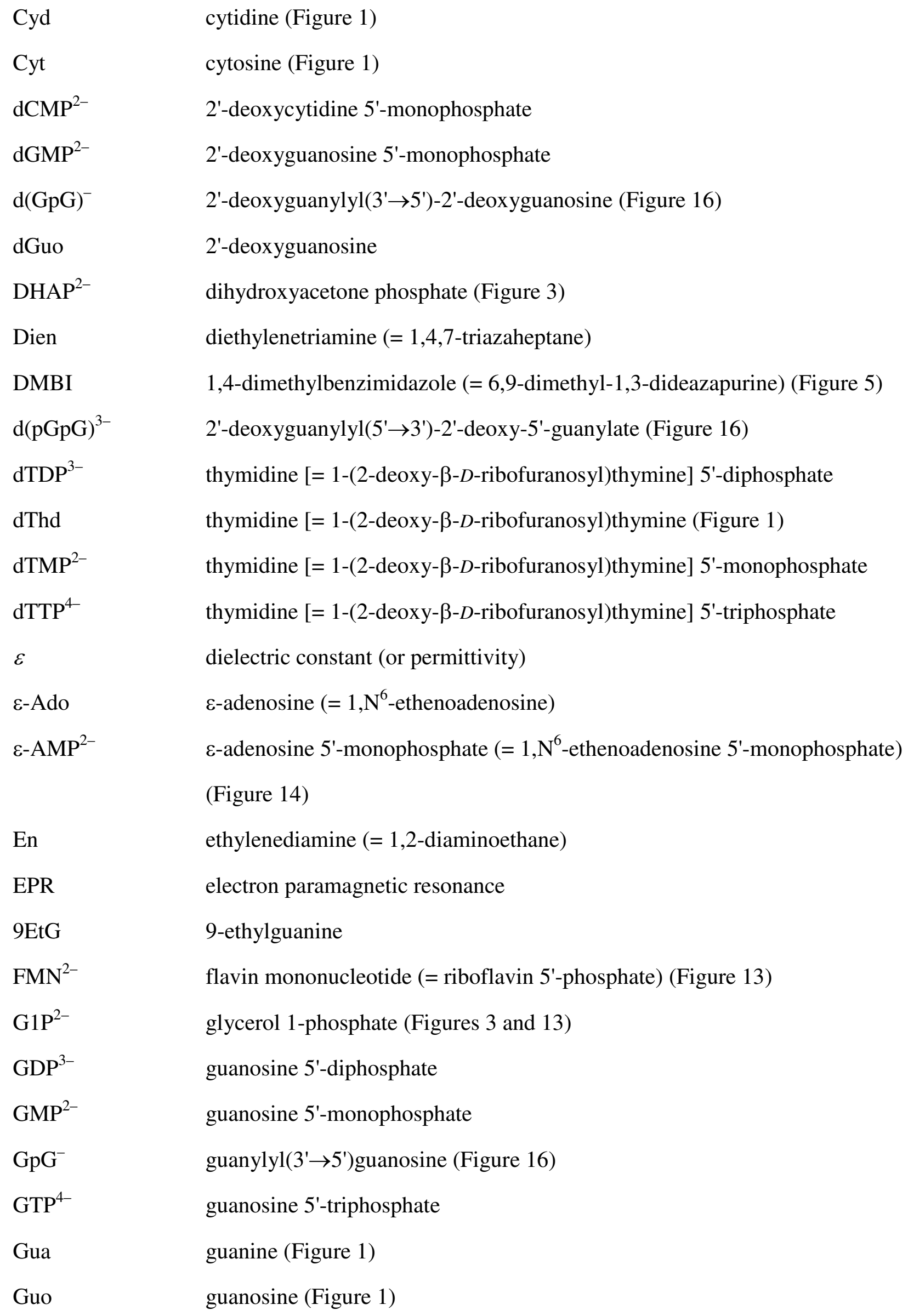




\begin{tabular}{|c|c|}
\hline $\mathrm{HMP}^{2-}$ & hydroxymethylphosphonate (Figure 4) \\
\hline $\mathrm{HOAc}^{-}$ & hydroxyacetate (Figure 4) \\
\hline HOMPy & $o$-(hydroxymethyl)pyridine (Figure 4) \\
\hline $\mathrm{H}(\mathrm{Or})$ & orotidine (Figure 8) \\
\hline Hyp & hypoxanthine (Figure 1) \\
\hline$I$ & ionic strength \\
\hline $\mathrm{IDP}^{3-}$ & inosine 5'-diphosphate \\
\hline IHF & integration host factor \\
\hline $\operatorname{Im}$ & imidazole \\
\hline $\mathrm{IMP}^{2-}$ & inosine 5'-monophosphate \\
\hline Ino & inosine \\
\hline $\mathrm{IpI}^{-}$ & inosylyl $\left(3^{\prime} \rightarrow 5^{\prime}\right)$ inosine (Figure 16 ) \\
\hline $\mathrm{ITP}^{4-}$ & inosine 5'-triphosphate \\
\hline$K_{\mathrm{I}}$ & intramolecular equilibrium constant \\
\hline$K_{\mathrm{a}}$ & general acidity constant \\
\hline $\mathrm{L}$ & general ligand \\
\hline Leu & leucine \\
\hline $\mathrm{Leu}^{-}$ & leucinate \\
\hline $\mathrm{M}^{2+}$ & divalent metal ion \\
\hline $1 \mathrm{MBI}$ & 1-methylbenzimidazole (Figure 5) \\
\hline $9 \mathrm{MeA}$ & 9-methyladenine \\
\hline 9МеHур & 9-methylhypoxanthine \\
\hline $9 \mathrm{MeG}$ & 9-methylguanine \\
\hline $\mathrm{MeOPS}^{2-}$ & methyl thiophosphate \\
\hline $1 \mathrm{MIm}$ & 1-methylimidazole (Figure 5) \\
\hline 2MPy & 2-methylpyridine (Figure 5) \\
\hline NAIM/NAIS & nucleotide analogue interference mapping/suppression \\
\hline NB & nucleobase derivative \\
\hline $\mathrm{NDP}^{3-}$ & nucleoside 5'-diphosphate \\
\hline
\end{tabular}




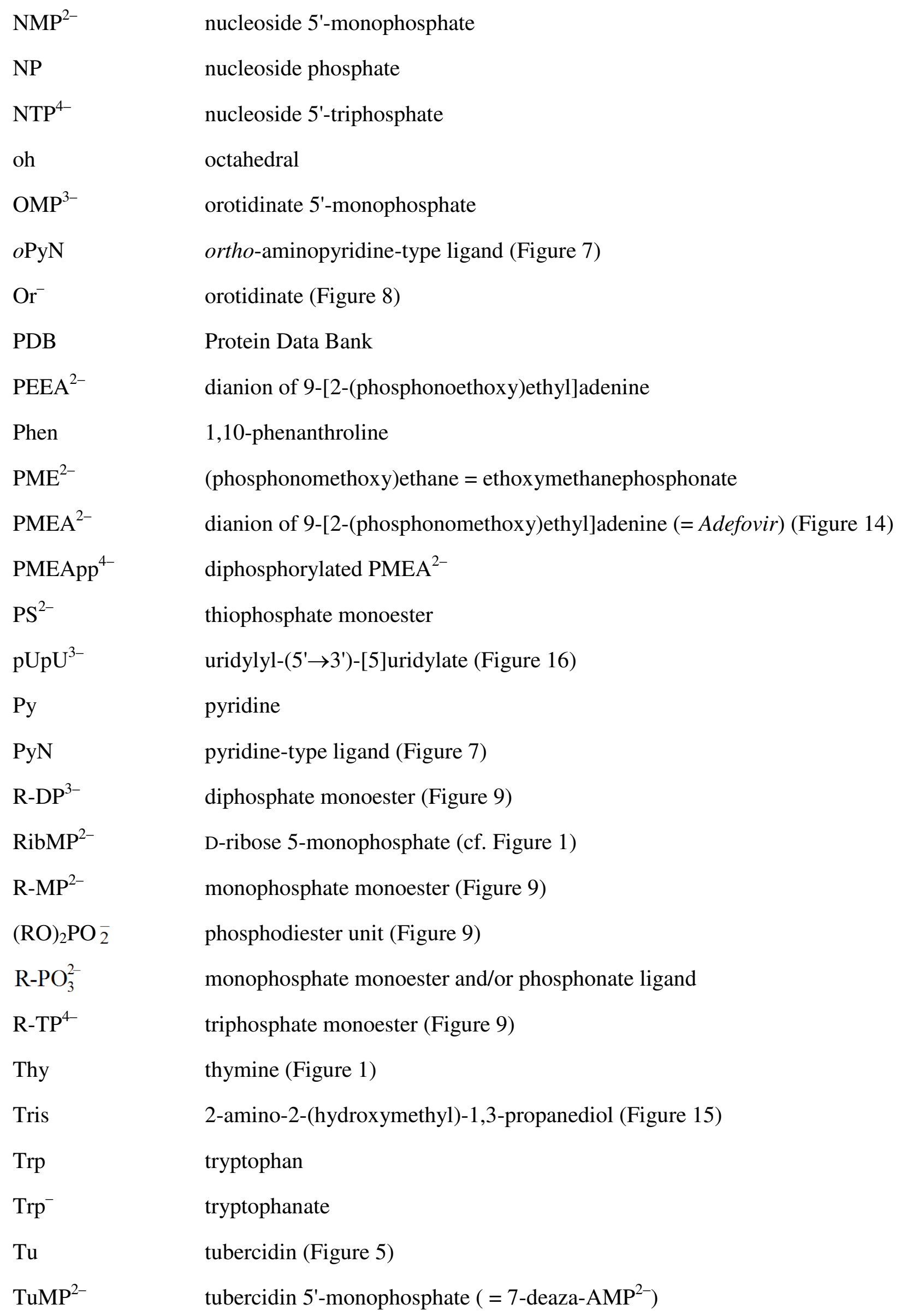


uridine-type ligand

$(\mathrm{U}-\mathrm{H})^{-} \quad$ uridinate-type ligand

U2S 2-thiouridine (Figure 8)

U4S 4-thiouridine (Figure 8)

$\mathrm{UDP}^{3-} \quad$ uridine 5'-diphosphate

$\mathrm{UMP}^{2-} \quad$ uridine 5'-monophosphate

$\mathrm{UMPS}^{2-} \quad$ uridine 5 '- $O$-thiomonophosphate (Figure 14)

Ura $\quad$ uracil (Figure 1)

Urd uridine (Figure 1)

$\mathrm{UTP}^{4-} \quad$ uridine 5'-triphosphate

Xao $\quad$ xanthosine (Figure 8)

$\mathrm{XMP}^{3-} \quad$ xanthosinate $5^{\prime}-$ monophosphate $=(\mathrm{XMP}-\mathrm{H})^{3-}=(\mathrm{X}-\mathrm{H} \cdot \mathrm{MP})^{3-}($ Figure 13)

Species written in the text without a charge do not carry one or represent the species in general (i.e., independent of the protonation degree); which of the two possibilities applies is always clear from the context. In formulas such as $\mathrm{M}(\mathrm{H} ; \mathrm{NMP})^{+}$the $\mathrm{H}^{+}$and $\mathrm{NMP}^{2-}$ are separated by a semicolon to facilitate reading; yet they appear within the same parenthesis to indicate that the proton is at the ligand without defining its location. A formula like $(\mathrm{NB}-\mathrm{H})^{-}$means that the ligand, here a nucleobase residue, has lost a proton and it is to be read as $\mathrm{NB}$ minus $\mathrm{H}^{+}$. The term (aq) is used to indicate that water is acting as a ligand.

\section{Acknowledgments}

Financial support from the Swiss National Science Foundation (R.K.O.S.), the European Research Council (ERC Starting Grant to R.K.O.S.), the Universities of Zürich (R.K.O.S.) and Basel (H.S.), and within the COST Action CM1105 (R.K.O.S.) are gratefully acknowledged.

\section{References}

1. J. K. Dunnick, B. A. Fowler, in Handbook on Toxicity of Inorganic Compounds, Eds H. G. 
Seiler, H. Sigel, A. Sigel, Marcel Dekker, New York, 1988, pp. 155-175.

2. C. E. Housecroft, A. G. Sharpe, Inorganic Chemistry, Pearson Education, Harlow, UK, 2001, p. 579.

3. L. Thunus, R. Lejeune, in Handbook on Metals in Clinical and Analytical Chemistry, Eds H. G. Seiler, A. Sigel, H. Sigel, Marcel Dekker, New York, 1994, p. 668.

4. R. F. M. Herber, in Handbook on Metals in Clinical and Analytical Chemistry, Eds H. G. Seiler, A. Sigel, H. Sigel, Marcel Dekker, New York, 1994, pp. 283-297.

5. Y. Xu, L. Feng, P. D. Jeffrey, Y. Shi, F. M. M. Morel, Nature 2008, 452, 56-61.

6. T. W. Lane, M. A. Saito, G. N. George, I. J. Pickering, R. C. Prince, F. M. M. Morel, Nature, 2005, 435, 42.

7. W.E. C. Wacker, B. L. Vallee, J. Biol. Chem. 1959, 234, 3257-3262.

8. M. C. Erat, R. K. O. Sigel, Met. Ions Life Sci. 2011, 9, 37-100.

9. D. Donghi, J. Schnabl, Met. Ions Life Sci. 2011, 9, 197-234.

10. M. Pechlaner, R. K. O. Sigel, Met. Ions Life Sci. 2012, 10, 1-42.

11. K. Aoki, Met. Ions Biol. Syst. 1996, 32, 91-134.

12. R. B. Martin, Y. H. Mariam, Met. Ions Biol. Syst. 1979, 8, 57-124.

13. R. Tribolet, H. Sigel, Eur. J. Biochem. 1987, 163, 353-363.

14. D. B. Davies, P. Rajani, H. Sadikot, J. Chem. Soc., Perkin Trans. 2, 1985, 279-285.

15. R. B. Martin, Met. Ions Biol. Syst. 1986, 20, 21-65.

16. P. B. Hammond, E. C. Foulkes, Met. Ions Biol. Syst. 1986, 20, 157-200.

17. R. B. Martin, in Handbook on Toxicity of Inorganic Compounds, Eds H. G. Seiler, H. Sigel, A. Sigel, Marcel Dekker, New York, 1988, pp. 9-25.

18. R. B. Martin, Met. Ions Biol. Syst. 1984, 17, 1-49.

19. E. Freisinger, R. K. O. Sigel, Coord. Chem. Rev. 2007, 251, 1834-1851.

20. R. D. Shannon, Acta Cryst. 1976, A32, 751-767.

21. H. Sigel, R. B. Martin, Chem. Soc. Rev. 1994, 23, 83-91.

22. H. Sigel, D. B. McCormick, Acc. Chem. Res. 1970, 3, 201-208.

23. C. F. Baes, Jr., R. E. Mesmer, The Hydrolysis of Cations, Krieger Publishing Co., Malabar, Florida, 1976, pp. 1-496. 
24. A. M. Pyle, Met. Ions Biol. Syst. 1996, 32, 479-520.

25. NIST Critically Selected Stability Contstants of Metal Complexes, Reference Database 46, Version 8.0; data collected and selected by R. M. Smith, A. E. Martell; U. S. Department of Commerce, National Institute of Standards and Technology, Gaithersburg, MD, 2004.

26. R. K. O. Sigel, H. Sigel, in Bioinorganic Fundamentals and Applications; Metals in Natural Living Systems and Metals in Toxicology and Medicine, Eds V. L. Pecoraro, T. Hambley, in Volume 3 of Comprehensive Inorganic Chemistry II, Eds J. Reedijk, K. Poeppelmeier, Elsevier, Oxford, UK, 2012, in press.

27. N. Saha, H. Sigel, J. Am. Chem. Soc. 1982, 104, 4100-4105.

28. R. K. O. Sigel, Eur. J. Inorg. Chem. 2005, 2281-2292.

29. H. Sigel, F. Hofstetter, R. B. Martin, R. M. Milburn, V. Scheller-Krattiger, K. H. Scheller, J. Am. Chem. Soc. 1984, 106, 7935-7946.

30. R. K. O. Sigel, A. M. Pyle, Chem. Rev. 2007, 107, 97-113.

31. A. Mucha, B. Knobloch, M. Jeżowska-Bojczuk, H. Kozłowski, R. K. O. Sigel, Chem. Eur. J. 2008, 14, 6663-6671.

32. H. Sigel, Chem. Soc. Rev. 1993, 22, 255-267.

33. B. Knobloch, D. Suliga, A. Okruszek, R. K. O. Sigel, Chem. Eur. J. 2005, 11, 4163-4170.

34. B. Lippert, Prog. Inorg. Chem. 2005, 54, 385-447.

35. B. Knobloch, H. Sigel, J. Biol. Inorg. Chem. 2004, 9, 365-373.

36. L. E. Kapinos, B. P. Operschall, E. Larsen, H. Sigel, Chem. Eur. J. 2011, 17, 8156-8164.

37. H. Sigel, E. M. Bianchi, N. A. Corfù, Y. Kinjo, R. Tribolet, R. B. Martin, J. Chem. Soc., Perkin Trans. 2, 2001, 507-511.

38. C. P. Da Costa, H. Sigel, Inorg. Chem. 2003, 42, 3475-3482.

39. H. Pezzano, F. Podo, Chem. Rev. 1980, 80, 365-401.

40. R. K. O. Sigel, H. Sigel, Met. Ions Life Sci. 2007, 2, 109-180.

41. K. Aoki, K. Murayama, Met. Ions Life Sci. 2012, 10, 43-102.

42. D. M. L. Goodgame, I. Jeeves, C. D. Reynolds, A. C. Skapski, Nucleic Acids Res. 1975, 2, $1375-1379$.

43. S. Yano, M. Otsuka, Met. Ions Biol. Syst. 1996, 32, 27-60. 
44. H. Kozłowski, P. Decock, I. Olivier, G. Micera, A. Pusino, L. D. Pettit, Carbohydrate Res. 1990, 197, 109-117.

45. B. Song, P. Mehrkhodavandi, P. Buglyó, Y. Mikata, Y. Shinohara, K. Yoneda, S. Yano, C. Orvig, J. Chem. Soc., Dalton Trans. 2000, 1325-1333.

46. H. Reinert, R. Weiss, Hoppe-Seylers Z. Physiol. Chem. 1969, 350, 1321-1326.

47. Y.-Y. H. Chao, D. R. Kearns, J. Am. Chem. Soc. 1977, 99, 6425-6434.

48. S. S. Massoud, H. Sigel, Eur. J. Biochem. 1989, 179, 451-458.

49. G. S. Padiyar, T. P. Seshadri, J. Biomolecular Structure \& Dynamics 1998, 15, 803-821.

50. H. Sigel, B. Song, Met. Ions Biol. Syst. 1996, 32, 135-205.

51. R. B. Martin, H. Sigel, Comments Inorg. Chem. 1988, 6, 285-314.

52. H. Sigel, L. E. Kapinos, Coord. Chem. Rev. 2000, 200-202, 563-594.

53. G. Liang, D. Chen, M. Bastian, H. Sigel, J. Am. Chem. Soc. 1992, 114, 7780-7785.

54. M. Furler, B. Knobloch, R. K. O. Sigel, Inorg. Chim. Acta 2009, 362, 771-776.

55. H. Sigel, C. P. Da Costa, B. Song, P. Carloni, F. Gregáň, J. Am. Chem. Soc. 1999, 121, $6248-6257$.

56. C. P. Da Costa, B. Song, F. Gregáň, H. Sigel, J. Chem. Soc., Dalton Trans. 2000, 899-904.

57. F. M. Al-Sogair, B. P. Operschall, A. Sigel, H. Sigel, J. Schnabl, R. K. O. Sigel, Chem. Rev. 2011, 111, 4964-5003.

58. R. K. O. Sigel, H. Sigel, Accounts Chem. Res. 2010, 43, 974-984.

59. L. E. Kapinos, H. Sigel, Inorg. Chim. Acta 2002, 337, 131-142; ICA issue in honor of K. E. Wieghardt.

60. L. E. Kapinos, B. Song, H. Sigel, Chem. Eur. J. 1999, 5, 1794-1802.

61. A. Sigel, B. P. Operschall, H. Sigel, Coord. Chem. Rev. 2012, 256, 260-278.

62. A. T. Perrotta, M. D. Been, Biochemistry 2007, 46, 5124-5130.

63. A. S. Burton, N. Lehman, Biochimie 2006, 88, 819-825.

64. N. Lehman, G. F. Joyce, Nature 1993, 361, 182-185.

65. N. Lehman, G. F. Joyce, Curr. Biol. 1993, 3, 723-734.

66. M. C. Erat, R. K. O. Sigel, J. Biol. Inorg. Chem. 2008, 13, 1025-1036.

67. M. Steiner, K. S. Karunatilaka, R. K. O. Sigel, D. Rueda, Proc. Natl. Acad. Sci. U.S.A. 
2008, 105, 13853-13858.

68. M. Steiner, D. Rueda, R. K. O. Sigel, Angew. Chem., Int. Ed. 2009, 48, 9739-9742.

69. R. Griesser, G. Kampf, L. E. Kapinos, S. Komeda, B. Lippert, J. Reedijk, H. Sigel, Inorg. Chem. 2003, 42, 32-41.

70. L. E. Kapinos, B. Song, H. Sigel, Inorg. Chim. Acta 1998, 280, 50-56; ICA issue in memory of Mark E. Vol'pin.

71. L. E. Kapinos, A. Holý, J. Günter, H. Sigel, Inorg. Chem. 2001, 40, 2500-2508.

72. L.-n. Ji, N. A. Corfù, H. Sigel, J. Chem. Soc., Dalton Trans. 1991, 1367-1375.

73. L. E. Kapinos, H. Sigel, results to be published.

74. H. Sigel, S. S. Massoud, N. A. Corfù, J. Am Chem. Soc. 1994, 116, 2958-2971.

75. B. Knobloch, A. Okruszek, H. Sigel, Inorg. Chem. 2008, 47, 2641-2648.

76. J. C. Morales, E. T. Kool, Nat. Struct. Biol. 1998, 5, 950-954.

77. H. Sigel, N. A. Corfù, L.-n. Ji, R. B. Martin, Comments Inorg. Chem. 1992, 13, 35-59.

78. M. A. Salam, K. Aoki, Inorg. Chim. Acta 2001, 314, 71-82.

79. H. Sigel, Pure Appl. Chem. 2004, 76, 1869-1886.

80. B. Song, J. Zhao, R. Griesser, C. Meiser, H. Sigel, B. Lippert, Chem. Eur. J. 1999, 5, 2374-2387.

81. H. Sigel, J. Am. Chem. Soc. 1975, 97, 3209-3214.

82. B. Knobloch, R. K. O. Sigel, B. Lippert, H. Sigel, Angew. Chem. Int. Ed. 2004, 43, 37933795.

83. Y Kinjo, L.-n. Ji, N. A. Corfù, H. Sigel, Inorg. Chem. 1992, 31, 5588-5596.

84. J. Hogle, M. Sundaralingam, G. H. Y. Lin, Acta Crystallogr., Sect. B 1980, 36, 564-570.

85. K. Aoki, W. Saenger, J. Inorg. Biochem. 1984, 20, 225-245.

86. G. R. Clark, J. D. Orbell, Acta Crystallogr., Sect. B. 1978, 34, 1815-1822.

87. B. Knobloch, C. P. Da Costa, W. Linert, H. Sigel, Inorg. Chem Commun. 2003, 6, 90-93.

88. B. Knobloch, W. Linert, H. Sigel, Proc. Natl. Acad. Sci. U.S.A. 2005, 102, 7459-7464.

89. H. Follmann, R. Pfeil, H. Witzel, Eur. J. Biochem. 1977, 77, 451-461.

90. H. R. Mahler, E. H. Cordes, Biological Chemistry, Harper \& Row, New York, 1966.

91. J. D. Rawn, Biochemistry, Neil Patterson Publ., Burlington, North Carolina, USA, 1989. 
92. M. Bastian, H. Sigel, Inorg. Chim. Acta 1990, 178, 249-259.

93. M. Bastian, H. Sigel, J. Coord. Chem. 1991, 23, 137-154.

94. R. Hille, Met. Ions Life Sci. 2009, 6, 395-416.

95. Y. Kinjo, R. Tribolet, N. A. Corfù, H. Sigel, Inorg. Chem. 1989, 28, 1480-1489.

96. S. S. Massoud, N. A. Corfù, R. Griesser, H. Sigel, Chem. Eur. J. 2004, 10, 5129-5137.

97. H. Sigel, B. P. Operschall, R. Griesser, Chem. Soc. Rev. 2009, 38, 2465-2494.

98. R. B. Martin, Met. Ions Biol. Syst. 1996, 32, 61-89.

99. H. Sierzputowska-Gracz, E. Sochacka, A. Malkiewicz, K. Kuo, C. W. Gehrke, P. F. Agris, J. Am. Chem. Soc. 1987, 109, 7171-7177.

100. L. Aravind, E. V. Koonin, Trends Biochem. Sci. 2001, 26, 215-217.

101. K. C. Rogers, A. T. Crescenzo, D. Söll, Biochimie, 1995, 77, 66-74.

102. T. Kowalik-Jankowska, H. Kozlowski, I. Sóvágó, B. Nawrot, E. Sochacka, A. J. Malkiewicz, J. Inorg. Biochem. 1994, 53, 49-56.

103. T. Kowalik-Jankowska, K. Varnagy, J. Swiatek-Kozlowska, A. Jon, I. Sóvágó, E. Sochacka, A. Malkiewicz, J. Spychala, H. Kozlowski, J. Inorg. Biochem. 1997, 65, 257262.

104. (a) R. B. Martin, in Encyclopedia of Inorganic Chemistry, Vol. 4, Ed R. B. King, Wiley, Chichester, UK, 1994, pp. 2185-2196. (b) R. B. Martin, in Encyclopedia of Molecular Biology and Molecular Medicine, Vol. 11, Ed R. A. Meyer, VCH, Weinheim, Germany, 1996, pp. 125-134.

105. A. Odani, H. Kozlowski, J. Swiatek-Kozlowska, J. Brasún, B. P. Operschall, H. Sigel, J. Inorg. Biochem. 2007, 101, 727-735.

106. P. T. Selvi, M. Murali, M. Palaniandavar, M. Köckerling, G. Henkel, Inorg. Chim. Acta 2002, 340, 139-146.

107. E. Dubler, Met. Ions Biol. Syst. 1996, 32, 301-338.

108. R. Leipuviene, Q. Qian, G. R. Björk, J. Bacteriol. 2004, 186, 758-766.

109. I. Lukovits, E. Kalman, F. Zucchi, Corrosion, 2001, 57, 3-8.

110. A. R. Van Rompay, A. Norda, K. Lindén, M. Johansson, A. Karlsson, Mol. Pharmacol. 2001, 59, 1181-1186. 
111. C. R. Raj, S. Behera, Biosens. Bioelectron. 2005, 21, 949-956.

112. J. Brasún, A. Matera, E. Sochacka, J. Swiatek-Kozlowska, H. Kozlowski, B. P. Operschall, H. Sigel, J. Biol. Inorg. Chem. 2008, 13, 663-674.

113. R. Stewart, M. G. Harris, Can. J. Chem. 1977, 55, 3807-3814.

114. S. S. Massoud, H. Sigel, Inorg. Chem. 1988, 27, 1447-1453.

115. S. A. A. Sajadi, B. Song, F. Gregán̆, H. Sigel, Inorg. Chem. 1999, 38, 439-448.

116. H. Sigel, R. Tribolet, R. Malini-Balakrishnan, R. B. Martin, Inorg. Chem. 1987, 26, 2149 2157.

117. H. Sigel, R. Griesser, Chem. Soc. Rev. 2005, 34, 875-900.

118. H. Sigel, Pure Appl. Chem. 2004, 76, 375-388.

119. H. Sigel, E. M. Bianchi, N. A. Corfù, Y. Kinjo, R. Tribolet, R. B. Martin, Chem. Eur. J. 2001, 7, 3729-3737.

120. H. Sigel, Eur. J. Biochem. 1987, 165, 65-72.

121. A. Mucha, B. Knobloch, M. Jeżowska-Bojczuk, H. Kozłowski, R. K. O. Sigel, Dalton Trans. 2008, 5368-5377.

122. H. Sigel, D. Chen, N. A. Corfù, F. Gregáň, A. Holý, M. Strašák, Helv. Chim. Acta 1992, $75,2634-2656$.

123. H. Diebler, F. Secco, M. Venturini, Biophys. Chem. 1987, 26, 193-205.

124. J. C. Thomas, C. M. Frey, J. E. Stuehr, Inorg. Chem. 1980, 19, 501-504.

125. K. J. Powell, P. L. Brown, R. H. Byrne, T. Gajda, G. Hefter, A.-K. Leuz, S. Sjöberg, H. Wanner, Pure Appl. Chem. 2011, 83, 1163-1214.

126. H. M. Irving, R. J. P. Williams, J. Chem. Soc. 1953, 3192-3210.

127. J. Schnabl, R. K. O. Sigel, Curr. Opin. Chem. Biol. 2010, 14, 269-275.

128. H. Sigel, R. B. Martin, Chem. Rev. 1982, 82, 385-426.

129. H. Brintzinger, G. G. Hammes, Inorg. Chem. 1966, 5, 1286-1287.

130. E. M. Bianchi, S. A. A. Sajadi, B. Song, H. Sigel, Chem. Eur. J. 2003, 9, 881-892.

131. A. Szent-Györgyi, in Enzymes; Units of Biological Structure and Function, Ed O. H. Gaebler, Academic Press, New York, 1956, p. 393.

132. M. Cohn, T. R. Hughes, Jr., J. Biol. Chem. 1962, 237, 176-181. 
133. P. W. Schneider, H. Brintzinger, H. Erlenmeyer, Helv. Chim. Acta 1964, 47, 992-1002.

134. (a) H. Sternlicht, R. G. Shulman, E. W. Anderson, J. Chem. Phys. 1965, 43, 3133-3143.

(b) R. G. Shulman, H. Sternlicht, J. Mol. Biol. 1965, 13, 952-955.

135. (a) H. Sigel, Experientia 1966, 22, 497-499. (b) H. Sigel, H. Erlenmeyer, Helv. Chim. Acta 1966, 49, 1266-1274.

136. H. Sigel, S. S. Massoud, R. Tribolet, J. Am. Chem. Soc. 1988, 110, 6857-6865.

137. K. H. Scheller, F. Hofstetter, P. R. Mitchell, B. Prijs, H. Sigel, J. Am. Chem. Soc. 1981, $103,247-260$.

138. B. Knobloch, A. Mucha, B. P. Operschall, H. Sigel, M. Jeżowska-Bojczuk, H. Kozlowski, R. K. O. Sigel, Chem. Eur. J. 2011, 17, 5393-5403.

139. O. Yamauchi, A. Odani, H. Masuda, H. Sigel, Met. Ions Biol. Syst. 1996, 32, 207-270.

140. N. A. Corfù, A. Sigel, B. P. Operschall, H. Sigel, J. Indian Chem. Soc. 2011, 88, 10931115. JICS issue to commemorate Sir Prafulla Chandra Ray.

141. B. Song, G. Feldmann, M. Bastian, B. Lippert, H. Sigel, Inorg. Chim. Acta 1995, 235, 99109.

142. A. Saha, N. Saha, L.-n. Ji, J. Zhao, F. Gregáň, S. A. A. Sajadi, B. Song, H. Sigel, J. Biol. Inorg. Chem. 1996, 1, 231-238.

143. G. Kampf, L. E. Kapinos, R. Griesser, B. Lippert, H. Sigel, J. Chem. Soc., Perkin Trans. 2, 2002, 1320-1327.

144. R. K. O. Sigel, E. Freisinger, B. Lippert, J. Biol. Inorg. Chem. 2000, 5, 287-299.

145. G. Liang, H. Sigel, Inorg. Chem. 1990, 29, 3631-3632.

146. E. M. Bianchi, R. Griesser, H. Sigel, Helv. Chim. Acta 2005, 88, 406-425.

147. B. P. Operschall, E. M. Bianchi, R. Griesser, H. Sigel, J. Coord. Chem. 2009, 62, 23-39.

148. (a) E. M. Bianchi, Comparison of the Stability and Solution Structures of Metal Ion Complexes Formed with 5'-Di- and 5'-Triphosphates of Purine Nucleotides (Ph. D. Thesis, University of Basel), Logos Verlag, Berlin, 2003, pp. 1-216. (b) H. Sigel, E. M. Bianchi, et al. details to be published.

149. K. H. Scheller, H. Sigel, J. Am. Chem. Soc. 1983, 105, 5891-5900.

150. H. Sigel, Coord. Chem. Rev. 1990, 100, 453-539. 
151. H. Sigel, M. C. F. Magalhães, J. Zhao, B. Song, results to be published.

152. W. Wirth, J. Blotevogel-Baltronat, U. Kleinkes, W. S. Sheldrick, Inorg. Chim. Acta 2002, $339,14-26$.

153. H. Sigel, Coord. Chem. Rev. 1995, 144, 287-319.

154. C. A. Blindauer, A. H. Emwas, A. Holý, H. Dvořáková, E. Sletten, H. Sigel, Chem. Eur. J. 1997, 3, 1526-1536.

155. C. Meiser, E. Freisinger, B. Lippert, J. Chem. Soc., Dalton Trans. 1998, 2059-2064.

156. M. A. Shipman, C. Price, A. E. Gibson, M. R. J. Elsegood, W. Clegg, A. Houlton, Chem. Eur. J. 2000, 6, 4371-4378.

157. C. Meiser, B. Song, E. Freisinger, M. Peilert, H. Sigel, B. Lippert, Chem. Eur. J. 1997, 3, $388-398$

158. G. Raudaschl-Sieber, H. Schöllhorn, U. Thewalt, B. Lippert, J. Am. Chem. Soc. 1985, 107, $3591-3595$.

159. E. Bugella-Altamirano, D. Choquesillo-Lazarte, J. M. González-Pérez, M. J. SánchezMoreno, R. Marín-Sanchez, J. D. Martín-Ramos, B. Covelo, R. Carballo, A. Castiñeiras, J. Niclós-Gutiérrez, Inorg. Chim. Acta 2002, 339, 160-170.

160. (a) A. Ciccarese, D. A. Clemente, A. Marzotto, M. Rosa, G. Valle, J. Inorg. Biochem. 1991, 43, 470. (b) A. Marzotto, D. A. Clemente, A. Ciccarese, G. Valle, J. Cryst. Spectroscop. Res. 1993, 23, 119-131.

161. E. Kulikowska, B. Kierdaszuk, D. Shugar, Acta Biochim. Polonica 2004, 51, 493-531.

162. H. Sigel, S. S. Massoud, B. Song, R. Griesser, B. Knobloch, B. P. Operschall, Chem. Eur. J. 2006, 12, 8106-8122.

163. H. Sigel, B. P. Operschall, S. S. Massoud, B. Song, R. Griesser, Dalton Trans. 2006, $5521-5529$.

164. M. J. Sánchez-Moreno, A. Fernández-Botello, R. B. Gómez-Coca, R. Griesser, J. Ochocki, A. Kotyński, J. Niclós-Gutiérrez, V. Moreno, H. Sigel, Inorg. Chem. 2004, 43, 1311-1322.

165. J. Swiatek-Kozlowska, J. Brasún, A. Dobosz, E. Sochacka, A. Glowacka, J. Inorg. Biochem. 2003, 93, 119-124.

166. H. Sigel, B. Song, G. Liang, R. Halbach, M. Felder, M. Bastian, Inorg. Chim. Acta 1995, 
$240,313-322$.

167. J. Bidwell, J. Thomas, J. Stuehr, J. Am. Chem. Soc. 1986, 108, 820-825.

168. M. Bastian, H. Sigel, Inorg. Chem. 1997, 36, 1619-1624.

169. M. Bastian, H. Sigel, Biophys. Chem. 1997, 67, 27-34.

170. R. K. O. Sigel, B. Song, H. Sigel, J. Am. Chem. Soc. 1997, 119, 744-755.

171. H. Sigel, Chimia, 1987, 41, 11-26.

172. D. D. Perrin, J. Am. Chem. Soc. 1960, 82, 5642-5645.

173. H. Sigel, H. Brintzinger, Helv. Chim. Acta 1964, 47, 1701-1717; see also H. Sigel, B. Prijs, Helv. Chim. Acta 1967, 50, 2357-2362.

174. H. Sigel, Met. Ions Biol. Syst. 1979, 8, 125-158.

175. K. H. Scheller, H. Sigel, J. Am. Chem. Soc. 1983, 105, 3005-3014.

176. C. A. Blindauer, A. Holý, H. Dvořáková, H. Sigel, J. Chem. Soc., Perkin Trans. 2 1997, $2353-2363$.

177. C. H. Schwalbe, W. Thomson, S. Freeman, J. Chem. Soc., Perkin Trans. 1 1991, 13481349.

178. H. Sigel, K. H. Scheller, Eur. J. Biochem. 1984, 138, 291-299.

179. H. Sigel, K. H. Scheller, V. Scheller-Krattiger, B. Prijs, J. Am. Chem. Soc. 1986, 108, 4171-4178.

180. V. Scheller-Krattiger, H. Sigel, Inorg. Chem. 1986, 25, 2628-2634.

181. L. Claus, S. Vortler, F. Eckstein, Methods Enzymol. 2000, 317, 74-91.

182. C. P. Da Costa, A. Okruszek, H. Sigel, ChemBioChem 2003, 4, 593-602.

183. B. Song, R. K. O. Sigel, H. Sigel, Chem. Eur. J. 1997, 3, 29-33.

184. M. Vašák, J. H. R. Kägi, Met. Ions Biol. Syst. 1983, 15, 213-273; cf. p. 261.

185.H. Sigel, Pure Appl. Chem. 1999, 71, 1727-1740.

186. H. Sigel, Chem. Soc. Rev. 2004, 33, 191-200.

187. E. De Clercq, A. Holý, Nature Rev. Drug Discovery 2005, 4, 928-940.

188. T. Tichý, G. Andrei, M. Dračínský, A. Holý, J. Balzarini, R. Snoeck, M. Krečmerová, Bioinorg. Med. Chem. 2011, 19, 3527-3539.

189. R. B. Gómez-Coca, C. A. Blindauer, A. Sigel, B. P. Operschall, H. Sigel, Chem. 
Biodiversity 2012, in press.

190. R. B. Gómez-Coca, L. E. Kapinos, A. Holý, R. A. Vilaplana, F. González-Vilchez, H. Sigel, J. Chem. Soc., Dalton Trans. 2000, 2077-2084.

191. R. B. Gómez-Coca, A. Holý, R. A. Vilaplana, F. González-Vilchez, H. Sigel, Bioinorg. Chem. Appl. 2004, 2, 331-352.

192. R. B. Gómez-Coca, L. E. Kapinos, A. Holý, R. A. Vilaplana, F. González-Vilchez, H. Sigel, J. Biol. Inorg. Chem. 2004, 9, 961-972.

193. A. Fernández-Botello, R. Griesser, A. Holý, V. Moreno, H. Sigel, Inorg. Chem. 2005, 44, $5104-5117$.

194. B. Song, G. Oswald, J. Zhao, B. Lippert, H. Sigel, Inorg. Chem. 1998, 37, 4857-4864.

195. B. Song, G. Oswald, M. Bastian, H. Sigel, B. Lippert, Metal-Based Drugs 1996, 3, 131141.

196. H. Sigel, B. Song, G. Oswald, B. Lippert, Chem. Eur. J. 1998, 4, 1053-1060.

197. G. Kampf, M. S. Lüth, L. E. Kapinos, J. Müller, A. Holý, B. Lippert, H. Sigel, Chem. Eur. J. 2001, 7, 1899-1908.

198. G. Kampf, M. S. Lüth, J. Müller, A. Holý, B. Lippert, H. Sigel, Z. Naturforsch. 2000, 55b, $1141-1152$.

199. H. Sigel, Angew. Chemie, Internat. Ed. Engl. 1975, 14, 394-402.

200. H. Sigel, in Coordination Chemistry-20, Ed D. Banerjea, published by IUPAC through Pergamon Press, Oxford and New York, 1980, pp. 27-45.

201. B. E. Fischer, H. Sigel, J. Am. Chem. Soc. 1980, 102, 2998-3008.

202. A. Fernández-Botello, A. Holý, V. Moreno, H. Sigel, J. Inorg. Biochem. 2004, 98, 2114 2124.

203. H. Sigel, B. E. Fischer, B. Prijs, J. Am. Chem. Soc. 1977, 99, 4489-4496.

204. H. Sigel, Inorg. Chem. 1980, 19, 1411-1413.

205. R. Malini-Balakrishnan, K. H. Scheller, U. K. Häring, R. Tribolet, H. Sigel, Inorg. Chem. 1985, 24, 2067-2076.

206. P. Champeil, T. Menguy, S. Soulié, B. Juul, A. Gomez de Gracia, F. Rusconi, P. Falson, L. Denoroy, F. Henao, M. le Maire, J. V. Møller, J. Biol. Chem. 1998, 273, 6619-6631. 
207. C. Montigny, P. Champeil, Analyt. Biochem. 2007, 366, 96-98.

208. P. Leverrier, C. Montigny, M. Garrigos, P. Champeil, Analyt. Biochem. 2007, 371, 215228.

209. P. E. Amsler, H. Sigel, Eur. J. Biochem. 1976, 63, 569-581.

210. D. H. Buisson, H. Sigel, Biochim. Biophys. Acta 1974, 343, 45-63.

211. H. Sigel, P. E. Amsler, J. Am. Chem. Soc. 1976, 98, 7390-7400.

212. B. E. Fischer, U. K. Häring, R. Tribolet, H. Sigel, Eur. J. Biochem. 1979, 94, 523-530.

213. K. H. Scheller, T. H. J. Abel, P. E. Polanyi, P. K. Wenk, B. E. Fischer, H. Sigel, Eur. J. Biochem. 1980, 107, 455-466.

214. N. A. Corfù, B. Song, L.-n. Ji, Inorg. Chim. Acta 1992, 192, 243-251.

215. H. Sigel, Coord. Chem. Rev. 1993, 122, 227-242.

216. N. E. Good, G. D. Winget, W. Winter, T. N. Connolly, S. Izawa, R. M. M. Singh, Biochemistry 1966, 5, 467-477.

217. C. F. Naumann, B. Prijs, H. Sigel, Eur. J. Biochem. 1974, 41, 209-216.

218. C. F. Naumann, H. Sigel, J. Am. Chem. Soc. 1974, 96, 2750-2756.

219. P. Chaudhuri, H. Sigel, J. Am. Chem. Soc. 1977, 99, 3142-3150.

220. P. R. Mitchell, H. Sigel, J. Am. Chem. Soc. 1978, 100, 1564-1570.

221. E. M. Bianchi, S. A. A. Sajadi, B. Song, H. Sigel, Inorg. Chim. Acta 2000, 300-302, 487498.

222. P. R. Mitchell, B. Prijs, H. Sigel, Helv. Chim. Acta 1979, 62, 1723-1735.

223. R. Tribolet, R. Malini-Balakrishnan, H. Sigel, J. Chem. Soc., Dalton Trans. 1985, 22912303.

224. K. Aoki, J. Am. Chem. Soc. 1978, 100, 7106-7108.

225. P. Orioli, R. Cini, D. Donati, S. Mangani, J. Am. Chem. Soc. 1981, 103, 4446-4452.

226. W. S. Sheldrick, Z. Naturforsch. 1982, 37b, 863-871.

227. H. Sigel, K. H. Scheller, R. M. Milburn, Inorg. Chem. 1984, 23, 1933-1938.

228. R. Tribolet, R. B. Martin, H. Sigel, Inorg. Chem. 1987, 26, 638-643.

229. H. Sigel, R. Tribolet, O. Yamauchi, Comments Inorg. Chem. 1990, 9, 305-330.

230. H. Sigel, B. E. Fischer, E. Farkas, Inorg. Chem. 1983, 22, 925-934. 
231. S. S. Massoud, H. Sigel, Inorg. Chim. Acta 1989, 159, 243-252.

232. S. S. Massoud, R. Tribolet, H. Sigel, Eur. J. Biochem. 1990, 187, 387-393.

233. C. F. Naumann, H. Sigel, FEBS Lett. 1974, 47, 122-124.

234. H. Sigel, C. F. Naumann, J. Am. Chem. Soc. 1976, 98, 730-739.

235. J.-J. Toulmé, Bioinorg. Chem. 1978, 8, 319-329.

236. R. Basosi, E. Gaggelli, E. Tiezzi, J. Chem. Res. (S') 1977, 278-279.

237. G. Arena, R. Calì, V. Cucinotta, S. Musumeci, E. Rizzarelli, S. Sammartano, J. Chem. Soc., Dalton Trans. 1984, 1651-1658.

238. H. Sigel, Chimia, 1967, 21, 489-500.

239. J. Zhao, B. Song, N. Saha, A. Saha, F. Gregáň, M. Bastian, H. Sigel, Inorg. Chim. Acta 1996, 250, 185-188.

240. B. E. Fischer, H. Sigel, Inorg. Chem. 1979, 18, 425-428.

241. B. Knobloch, H. Sigel, A. Okruszek, R. K. O. Sigel, Chem. Eur. J. 2007, 13, 1804-1814.

242. B. Knobloch, B. Nawrot, A. Okruszek, R. K. O. Sigel, Chem. Eur. J. 2008, 14, 3100-3109.

243. B. Knobloch, H. Sigel, A. Okruszek, R. K. O. Sigel, Organic Biomol. Chem. 2006, 4, 1085-1090.

244. B. Song, H. Sigel, Inorg. Chem. 1998, 37, 2066-2069.

245. A. Mucha, B. Knobloch, M. Jeżowska-Bojczuk, H. Kozłowski, R. K. O. Sigel, Chem. Eur. J. 2008, 14, 6663-6671.

246. (a) J. Kozelka, G. Barre, Chem. Eur. J. 1997, 3, 1405-1409. (b) T. Weber, F. Legendre, V. Novozamsky, J. Kozelka, Metal-Based Drugs 1999, 6, 5-16.

247. N. A. Corfù, H. Sigel, Eur. J. Biochem. 1991, 199, 659-669.

248. H. Sigel, Biol. Trace Elem. Res. 1989, 21, 49-59.

249. J. C. Chottard, J. P. Girault, G. Chottard, J. Y. Lallemand, D. Mansuy, J. Am. Chem. Soc. 1980, 102, 5565-5572.

250. J. C. Chottard, J. P. Girault, G. Chottard, J. Y. Lallemand, D. Mansuy, Nouv. J. Chim. 1978, 2, 551-553.

251. G. Bertin, D. Averbeck, Biochimie 2006, 88, 1549-1559.

252. V. L. Pecoraro, J. D. Hermes, W. W. Cleland, Biochemistry 1984, 23, 5262-5271. 
253. M. D. Erlacher, N. Polacek, Methods Mol. Biol. 2012, 848, 215-226.

254. S. Basu, M. J. Morris, C. Pazsint, Methods Mol. Biol. 2012, 848, 275-296.

255. O. Fedorova, A. M. Pyle, EMBO J. 2005, 24, 3906-3916.

256. P. M. Gordon, R. Fong, J. A. Piccirilli, Chem. Biol. 2007, 14, 607-612.

257. P. M. Gordon, J. A. Piccirilli, Nat. Struct. Biol. 2001, 8, 893-898.

258. P. M. Gordon, E. J. Sontheimer, J. A. Piccirilli, Biochemistry 2000, 39, 12939-12952.

259. S.-O. Shan, A. V. Kravchuk, J. A. Piccirilli, D. Herschlag, Biochemistry 2001, 40, 51615171

260. S.-O. Shan, A. Yoshida, S. Sun, J. A. Piccirilli, D. Herschlag, Proc. Natl. Acad. Sci. USA 1999, 96, 12299-12304.

261. M. Boudvillain, A. de Lencastre, A. M. Pyle, Nature 2000, 406, 315-318.

262. M. Boudvillain, A. M. Pyle, EMBO J. 1998, 17, 7091-7104.

263. M. Cohn, N. Shih, J. Nick, J. Biol. Chem. 1982, 257, 7646-7649.

264. P. M. Burgers, F. Eckstein, J. Biol. Chem. 1980, 255, 8229-8233.

265. J. M. Warnecke, J. P. Fürste, W. D. Hardt, V. A. Erdmann, R. K. Hartmann, Proc. Natl. Acad. Sci. USA 1996, 93, 8924-8928.

266. J. M. Warnecke, R. Held, S. Busch, R. K. Hartmann, J. Mol. Biol. 1999, 290, 433-445.

267. E. J. Sontheimer, P. M. Gordon, J. A. Piccirilli, Genes Dev. 1999, 13, 1729-1741.

268. S.-L. Yean, G. Wuenschell, J. Termini, R.-J. Lin, Nature 2000, 408, 881-884.

269. L. B. Weinstein, B. C. N. M. Jones, R. Cosstick, T. R. Cech, Nature 1997, 388, 805-808.

270. A. Yoshida, S. Sun, J. A. Piccirilli, Nature Struct. Mol. Biol. 1999, 6, 318-321.

271. E. C. Scott, O. C. Uhlenbeck, Nucleic Acids Res. 1999, 27, 479-484.

272. A. Peracchi, L. Beigelman, E. C. Scott, O. C. Uhlenbeck, D. Herschlag, J. Biol. Chem. 1997, 272, 26822-26826.

273. N. Kisseleva, A. Khvorova, E. Westhof, O. Schiemann, RNA 2005, 11, 1-6.

274. M. Maderia, L. M. Hunsicker, V. J. DeRose, Biochemistry 2000, 39, 12113-12120.

275. E. M. Osborne, W. L. Ward, M. Z. Ruehle, V. J. DeRose, Biochemistry 2009, 48, 1065410664.

276. K.-i. Suzumura, K. Yoshinari, Y. Tanaka, Y. Takagi, Y. Kasai, M. Warashina, T. 
Kuwabara, M. Orita, K. Taira, J. Am. Chem. Soc. 2002, 124, 8230-8236.

277. Y. Tanaka, C. Kojima, E. H. Morita, Y. Kasai, K. Yamasaki, A. Ono, M. Kainosho, K. Taira, J. Am. Chem. Soc. 2002, 124, 4595-4601.

278. J. B. Murray, A. A. Seyhan, N. G. Walter, J. M. Burke, W. G. Scott, Chem. Biol. 1998, 5, $587-595$.

279. H. Sigel, R. Tribolet, J. Inorg. Biochem. 1990, 40, 163-179.

280. H. Sigel, Inorg. Chim. Acta 1992, 198-200, 1-11.

281. A. Serganov, S. Keiper, L. Malinina, V. Tereshko, E. Skripkin, C. Höbartner, A. Polonskaia, A. T. Phan, R. Wombacher, R. Micura, Z. Dauter, A. Jäschke, D. J. Patel, Nature Struct. Mol. Biol. 2005, 12, 218-224.

282. J. B. Murray, H. Szöke, A. Szöke, W. G. Scott, Mol. Cell 2000, 5, 279-287.

283. P. A. Rice, S.-w. Yang, K. Mizuuchi, H. A. Nash, Cell 1996, 87, 1295-1306.

284. K. K. Swinger, P. A. Rice, J. Mol. Biol. 2007, 365, 1005-1016.

285. H. Pelletier, M. R. Sawaya, Biochemistry 1996, 35, 12778-12787.

286. R. Koradi, M. Billeter, K. Wüthrich, J. Mol. Graphics 1996, 14, 29-32, 51-55.

287. B. T. Wimberly, R. Guymon, J. P. McCutcheon, S. W. White, V. Ramakrishnan, Cell 1999, 97, 491-502.

288. N. Kisseleva, S. Kraut, A. Jäschke, O. Schiemann, HFSP J. 2007, 1, 127-136.

289. B. Knobloch, M. C. Erat, R. K. O. Sigel, to be submitted for publication.

290. J. Loebus, E. A. Peroza, N. Bluthgen, T. Fox, W. Meyer-Klaucke, O. Zerbe, E. Freisinger, J. Biol. Inorg. Chem. 2011, 16, 683-694.

291. E. A. Peroza, A. Al Kaabi, W. Meyer-Klaucke, G. Wellenreuther, E. Freisinger, J. Inorg. Biochem. 2009, 103, 342-353.

292. D. Donghi, M. Pechlaner, B. Knobloch, C. Finazzo, R. K. O. Sigel, 2012, submitted for publication. 
Table 1 Collection of some physicochemical properties of metal ions $\left(\mathrm{M}^{2+}\right)$, that is, preferred coordination numbers with the corresponding radii, preferred ligand atoms, $\mathrm{p} K_{\mathrm{a} / \mathrm{aq}}$ values of bound water molecules (eq. 1), and stability constants (eq. 2) of 1:1 complexes formed with acetate, $\mathrm{CH}_{3} \mathrm{COO}^{-}$ $\left(\mathrm{Ac}^{-}\right)$, and ammonia, $\mathrm{NH}_{3}$, together with apparent stability constants (eq. 4) of the $\mathrm{M}\left(\mathrm{NH}_{3}\right)^{2+}$ complexes at $\mathrm{pH}$ 7.5.

\begin{tabular}{|c|c|c|c|c|c|c|c|c|}
\hline \multirow[t]{2}{*}{ Metal ion } & \multicolumn{3}{|c|}{ Coordination number } & \multirow{2}{*}{$\begin{array}{c}\text { Preferred ligand } \\
\text { atoms }^{d}\end{array}$} & \multirow{2}{*}{$\mathrm{p} K_{\mathrm{a} / \mathrm{aq}}{ }^{e}$} & \multirow{2}{*}{$\log K_{\mathrm{M}(\mathrm{Ac})}^{\mathrm{M}}{ }^{f}$} & \multirow{2}{*}{$\log K_{\mathrm{M}\left(\mathrm{NH}_{3}\right)}^{\mathrm{M}}{ }^{i}$} & \multirow{2}{*}{$\log K_{\mathrm{M}\left(\mathrm{NH}_{3}\right) \mathrm{app}}^{\mathrm{M}}$} \\
\hline & $4^{a}$ & $6^{a}$ & $8^{a}$ & & & & & \\
\hline $\mathrm{Mg}^{2+}$ & 57 & 72 & 89 & $\mathrm{O}$ & 11.44 & $0.51 \pm 0.05$ & $0.24 \pm 0.01$ & -1.65 \\
\hline $\mathrm{Ca}^{2+}$ & & 100 & 112 & $\mathrm{O}$ & 12.85 & $0.55 \pm 0.05$ & $0.0 \pm 0.1$ & -1.89 \\
\hline $\mathrm{Fe}^{2+}$ & 63 & $78^{b}$ & 92 & $\mathrm{O}, \mathrm{N}$ & 9.5 & $0.83^{g}$ & $1.68 \pm 0.11$ & -0.21 \\
\hline $\mathrm{Co}^{2+}$ & 58 & 74 & 90 & $\mathrm{~N}, \mathrm{O}, \mathrm{S}$ & 9.65 & $0.86 \pm 0.05$ & $2.08 \pm 0.03$ & 0.19 \\
\hline $\mathrm{Cu}^{2+}$ & 57 & 73 & & $\mathrm{~N}, \mathrm{O}$ & 7.5 & $1.79 \pm 0.06$ & $4.18 \pm 0.03$ & 2.29 \\
\hline $\mathrm{Zn}^{2+}$ & 60 & $74^{c}$ & 90 & $\mathrm{~N}, \mathrm{O}, \mathrm{S}$ & 8.96 & $0.98 \pm 0.13^{h}$ & $2.41 \pm 0.09$ & 0.52 \\
\hline $\mathrm{Cd}^{2+}$ & 78 & 95 & 110 & $\mathrm{~S}, \mathrm{~N}, \mathrm{O}$ & 10.08 & $1.26 \pm 0.07^{h}$ & $2.67 \pm 0.03$ & 0.78 \\
\hline
\end{tabular}

${ }^{a}$ Effective ionic radii (pm); those with the more common coordination numbers are printed in italics. The values are taken from refs [15] and [20].

${ }^{b}$ High-spin value; the low-spin value is $61 \mathrm{pm} .{ }^{c} \mathrm{Zn}^{2+}$ has a chameleon-type coordination sphere; coordination number 4 (tetrahedral) is common as well [21]. $\quad{ }^{d}$ According to refs [15,22] and our own intuition. $\quad{ }^{e}$ From ref. [23] (see also [24]). ${ }^{f}$ From ref. [25]; 25 ${ }^{\circ} \mathrm{C} ; I=0.1 \mathrm{M} ; \mathrm{p} K_{\mathrm{H}(\mathrm{Ac})}^{\mathrm{H}}=$ $4.56 \pm 0.03$ [25]. $\quad{ }^{g}$ Estimated value [26]; we estimate the error limit as $\pm 0.06 \log$ unit. $\quad{ }^{h}$ For the $\mathrm{Zn}(\mathrm{Ac})^{+}$complex the listed stability constant (with an estimated error) is the average of those given for $I=0.1$ and $0.5 \mathrm{M}\left(25^{\circ} \mathrm{C}\right)$ in ref. [25]. The listed value for $\mathrm{Cd}(\mathrm{Ac})^{+}$refers to $I=0.5 \mathrm{M}$ $\left(25^{\circ} \mathrm{C}\right)[25] . \quad{ }^{i}$ The values for $\mathrm{M}\left(\mathrm{NH}_{3}\right)^{2+}$, where $\mathrm{M}^{2+}=\mathrm{Co}^{2+}, \mathrm{Cu}^{2+}, \mathrm{Zn}^{2+}$ or $\mathrm{Cd}^{2+}$, are from Table 1 in ref. [27]; $25^{\circ} \mathrm{C}, I=0.1 \mathrm{M} ; \mathrm{p} K_{\mathrm{H}\left(\mathrm{NH}_{3}\right)}^{\mathrm{H}}=9.38 \pm$ 0.01 [27]. The value for $\mathrm{Fe}\left(\mathrm{NH}_{3}\right)^{2+}$ is an estimate based on $\log K_{\mathrm{Mn}\left(\mathrm{NH}_{3}\right)}^{\mathrm{Mn}}=1.27 \pm 0.10$ [27] and $\log K_{\mathrm{Co}\left(\mathrm{NH}_{3}\right)}^{\mathrm{Co}}=2.08 \pm 0.03$. The values for $\mathrm{Mg}\left(\mathrm{NH}_{3}\right)^{2+}\left(I=2.0 \mathrm{M}, \mathrm{NH}_{4} \mathrm{NO}_{3}\right)$ and $\mathrm{Ca}\left(\mathrm{NH}_{3}\right)^{2+}\left(I=1.0 \mathrm{M}, \mathrm{NH}_{4} \mathrm{NO}_{3}\right)$ are from ref. [25]. ${ }^{j}$ The apparent stability constants valid for $\mathrm{pH}=7.5 \mathrm{were}$ calculated with eq. (4) and the stability constants listed in column 8 and the acidity constant given in footnote " $i$ ". 
Table 2 Comparison of the stability constants (eq. 2), the stability enhancements, $\log \Delta_{\mathrm{M} / \mathrm{L}}$, and the percentage of the chelated or closed (cl) species, $\% \mathrm{M}(\mathrm{L})_{\mathrm{cl}}$, for the $1: 1$ complexes formed by hydroxymethylphosphonate $\left(\mathrm{HMP}^{2-}\right)$, hydroxyacetate $\left(\mathrm{HOAc}^{-}\right)$or $o$-(hydroxymethyl)pyridine $\left(\mathrm{HOMPy}^{-}\right)$ and several metal ions in aqueous solution $\left(25^{\circ} \mathrm{C}\right)^{a, b}$

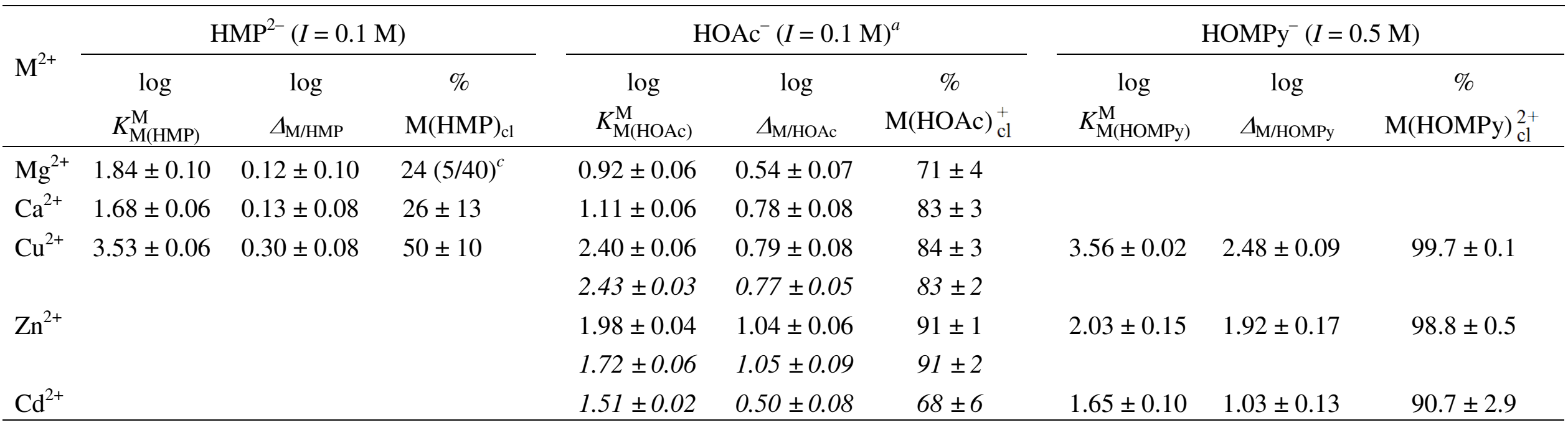

Solvent: Water containing $50 \%(\mathrm{v} / \mathrm{v}) 1,4$-dioxane $\left(25^{\circ} \mathrm{C} ; I=0.1 \mathrm{M}, \mathrm{NaClO}_{4}\right)^{d}$

\begin{tabular}{llll}
\hline $\mathrm{Cu}^{2+}$ & $3.96 \pm 0.06$ & $1.10 \pm 0.06$ & $92 \pm 1$ \\
$\mathrm{Zn}^{2+}$ & $3.26 \pm 0.06$ & $1.24 \pm 0.07$ & $94 \pm 1$ \\
\hline
\end{tabular}

${ }^{a}$ Note, the values printed in italics refer to an ionic strength $(I)$ of $2 \mathrm{M} .{ }^{b}$ All values are collected from various tables in ref. [57]. The acidity constants $\left(25^{\circ} \mathrm{C}\right)$ of the ligands are $\mathrm{p} K_{\mathrm{H}(\mathrm{HMP})}^{\mathrm{H}}=6.97, \mathrm{p} K_{\mathrm{H}(\mathrm{HOAc})}^{\mathrm{H}}=3.62 \pm 0.03(I=0.1 \mathrm{M})$ and $3.74 \pm 0.03(I=2 \mathrm{M})$, and $\mathrm{p} K_{\mathrm{H}(\mathrm{HOMPy})}^{\mathrm{H}}=4.95[57]$.

${ }^{c}$ The values in parenthesis are the lower and upper limits of $\% \mathrm{Mg}(\mathrm{HMP})_{\mathrm{cl}}$, respectively. $\quad{ }^{d}$ Abstracted from Table 14 in ref. [57]; $K_{\mathrm{H}(\mathrm{HOAc})}^{\mathrm{H}}=4.88$ \pm 0.03 . 
Table 3 Negative logarithms of the acidity constants (eq. 3) of some monoprotonated purine nucleobase (NB) derivatives and logarithms of the stability constants (eq. 2) of the corresponding $\mathrm{Cd}(\mathrm{NB})^{2+}$ and $\mathrm{Cd}(\mathrm{NB}-\mathrm{H})^{+}$complexes as determined by potentiometric $\mathrm{pH}$ titration in aqueous solution at $25^{\circ} \mathrm{C}$ and $I=0.5 \mathrm{M}$ (entries $\left.1-7\right)$ or $0.1 \mathrm{M}$ (entries $\left.8-10\right)\left(\mathrm{NaNO}_{3}\right)$, together with data for 1-methylimidazole $(1 \mathrm{MIm})$ or pyridine (Py) derivatives (see Figure 5$)^{a}$

\begin{tabular}{clccccc}
\hline \multirow{2}{*}{} & \multirow{2}{*}{$\mathrm{H}(\mathrm{NB})^{+}$} & \multicolumn{2}{c}{$\mathrm{p} K_{\mathrm{a}}$ for } & $\log K_{\mathrm{Cd}(\mathrm{NB})}^{\mathrm{Cd}}$ & $\log K_{\mathrm{Cd}(\mathrm{NB}-\mathrm{H})}^{\mathrm{Cd}}$ & Ref. \\
\cline { 3 - 5 } & & $(\mathrm{N} 7) \mathrm{H}^{+}$ & $(\mathrm{N} 1) \mathrm{H}^{+/ 0}$ & & {$[70]$} \\
\hline $1^{b}$ & $\mathrm{H}(1 \mathrm{MIm})^{+}$ & $7.20 \pm 0.02$ & & $2.76 \pm 0.01$ & {$[60]$} \\
$2^{b}$ & $\mathrm{H}(1 \mathrm{MBI})^{+}$ & $5.67 \pm 0.01$ & & $2.10 \pm 0.06$ & {$[71]$} \\
$3^{b}$ & $\mathrm{H}(\mathrm{DMBI})^{+}$ & $5.78 \pm 0.02$ & & $0.72 \pm 0.06$ & \\
& & & & & {$[59]$} \\
$4^{c}$ & $\mathrm{H}(\mathrm{Py})^{+}$ & & $5.34 \pm 0.02$ & $1.51 \pm 0.05$ & & {$[59]$} \\
$5^{c}$ & $\mathrm{H}(2 \mathrm{MPy})^{+}$ & & $6.14 \pm 0.02$ & $0.68 \pm 0.03$ & & {$[59,72]$} \\
$6^{c}$ & $\mathrm{H}(\mathrm{Tu})^{+}$ & & $5.27 \pm 0.02$ & $0.71 \pm 0.07$ & & {$[32,73]$} \\
& & & & & & {$[74,75]$} \\
$7^{c}$ & $\mathrm{H}(\mathrm{Ado})^{+}$ & $(2.15 \pm 0.15)^{d}$ & $3.64 \pm 0.02$ & $0.64 \pm 0.03$ & & {$[74]$} \\
8 & $\mathrm{H}(\mathrm{Ino})^{+}$ & $1.06 \pm 0.06$ & $8.76 \pm 0.03^{e}$ & $0.85 \pm 0.2^{f}$ & $2.6 \pm 0.25^{f}$ & \\
9 & $\mathrm{H}(\mathrm{Guo})^{+}$ & $2.11 \pm 0.04$ & $9.22 \pm 0.02^{e}$ & & & {$[38]$} \\
10 & $\mathrm{H}(\mathrm{dGuo})^{+}$ & $2.34 \pm 0.03$ & $9.25 \pm 0.02^{e}$ & $1.53 \pm 0.07$ & $3.15 \pm 0.03$ & \\
\hline
\end{tabular}

${ }^{a}$ The errors given are three times the standard error of the mean value or the sum of the probable systematic errors, whichever is larger. ${ }^{b} \mathrm{In} \mathrm{H}(1 \mathrm{MIm})^{+}, \mathrm{H}(1 \mathrm{MBI})^{+}$, and $\mathrm{H}(\mathrm{DMBI})^{+}$the proton is at N3. ${ }^{c}$ The proton is released from the positively charged $(\mathrm{N} 1) \mathrm{H}^{+}$site. ${ }^{d}$ Micro acidity constant, P $k_{\mathrm{HgN7} \text {-N1 }}^{\mathrm{N} \text {, }}$, for the $(\mathrm{N} 7) \mathrm{H}^{+}$site of Ado under conditions where $\mathrm{N} 1$ does not carry a proton [32]. ${ }^{e}$ The proton is released from the neutral $(\mathrm{N} 1) \mathrm{H}$ site (see Figure 1). ${ }^{f}$ Estimated values (I ca. $\left.0.5-1 \mathrm{M}\right)$ [75]. 
Table 4 Extent of the (N1)H acidification by (N7)-coordinated $\mathrm{Cd}^{2+}$ at inosine (Ino) and 2'deoxyguanosine (dGuo) as defined by equation (12). The corresponding data of the $\mathrm{Ni}^{2+}$ complexes including those for 9-ethylguanine (9EtG) are given for comparison (aqueous solution; $\left.25^{\circ} \mathrm{C} ; I=0.1 \mathrm{M}, \mathrm{NaNO}_{3}\right)^{a}$

\begin{tabular}{lrcccc}
\hline $\mathrm{M}(\mathrm{NB})^{2+}$ & $\begin{array}{r}\mathrm{p} K_{\mathrm{NB}}^{\mathrm{H}} \\
\text { (eq. 7) }\end{array}$ & $\begin{array}{c}\log K_{\mathrm{M}(\mathrm{NB})}^{\mathrm{M}} \\
\text { (eq. 2) }\end{array}$ & $\begin{array}{c}\log K_{\mathrm{M}(\mathrm{NB}-\mathrm{H})}^{\mathrm{M}} \\
(\text { eq. 8) }\end{array}$ & $\begin{array}{c}\mathrm{p} K_{\mathrm{M}(\mathrm{NB})}^{\mathrm{H}} \\
(\text { eqs 9, 11) }\end{array}$ & $\begin{array}{c}\Delta \mathrm{p} K_{\mathrm{a}} \\
\text { (eq. 12) }\end{array}$ \\
\hline $\mathrm{Cd}(\mathrm{Ino})^{2+}$ & $8.76 \pm 0.03$ & $0.85 \pm 0.2$ & $2.6 \pm 0.25$ & $7.01 \pm 0.32^{b}$ & $1.75 \pm 0.32$ \\
$\mathrm{Cd}(\mathrm{dGuo})^{2+}$ & $9.25 \pm 0.02$ & $1.53 \pm 0.07$ & $3.15 \pm 0.03$ & $7.63 \pm 0.08^{b}$ & $1.62 \pm 0.08$ \\
& & & & & \\
$\mathrm{Ni}(\mathrm{Ino})^{2+}$ & $8.76 \pm 0.03$ & $1.15 \pm 0.13$ & $2.8 \pm 0.2$ & $7.11 \pm 0.24^{c}$ & $1.65 \pm 0.24$ \\
$\mathrm{Ni}(\mathrm{dGuo})^{2+}$ & $9.24 \pm 0.03$ & $1.53 \pm 0.09$ & $3.20 \pm 0.18$ & $7.57 \pm 0.20^{c}$ & $1.67 \pm 0.21$ \\
$\mathrm{Ni}(9 \mathrm{EtG})^{2+}$ & $9.57 \pm 0.05$ & $1.76 \pm 0.10$ & $3.48 \pm 0.13$ & $7.85 \pm 0.17^{c}$ & $1.72 \pm 0.18$ \\
\hline
\end{tabular}

${ }^{a}$ For the error limits see footnotes " $a$ " of Table 3; the error limits of the derived data were calculated according to the error propagation after Gauss. $\quad{ }^{b}$ Values for $\mathrm{p} K_{\mathrm{Cd}(\mathrm{NB})}^{\mathrm{H}}$ were calculated according to equation (11b) with the values listed above in columns $2-4$ and which are taken from Table 3. ${ }^{c}$ The entries for the $\mathrm{Ni}^{2+}$ complexes are taken from Table 2 in ref. [40] (see also [80]). 
Table 5 Comparison of the measured stability constants, $K_{\mathrm{M}(\mathrm{Cyd})}^{\mathrm{M}}($ eqs 2,18$)$, of the $\mathrm{M}(\mathrm{Cyd})^{2+}$ complexes with the stability constants, $K_{\mathrm{M}(\mathrm{Cyd}) \text { op }}^{\mathrm{M}}\left(=K_{\mathrm{M}(o \mathrm{PyN})}^{\mathrm{M}}\right.$; eq. 19), of the corresponding isomers with a sole $\mathrm{N} 3$ coordination of $\mathrm{M}^{2+}$, and extent of the total chelate formation according to equilibrium (13) in the $\mathrm{M}(\mathrm{Cyd})^{2+}$ complexes in aqueous solution at $25^{\circ} \mathrm{C}$ and $I=0.5 \mathrm{M}$ $\left(\mathrm{NaNO}_{3}\right)$ as expressed by $K_{\mathrm{I}}$ (eqs 16,17$)$ and the percentages of $\mathrm{M}(\mathrm{Cyd})_{\mathrm{cl}}^{2+}(\text { eq. } 20)^{a}$

\begin{tabular}{lcccll}
\hline $\mathrm{M}^{2+}$ & $\log K_{\mathrm{M}(\mathrm{Cyd})}^{\mathrm{M}}$ & $\log K_{\mathrm{M}(\mathrm{Cyd}) \mathrm{op}}^{\mathrm{M}}$ & $\log \Delta_{\mathrm{M} / \mathrm{Cyd}}$ & \multicolumn{1}{l}{$K_{I}$} & $\% \mathrm{M}(\mathrm{Cyd})_{\mathrm{cl}}^{2+}$ \\
\hline $\mathrm{Mg}^{2+}$ & $0.12 \pm 0.04$ & $-0.06 \pm 0.06$ & $0.18 \pm 0.07$ & $0.51 \pm 0.25$ & $34 \pm 11$ \\
$\mathrm{Ca}^{2+}$ & $0.18 \pm 0.06$ & $-0.13 \pm 0.13$ & $0.31 \pm 0.14$ & $1.04 \pm 0.67$ & $51 \pm 16$ \\
$\mathrm{Co}^{2+}$ & $0.03 \pm 0.08$ & $0.03 \pm 0.08$ & $0.00 \pm 0.11$ & $0.00 \pm 0.26$ & $\sim 0$ \\
$\mathrm{Cu}^{2+}$ & $1.56 \pm 0.06$ & $0.79 \pm 0.07$ & $0.77 \pm 0.09$ & $4.89 \pm 1.25$ & $83 \pm 4$ \\
$\mathrm{Zn}^{2+}$ & $0.20 \pm 0.11$ & $0.04 \pm 0.08$ & $0.16 \pm 0.14$ & $0.45(0.05 / 1.00)^{b}$ & $31(5 / 50)^{b}$ \\
$\mathrm{Cd}^{2+}$ & $0.91 \pm 0.07$ & $0.53 \pm 0.09$ & $0.38 \pm 0.11$ & $1.40 \pm 0.63$ & $58 \pm 11$ \\
\hline
\end{tabular}

${ }^{a}$ For the error limits see footnotes " $a$ " of Tables 3 and 4 . The values of column 2 are from ref. [83], all the other values were calculated as described in the text based on the straight-line parameters (eq. 15) listed in ref. [59] and $\mathrm{p} K_{\mathrm{H}(\mathrm{Cyd})}^{\mathrm{H}}=\mathrm{p} K_{\mathrm{H}(o \mathrm{PyN})}^{\mathrm{H}}=4.24 \pm 0.02$ [83] (for details see [35]. $\quad{ }^{b}$ The values in parentheses correspond to the lower and upper limits. 
Table 6 Negative logarithms of the acidity constants (eq. 3) of uridine (Figure 1) and its thio derivatives (U) shown in Figure 8, together with the stability constant comparisons (log $\Delta$; eq. 14) for several $\mathrm{M}(\mathrm{U}-\mathrm{H})^{-}$complexes between the measured stability constants (eq. 2) and those calculated based on $\mathrm{p} K_{\mathrm{U}}^{\mathrm{H}}$, equation (15) and the corresponding straight-line parameters given in ref. $[88]^{a}$

\begin{tabular}{rrrrlll}
\hline No. & $\mathrm{U}$ & $\mathrm{p} K_{\mathrm{U}}^{\mathrm{H}}$ & $\mathrm{M}^{2+}$ & $\log K_{\mathrm{M}(\mathrm{U}-\mathrm{H})}^{\mathrm{M}}$ & $\log K_{\mathrm{M}(\mathrm{U}-\mathrm{H}) \text { calc }}^{\mathrm{M}}$ & $\log \square \Delta$ \\
\hline $1 \mathrm{a}$ & $\mathrm{Urd}$ & $9.18 \pm 0.02$ & $\mathrm{Cu}^{2+}$ & $4.13 \pm 0.20$ & $4.13 \pm 0.21$ & 0 \\
$\mathrm{~b}$ & & & $\mathrm{Cd}^{2+}$ & $3.16 \pm 0.04$ & $3.21 \pm 0.05$ & $-0.05 \pm 0.06$ \\
& & & & & & \\
$2 \mathrm{a}$ & $\mathrm{U} 2 \mathrm{~S}$ & $8.05 \pm 0.04$ & $\mathrm{Cu}^{2+}$ & $5.91 \pm 0.06$ & $3.62 \pm 0.21$ & $2.29 \pm 0.22$ \\
$\mathrm{~b}$ & & & $\mathrm{Cd}^{2+}$ & $4.11 \pm 0.03$ & $2.77 \pm 0.05$ & $1.34 \pm 0.06$ \\
$3 \mathrm{~b}$ & $\mathrm{U} 4 \mathrm{~S}$ & $8.01 \pm 0.01$ & $\mathrm{Cd}^{2+}$ & $4.34 \pm 0.01$ & $2.75 \pm 0.05$ & $1.59 \pm 0.05$ \\
\hline
\end{tabular}

${ }^{a}$ The above data are abstracted from Table 1 in ref. [105]. The values in entries 1 are from ref. [88] $\left(25^{\circ} \mathrm{C} ; I=0.1 \mathrm{M}, \mathrm{NaNO}_{3}\right)(3 \sigma)$. The stability constant for $\mathrm{Cu}(\mathrm{Urd}-\mathrm{H})^{+}$(entry 1a) is calculated from the $\log K_{\mathrm{Cu}(\mathrm{U}-\mathrm{H})}^{\mathrm{Cu}}$ versus $\mathrm{p} K_{\mathrm{U}}^{\mathrm{H}}$ plot [88]; this result agrees well with constants found in the literature (for details see [83]). Entry 2a is from ref. [102] and the values of entries $2 \mathrm{~b}$ and $3 \mathrm{~b}$ are from ref. [103] $\left(25^{\circ} \mathrm{C} ; I=0.2 \mathrm{M}, \mathrm{KCl}\right)(1 \sigma)$. The error limits listed above $(\sigma=$ standard deviation) are those given in the various studies. The error limits of the derived data, in the present case for $\log \Delta$, were calculated according to the error propagation after Gauss. 
Table 7 Comparison of the stability constants (eq. 2) of $\mathrm{M}^{2+}$ complexes formed with acetate $\left(\mathrm{Ac}^{-}\right)$, as a simple mimic of the phosphodiester bridge (Figure 9), mono- $\left(\mathrm{R}^{-} \mathrm{MP}^{2-}\right)$, di- $\left(\mathrm{R}^{-} \mathrm{DP}^{3-}\right)$, and triphosphate monoesters $\left(\mathrm{R}^{-\mathrm{TP}^{4-}}\right)$ in aqueous solution at $25^{\circ} \mathrm{C}$ and $I=0.1 \mathrm{M}\left(\mathrm{NaNO}_{3}\right)$, together with the corresponding stability differences as they follow from the data listed in neighboring columns ${ }^{a, b, c}$

\begin{tabular}{|c|c|c|c|c|}
\hline \multirow{2}{*}{$\mathrm{M}^{2+}$} & \multicolumn{4}{|c|}{$\log K_{\mathrm{M}(\mathrm{L})}^{\mathrm{M}}($ eq. 2$)$ for $\mathrm{L}=$} \\
\hline & $\mathrm{Ac}^{-}$ & $\mathrm{R}-\mathrm{MP}^{2-}$ & $\mathrm{R}-\mathrm{DP}^{3-}$ & $\mathrm{R}-\mathrm{TP}^{4-}$ \\
\hline $\mathrm{H}^{+}$ & $(4.56 \pm 0.03)^{d, e}$ & $6.20^{d}$ & $6.40^{d}$ & $6.50^{d}$ \\
\hline $\mathrm{Mg}^{2+}$ & $0.51 \pm 0.05$ & $1.56 \pm 0.03$ & $3.30 \pm 0.03$ & $4.21 \pm 0.04$ \\
\hline $\mathrm{Ca}^{2+}$ & $0.55 \pm 0.05$ & $1.45 \pm 0.05$ & $2.91 \pm 0.03$ & $3.84 \pm 0.05$ \\
\hline $\mathrm{Fe}^{2+}$ & $0.83 \pm 0.06$ & $2.05 \pm 0.10^{f}$ & $3.92 \pm 0.10^{f}$ & $4.85 \pm 0.10^{f}$ \\
\hline $\mathrm{Co}^{2+}$ & $0.86 \pm 0.05$ & $1.94 \pm 0.06$ & $3.72 \pm 0.05$ & $4.76 \pm 0.03$ \\
\hline $\mathrm{Cu}^{2+}$ & $1.46 \pm 0.13^{b}$ & $2.87 \pm 0.06$ & $5.27 \pm 0.04$ & $5.86 \pm 0.03$ \\
\hline $\mathrm{Zn}^{2+}$ & $0.98 \pm 0.13$ & $2.12 \pm 0.06$ & $4.12 \pm 0.03$ & $5.02 \pm 0.02$ \\
\hline $\mathrm{Cd}^{2+}$ & $1.26 \pm 0.07$ & $2.44 \pm 0.05$ & $4.27 \pm 0.03$ & $5.07 \pm 0.03$ \\
\hline $\mathrm{sM}^{2+}$ & $\log \Delta_{\mathrm{r}}$ & & R-DP/R-MP & R-DP \\
\hline $\mathrm{Mg}^{2+}$ & 1.05 & & \pm 0.04 & $=0.05$ \\
\hline $\mathrm{Ca}^{2+}$ & 0.90 & & \pm 0.06 & $=0.06$ \\
\hline $\mathrm{Fe}^{2+}$ & 1.22 & & \pm 0.14 & $=0.14$ \\
\hline $\mathrm{Co}^{2+}$ & 1.08 & & \pm 0.08 & $=0.06$ \\
\hline $\mathrm{Cu}^{2+}$ & 1.41 & & \pm 0.07 & $=0.05$ \\
\hline $\mathrm{Zn}^{2+}$ & 1.14 & & \pm 0.07 & $=0.04$ \\
\hline $\mathrm{Cd}^{2+}$ & 1.18 & & \pm 0.06 & $=0.04$ \\
\hline
\end{tabular}

${ }^{a}$ For the error limits see footnotes " $a$ " of Tables 3 and $4 .{ }^{b}$ The constants for the M(Ac) ${ }^{+}$ complexes are from column 7 of Table 1, with the exception of the value for the $\mathrm{Cu}^{2+}$ complex which corresponds to the $\mathrm{Cu}$ (chloroacetate) ${ }^{+}$complex because $\mathrm{p} K_{\mathrm{H}(\mathrm{ClAc})}^{\mathrm{H}}=2.7$ [25] is closer to $\mathrm{p} K_{\mathrm{H}\left[(\mathrm{RO})_{2} \mathrm{P}(\mathrm{O})(\mathrm{OH})\right)}^{\mathrm{H}}=$ ca $1[33,121]$. The basicity effect in the other instances is small. ${ }^{e}$ ${ }^{c}$ The values for the $\mathrm{M}(\mathrm{R}-\mathrm{MP})$ complexes (column 3 ) were calculated with $\mathrm{p} K_{\mathrm{H}(\mathrm{R}-\mathrm{MP})}^{\mathrm{H}}=6.20$ $[114,115]$ and the straight-line equations given in refs $[50,52,74,122]$. The values for the $M(R-$ DP $)^{-}$complexes (column 4, including the acidity constant) are from Table 7 in Ref. [115], and for the values of the $\mathrm{M}(\mathrm{R}-\mathrm{TP})^{2-}$ species it holds: Those for the alkaline earth ion complexes are from Table 2 in ref. [119] and all the others from Table IV of ref. [116] (see also [117]).

${ }^{d}$ These values are the acidity constants of the monoprotonated ligands and refer to $\mathrm{p} K_{\mathrm{H}(\mathrm{L})}^{\mathrm{H}}$ (eq. 3). ${ }^{e}$ The $\mathrm{p} K_{\mathrm{a}}$ value of $(\mathrm{RO})_{2} \mathrm{P}(\mathrm{O})(\mathrm{OH})$ is ca. 1 ; despite the $\mathrm{p} K_{\mathrm{a}}$ difference acetate mimics the complex stabilities of the $\mathrm{M}\left[(\mathrm{RO})_{2}\left(\mathrm{PO}_{2}\right]^{+}\right.$species relatively well [58] (see also text). ${ }^{f}$ The values for the $\mathrm{Fe}^{2+}$ complexes are estimates as are the error limits; they are taken from the terminating paragraph of ref. [115]. 
Table 8 Acidity constants of protonated pyrimidine-NMPs (analogous to eqs 3,7 ) and stability constants of their $\mathrm{Cd}(\mathrm{NMP})$ complexes (eq. 2). The corresponding data are also given for

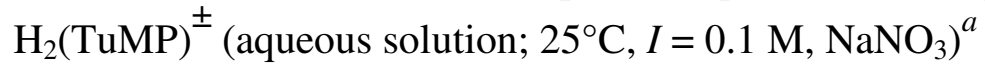

\begin{tabular}{|c|c|c|c|c|c|}
\hline Acid & $\mathrm{p} K_{\mathrm{H}_{2}(\mathrm{NMP})}^{\mathrm{H}}$ & $\mathrm{p} K_{\mathrm{H}(\mathrm{NMP})}^{\mathrm{H}}$ & $\mathrm{p} K_{\mathrm{NMP}}^{\mathrm{H}}$ & $\log K_{\mathrm{Cd}(\mathrm{NMP})}^{\mathrm{Cd}}$ & Ref. \\
\hline $\mathrm{H}_{2}(\mathrm{CMP})^{ \pm}$ & $4.33 \pm 0.04^{b}$ & $6.19 \pm 0.02$ & & $2.40 \pm 0.08$ & {$[114]^{c}$} \\
\hline $\mathrm{H}(\mathrm{UMP})^{-}$ & & $6.15 \pm 0.01$ & $9.45 \pm 0.02^{d}$ & $2.38 \pm 0.04$ & [114] \\
\hline $\mathrm{H}(\mathrm{dTMP})^{-}$ & & $6.36 \pm 0.01$ & $9.90 \pm 0.03^{d}$ & $2.42 \pm 0.03$ & {$[114]$} \\
\hline $\mathrm{H}_{2}(\mathrm{TuMP})^{ \pm}$ & $5.28 \pm 0.02^{e}$ & $6.32 \pm 0.01$ & & $2.42 \pm 0.07$ & [136] \\
\hline
\end{tabular}

${ }^{a}$ For the error limits see footnotes " $a$ " of Tables 3 and $4 .{ }^{b}$ This proton is released from the $(\mathrm{N} 3) \mathrm{H}^{+}$site (see Figure 10). ${ }^{c}$ See also ref. [141]. ${ }^{d}$ The proton is released from the (N3)H site (see Figure 1). $\quad{ }^{e}$ This proton is released from the $(\mathrm{N} 1) \mathrm{H}^{+}$site of the 7-deaza-purine residue (see Figures 1 and 5). 
Table 9 Logarithms of the stability constants of several M(NMP) complexes as determined by potentiometric $\mathrm{pH}$ titration, together with the calculated stability constants of the 'open' forms, as well as with the enhanced complex stabilities, $\log \Delta_{\mathrm{M} / \mathrm{NMP}}$ (eq. 14), and the extent of intramolecular macrochelate formation according to equilibrium (22) for aqueous solutions at $25^{\circ} \mathrm{C}$ and $I=0.1 \mathrm{M}\left(\mathrm{NaNO}_{3}\right)^{a, b}$

\begin{tabular}{|c|c|c|c|c|c|}
\hline $\mathrm{M}(\mathrm{NMP})$ & $\begin{array}{c}\log K_{\mathrm{M}(\mathrm{NMP})}^{\mathrm{M}} \\
(\text { eqs } 2,18)\end{array}$ & $\begin{array}{c}\log K_{\mathrm{M}(\mathrm{NMP}) \mathrm{op}}^{\mathrm{M}} \\
(\text { eq. 19) }\end{array}$ & $\begin{array}{c}\log \Delta_{\mathrm{M} / \mathrm{NMP}} \\
\text { (eq. } 14 \text { ) }\end{array}$ & $\begin{array}{c}K_{\mathrm{I}} \\
(\text { eqs } 16,17)\end{array}$ & $\begin{array}{c}\% \mathrm{M}(\mathrm{NMP})_{\mathrm{cl}} \\
(\text { eqs } 20,22)\end{array}$ \\
\hline $\mathrm{Mg}(\mathrm{AMP})$ & $1.62 \pm 0.04$ & $1.56 \pm 0.03$ & $0.06 \pm 0.05$ & $0.15 \pm 0.13$ & $13 \pm 10$ \\
\hline $\mathrm{Ca}(\mathrm{AMP})$ & $1.48 \pm 0.03$ & $1.45 \pm 0.05$ & $0.03 \pm 0.06$ & $0.07 \pm 0.14$ & $7 \pm 13$ \\
\hline $\mathrm{Co}(\mathrm{AMP})$ & $2.30 \pm 0.04$ & $1.94 \pm 0.06$ & $0.36 \pm 0.07$ & $1.29 \pm 0.38$ & $56 \pm 7$ \\
\hline $\mathrm{Zn}(\mathrm{AMP})$ & $2.38 \pm 0.07$ & $2.13 \pm 0.06$ & $0.25 \pm 0.09$ & $0.78 \pm 0.38$ & $44 \pm 12$ \\
\hline $\mathrm{Cd}(\mathrm{AMP})$ & $2.74 \pm 0.05$ & $2.44 \pm 0.05$ & $0.30 \pm 0.07$ & $1.00 \pm 0.32$ & $50 \pm 8$ \\
\hline $\operatorname{Mg}(\mathrm{IMP})$ & $1.68 \pm 0.05$ & $1.57 \pm 0.03$ & $0.11 \pm 0.06$ & $0.29 \pm 0.17$ & $22 \pm 10$ \\
\hline $\mathrm{Ca}(\mathrm{IMP})$ & $1.51 \pm 0.03$ & $1.45 \pm 0.05$ & $0.06 \pm 0.06$ & $0.15 \pm 0.15$ & $13 \pm 12$ \\
\hline $\mathrm{Co}(\mathrm{IMP})$ & $2.74 \pm 0.03$ & $1.94 \pm 0.06$ & $0.80 \pm 0.07$ & $5.31 \pm 0.97$ & $84 \pm 2$ \\
\hline $\mathrm{Zn}(\mathrm{IMP})$ & $2.59 \pm 0.04$ & $2.13 \pm 0.06$ & $0.46 \pm 0.07$ & $1.88 \pm 0.48$ & $65 \pm 6$ \\
\hline $\mathrm{Cd}(\mathrm{IMP})$ & $3.02 \pm 0.05$ & $2.45 \pm 0.05$ & $0.57 \pm 0.07$ & $2.72 \pm 0.60$ & $73 \pm 4$ \\
\hline $\mathrm{Mg}(\mathrm{GMP})$ & $1.73 \pm 0.03$ & $1.57 \pm 0.03$ & $0.16 \pm 0.04$ & $0.45 \pm 0.14$ & $31 \pm 7$ \\
\hline $\mathrm{Ca}(\mathrm{GMP})$ & $1.57 \pm 0.03$ & $1.45 \pm 0.05$ & $0.12 \pm 0.06$ & $0.32 \pm 0.18$ & $24 \pm 10$ \\
\hline $\mathrm{Co}(\mathrm{GMP})$ & $2.99 \pm 0.04$ & $1.95 \pm 0.06$ & $1.04 \pm 0.07$ & $9.96 \pm 1.82$ & $91 \pm 2$ \\
\hline $\mathrm{Zn}(\mathrm{GMP})$ & $2.83 \pm 0.03$ & $2.14 \pm 0.06$ & $0.69 \pm 0.07$ & $3.90 \pm 0.76$ & $80 \pm 3$ \\
\hline $\mathrm{Cd}(\mathrm{GMP})$ & $3.25 \pm 0.03$ & $2.46 \pm 0.05$ & $0.79 \pm 0.06$ & $5.17 \pm 0.83$ & $84 \pm 2$ \\
\hline
\end{tabular}

${ }^{a}$ For the error limits see footnotes " $a$ " of Tables 3 and 4. The values for AMP are from ref. [130], those for IMP and GMP from ref. [50]. ${ }^{b}$ The acidity constants are for $\mathrm{H}_{2}$ (AMP) ${ }^{ \pm}$ $\mathrm{p}_{\mathrm{H}_{2} \text { (AMP) }}^{\mathrm{H}}=3.84 \pm 0.02$ (eq. 23) $\left[(\mathrm{N} 1) \mathrm{H}^{+}\right.$site $]$and $\mathrm{p} K_{\mathrm{H}(\mathrm{AMP})}^{\mathrm{H}}=6.21 \pm 0.01$ (eq. 3), for $\mathrm{H}_{2}(\mathrm{IMP})^{ \pm} \mathrm{p} K_{\mathrm{H}_{2} \text { (IMP) }}^{\mathrm{H}}=1.30 \pm 0.10$ (eq. 23) [mainly (N7) $\mathrm{H}^{+}$; see Figure 2 in ref. [74] for the micro acidity constants], $K_{\mathrm{H}(\mathrm{IMP})}^{\mathrm{H}}=6.22 \pm 0.01$ (eq. 3) and $\mathrm{p} K_{\mathrm{IMP}}^{\mathrm{H}}=9.02 \pm 0.02$ (eq. 7), and for $\mathrm{H}_{2}(\mathrm{GMP})^{ \pm} \mathrm{p}_{\mathrm{H}_{2}(\mathrm{GMP})}^{\mathrm{H}}=2.48 \pm 0.04$ (eq. 23) [(N7) $\mathrm{H}^{+}$site $], \mathrm{p} K_{\mathrm{H}(\mathrm{GMP})}^{\mathrm{H}}=6.25 \pm 0.02$ (eq. 3) and $\mathrm{p} K_{\mathrm{GMP}}^{\mathrm{H}}=9.49 \pm 0.02$ (eq. 7) [74]. $\quad{ }^{c}$ The values in this column were calculated with $\mathrm{p} K_{\mathrm{H}(\mathrm{NMP})}^{\mathrm{H}}$ and eq. (15) by using the straight-line parameters listed in refs $[50,52,122]$. 
Table 10 Comparison of the measured stability constants, $K_{\mathrm{M}(\mathrm{NDP})}^{\mathrm{M}}$, of the $\mathrm{M}(\mathrm{ADP})^{-}, \mathrm{M}(\mathrm{IDP})^{-}$ and $\mathrm{M}(\mathrm{GDP})^{-}$complexes with the stability constants, $K_{\mathrm{M}(\mathrm{NDP}) \text { op }}^{\mathrm{M}}$, of the corresponding isomers with a sole diphosphate coordination of $\mathrm{M}^{2+}$, and extent of the intramolecular macrochelate formation according to equilibrium (22) in the mentioned $\mathrm{M}(\mathrm{NDP})^{-}$complexes in aqueous solution at $25^{\circ} \mathrm{C}$ and $I=0.1 \mathrm{M}\left(\mathrm{NaNO}_{3}\right)^{a, b}$

\begin{tabular}{lccccc}
\hline & $\log K_{\mathrm{M}(\mathrm{NDP})}^{\mathrm{M}}$ & $\log K_{\mathrm{M}(\mathrm{NDP}) \mathrm{mp}}^{\mathrm{M}}$ & $\log \Delta_{\mathrm{M} / \mathrm{NDP}}$ & $K_{\mathrm{I}}$ & $\% \mathrm{M}(\mathrm{NDP})_{\mathrm{cl}}^{-}$ \\
& $($eqs 2,18$)$ & eq. 19) $^{c}$ & $($ eq. 14) & (eqs 16, 17) & (eqs 20, 22) \\
\hline $\mathrm{Mg}(\mathrm{ADP})^{-}$ & $3.36 \pm 0.03$ & $3.30 \pm 0.03$ & $0.06 \pm 0.04$ & $0.15 \pm 0.11$ & $13 \pm 9$ \\
$\mathrm{Ca}(\mathrm{ADP})^{-}$ & $2.95 \pm 0.02$ & $2.91 \pm 0.03$ & $0.04 \pm 0.04$ & $0.10 \pm 0.09$ & $9 \pm 8$ \\
$\mathrm{Co}(\mathrm{ADP})^{-}$ & $3.92 \pm 0.02$ & $3.72 \pm 0.05$ & $0.20 \pm 0.05$ & $0.58 \pm 0.20$ & $37 \pm 8$ \\
$\mathrm{Zn}(\mathrm{ADP})^{-}$ & $4.28 \pm 0.05$ & $4.12 \pm 0.03$ & $0.16 \pm 0.06$ & $0.44 \pm 0.19$ & $31 \pm 9$ \\
$\mathrm{Cd}(\mathrm{ADP})^{-}$ & $4.63 \pm 0.04$ & $4.27 \pm 0.03$ & $0.36 \pm 0.05$ & $1.29 \pm 0.26$ & $56 \pm 5$ \\
$\mathrm{Mg}(\mathrm{IDP})^{-}$ & $3.33 \pm 0.03$ & $3.29 \pm 0.03$ & $0.04 \pm 0.04$ & $0.10 \pm 0.11$ & $9 \pm 9$ \\
$\mathrm{Ca}(\mathrm{ADP})^{-}$ & $2.96 \pm 0.06$ & $2.90 \pm 0.03$ & $0.06 \pm 0.07$ & $0.15 \pm 0.18$ & $13 \pm 13$ \\
$\mathrm{Co}(\mathrm{ADP})^{-}$ & $4.16 \pm 0.05$ & $3.70 \pm 0.05$ & $0.46 \pm 0.07$ & $1.88 \pm 0.47$ & $65 \pm 6$ \\
$\mathrm{Zn}(\mathrm{IDP})^{-}$ & $4.34 \pm 0.05$ & $4.09 \pm 0.03$ & $0.25 \pm 0.06$ & $0.78 \pm 0.24$ & $44 \pm 8$ \\
$\mathrm{Cd}(\mathrm{IDP})^{-}$ & $4.63 \pm 0.06$ & $4.25 \pm 0.03$ & $0.38 \pm 0.07$ & $1.40 \pm 0.37$ & $58 \pm 6$ \\
$\mathrm{Mg}(\mathrm{GDP})^{-}$ & $3.39 \pm 0.04$ & $3.29 \pm 0.03$ & $0.10 \pm 0.05$ & $0.26 \pm 0.14$ & $21 \pm 9$ \\
$\mathrm{Ca}(\mathrm{GDP})^{-}$ & $3.05 \pm 0.05$ & $2.90 \pm 0.03$ & $0.15 \pm 0.06$ & $0.41 \pm 0.19$ & $29 \pm 10$ \\
$\mathrm{Co}(\mathrm{GDP})^{-}$ & $4.31 \pm 0.05$ & $3.70 \pm 0.05$ & $0.61 \pm 0.07$ & $3.07 \pm 0.66$ & $75 \pm 4$ \\
$\mathrm{Zn}(\mathrm{GDP})^{-}$ & $4.52 \pm 0.03$ & $4.09 \pm 0.03$ & $0.43 \pm 0.04$ & $1.69 \pm 0.26$ & $63 \pm 4$ \\
$\mathrm{Cd}(\mathrm{GDP})^{-}$ & $4.86 \pm 0.03$ & $4.25 \pm 0.03$ & $0.61 \pm 0.04$ & $3.07 \pm 0.40$ & $75 \pm 2$ \\
\hline
\end{tabular}

${ }^{a}$ For the error limits see footnotes " $a$ " of Tables 3 and 4. The values for ADP are from ref. [130], those for IDP and GDP from ref. [148]. ${ }^{b}$ The acidity constants [130,148] are for $\mathrm{H}_{2}(\mathrm{ADP})^{-}$ $\mathrm{p}_{\mathrm{H}_{2}(\mathrm{ADP})}^{\mathrm{H}}=3.92 \pm 0.02$ (eq. 23) $\left[(\mathrm{N} 1) \mathrm{H}^{+}\right.$site $]$and $\mathrm{p} K_{\mathrm{H}(\mathrm{ADP})}^{\mathrm{H}}=6.40 \pm 0.01$ (eq. 3), for $\mathrm{H}_{2}(\mathrm{IDP})^{-}$ $\mathrm{p}_{\mathrm{H}_{2}(\mathrm{IDP})}^{\mathrm{H}}=1.82 \pm 0.03$ (eq. 23) [mainly (N7) $\left.\mathrm{H}^{+}\right], \mathrm{p} K_{\mathrm{H}(\mathrm{IDP})}^{\mathrm{H}}=6.38 \pm 0.02$ (eq. 3) and $\mathrm{p} K_{\mathrm{IDP}}^{\mathrm{H}}=$ $9.07 \pm 0.02$ (eq. 7), and for $\mathrm{H}_{2}(\mathrm{GDP})^{-} \mathrm{p} K_{\mathrm{H}_{2}(\mathrm{GDP})}^{\mathrm{H}}=2.67 \pm 0.02$ (eq. 23) [(N7) $\mathrm{H}^{+}$site], $\mathrm{p} K_{\mathrm{H}(\mathrm{GDP})}^{\mathrm{H}}$ $=6.38 \pm 0.01$ (eq. 3 ) and $\mathrm{p} K_{\mathrm{GDP}}^{\mathrm{H}}=9.56 \pm 0.03$ (eq. 7). ${ }^{c}$ The values in this column were calculated with $\mathrm{p} K_{\mathrm{H}(\mathrm{NDP})}^{\mathrm{H}}$ and eq. (15) by using the straight-line parameters listed in ref. [115]. 
Table 11 Comparison of the measured stability constants, $K_{\mathrm{M}(\mathrm{NTP})}^{\mathrm{M}}$, of the $\mathrm{M}(\mathrm{ATP})^{2-}, \mathrm{M}(\mathrm{ITP})^{2-}$ and $\mathrm{M}(\mathrm{GTP})^{2-}$ complexes with the stability constants, $K_{\mathrm{M}(\mathrm{NTP}) \mathrm{op}}^{\mathrm{M}}$, of the corresponding isomers with a sole coordination of $\mathrm{M}^{2+}$ to the triphosphate chain, and extent of the intramolecular macrochelate formation according to equilibrium (22) in the mentioned $\mathrm{M}(\mathrm{NTP})^{2-}$ complexes in aqueous solution at $25^{\circ} \mathrm{C}$ and $I=0.1 \mathrm{M}\left(\mathrm{NaNO}_{3}\right)^{a, b}$

\begin{tabular}{lccccc}
\hline $\mathrm{M}(\mathrm{NTP})^{2-}$ & $\begin{array}{c}\log K_{\mathrm{M}(\mathrm{NTP})}^{\mathrm{M}} \\
(\text { eqs } 2,18)\end{array}$ & $\begin{array}{c}\log K_{\mathrm{M}(\mathrm{NTP}) \mathrm{Mp}}^{\mathrm{eq.} \mathrm{19})^{c}} \\
\text { (eq }^{2-}\end{array}$ & $\begin{array}{c}\log \Delta_{\mathrm{M} / \mathrm{NTP}} \\
\text { (eq 14) }\end{array}$ & $\begin{array}{c}K_{I} \\
\text { (eqs. 16, 17) }\end{array}$ & $\begin{array}{c}\% \mathrm{M}(\mathrm{NTP})_{\mathrm{cl}}^{-} \\
\text {(eqs. 20, 22) }\end{array}$ \\
\hline $\mathrm{Mg}(\mathrm{ATP})^{2-}$ & $4.29 \pm 0.03$ & $4.21 \pm 0.04$ & $0.08 \pm 0.05$ & $0.20 \pm 0.14$ & $17 \pm 10$ \\
$\mathrm{Ca}(\mathrm{ATP})^{2-}$ & $3.91 \pm 0.03$ & $3.84 \pm 0.05$ & $0.07 \pm 0.06$ & $0.17 \pm 0.16$ & $15 \pm 12$ \\
$\mathrm{Co}(\mathrm{ATP})^{2-}$ & $4.97 \pm 0.09$ & $4.76 \pm 0.03$ & $0.21 \pm 0.09$ & $0.62 \pm 0.34$ & $38 \pm 13$ \\
$\mathrm{Zn}(\mathrm{ATP})^{2-}$ & $5.16 \pm 0.06$ & $5.02 \pm 0.02$ & $0.14 \pm 0.06$ & $0.38 \pm 0.19$ & $28 \pm 10$ \\
$\mathrm{Cd}(\mathrm{ATP})^{2-}$ & $5.34 \pm 0.03$ & $5.07 \pm 0.03$ & $0.27 \pm 0.04$ & $0.86 \pm 0.17$ & $46 \pm 5$ \\
$\mathrm{Mg}(\mathrm{ITP})^{2-}$ & $4.29 \pm 0.04$ & $4.21 \pm 0.04$ & $0.08 \pm 0.06$ & $0.20 \pm 0.17$ & $17 \pm 11$ \\
$\mathrm{Ca}(\mathrm{ITP})^{2-}$ & $3.93 \pm 0.05$ & $3.84 \pm 0.05$ & $0.09 \pm 0.07$ & $0.23 \pm 0.20$ & $19 \pm 13$ \\
$\mathrm{Co}(\mathrm{ITP})^{2-}$ & $5.08 \pm 0.07$ & $4.76 \pm 0.03$ & $0.32 \pm 0.08$ & $1.09 \pm 0.38$ & $52 \pm 9$ \\
$\mathrm{Zn}(\mathrm{ITP})^{2-}$ & $5.32 \pm 0.06$ & $5.02 \pm 0.02$ & $0.30 \pm 0.06$ & $1.00 \pm 0.28$ & $50 \pm 7$ \\
$\mathrm{Cd}(\mathrm{ITP})^{2-}$ & $5.62 \pm 0.05$ & $5.07 \pm 0.03$ & $0.55 \pm 0.06$ & $2.55 \pm 0.49$ & $72 \pm 4$ \\
$\mathrm{Mg}(\mathrm{GTP})^{2-}$ & $4.31 \pm 0.04$ & $4.21 \pm 0.04$ & $0.10 \pm 0.06$ & $0.26 \pm 0.17$ & $21 \pm 11$ \\
$\mathrm{Ca}(\mathrm{GTP})^{2-}$ & $3.96 \pm 0.03$ & $3.84 \pm 0.05$ & $0.12 \pm 0.06$ & $0.32 \pm 0.18$ & $24 \pm 10$ \\
$\mathrm{Co}(\mathrm{GTP})^{2-}$ & $5.34 \pm 0.05$ & $4.76 \pm 0.03$ & $0.58 \pm 0.06$ & $2.80 \pm 0.53$ & $74 \pm 4$ \\
$\mathrm{Zn}(\mathrm{GTP})^{2-}$ & $5.52 \pm 0.05$ & $5.02 \pm 0.02$ & $0.50 \pm 0.05$ & $2.16 \pm 0.36$ & $68 \pm 4$ \\
$\mathrm{Cd}(\mathrm{GTP})^{2-}$ & $5.82 \pm 0.05$ & $5.07 \pm 0.03$ & $0.75 \pm 0.06$ & $4.62 \pm 0.78$ & $82 \pm 2$ \\
\hline
\end{tabular}

${ }^{a}$ For the error limits see footnotes " $a$ " of Tables 3 and 4 . The values for ATP are from refs [116,119], those for ITP and GTP from ref. [119]. ${ }^{b}$ The acidity constants [37] are for $\mathrm{H}_{2}$ (ATP) $^{2-} \mathrm{p}_{\mathrm{H}_{2} \text { (ATP) }}^{\mathrm{H}}=4.00 \pm 0.01$ (eq. 23) $\left[(\mathrm{N} 1) \mathrm{H}^{+}\right.$site $]$and $\mathrm{p} K_{\mathrm{H}(\mathrm{ATP})}^{\mathrm{H}}=6.47 \pm 0.01$ (eq. 3), for $\mathrm{H}_{2}(\mathrm{ITP})^{2-} \mathrm{p}_{\mathrm{H}_{2} \text { (ITP) }}^{\mathrm{H}}=2.19 \pm 0.05$ (eq. 23) [mainly (N7) $\mathrm{H}^{+}$; see [33]], $\mathrm{p} K_{\mathrm{H}(\mathrm{ITP})}^{\mathrm{H}}=6.47 \pm 0.02$ (eq. 3) and $\mathrm{p} K_{\mathrm{ITP}}^{\mathrm{H}}=9.11 \pm 0.03$ (eq. 7), and for $\mathrm{H}_{2}(\mathrm{GTP})^{2-} \mathrm{p}_{\mathrm{H}_{2}(\mathrm{GTP})}^{\mathrm{H}}=2.94 \pm 0.02$ (eq. 23) $\left[(\mathrm{N} 7) \mathrm{H}^{+}\right.$site], $\mathrm{p} K_{\mathrm{H}(\mathrm{GTP})}^{\mathrm{H}}=6.50 \pm 0.02$ (eq. 3) and $\mathrm{p} K_{\mathrm{GTP}}^{\mathrm{H}}=9.57 \pm 0.02$ (eq. 7). ${ }^{c} \log$ $K_{\mathrm{M}(\mathrm{NTP}) \mathrm{pp}}^{\mathrm{M}}=K_{\mathrm{M}(\mathrm{PyNT})}^{\mathrm{M}}$, where PyNTP ${ }^{4-}=$ pyrimidine-nucleoside 5'-triphosphate; this means, for each metal ion the stability constants of the $\mathrm{M}(\mathrm{UTP})^{2-}, \mathrm{M}(\mathrm{dTTP})^{2-}$, and $\mathrm{M}(\mathrm{CTP})^{2-}$ complexes have been averaged, with the exception for $\mathrm{Cu}^{2+}$, where only the values for $\mathrm{Cu}(\mathrm{UTP})^{2-}$ and $\mathrm{Cu}(\mathrm{dTTP})^{2-}$ have been used [116] (see also [119]). 
Table 12 Stability constant comparisons for the M(PS) complexes formed by $\mathrm{Mg}^{2+}, \mathrm{Cd}^{2+}$, or $\mathrm{Zn}^{2+}$ and methyl thiophosphate $\left(\mathrm{MeOPS}^{2-}\right.$ ), uridine 5 - $O$-thiomonophosphate (UMPS ${ }^{2-}$ ) or adenosine 5 '- $O$-thiomonophosphate $\left(\mathrm{AMPS}^{2-}\right.$ ) between the measured stability constants, log $K_{\mathrm{M}(\mathrm{PS})}^{\mathrm{M}}$ (eq. 2), or the stability constants of M(AMPS) corrected for the macrochelate effect, log $K_{\mathrm{M}(\mathrm{AMPS})}^{\mathrm{M} / \mathrm{cor}}$, and the calculated stability constants, $\log K_{\mathrm{M}(\mathrm{PS}) \text { calc }}^{\mathrm{M}}$, together with the stability difference (eq. 25) for aqueous solutions at $25^{\circ} \mathrm{C}$ and $I=0.1 \mathrm{M}\left(\mathrm{NaNO}_{3}\right)^{a, b}$

\begin{tabular}{|c|c|c|c|c|c|}
\hline $\mathrm{M}(\mathrm{PS})$ & $\log K_{\mathrm{M}(\mathrm{PS})}^{\mathrm{M}}$ & $\log \Delta_{\mathrm{M} / \mathrm{AMP}}{ }^{c}$ & $\log K_{\mathrm{M} \text { (AMPS) }}^{\mathrm{M} / \mathrm{cor}}$ & $\log K_{\mathrm{M}(\mathrm{PS}) \mathrm{calc}}^{\mathrm{M}}$ & $\log \Delta_{\mathrm{M} / \mathrm{PS}}$ \\
\hline $\mathrm{Mg}(\mathrm{MeOPS})$ & $1.33 \pm 0.07$ & & & $1.30 \pm 0.03$ & $0.03 \pm 0.08$ \\
\hline Mg(UMPS) & $1.24 \pm 0.05$ & & & $1.27 \pm 0.03$ & $-0.03 \pm 0.06$ \\
\hline $\operatorname{Mg}$ (AMPS) & $1.28 \pm 0.04$ & $0.06 \pm 0.05$ & $1.22 \pm 0.06$ & $1.25 \pm 0.03$ & $-0.03 \pm 0.07$ \\
\hline $\mathrm{Cd}(\mathrm{MeOPS})$ & $4.50 \pm 0.06$ & & & $2.03 \pm 0.05$ & $2.47 \pm 0.08$ \\
\hline Cd(UMPS) & $4.37 \pm 0.08$ & & & $1.97 \pm 0.05$ & $2.40 \pm 0.09$ \\
\hline Cd(AMPS) & $4.62 \pm 0.12$ & $0.30 \pm 0.07$ & $4.32 \pm 0.14$ & $1.95 \pm 0.05$ & $2.37 \pm 0.15$ \\
\hline $\mathrm{Zn}(\mathrm{MeOPS})$ & $2.34 \pm 0.05$ & & & $1.69 \pm 0.06$ & $0.65 \pm 0.08$ \\
\hline Zn(UMPS) & $2.21 \pm 0.06$ & & & $1.63 \pm 0.06$ & $0.58 \pm 0.08$ \\
\hline $\mathrm{Zn}(\mathrm{AMPS})$ & $2.52 \pm 0.18$ & $0.25 \pm 0.09$ & $2.27 \pm 0.20$ & $1.61 \pm 0.06$ & $0.66 \pm 0.21$ \\
\hline
\end{tabular}

${ }^{a}$ For the error limits see footnotes " $a$ " of Tables 3 and 4. The values for AMPS are from ref. [170], those for MeOPS and UMPS from ref. [182]. ${ }^{b}$ The acidity constants are for $\mathrm{H}(\mathrm{MeOPS})^{-} \mathrm{p} K_{\mathrm{H}(\mathrm{MeOPS})}^{\mathrm{H}}=4.96 \pm 0.02$ (eq. 3), for $\mathrm{H}(\mathrm{UMPS})^{-} \mathrm{p} K_{\mathrm{H}(\mathrm{UMPS})}^{\mathrm{H}}=4.78 \pm 0.02$ (eq. 3) and $\mathrm{p} K_{\mathrm{UMPS}}^{\mathrm{H}}=9.47 \pm 0.02$ (eq. 7) [182], and for $\mathrm{H}_{2}$ (AMPS) ${ }^{ \pm} \mathrm{p}_{\mathrm{H}_{2} \text { (AMPS) }}^{\mathrm{H}}=3.72 \pm 0.03$ (eq. 23) and $\mathrm{p} K_{\mathrm{H} \text { (AMPS) }}^{\mathrm{H}}=4.83 \pm 0.02$ (eq. 3) [183]; the micro acidity constants for $\mathrm{H}_{2}(\mathrm{AMPS})^{ \pm}$, the second one being needed for the straight-line calculation, ${ }^{d}$ are $\mathrm{p}_{\mathrm{H}}^{\mathrm{HMAMSgH}} \mathrm{\textrm {AMH }}=3.84 \pm 0.02\left[(\mathrm{~N} 1) \mathrm{H}^{+}\right.$ deprotonation] and $\mathrm{p} k_{\mathrm{AMPS}}^{\mathrm{AMPS}}=4.71 \pm 0.04$ (deprotonation of the thiophosphate group) [183] ${ }^{c}$ See Table 9 in Section 6.2.3 or ref. [170]. ${ }^{d}$ The values in this column were calculated with the $\mathrm{p} K_{\mathrm{H}(\mathrm{PS})}^{\mathrm{H}}$ values given above ${ }^{b}$ and eq. (15) by using the straight-line parameters listed in refs. $[50,52,122]$. 
Table 13 Stability constants of some ternary M(ATP)(L) (eq. 28) and binary M(L) complexes (eq. 37), where $\mathrm{L}=$ Tris [212], Bistris [213], or Bicinate [214], as determined by potentiometric $\mathrm{pH}$ titrations [212,213] or spectrophotometric measurements [214] in aqueous solutions at $25^{\circ} \mathrm{C}$, together with the stability differences according to eq. (30) $)^{a, b}$

\begin{tabular}{lllcl}
\hline $\mathrm{L}$ & $\mathrm{M}^{2+}$ & $\log K_{\mathrm{M}(\mathrm{L})}^{\mathrm{M}}$ & $\log K_{\mathrm{M}(\mathrm{ATP})(\mathrm{L})}^{\mathrm{M}(\mathrm{ATP})}$ & $\Delta \log K_{\mathrm{M} / \mathrm{ATP} / \mathrm{L}}$ \\
\hline Tris & $\mathrm{Ca}^{2+}$ & $\leq 0.7$ & & \\
& $\mathrm{Co}^{2+}$ & $1.73 \pm 0.02$ & $1.57 \pm 0.05$ & $-0.16 \pm 0.05$ \\
& $\mathrm{Cu}^{2+}$ & $4.05 \pm 0.02$ & $3.50 \pm 0.05$ & $-0.55 \pm 0.05$ \\
& $\mathrm{Cd}^{2+}$ & $1.94 \pm 0.02$ & $1.17 \pm 0.05$ & $-0.77 \pm 0.05$ \\
& & & & \\
Bistris & $\mathrm{Ca}^{2+}$ & $2.25 \pm 0.02$ & $1.85 \pm 0.09$ & $-0.40 \pm 0.09$ \\
& $\mathrm{Co}^{2+}$ & $1.78 \pm 0.03$ & $1.33 \pm 0.03$ & $-0.45 \pm 0.04$ \\
& $\mathrm{Cu}^{2+}$ & $5.27 \pm 0.01$ & $3.62 \pm 0.03$ & $-1.65 \pm 0.03$ \\
& $\mathrm{Cd}^{2+}$ & $2.47 \pm 0.02$ & $1.14 \pm 0.07$ & $-1.33 \pm 0.07$ \\
& & & & $-0.55 \pm 0.26$ \\
& $\mathrm{Co}^{2+}$ & $5.08 \pm 0.13$ & $4.53 \pm 0.22$ & $-1.67 \pm 0.33$ \\
\hline & $\mathrm{Cu}^{2+}$ & $8.24 \pm 0.09$ & $6.57 \pm 0.32$ &
\end{tabular}

${ }^{a}$ For the error limits see footnotes " $a$ " of Tables 3 and $4 . \quad{ }^{b}$ The acidity constants and employed ionic strengths $(I)$ are: (i) $\mathrm{p} K_{\mathrm{H}(\text { Tris })}^{\mathrm{H}}=8.13 \pm 0.01 ; I=0.1 \mathrm{M}, \mathrm{KNO}_{3}$ [212]. (ii) $\mathrm{p} K_{\mathrm{H} \text { (Bistris) }}^{\mathrm{H}}=6.72 \pm 0.01 ; I=1.0 \mathrm{M}, \mathrm{KNO}_{3}$ [213]. For the acidity constant of $\mathrm{H}$ (Bistris) ${ }^{+}$at $25^{\circ} \mathrm{C}$ and $I=0.1 \mathrm{M}\left(\mathrm{KNO}_{3}\right)$ it holds $\mathrm{p} K_{\mathrm{H}(\text { Bistris })}^{\mathrm{H}}=6.56 \pm 0.04$ [213]. (iii) The acidity constants of $\mathrm{H}_{2}$ (Bicinate) ${ }^{+}$as determined by potentiometric $\mathrm{pH}$ titration are $\mathrm{pK}_{\mathrm{H}_{2} \text { (Bicinate) }}^{\mathrm{H}}=2.13 \pm 0.06$ and $\mathrm{p} K_{\mathrm{H}(\text { Bicinate })}^{\mathrm{H}}=8.33 \pm 0.03 ; I=1.0 \mathrm{M}, \mathrm{KNO}_{3}[214]$. 
Table 14 Extent of intramolecular aromatic-ring stacking or hydrophobic adduct formation in ternary $\mathrm{M}(\mathrm{N})(\mathrm{L})$ complexes, where $\mathrm{N}=$ nucleotide and $\mathrm{L}=$ another ligand, as depicted for example in equilibrium (34) and as calculated from stability constants determined via potentiometric (pot.) $\mathrm{pH}$ titrations: Stability enhancement $\log \Delta_{\mathrm{M} / \mathrm{N} / \mathrm{L}}$ (analogous to eq. 14), intramolecular and dimensionless equilibrium constant $K_{\mathrm{I} / \mathrm{st}}$ (eq. 34), and percentage of the "closed" $\mathrm{M}(\mathrm{N})(\mathrm{L})_{\mathrm{cl}}$ species in aqueous solution at $25^{\circ} \mathrm{C}$ and $I=0.1 \mathrm{M}\left(\mathrm{NaClO}_{4}\right.$ or $\left.\mathrm{KNO}_{3}\right){ }^{a, b}$ For comparison some results obtained from ${ }^{1} \mathrm{H}$ NMR shift experiments are also given.

\begin{tabular}{|c|c|c|c|c|c|c|}
\hline \multirow{2}{*}{ No. } & \multirow{2}{*}{$\begin{array}{l}M(\mathrm{~L})(\mathrm{N}) \text { or } \\
\mathrm{M}(\mathrm{N})(\mathrm{L})\end{array}$} & \multirow{2}{*}{$\log \Delta_{\mathrm{M} / \mathrm{N} / \mathrm{L}}$} & \multirow{2}{*}{$K_{\mathrm{I} / \mathrm{st}}$} & \multicolumn{2}{|c|}{$\% \mathrm{M}(\mathrm{N})(\mathrm{L})_{\mathrm{st}}$} & \multirow{2}{*}{$\begin{array}{c}\text { Ref. } \\
{[139,140]}\end{array}$} \\
\hline & & & & pot. $^{b}$ & NMR & \\
\hline 1 & $\mathrm{Cu}$ (Phen)(UMP) & $0.33 \pm 0.07$ & $1.14 \pm 0.34$ & $53 \pm 7$ & & [231] \\
\hline 2 & $\mathrm{Cu}($ Phen $)(\mathrm{AMP})$ & $0.99 \pm 0.08$ & $8.77 \pm 1.81$ & $90 \pm 2$ & & {$[232]$} \\
\hline 3 & $\mathrm{Cu}($ Phen $)(\mathrm{ATP})^{2-}$ & 1.07 & 11 & $92 \pm(2)$ & & [233] \\
\hline 4 & $\mathrm{Zn}(\mathrm{Phen})(\mathrm{ATP})^{2-}$ & & & & $\geq 95^{c}$ & [222] \\
\hline 5 & $\mathrm{Zn}(\mathrm{Bpy})(\mathrm{ATP})^{2-}$ & 0.54 & 2.5 & 70 & $55^{c}$ & {$[222,227]$} \\
\hline 6 & $\mathrm{Zn}(\mathrm{Bpy})(\mathrm{UTP})^{2-}$ & 0.45 & 1.8 & 65 & $40^{c}$ & {$[222,227]$} \\
\hline 7 & $\mathrm{Cd}(\mathrm{Bpy})(\mathrm{ATP})^{2-}$ & 0.38 & 1.4 & 60 & & [227] \\
\hline 8 & $\mathrm{Cd}(\mathrm{Bpy})(\mathrm{CTP})^{2-}$ & 0.37 & 1.3 & 55 & & [227] \\
\hline 9 & Zn (ATP)(Trp) $)^{3-}$ & $0.59 \pm 0.06$ & $2.89 \pm 0.51$ & $74 \pm 3$ & $40 \pm 15^{c}$ & {$[179,230]$} \\
\hline 10 & $\mathrm{Zn}(\mathrm{ATP})(\mathrm{Leu})^{3-}$ & $0.02 \pm 0.09$ & $0.05(0 / 0.29)^{d}$ & $5(0 / 22)^{d}$ & $30(20 / 75)^{d, e}$ & [230] \\
\hline 11 & $\mathrm{Cd}(\mathrm{ATP})(\mathrm{Leu})^{3-}$ & & & & $10(5 / 25)^{d, e}$ & {$[230]$} \\
\hline 12 & $\mathrm{Cd}(\mathrm{ATP})(\mathrm{Im})^{2-}$ & & & & $35(15 / 50)^{c, d, f}$ & [229] \\
\hline
\end{tabular}

${ }^{a}$ For the error limits (where given) see footnotes "a" of Tables 3 and $4 .{ }^{b}$ The calculations were done in analogy to equations (14) and (16) to (20) given in Section 4.2 (see also refs, e.g., [51,221,230,231]. ${ }^{c}$ These NMR experiments were carried out in $\mathrm{D}_{2} \mathrm{O}$ at $27^{\circ} \mathrm{C}$ and $I=0.1 \mathrm{M}$ $\left(\mathrm{NaNO}_{3}\right) . \quad{ }^{d}$ In parentheses the lower and upper limits are given, respectively. $\quad{ }^{e}$ Based on NMR experiments carried out in $\mathrm{H}_{2} \mathrm{O}$ at $34^{\circ} \mathrm{C}$ and $I=0.1-1.5 \mathrm{M}\left(\mathrm{KNO}_{3}\right) .{ }^{f}$ The same result has been obtained for $\mathrm{Zn}(\mathrm{ATP})(\text { imidazole })^{2-}$ [229]. 
Table 15 Comparison of the stability constants for the $\mathrm{Cd}(\mathrm{pUpU})^{-}, \mathrm{Cd}[\mathrm{d}(\mathrm{pGpG})]^{-}$, and $\mathrm{Cd}(\mathrm{pUp}(\mathrm{s}) \mathrm{U})^{-}$complexes (Figure 16) between the measured stability constants (eq. 2 ) and the calculated stability constants for $\mathrm{M}\left(\mathrm{R}-\mathrm{PO}_{3}\right)$ species, ${ }^{a}$ based on the basicity of the terminal phosphate group $^{b}$ of the corresponding dinucleotide and the reference-line equation (25) with its corresponding parameters $[50,52,122]$, together with the stability differences $\log \Delta_{\mathrm{M} / \mathrm{L}}$ as defined in equation (14) (aqueous solution; $25^{\circ} \mathrm{C}$ and $\left.I=0.1 \mathrm{M}, \mathrm{NaNO}_{3}\right)^{a, b}$

\begin{tabular}{llll}
\hline \multicolumn{1}{c}{ Ligand $(\mathrm{L})$} & $\log K_{\mathrm{Cd}(\mathrm{L})}^{\mathrm{Cd}}$ & $\log K_{\left.\mathrm{Cd}(\mathrm{R}-\mathrm{PO})_{3}\right)}^{\mathrm{Cd}}$ & $\log \Delta_{\mathrm{Cd} / \mathrm{L}}$ \\
\hline $\mathrm{pUpU}{ }^{3-}$ & $2.75 \pm 0.03$ & $2.52 \pm 0.05$ & $0.23 \pm 0.05$ \\
$\mathrm{~d}(\mathrm{pGpG})^{3-}$ & $4.01 \pm 0.06$ & $2.56 \pm 0.05$ & $1.45 \pm 0.08$ \\
$\mathrm{pUp}(\mathrm{s}) \mathrm{U}^{3-}$ & $3.16 \pm 0.07$ & $2.48 \pm 0.05$ & $0.68 \pm 0.09$ \\
\hline
\end{tabular}

${ }^{a}$ For the error limits see footnotes " $a$ " of Tables 3 and 4. The values for the M(pUpU) ${ }^{-}$, $\mathrm{M}[\mathrm{d}(\mathrm{pGpG})]^{-}$, and $\mathrm{M}(\mathrm{pUp}(\mathrm{s}) \mathrm{U})^{-}$systems are from refs [33], [241], and [242], respectively. ${ }^{b}$ Acidity constants (eq. 3) for the deprotonation of the monoprotonated terminal phosphate groups of the dinucleotides (Figue 16): $K_{\mathrm{H}(\mathrm{pUpU})}^{\mathrm{H}}=6.44 \pm 0.02[33,243], \mathrm{p} K_{\mathrm{H}[\mathrm{d}(\mathrm{pGpG})]}^{\mathrm{H}}=6.56 \pm$ 0.03 [241,243], and $\mathrm{p} K_{\mathrm{H}(\mathrm{pUp}(\mathrm{s}) \mathrm{U})}^{\mathrm{H}}=6.32 \pm 0.03$ [242]. For the other acidity constants of the three dinucleotides see the given refs. 


\section{LEGENDS FOR THE FIGURES}

Figure 1 Chemical structures of the nucleobases $(\mathrm{NB})(\mathrm{R}=\mathrm{H})$ occurring in RNA: adenine (Ade), guanine (Gua), cytosine (Cyt), and uracil (Ura). Hypoxanthine (Hyp) is a rare nucleobase and shown for comparison with guanine. Thymine (Thy), which occurs in DNA, can also be addressed as 5-methyluracil. The corresponding nucleosides (Ns) ( $\mathrm{R}=$ ribosyl residue) are adenosine (Ado), inosine (Ino), guanosine (Guo), cytidine (Cyd), uridine (Urd), and thymidine (dThd); in thymidine $\mathrm{R}$ is the 2'-deoxyribosyl residue. The dominating conformation of the nucleosides is the anti one [11-14]; this conformation is obtained if the substitution at C1' of the ribosyl residue is done in the way the bases are depicted within the plane.

Figure 2 Interdependencies between several elements relevant for mammals. An arrow from element $\mathrm{A} \rightarrow \mathrm{B}$ indicates that administration of element A may reduce toxicity due to element $\mathrm{B}$. Note, there may be further interdependencies which are not shown (see also text in Section 2). This figure is based on information provided by Martin in Figure 2 and the connected text of ref. [17].

Figure 3 Chemical structures of dihydroxyacetone phosphate $\left(\mathrm{DHAP}^{2-}\right)$, glycerol 1-phosphate $\left(\mathrm{G}^{2} \mathrm{P}^{2-}\right)$, acetyl phosphate $\left(\mathrm{AcP}^{2-}\right)$, and acetonylphosphonate $\left(\mathrm{AnP}^{2-}\right)$.

Figure 4 Chemical structures of hydroxymethylphosphonate $\left(\mathrm{HMP}^{2-}\right)$, hydroxyacetate $\left(\mathrm{HOAc}^{-}\right)$, and $o$-(hydroxymethyl)pyridine.

Figure 5 Chemical structures of 1-methylimidazole (1MIm) derivatives, i.e., 1methylbenzimidazole (1MBI) and 1,4-dimethylbenzimidazole (DMBI = 6,9-dimethyl-1,3dideazapurine), as mimics of the purine N7 site, and of pyridine (Py) derivatives, i.e., 2methylpyridine and tubercidin for $\mathrm{R}=$ ribosyl residue (see Figure 1$)(\mathrm{Tu}=7$-deazaadenosine), as mimics of the purine N1 site. For tubercidin, like for adenosine (Figure 1), the anti conformation is dominant [13]. 
Figure 6 Evidence for the varying coordinating properties of cytidine $(0)$ depending on the metal ion involved. This observation is based on the $\log K_{\mathrm{M}(\mathrm{L})}^{\mathrm{M}}$ versus $\mathrm{p} K_{\mathrm{H}(\mathrm{L})}^{\mathrm{H}}$ relationship for simple pyridine-type $(\bigcirc)$ as well as ortho-aminopyridine-type $(\otimes)$ ligands; the reduced stability of the complexes formed with the latter ligands reflects the steric inhibition due to an orthoamino (or -methyl) group. The least-squares straight-reference lines for the simple pyridine-type ligands are defined by the equilibrium constants for the systems containing $(\bigcirc)$ (at the top from left to right) 3-chloropyridine (3ClPy), 4-bromopyridine (4BrPy), 4-(chloromethyl)pyridine (4ClMPy), pyridine (Py), $\beta$-picoline (= 3-methylpyridine, 3MPy), and 3,5-lutidine (=3,5dimethylpyridine, 3,5DMPy) and those for the ortho-aminopyridine-type ligands by the constants for the systems containing $(\otimes)$ (at the bottom from left to right) 2-methyl-5bromopyridine (2M5BrPy), 2-amino-5-bromopyridine (2A5BrPy), tubercidin (=7deazaadenosine, Tu), $\alpha$-picoline (=2-methylpyridine, 2MPy) and 2-aminopyridine (2APy). All plotted equilibrium constants refer to aqueous solution at $25^{\circ} \mathrm{C}$ and $I=0.5 \mathrm{M}\left(\mathrm{NaNO}_{3}\right)$; the data for Cyd are from [83] and those for the pyridine derivatives from [59].

Figure 7 Comparison of the $\log K_{\mathrm{M}(\mathrm{U}-\mathrm{H})}^{\mathrm{M}}$ versus $\mathrm{p} K_{\mathrm{U}}^{\mathrm{H}}$ relationships (+) for $\mathrm{Ca}^{2+}, \mathrm{Co}^{2+}$, and $\mathrm{Cd}^{2+}$ [88] with the corresponding $\log K_{\mathrm{M}(\mathrm{L})}^{\mathrm{M}}$ versus $\mathrm{p} K_{\mathrm{H}(\mathrm{L})}^{\mathrm{H}}$ relationships [35] for simple pyridine-type $(\mathrm{PyN})(\mathbf{O})$ and sterically inhibited ortho-amino(methyl)pyridine-type ligands $(o \mathrm{PyN})(\boldsymbol{\square})$. For the definition of the data points of the PyN and $o \mathrm{PyN}$ systems see legend of Figure 6 (compare from left to right) $\left(25^{\circ} \mathrm{C} ; I=0.5 \mathrm{M}, \mathrm{NaNO}_{3}\right)$. The straight-reference line for the uridinate-type complexes (+) is defined (from left to right) by 5-fluorouridinate, 5-chloro-2'deoxyuridinate, uridinate, and thymidinate $\left(25^{\circ} \mathrm{C} ; I=0.1 \mathrm{M}, \mathrm{NaNO}_{3}\right.$; the corresponding equilibrium constants are listed in ref. [88]).

Figure 8 Chemical structures of some less common nucleosides, that is, orotidine [H(Or)], xanthosine (Xao), 2-thiouridine (U2S), 4-thiouridine (U4S), and 2-thiocytidine (C2S). US = U2S and/or U4S. Orotidine exists in solution mostly in the syn conformation [89]; for all the other nucleosides the anti conformation dominates. 
Figure 9 Chemical structures of simple monoesters of triphosphate $\left(\mathrm{R}_{-} \mathrm{TP}^{4-}\right)$, diphosphate $(\mathrm{R}$ $\left.\mathrm{DP}^{3-}\right)$, and monophosphate $\left(\mathrm{R}^{-} \mathrm{MP}^{2-}\right)$. $\mathrm{R}$ represents a residue which does not affect metal ion coordination at the phosphate, i.e., neither in a positive nor negative sense. $(\mathrm{RO})_{2} \mathrm{PO}_{2}^{-}$represents the phosphodiester bridge of a nucleic acid; acetate $\left(\mathrm{Ac}^{-}\right)$is used as a primitive and simple mimic of such a singly negatively charged situation (see also [58]).

Figure 10 Chemical structures of adenosine 5'-monophosphate $\left(\mathrm{n}=1\right.$ : $\left.\mathrm{AMP}^{2-}\right)$, adenosine 5'diphosphate $\left(\mathrm{n}=2: \mathrm{ADP}^{3-}\right)$, and adenosine $5^{\prime}$-triphosphate $\left(\mathrm{n}=3: \mathrm{ATP}^{4-}\right)$ as well as of cytidine 5'-monophosphate $\left(\mathrm{n}=1: \mathrm{CMP}^{2-}\right)$, cytidine 5'-diphosphate $\left(\mathrm{n}=2: \mathrm{CDP}^{3-}\right)$, and cytidine 5'triphosphate $\left(\mathrm{n}=3: \mathrm{CTP}^{4-}\right)$ in their dominating anti conformation [11-14,50]. Note, the triphosphate chain in nucleoside 5'-triphosphates $\left(\mathrm{NTP}^{4-}\right)$ is labeled $\alpha, \beta$, and $\gamma$, where $\gamma$ refers to the terminal phosphate group (see also Figure 9); for nucleoside 5 '-diphosphates $\left(\mathrm{NDP}^{3-}\right.$ ) the situation is analogous with $\alpha$ and $\beta$ (see Figure 9). The adenine and cytosine residues in the nucleotide structures shown above may be replaced by one of the other nucleobase residues shown in Figure 1; if this substitution is done in the way the bases are depicted within the plane (Figure 1), then the anti conformation will also result for the corresponding nucleoside 5'phosphates. The abbreviations $\mathrm{AMP}^{2-}, \mathrm{ADP}^{3-}, \mathrm{ATP}^{4-}, \mathrm{IMP}^{2-}$, etc. in this text always represent the 5'-derivatives; 2 '- and 3 '-derivatives are defined by $2^{\prime} \mathrm{AMP}^{2-}, 3^{\prime} \mathrm{AMP}^{2-}$, etc.; in a few instances where uncertainties might otherwise occur, the abbreviations $5 \mathrm{AMP}^{2-}, 5^{\prime} \mathrm{ADP}^{3-}$, etc. are also used.

Figure 11 Evidence for an enhanced stability of the $\mathrm{Cd}^{2+}$ and $\mathrm{Ca}^{2+} 1: 1$ complexes (eq. 2) of $\mathrm{AMP}^{2-}(\Theta), \mathrm{IMP}^{2-}(\otimes)$, and $\mathrm{GMP}^{2-}(\bigcirc)$, based on the relationship between $\log K_{\mathrm{M}\left(\mathrm{R}-\mathrm{PO}_{3}\right)}^{\mathrm{M}}$ and $\mathrm{p} K_{\mathrm{H}\left(\mathrm{R}-\mathrm{PO}_{3}\right)}^{\mathrm{H}}$ for $\mathrm{M}\left(\mathrm{R}-\mathrm{PO}_{3}\right)$ complexes of some simple phosphate monoester and phosphonate ligands ( ${\mathrm{R}-\mathrm{PO}_{3}^{2-}}^{2-}(\mathrm{O})$ : 4-nitrophenyl phosphate $\left(\mathrm{NPhP}^{2-}\right)$, phenyl phosphate $\left(\mathrm{PhP}^{2-}\right.$, uridine $5^{\prime}-$ monophosphate $\left(\mathrm{UMP}^{2-}\right)$, D-ribose 5-monophosphate $\left(\operatorname{RibMP}^{2-}\right)$, thymidine [= 1-(2-deoxy- $\beta$-Dribofuranosyl)thymine] 5'-monophosphate $\left(\mathrm{dTMP}^{2-}\right), n$-butyl phosphate $\left(\mathrm{BuP}^{2-}\right)$, methanephosphonate $\left(\mathrm{MeP}^{2-}\right)$, and ethanephosphonate $\left(\mathrm{EtP}^{2-}\right)$ (from left to right). The least- 
squares lines (eq. 15) are drawn through the corresponding 8 data sets $(\bigcirc)$ taken from ref. [114] for the phosphate monoesters and from ref. [122] for the phosphonates. The points due to the equilibrium constants for the $\mathrm{M}^{2+} / \mathrm{NMP}$ systems $(\mathrm{O}, \otimes, \bigcirc)$ are based on the values listed in Table 9. The equilibrium data for the $\mathrm{M}^{2+} / \mathrm{PMEA}$ systems $(\diamond)$ are from ref. [122]. These results are discussed in Section 7.3. The vertical (broken) lines emphasize the stability differences from the reference lines; they equal $\log \Delta_{\mathrm{M} / \mathrm{NMP}}$ and $\log \Delta_{\mathrm{M} / \mathrm{PMEA}}$, as defined in equation (14), for the $\mathrm{M}(\mathrm{NMP})$ complexes. All the plotted equilibrium constants refer to aqueous solutions at $25^{\circ} \mathrm{C}$ and $I=0.1 \mathrm{M}\left(\mathrm{NaNO}_{3}\right)$.

Figure 12 Evidence for an enhanced stability of the $\mathrm{Cd}^{2+}$ as well as the $\mathrm{Ca}^{2+}, \mathrm{Mg}^{2+}$, and $\mathrm{Co}^{2+} 1: 1$ complexes (eq. 2) of $\operatorname{ADP}^{3-}(\mathbf{O}), \operatorname{IDP}^{3-}(\otimes)$, and $\mathrm{GDP}^{3-}(\mathbf{O})$, based on the relationship between $\log K_{\mathrm{M}(\mathrm{R}-\mathrm{DP})}^{\mathrm{M}}$ and $\mathrm{p} K_{\mathrm{H}(\mathrm{R}-\mathrm{DP})}^{\mathrm{H}}$ for simple $\mathrm{M}(\mathrm{R}-\mathrm{DP})^{-}$complexes $(\mathrm{O})$, where $\mathrm{R}^{-\mathrm{DP}^{3-}}=$ phenyl diphosphate $\left(\mathrm{PhDP}^{3-}\right)$, methyl diphosphate $\left(\mathrm{MeDP}^{3-}\right)$, uridine 5'-diphosphate $\left(\mathrm{UDP}^{3-}\right)$, cytidine 5 -diphosphate $\left(\mathrm{CDP}^{3-}\right)$, thymidine [= 1-(2-deoxy- $\beta$-D-ribofuranosyl)thymine] 5'-diphosphate $\left(\mathrm{dTDP}^{3-}\right)$, and $n$-butyl diphosphate $\left(\mathrm{BuDP}^{3-}\right)$ (from left to right). The least-squares lines (eq. 15) are drawn through the indicated six data sets taken from ref. [115]. The points due to the $\mathrm{M}^{2+} / \mathrm{NDP}$ systems are based on the values listed in Table 10. The vertical broken lines emphasize the stability differences from the reference lines; they equal $\log \Delta_{\mathrm{M} / \mathrm{NDP}}$ as defined in analogy to equation (14) (see also Table 10, column 4). All the plotted equilibrium constants refer to aqueous solutions at $25^{\circ} \mathrm{C}$ and $I=0.1 \mathrm{M}\left(\mathrm{NaNO}_{3}\right)$.

Figure 13 Chemical structures of xanthosinate 5'-monophosphate, which exists at the physiological $\mathrm{pH}$ of about 7.5 as $(\mathrm{XMP}-\mathrm{H})^{3-}$, with a tautomeric equilibrium between $(\mathrm{N} 1)^{-}$ $/(\mathrm{N} 3) \mathrm{H}$ and $(\mathrm{N} 1) \mathrm{H} /(\mathrm{N} 3)^{-}$sites $[96,97,162]$, and flavin mononucleotide $\left(\mathrm{FMN}^{2-}=\right.$ riboflavin $5^{\prime}-$ phosphate) as well as for comparison of glycerol 1-phosphate $\left(\mathrm{G}^{2} \mathrm{P}^{2-}\right)$. $(\mathrm{XMP}-\mathrm{H})^{3-}$ is shown in its dominating anti conformation [11-13].

Figure 14 Chemical structures of $1, \mathrm{~N}^{6}$-ethenoadenosine 5 -'monophosphate $\left(\varepsilon-\mathrm{AMP}^{2-}\right)$ and of uridine $5^{\prime}-O$-thiomonophosphate $\left(\mathrm{UMPS}^{2-}\right)$, as well as of the dianion of the acyclic nucleotide 
analogue 9-[2-(phosphonomethoxy)ethyl]adenine $\left(\mathrm{PMEA}^{2-}\right)$. To facilitate comparisons between $\varepsilon-\mathrm{AMP}^{2-}$ and $\mathrm{AMP}^{2-}$ the conventional atom numbering for adenines is adapted, a procedure which is common [171]. The purine-nucleotide $\varepsilon-\mathrm{AMP}^{2-}[11-13]$ and the pyrimidine-nucleotide $\mathrm{UMPS}^{2-}[11,14]$ are shown in their dominating anti conformation. ${ }^{1} \mathrm{H}-\mathrm{NMR}$ shift measurements have shown [176] that in solution $\mathrm{PMEA}^{2-}$ adopts an orientation which is similar to the anti conformation of $\mathrm{AMP}^{2-}$; this conclusion is in accord with a crystal structure study [177] of the $\mathrm{H}_{2}(\mathrm{PMEA})^{ \pm}$zwitterion.

Figure 15 Chemical structures of 2-amino-2-(hydroxymethyl)-1,3-propanediol (Tris), 2-[bis(2hydroxyethyl)amino]-2-(hydroxymethyl)-1,3-propanediol (Bistris), and N,N-bis(2hydroxyethyl)glycine (Bicine).

Figure 16 Chemical structures of three dinucleotides, i.e., uridylyl-(5' $\left.\rightarrow 3^{\prime}\right)-5^{\prime}$-uridylate $\left(\mathrm{pUpU}^{3-}\right)$, $p$-thiouridylyl-(5' $\left.\rightarrow 3^{\prime}\right)$-5'-uridylate $\left(\mathrm{pUp}(\mathrm{s}) \mathrm{U}^{3-}\right)$, and 2'-deoxyguanylyl $\left(5^{\prime} \rightarrow 3^{\prime}\right)-2^{\prime}-$ deoxy-5'guanylate $\left[\mathrm{d}\left(\mathrm{pGpG}^{3-}\right]\right.$, as well as of three dinucleoside monophosphates, i.e., guanylyl $\left(3^{\prime} \rightarrow 5^{\prime}\right)$ guanosine $\left(\mathrm{GpG}^{-}\right), 2^{\prime}$-deoxyguanylyl $\left(3^{\prime} \rightarrow 5^{\prime}\right)$-2-deoxyguanosine $\left[\mathrm{d}(\mathrm{GpG})^{-}\right]$, and inosylyl $\left(3^{\prime} \rightarrow 5^{\prime}\right)$ inosine $\left(\mathrm{IpI}^{-}\right)$.

Figure $17 \mathrm{Cd}^{2+}$ coordination within the hammerhead ribozyme. Two innersphere contacts of $\mathrm{Cd}^{2+}$ (green sphere) to N7 of G10.1 (blue) and OP2 of A9 (red) are shown. Further ligands for outersphere interactions at a distance less than $5 \AA$ to $\mathrm{Cd}^{2+}$ are shown as blue (nitrogen) and red (oxygen) spheres. The figure was prepared with MOLOL [286] using PDB entry 488D [282]. 


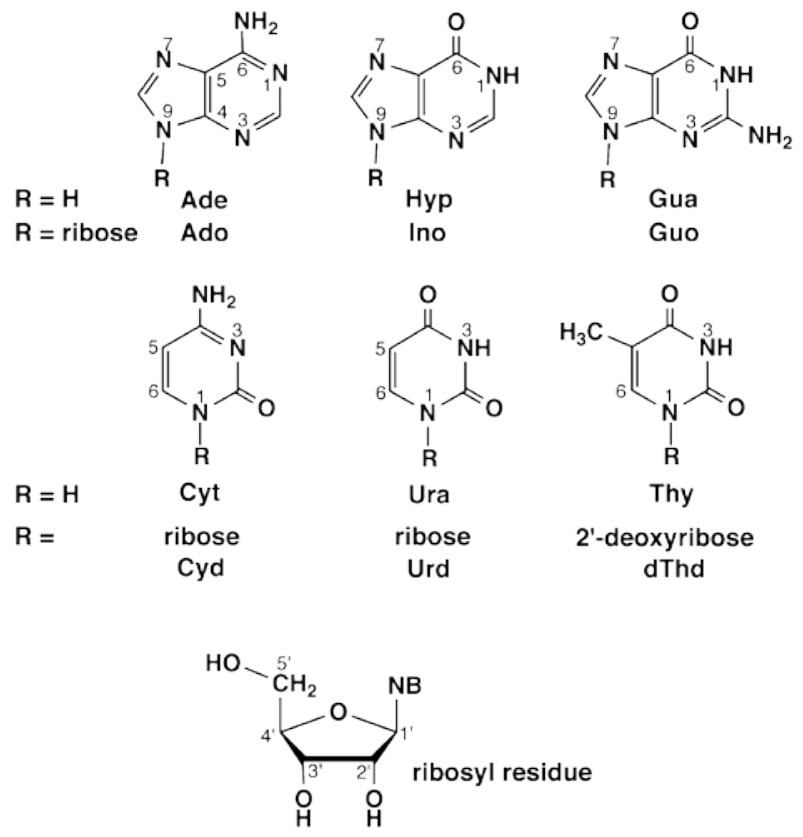

Figure 1 


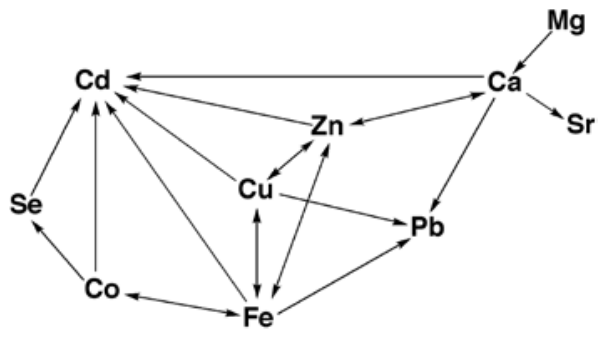

Figure 2 


$\begin{array}{llll}\mathrm{H}_{2} \mathrm{C}^{3}-\mathrm{OH} & \mathrm{H}_{2} \mathrm{C}^{3}-\mathrm{OH} & \mathrm{CH}_{3} & \mathrm{CH}_{3} \\ \mathrm{C}^{2}=\mathrm{O} & \mathrm{HC}^{2}-\mathrm{OH} & \mathrm{C}=\mathrm{O} & \mathrm{C}=\mathrm{O} \\ \mathrm{H}_{2} \mathrm{C}^{1}-\mathrm{O}-\mathrm{PO}_{3}^{2-} & \mathrm{H}_{2} \mathrm{C}^{1}-\mathrm{O}-\mathrm{PO}_{3}^{2-} & \mathrm{O}-\mathrm{PO}_{3}^{2-} & \mathrm{H}_{2} \mathrm{C}-\mathrm{PO}_{3}^{2-} \\ \mathrm{DHAP}^{2-} & \mathrm{G}_{1} \mathrm{P}^{2-} & \mathrm{ACP}^{2-} & \mathrm{AnP}^{2-}\end{array}$

Figure 3 


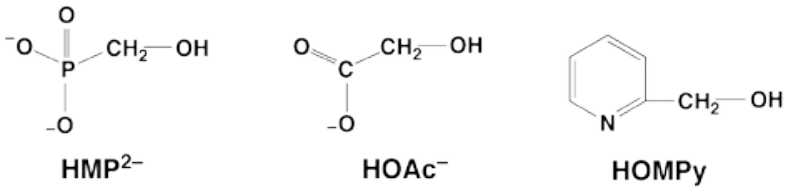

Figure 4 

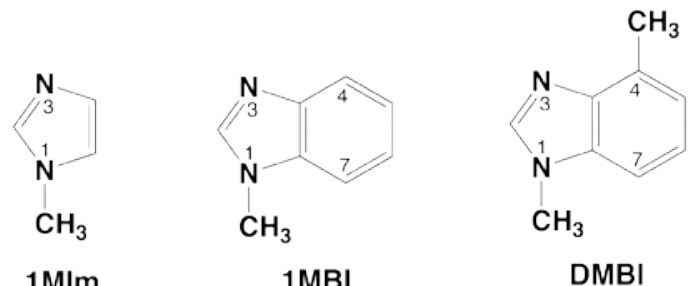

$\mathrm{CH}_{3}$

$\mathrm{CH}_{3}$

$\mathrm{CH}_{3}$

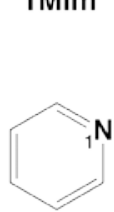

$1 \mathrm{MBI}$

DMBI

Py<smiles>Cc1ccccn1</smiles>

2MPy

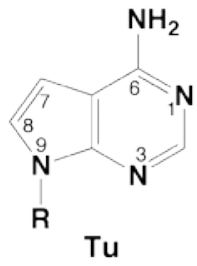

Figure 5 


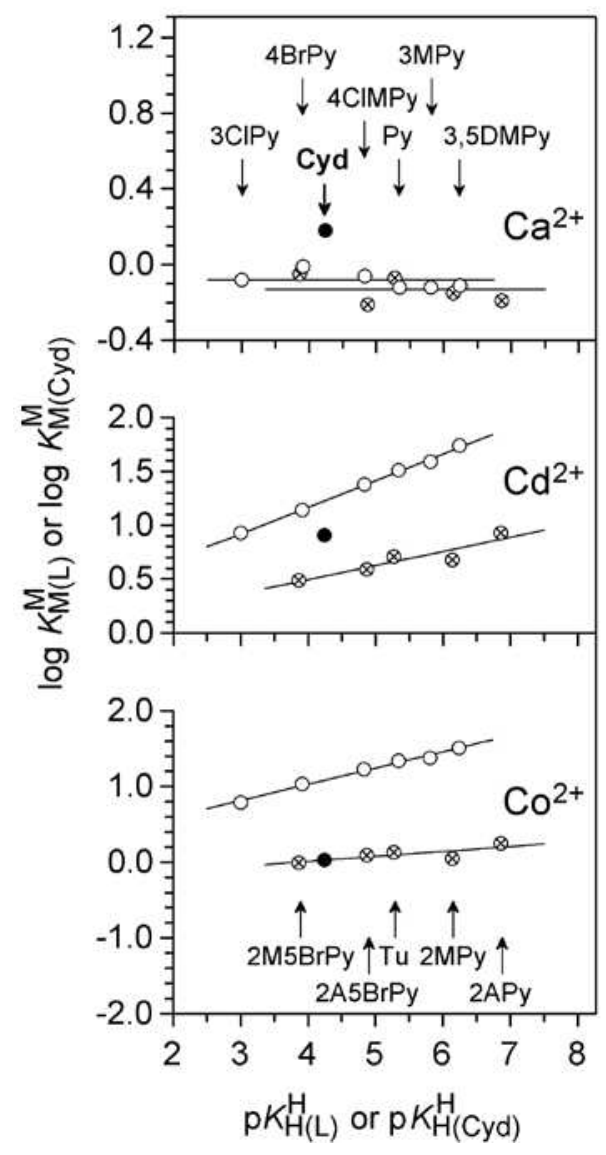

Figure 6 


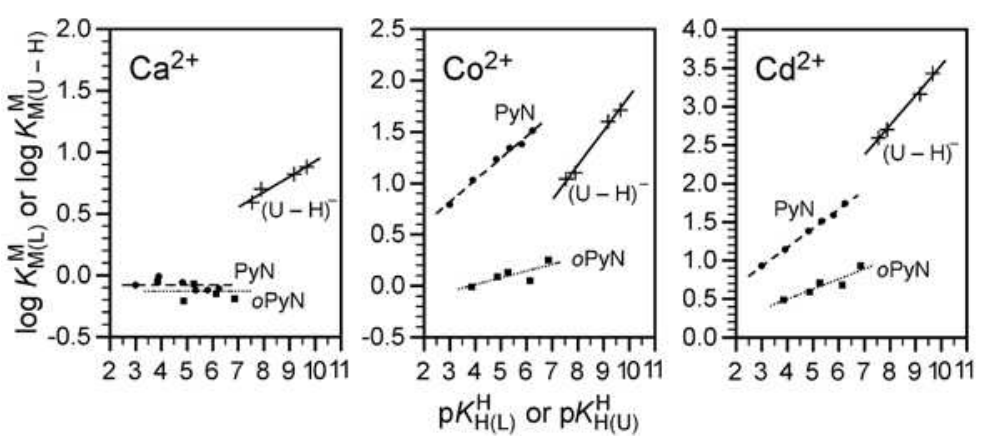

Figure 7 

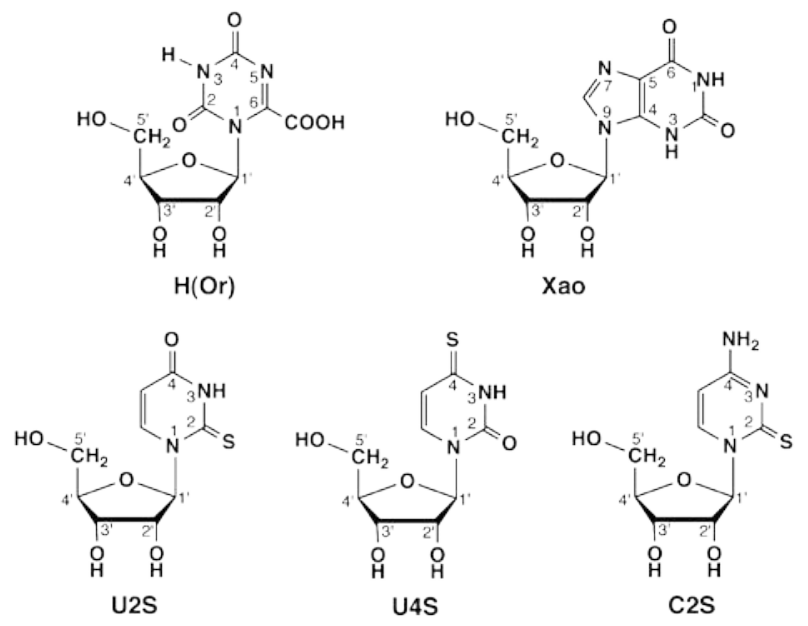

Figure 8 


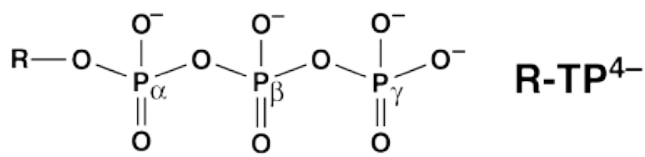

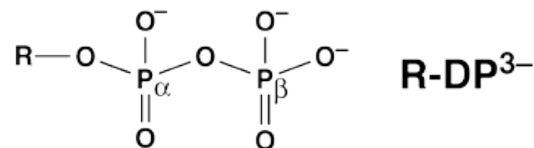

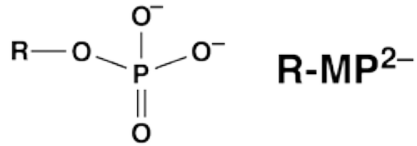

$$
\begin{aligned}
& \mathrm{R}-\mathrm{O} \backslash \underset{\mathrm{P}}{\|_{\mathrm{P}}^{\mathrm{O}^{-}}-\mathrm{O}-\mathrm{R}}(\mathrm{RO})_{2} \mathrm{PO}^{-} \\
& {\stackrel{0}{\mathrm{O}^{-}}}_{\mathrm{C}_{\mathrm{CH}_{3}}} \mathrm{Ac}^{-}
\end{aligned}
$$

Figure 9 

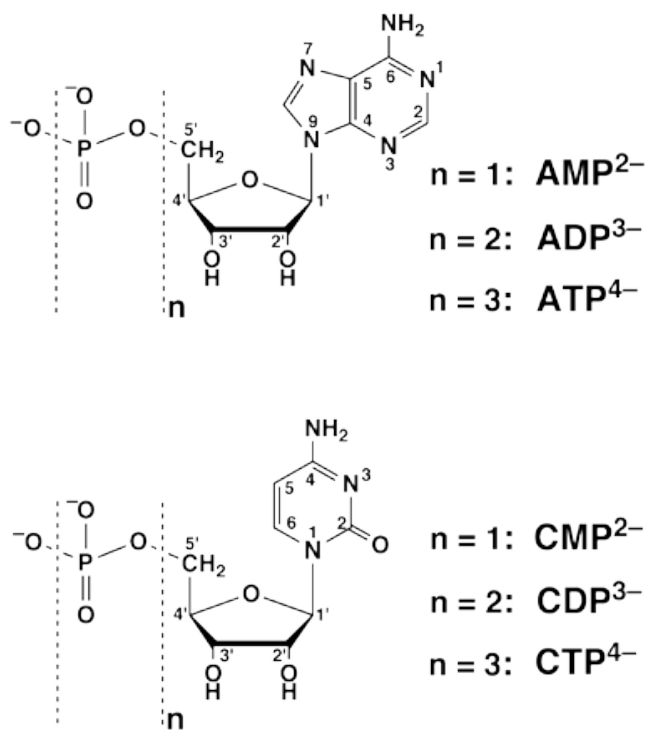

Figure 10 


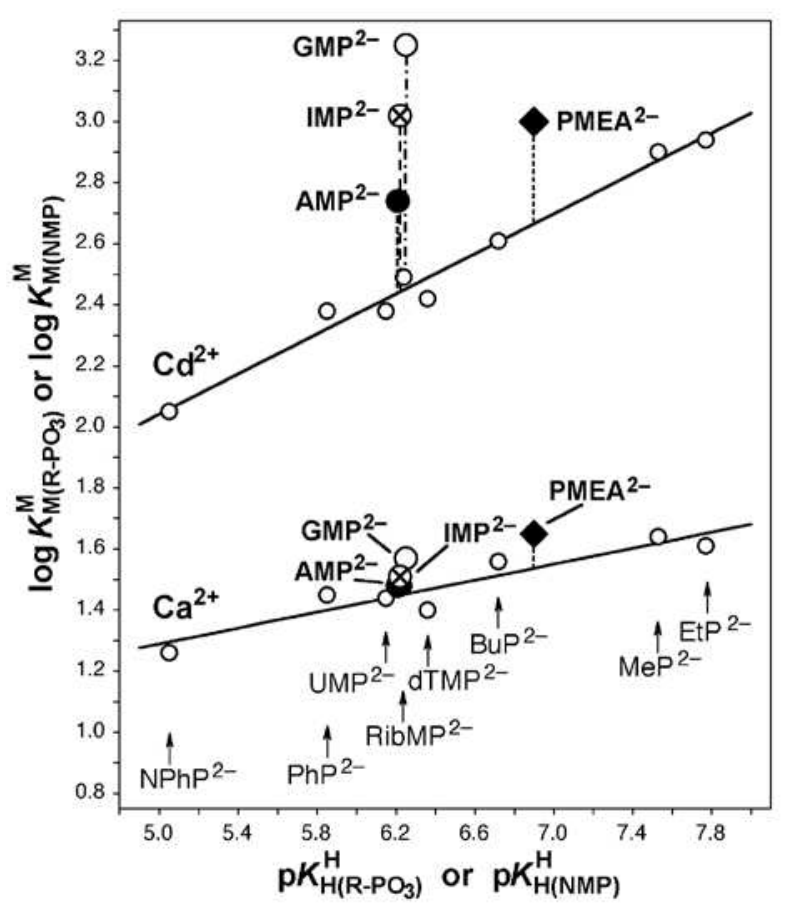

Figure 11 


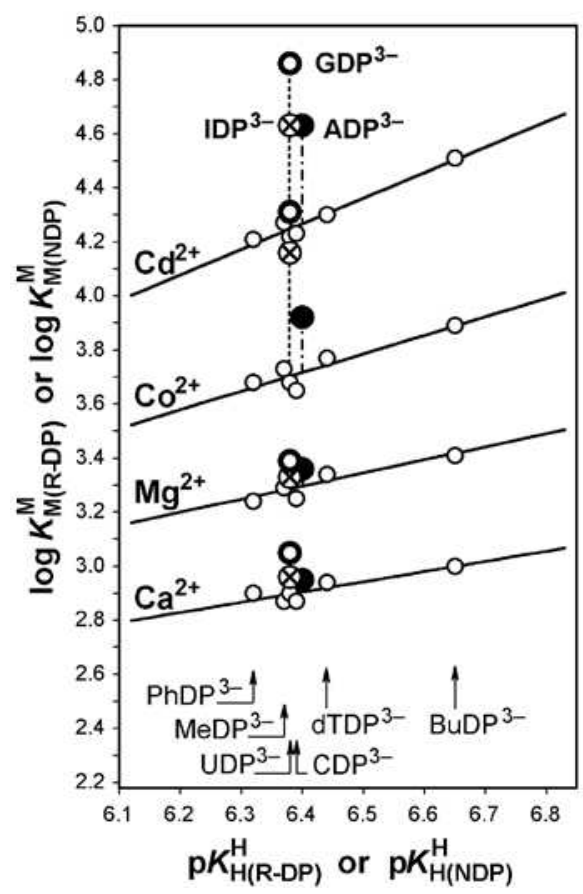

Figure 12 
Figure 13 

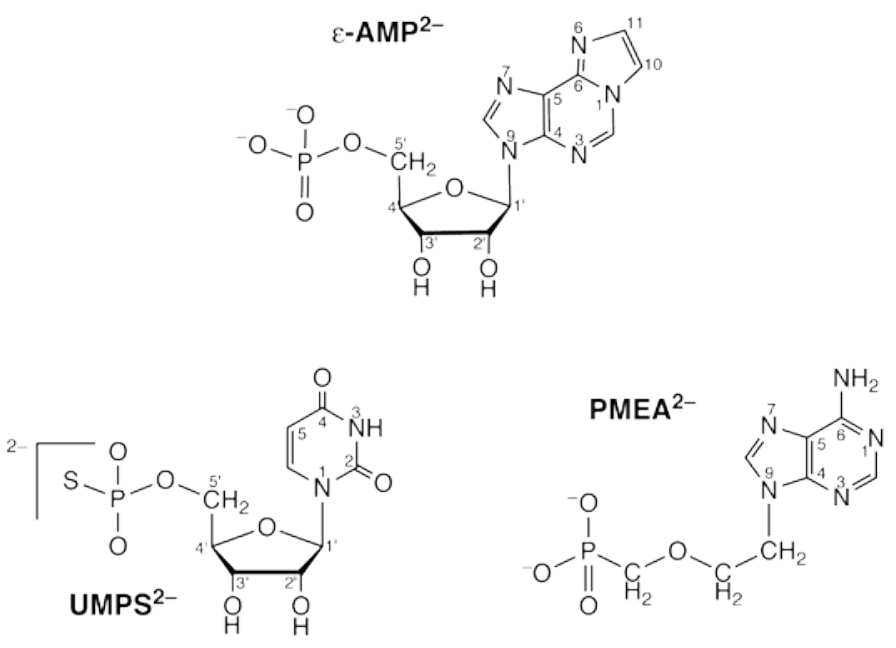

Figure 14 


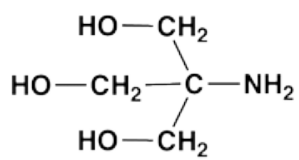

Tris

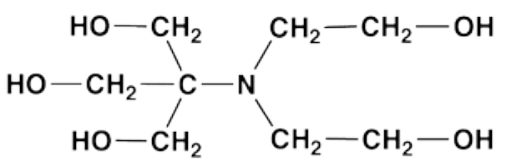

\section{Bistris}

\section{Bicine}

Figure 15 
Figure 16 


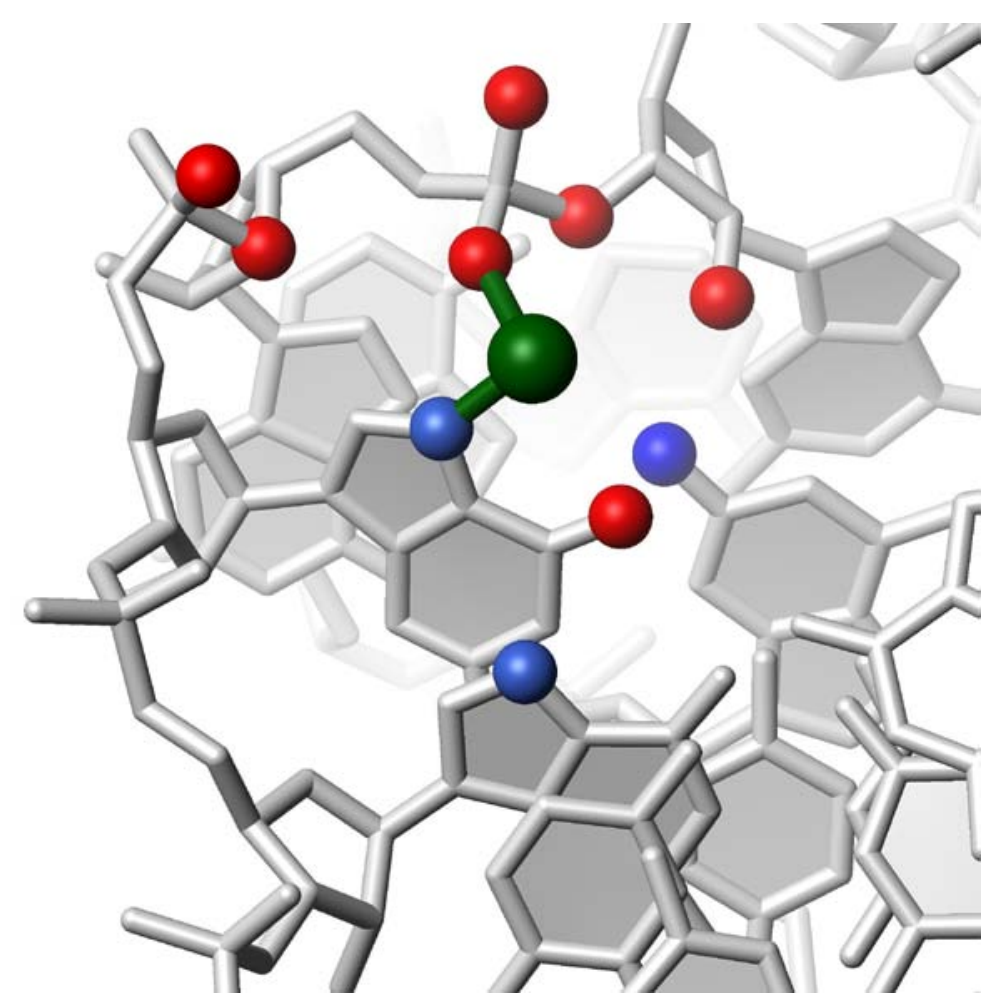

Figure 17 


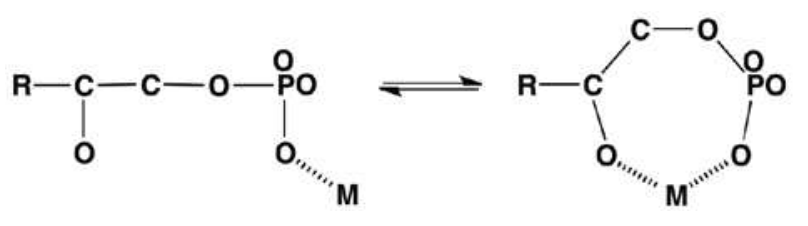

Equation 5 


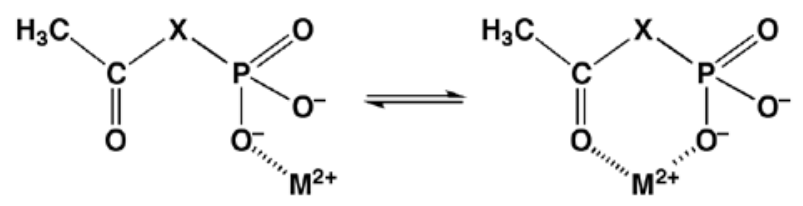

Equation 6 


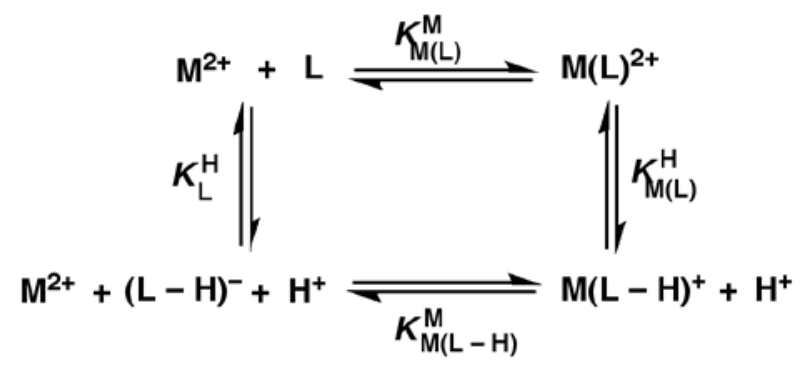

Equation 10 


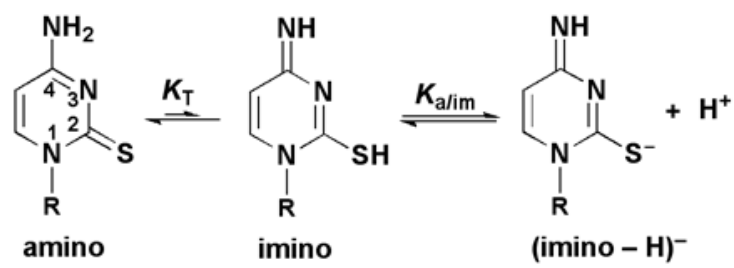

Equation 21 


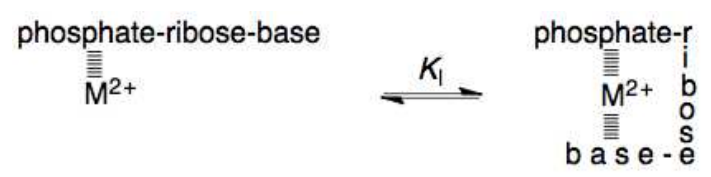

Equation 22 


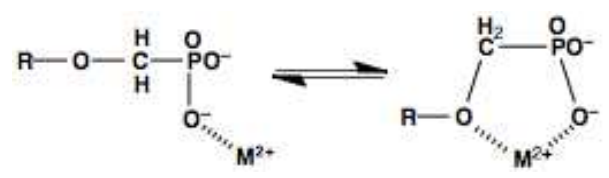

Equation 26 


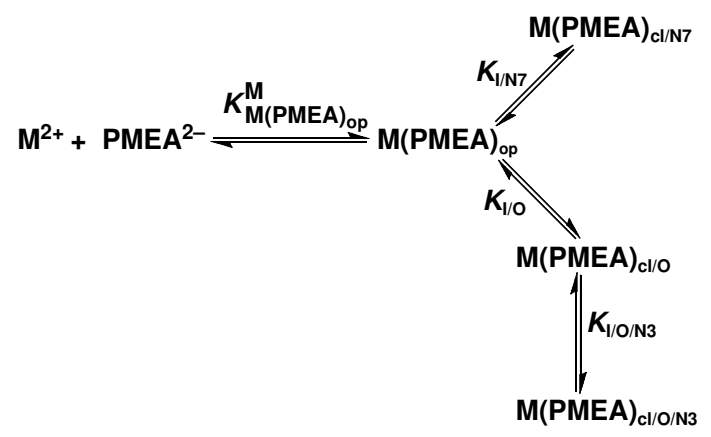

Equation 27 

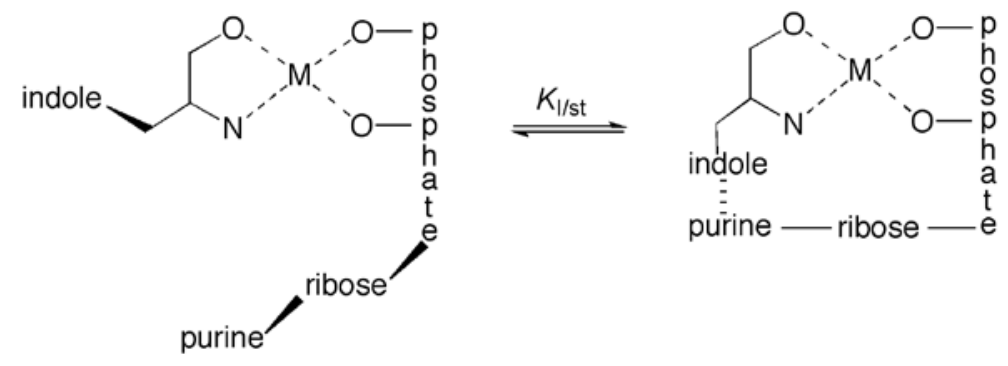

Equation 34 